\title{
EFEITO DAS VARIAÇÕES INTRA E INTERCLONAIS E DO EFEITO DO TIPO DE COAGULAÇÃO E DO PORTA-ENXERTO NAS PROPRIEDADES DA BORRACHA NATURAL DE CLONES RECOMENDADOS PARA O PLANTIO NO ESTADO DE SÃo PAULO
}

\author{
Mariselma Ferreira
}

\begin{abstract}
Tese apresentada à Área Interunidades em Ciência e Engenharia de Materiais, da Universidade de São Paulo, para obtenção do título de Doutor em Ciências e Engenharia de Materiais.
\end{abstract}

Orientador: Dr. Luiz Henrique Capparelli Mattoso 
Ferreira, Mariselma

“Efeito das Variações Intra e Interclonais e do Efeito do Tipo de Coagulação e do Porta-Enxerto nas Propriedades da Borracha Natural de Clones Recomendados para o Plantio no Estado de São Paulo" / Mariselma Ferreira - São Carlos, 2003

Tese (Doutorado) - Interunidades Ciência e Engenharia de Materiais da Universidade de São Paulo, 2003 - páginas: 168

Área: Ciência e Engenharia de Materiais

Orientador: Dr. Luiz Henrique Capparelli Mattoso

1. Borracha Natural; 2. Clones; 3.Hevea brasiliensis; 4.Tipo de Coagulação nanoindentação.

1. Título 
Uiversidado de Sto Paulo

Ciencia e Engenharia de Materiais

MEMBROS DA COMISSÃO JULGADORA DA TESE DE DOUTORADO DE MARISELMA FERREIRA APRESENTADA À ÁREA INTERUNIDADES CIÊNCIA E ENGENHARIA DE MATERIAIS, UNIVERSIDADE DE SÃO PAULO, EM 22-10-2003.

COMISSÃO JULGADORA:

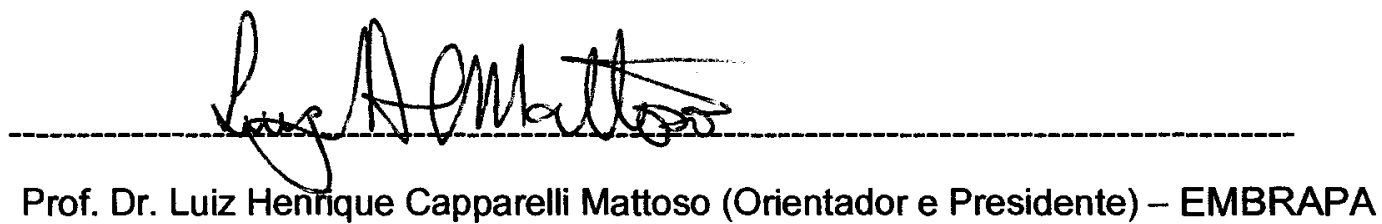

Prof. Dr. Luiz Henrique Capparelli Mattoso (Orientador e Presidente) - EMBRAPA

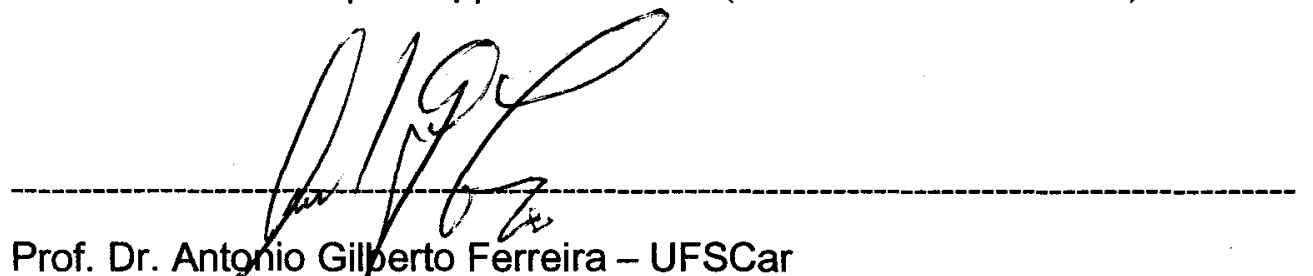

Prof. Dr. Antọnio Gilperto Ferreira - UFSCar

Maric Alve Marturis

Dra. Maria Alice Martins - EMBRAPA

Sirabele Shdlini

Profa. Dra. Elisabete Frollini - IQSC/USP

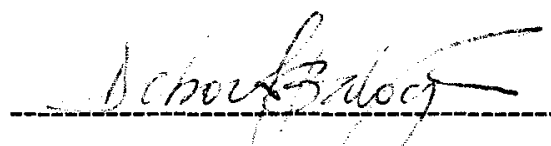

Dra. Débora Terezia Balogh - IFSC/USP

USP - Educação para o Brasil 


\section{DEDICATÓRIA}

À Deus pela vida e por todas as suas maravilhas

Aos meus pais pelo apoio incentivo e dedicação 


\section{AGRADECIMENTOS}

Ao Dr. Luiz Henrique Capparelli Mattoso pela orientação, apoio e dedicação.

Ao Dr. Paulo de Souza Gonçalves da Embrapa/IAC pela, atenção, ajuda, colaboração e por tornar possível esse trabalho. Muito Obrigada!

A todo o pessoal do IAC pela atenção, paciência e pela ajuda com as análises estatísticas.

À Professora Christine Ortiz do Massachusetts Institute of Technology por me receber em seu grupo de pesquisa, pela atenção, paciência, ajuda e pelas valiosas discussões.

Ao Dr. Aldo Job da Unesp de Presidente Prudente pelo auxílio na realização das análises térmicas.

À Eveline Y. Vaidergorin e Renato dos Santos do IPT pela atenção e agilidade na obtenção das análises de plasticidade Wallace, índice de retenção de plasticidade e viscosidade Mooney.

Ao Gilberto Batista de Souza, da Embrapa Pecuária Sudeste, pela atenção e agilidade na obtenção das análises de \% de nitrogênio.

Ao Renê de Oste pela grande ajuda no trabalho de coleta do látex, coleta dos coágulos de borracha natural e, pela ajuda nos diversos problemas surgidos durante o trabalho.

Ao José Ferrazini Jr pela amizade e enorme ajuda em todos os momentos. 
Ao Valentim pela ajuda na reprodução das figuras.

À Ana Maria Felicori pela confecção dos relatórios de aplicação dos recursos de reserva técnica.

À Maria Alice pela leitura da tese, valiosas discussões e amizade.

À Deborah Balogh pelo auxílio nas análises de FTIR.

Aos colegas do MIT em especial a Monica Rixman, Joonil Seog e Delphine pela ajuda na utilização de equipamentos e discussões.

Aos funcionários e amigos da Embrapa Instrumentação Agropecuária pelo excelente ambiente de trabalho, pela organização, eficiência e pelo apoio concedido.

Ao pessoal da secretaria de pós-graduação do IFSC pelo auxílio e paciência.

À minha família, meus pais e irmãs pelo incentivo, apoio, carinho e amizade.

Ao Dornelas, meu grande amor, pelo apoio, paciência, ajuda, incentivo e por tornar a vida mais bonita.

À FAPESP e a CAPES pelo apoio financeiro 
1. INTRODUÇÃO

\section{SUMÁRIO}

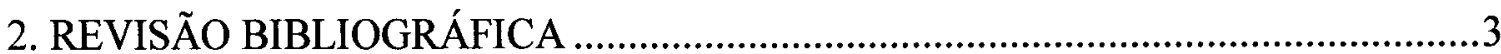

2.1. Aspectos Gerais e Importância da Borracha Natural ..............................................

2.2 Borracha Natural..........................................................................................12

2.2.a. Composição do Látex de Seringueira............................................................... 12

2.2.b. Propriedades Gerais da Borracha Natural ....................................................... 14

2.3. Estudo e Avaliação da Variação Intra e Interclonal nas Propriedades da Borracha

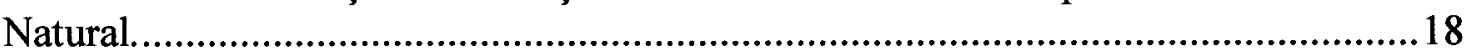

2.4. Avaliação da influência do tipo de porta-enxerto nas propriedades da Borracha

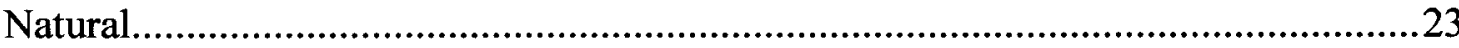

2.5. Efeito dos Tratamentos de Estabilização, Coagulação e Estocagem nas

Propriedades da Borracha Natural. ........................................................................25

2.6. Estudo das Propriedades nanomecânicas da borracha natural via técnica de

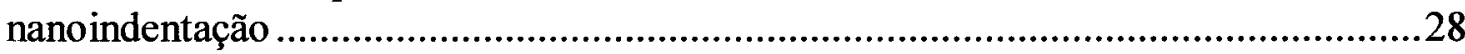

2.6.1 Medidas de Elasticidade através de técnica de nanoindentação........................35

2.6.2. Metodologia de aquisição das propriedades mecânicas de materiais via técnica

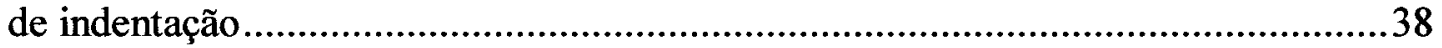

2.6.3. Metodologia de Oliver e Pharr ..................................................................... 41

2.6.4. Energia de adesão $W_{\text {ads }}$ em experimentos de nanoindentação. ........................46

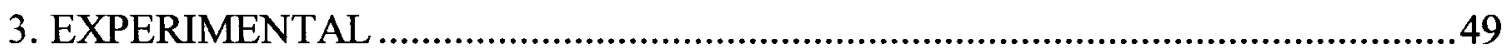

3.1. Estudo e Avaliação da Variação Intra e Interclonal nas Propriedades da Borracha

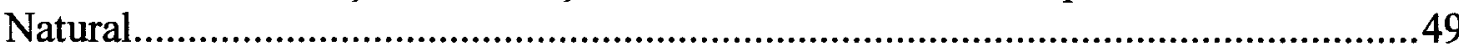

3.1.1. Descrição do Experimento instalado em Indiana - SP (região de Presidente

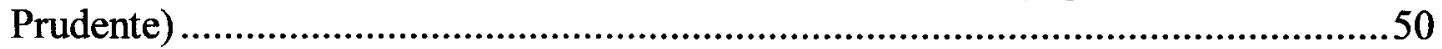

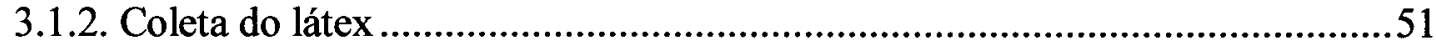

3.1.3. Descrição das Téenicas ..........................................................................52

3.2. Avaliação da influência do tipo de porta-enxerto nas propriedades da Borracha

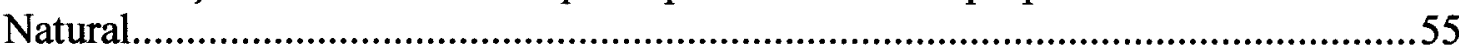

3.2.1. Descrição do Experimento instalado em Pindorama - SP (região de São José

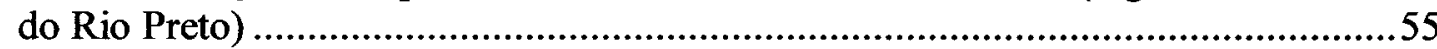

3.2.2. Coleta do Látex...........................................................................................57

3.2.3. Descrição das Técnicas ................................................................................58

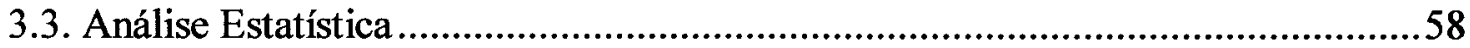

3.4. Avaliação do Efeito dos Tratamentos de Estabilização, Coagulação e Estocagem

nas Propriedades da Borracha Natural..............................................................58

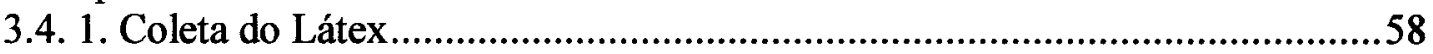

3.4.2. Descrição das Técnicas .............................................................................59

3.5. Estudo das Propriedades nanomecânicas da borracha natural via técnica de

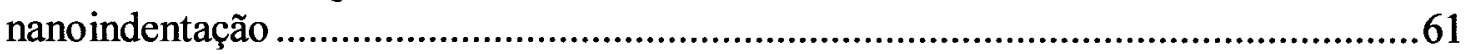

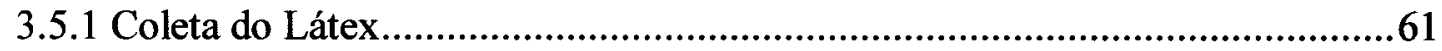

3.5.2. Preparação dos filmes de borracha ............................................................61

3.5.3. Descrição da Técnica de Espectroscopia de Força de alta resolução HRFS...62 
3.5.4. Determinação da área da ponta utilizada................................................64

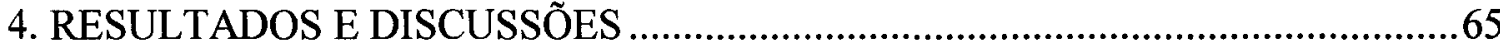

4.1. Estudo e Avaliação da Variação Intra e Interclonal nas Propriedades da Borracha

Natural .65

4.1.1 Variação do Conteúdo de Borracha Seca.................................................65

4.1.2. Variação Intraclonal da Porcentagem de Nitrogênio ..................................68

4.1.3. Variação da Viscosidade Mooney, Plasticidade Wallace e PRI.....................70

4.1.4. Variação da \% Extrato Acetônico ..................................................................77

4.2. Avaliação da influência do tipo de porta-enxerto nas propriedades da Borracha

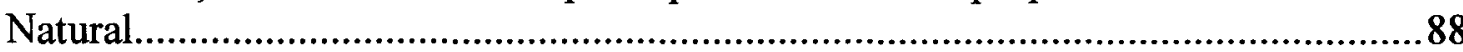
4.3. Avaliação do Efeito dos Tratamentos de Estabilização, Coagulação e Estocagem nas Propriedades da Borracha Natural ...................................................................95 4.4. Estudo das Propriedades nanomecânicas da borracha natural via técnica de nanoindentação

4.4.1 Determinação da área da ponta 123

4.4.2. Determinação de módulo de elasticidade e dureza ..................................... 124

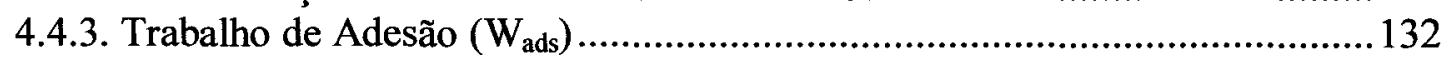

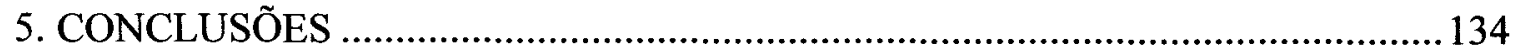

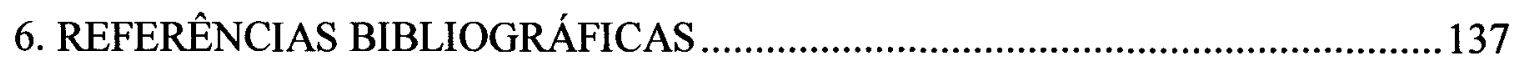

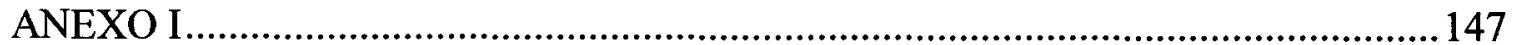

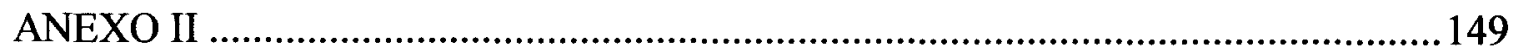

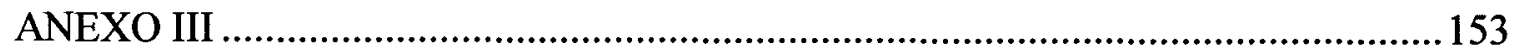




\section{LISTA DE FIGURAS}

Figura 1. Consumo de Borracha Natural e Sintética no mundo no ano de 1996..............5 Figura 2. Composição de borracha presente em pneus radial, de caminhão e de automóveis. .6

Figura 3. Projeções de Consumo Mundial para o ano de 2020 [21] ...............................8

Figura 4. Produção e Consumo de Borracha Natural no ano 2001 [22] ..........................9

Figura 5. Evolução da produção, consumo e importação da borracha natural no Brasil no

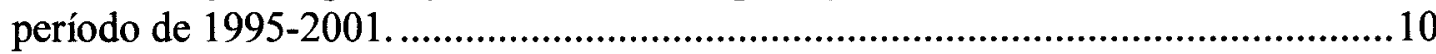

Figura 6. Principais Estados produtores de Borracha Natural no Brasil........................ 10

Figura 7. Frações do látex ultracentrifugado [30] .................................................... 13

Figura 8. Tipos de curvas de distribuição de massa molecular da borracha natural [39].16

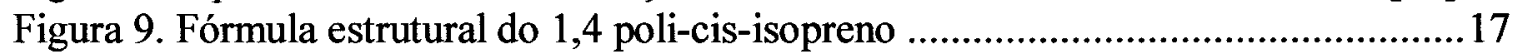

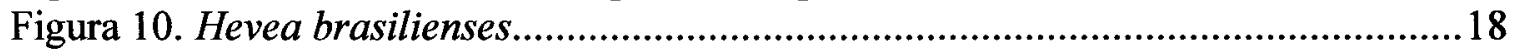

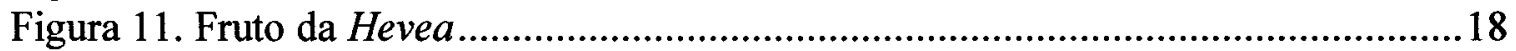

Figura 12. Sementes da Hevea .......................................................................... 18

Figura 13. Esquema de reação do grupo epóxi adjacente à cadeia isoprênica reagindo com o aminoácido presente no soro da borracha natural [51] . ..............................26

Figura 14. Foto de aparelho de AFM [54]. ...........................................................28

Figura 15. Representação esquemática do DNA ....................................................29

Figura 16. Representação esquemática da Hemoglobina.........................................29

Figura 17. Representação esquemática do Colágeno ................................................29

Figura 18. Esquema simplificado de um aparelho de Microscopia de Força Atômica. ..30

Figura 19. Imagem de Microscopia de Força Atômica (AFM) feita em amostra de látex diluído em água a $30 \%$. A deposição foi feita em superfície de quartzo através de técnica de "self-assembly" com 30 min de imersão...............................................30

Figura 20. Esquema de medida de AFM no modo contato conventional. Exemplo de adesão da amostra na sonda [54] .......................................................................... 31

Figura 21. Esquema de medida em "tapping mode" em microscopia de força atômica

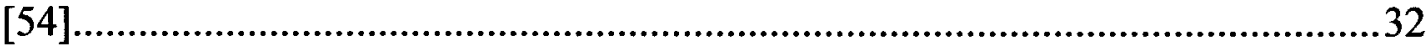

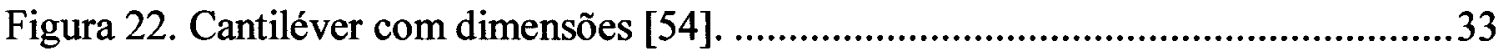

Figura 23. Esquema de uma medida de força versus distância realizada com técnica de

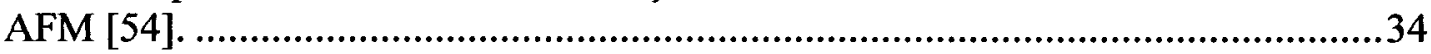

Figura 24. Curva força versus deslocamento determinada a partir de técnica de AFM. .34

Figura 25. Curva de força versus distância de indentação, obtida através de medida de nanoindentação via técnica de microscopia de força atômica AFM. ........................35

Figura 26. Exemplo de sonda de diamante utilizada para medidas de nanoindentação

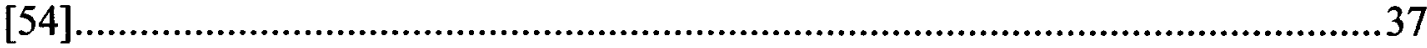

Figura 27. Esquema de uma curva de força versus distância de indentação. ................40

Figura 28. Esquema de curva de força versus distância de indentação e os parâmetros usados na metodologia de Oliver Pharr [80].

Figura 29. Figura esquemática da área de contato projetada na superfície da amostra no ponto $\mathrm{F}_{\max }, \mathrm{D}_{\max }$ segundo a metodologia de Oliver Pharr.......................................43

Figura 30. Figura esquemática de um teste típico de adesão [84] ..............................47

Figura 31. Figura esquemática do delineamento experimental do seringal de Indiana - SP (região de Presidente Prudente - SP) …................................................................51 


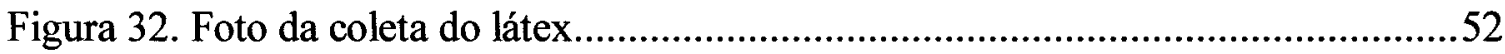

Figura 33. Figura esquemática do delineamento experimental do seringal de Pindorama $-\mathrm{SP}$.

Figura 34. Figura esquemática do filme de borracha depositado em substrato de vidro via técnica de "spin coating".

Figura 35. Esquema do equipamento de MFP usado no experimento de nanoindentação.

Figura 36. Esquema do cantiléver de nitreto de silício utilizado nas medidas de nanoindentação.

Figura 37. Curva de tendência para os valores de viscosidade, plasticidade e PRI em função dos dias de estocagem.

Figura 38. Correlação entre os valores de viscosidade Mooney e plasticidade Wallace para as amostras do clone RRIM 600 submetidas a sete diferentes tratamentos. .....97

Figura 39. Esquema da degradação da membrana fosfolipoprotéica presente na borracha natural [98]. 1-Partícula de borracha presente no látex intacta; 2-Partícula de borracha cuja membrana foi atacada por agentes de oxidação. Observa-se a degradação da membrana fosfolipoprotéica; 3-Partícula de borracha cuja membrana foi degradada. As setas mostram as cadeias isoprênicas susceptíveis aos agentes oxidantes.

Figura 40. Espectros na região do infravermelho da borracha natural submetida a diferentes tratamentos de coagulação.

Figura 41. Espectro na região do infravermelho da borracha natural submetida a diferentes tempos de estocagem.

Figura 42. Espectro na região do infravermelho da amostra estocada por 7 dias e envelhecida a $140^{\circ} \mathrm{C}$ por 30,60 e $120 \mathrm{~min}$.

Figura 43. Espectro na região do infravermelho da amostra estocada por 60 dias e envelhecida a $140^{\circ} \mathrm{C}$ por 30,60 e $120 \mathrm{~min}$.

Figura 44. Curvas de DSC para amostras do clone RRIM 600 submetidas a sete diferentes tratamentos.

Figura 45.Curvas de TG para amostras do clone RRIM 600 submetidas a sete diferentes tratamentos.

Figura 46. Detalhe das curvas de TG no intervalo de $0-300^{\circ} \mathrm{C}$.

Figura 47 Detalhe das curvas de TG no intervalo de $400-600^{\circ} \mathrm{C}$

Figura 48. Derivada da curva de TG para amostras do clone RRIM 600 submetidas a sete diferentes tratamentos.

Figura 49. Curvas do logaritmo do módulo de armazenamento versus temperatura para as borrachas submetidas a diferentes tratamentos

Figura 50. Variação do módulo E'em função da temperatura para o intervalo de temperatura de $0-50^{\circ} \mathrm{C}$

Figura 51. Curva de tendência para os valores de E'a $25^{\circ} \mathrm{C}$.

Figura 52. Relação entre os valores de $\mathrm{E}_{25}{ }_{\mathrm{C}} \mathrm{e} \mathrm{P}_{0}$ para as amostras de borracha submetidas a diferentes tratamentos de coagulação e estocagem.

Figura 53. Curvas do fator amortecimento $(\tan \delta)$ versus temperatura para borrachas do clone RRIM 600 submetidas a diferentes tratamentos 
Figura 54. Variação dos valores de $T_{\mathrm{g}}$ para amostras estocadas em diferentes tempos de estocagem.

Figura 55. Imagem de MEV da sonda utilizada nas medidas de nanoindentação..........123

Figura 56. Desenho esquemático do modelo utilizado no cálculo da área de contato .. 123 Figura 57. Gráfico de Força $(\mathrm{nN})$ versus deslocamento do piezo em $(\mathrm{nm})$ para medida de nanoindentação para clone RRIM 600.

Figura 58. Gráfico de Força $(\mathrm{nN})$ versus distância de nanoindentação para medida de nanoindentação para clone RRIM 600.

Figura 59. Ajuste dos dados experimentais utilizando uma função não linear .............. 125

Figura 60. Ajuste dos dados experimentais utilizando a rotina "spline smooth" .......... 125

Figura 61. Curvas do E' e fator de $\tan \delta$ versus temperatura para o clone GT 1 .........127

Figura 62. Curvas de E' e $\tan \delta$ versus temperatura para o clone PB $235 \ldots \ldots \ldots \ldots \ldots \ldots . . .127$

Figura 63 Curvas do E' e fator de $\tan \delta$ versus temperatura para o clone IAN 873 $\ldots . . .127$

Figura 64 Curvas do E' e fator de $\tan \delta$ versus temperatura para o clone RRIM $600 \ldots 127$

Figura 65. Valores de módulo elástico obtidos via técnica de nanoindentação e DMTA. 


\section{LISTAS DE TABELAS}

Tabela 1. Pesos moleculares médios de borrachas crepe de alguns clones [38] ............ 15

Tabela 2. Origem e parentais dos clones GT 1, RRIM 600 e PB 235 .........................20

Tabela 3. Valores da constante $\varepsilon$ para diferentes geometrias do indentador....................44

Tabela 4.Variação dos valores de DRC para o clone GT 1 em três blocos distintos (I, II e

III) para quatro coletas realizadas.

Tabela 5. Variação dos valores de DRC para o clone RRIM 600 em três blocos distintos

(I, II e III) para quatro coletas realizadas.............................................................66

Tabela 6.Variação dos valores de DRC para o clone PB 235 em três blocos distintos (I,

II e III) para quatro coletas realizadas.

Tabela 7. Variação dos valores de \% de Nitrogênio para o clone GT 1 em três blocos distintos (I, II e III) para quatro coletas realizadas.

Tabela 8.Variação dos valores de \% de Nitrogênio para o clone RRIM 600 em três blocos distintos (I, II e III) para quatro coletas realizadas.

Tabela 9.Variação dos valores de \% de Nitrogênio para o clone PB 235 em três blocos distintos (I, II e III) para quatro coletas realizadas.

Tabela 10. Variação dos valores de Viscosidade Mooney para o clone GT 1 em três blocos distintos (I, II e III) para quatro coletas realizadas.

Tabela 11. Variação dos valores de Viscosidade Mooney para o clone RRIM 600 em três blocos distintos (I, II e III) para quatro coletas realizadas.

Tabela 12. Variação dos valores de Viscosidade Mooney para o clone PB 235 em três blocos distintos (I, II e III) para quatro coletas realizadas.

Tabela 13. Variação dos valores de Plasticidade Wallace para o clone GT 1em três blocos distintos (I, II e III) para quatro coletas realizadas.

Tabela 14. Variação dos valores de Plasticidade Wallace para o clone RRIM 600 em três blocos distintos (I, II e III) para quatro coletas realizadas.

Tabela 15. Variação dos valores de Plasticidade Wallace para o clone PB 235 em três blocos distintos (I, II e III) para quatro coletas realizadas.

Tabela 16. Variação dos valores de PRI para o clone GT 1 em três blocos distintos (I, II e III) para quatro coletas realizadas.

Tabela 17. Variação dos valores de PRI para o clone RRIM 600 em três blocos distintos (I, II e III) para quatro coletas realizadas.

Tabela 18.Variação dos valores de PRI para o clone PB 235 em três blocos distintos (I, II e III) para quatro coletas realizadas.

Tabela 19. Variação dos valores extrato acetônico para o clone GT 1 em três blocos distintos (I, II e III) para quatro coletas realizadas.

Tabela 20. Variação dos valores extrato acetônico para o clone RRIM 600 em três blocos distintos (I, II e III) para quatro coletas realizadas.

Tabela 21. Variação dos valores extrato acetônico para o clone PB 235 em três blocos distintos (I, II e III) para quatro coletas realizadas.

Tabela 22. Propriedades da borracha natural dos clones RRIM 600, GT 1 e PB 235 cultivados na Malásia [91].

Tabela 23 Valor de $\mathrm{F}$ ao nível de significância de 5\%, com 3 e 5 graus de liberdade [105] 
Tabela 24. Valores dos quadrados médios e coeficientes de variação experimental (CV\%) obtidos para as propriedades do látex e da borracha dos clones RRIM 600, GT 1 e PB 235.

Tabela 25. Quadrados médios (QM) das análises de variância para as propriedades do látex e da borracha dos clones RRIM 600, GT 1 e PB 235.

Tabela 26. Variação das propriedades de \% DRC, \% de nitrogênio, \% de extrato acetônico, viscosidade mooney, plasticidade Wallace e PRI para o clone RRIM 600 em cinco diferentes porta-enxertos e para quatro coletas.

Tabela 27. Variação das propriedades de \% DRC, \% de nitrogênio, \% de extrato acetônico, viscosidade mooney, plasticidade Wallace e PRI para o clone PB $235 \mathrm{em}$ cinco diferentes porta-enxertos.

Tabela 28. Quadrados médios (QM) das análises de variância relativas ao estudo da influência do porta-enxerto nas propriedades da borracha e látex do clone.

Tabela 29. Valores de viscosidade, plasticidade e PRI para amostras do clone RRIM 600 submetido a sete diferentes tratamentos: três de coagulação e quatro de estocagem.

Tabela 30. Valores de Tg obtidos através de medidas de DSC para amostras de borracha natural do clone RRIM 600 submetidas a diferentes tratamentos.

Tabela 31. Valores de $\mathrm{E}^{\prime} 25^{\circ} \mathrm{C}$ e $\mathrm{P}_{0}$ para as amostras de borracha submetidas a diferentes tipos de tratamento.

Tabela 32. Valores de $T_{g}$ obtidos via técnica de DSC e DMTA para o clone RRIM 600.

Tabela 33. Valores de Dureza S, módulo de Young e força de adesão máxima para diferentes clones determinados via técnica de nanoindentação.

Tabela 34. Valores de $E_{\text {máx }}$ 'e temperatura de transição vítrea obtidos através de ensaio de DMTA.

Tabela 35. Valores de módulo elástico para os diferentes clones obtidos através de técnica de nanoindentação e ensaio de DMTA.

Tabela 36. Valores de trabalho de adesão para diferentes clones estudados via técnica de nanoindentação. 


\section{LISTA DE ABREVIATURAS E SÍMBOLOS}

\section{SÍMBOLOS}

$1 / 2 \mathrm{~S} \mathrm{~d} / 26 \mathrm{~d} / 7$ (sangria em meia espiral ( $\mathrm{S} / 2)$, realizada em intervalos de $4 \mathrm{dias}(\mathrm{d} / 4)$, sendo a sangria realizada no primeiro painel, com estimulação feita com Ethrel a 2,5\% de ingrediente ativo (ET 2,5\%))

E': módulo de elasticidade dinâmico;

$\mathrm{P}_{0}$ : plasticidade Wallace;

dp: desvio padrão;

$\tan \delta: \quad$ tangente de perda;

$\mathrm{T}_{\mathrm{g}}$ : temperatura de transição vítrea;

$\mathrm{V}_{0}$ : viscosidade Mooney;

$\mathrm{A}_{(\mathrm{hc})}$ : área de contato;

$\mathrm{W}_{\text {ads: }}$ trabalho de adesão;

Ethrel $^{\circledR}$ : ácido cloroetilfosfonico

S: dureza

\section{ABREVIATURA}

DRC: dry rubber content;

EA: extrato acetônico;

AFM: atomic force microscope;

HRFS: high resolution force spectroscopy;

MFP: molecular force probe;

MEV: microscopia eletrônica de varredura;

DMTA: análise térmica dinâmico-mecânica;

PRI: índice de retenção de plasticidade;

TG: análise termogravimétrica;

DSC: Calorimetria Diferencial de Varredura

FTIR: Espectroscopia na região do infravermelho 


\section{RESUMO}

A borracha natural é uma matéria-prima importante na fabricação de uma variedade de artefatos. Atualmente, o Estado de São Paulo é o maior produtor de borracha natural do país. Para as indústrias de transformação de materiais poliméricos é importante que a matéria-prima tenha qualidade e uniformidade. Neste sentido, esse trabalho avaliou as variações intra e interclonais e os efeitos do tipo de coagulação e do porta-enxerto nas propriedades da borracha natural, visando à avaliação da uniformidade da mesma. Foram estudados diferentes clones de seringueira como o RRIM 600, IAN 873 e GT 1. O projeto foi desenvolvido em colaboração com o Instituto Agronômico de Campinas (IAC), que vem avaliando a interação genótipo versus ambiente de clones seringueira [Hevea brasilienses (Willd. Ex Adr. de Juss.) Muell. Arg.] recomendados para o plantio no Estado de São Paulo. A avaliação da borracha natural foi realizada através de ensaios padrões e técnicas de espectroscopia na região do infravermelho, calorimetria diferencial de varredura (DSC), análise termogravimétrica (TG), análise termo dinâmico-mecânica (DMTA) e nanoindentação. Os resultados mostraram que as propriedades da borracha são uniformes dentro de um mesmo clone. Já o estudo da variação interclonal das propriedades avaliadas mostrou que existem diferenças significativas entre as borrachas dos clones para todas as propriedades estudadas. As propriedades da borracha são uniformes independentemente do porta-enxerto (RRIM 600 , PB 235, SNS, GT 1, IAN 873), utilizado nos clones, com exceção da viscosidade Mooney. No estudo do efeito dos tratamentos de estocagem e coagulação, os resultados mostraram que a coagulação química do látex resulta em borrachas com altos valores de plasticidade e viscosidade. Já para as amostras coaguladas espontaneamente, observouse que aquelas estocadas por períodos não superiores a 7 dias apresentaram melhores propriedades de plasticidade, viscosidade e PRI, de acordo com as normas da ABNT e da literatura internacional. No estudo das propriedades da borracha natural via técnica de nanoindentação, concluiu-se que a técnica é uma ferramenta que deve ser melhor explorada para a determinação das propriedades da borracha em nanoescala. De uma forma geral, o trabalho desenvolvido nesta tese de doutorado apresenta resultados inéditos de um estudo sistemático sobre a variação das propriedades da borracha natural e vem contribuir com mais uma etapa do estudo que vem sendo feito pela Embrapa e pelo IAC de avaliação dos aspectos agronômicos da seringueira e das propriedades do produto pós-colheita. 


\begin{abstract}
Natural rubber is an important raw material used for manufacturing a large variety of products. Nowadays the state of São Paulo is the largest producer of natural rubber in Brazil. Polymeric material industries need raw materials with high quality and uniformity. In this sense, the proposal of this work was to study and evaluate the properties of natural rubber in order to assess the quality of the product. In the study reported here, the intra and inter clonal variations were analyzed systematically. In addition, the effect of rootstocks and methods of coagulation on the properties of natural rubber were investigated. This project was developed in collaboration with Agronomic Institute of Campinas that investigates the agronomic aspects of rubber tree [Hevea brasilienses (Willd. Ex Adr. de Juss.) Muell. Arg.] clones for wide-scale plantation in various regions of São Paulo State. The evaluation of natural rubber's quality was done using standard methods of industry and other techniques such as infrared spectroscopy, differential scanning calorimeter (DSC), thermal gravimetric analyzer (TGA), dynamic mechanical analyzer (DMTA) and nanoindentation. Results showed that the properties of natural rubber do not change among trees of the same clone. Besides, it was found that the rootstocks (RRIM 600, PB 236 SNS, GT 1 and IAN 873) have no marked influence in the properties of natural rubber clones (RRIM 600 and PB 235). On the other hand, the results of interclonal study have shown highly and significant variations among clones for the rubber properties evaluated. Other investigation carried out was the effect of coagulation and storage. Results showed that chemical coagulation and larger periods of storage yields rubber with high values of plasticity and viscosity. Nanoindentation studies of natural rubber demonstrated that this technique might be improved to study elastomers at nanoscale level. In this sense, the work developed shows a systematic study on the evaluation of natural rubber clones that has not previously performed. It contributes with one more step in the study that has been developed by Embrapa and IAC to improve the quality of natural rubber in São Paulo State.
\end{abstract}




\section{INTRODUÇÃO}

A borracha natural é uma matéria-prima importante na fabricação de uma variedade de artefatos na indústria automobilística e de produtos bélicos, por ser um material resistente e com boas propriedades isolantes e impermeabilizantes. Outro campo de aplicação da borracha natural é a indústria de produtos cirúrgicos, médico/hospitalares e de cuidado pessoal, onde ela é utilizada como matéria-prima na confecção de preservativos, luvas cirúrgicas e curativos de borracha. Apesar de a borracha natural poder, em alguns casos, ser substituída pela sintética, a impossibilidade de se reproduzir quimicamente um polímero com as mesmas qualidades do polímero natural faz com que ele seja ainda bastante consumido $[1,2]$. Além do mais, a busca atual de materiais provenientes de fonte renovável está devolvendo à borracha natural o espaço perdido para a borracha sintética $[3,4]$. Além das vantagens para o meio ambiente, a borracha natural possui uma série de vantagens em relação à sintética, principalmente em termos de resistência mecânica, elasticidade, propriedades de coesão, força e resistência a abrasivos e ao impacto. Só um pneu com borracha natural pode resistir a bruscas variações de temperatura como as extremamente baixas nas grandes altitudes, para o súbito calor de um pouso na pista de um aeroporto [5]. Além do mais, na indústria pneumática a borracha natural é imprescindível no manufaturamento de pneus para caminhão, devido à capacidade da borracha em dissipar o calor gerado pelo atrito do pneu com o solo e de absorver melhor o impacto. A indústria pneumática consome alta porcentagem da borracha produzida no mundo. Em 1997, este consumo correspondia a $85 \%$ [5].

Em busca de um produto com melhor qualidade para satisfazer as normas que avaliam a borracha natural, os setores de transformação de matéria-prima são exigentes em relação à uniformidade do material comprado. $\mathrm{O}$ fato de a borracha natural provir de plantações e usinas diferentes, onde o látex é coagulado espontaneamente no campo sem nenhum tipo de cuidado, estocado e processado sem padronização, prejudicam a qualidade do produto final.

O Brasil que já foi o principal produtor e exportador de borracha no mundo produz hoje apenas cerca de $1 \%$ da produção mundial, o que é insuficiente para o consumo interno, sendo necessária a importação de aproximadamente $60 \%$ da borracha consumida no país. Outro aspecto relevante é o fato de que a qualidade e 
produtividade da borracha natural brasileira estão, em alguns casos, abaixo dos níveis da importada. Para mudar esta situação, é importante a pesquisa voltada tanto para a melhoria dos aspectos agronômicos da seringueira tanto para o estudo da qualidade $\mathrm{e}$ caracterização da borracha natural extraída. Dessa forma, o Brasil pode melhorar a sua posição no mercado produtor e ampliar o seu o leque de consumidores [5]. Neste contexto, o IAC (Instituto Agronômico de Campinas) vem, há algumas décadas, estudando as propriedades agronômicas da seringueira como resistência a pragas, aumento de produtividade e desenvolvimento de novos clones mais adequados para plantação em grande escala no Estado de São Paulo $[6,7,8]$. O pesquisador Dr. Paulo de Souza Gonçalves do IAC foi um dos responsáveis pela implementação de seringais de cultivo no Estado de São Paulo, que hoje é o maior produtor do país. Até agora, poucos são os trabalhos na literatura nacional e internacional que avaliem a influência do tipo de clone, do clima, método de sangria e do tipo de processamento nas propriedades finais da borracha natural brasileira. No Brasil a Embrapa Instrumentação Agropecuária vem, nos últimos anos, desenvolvendo pesquisas para estudar a qualidade do produto pós-colheita $[9,10,11]$. Esse trabalho é fruto da colaboração do IAC que estuda a parte genética e agronômica da seringueira com a Embrapa que tem estudado as propriedades da borracha natural de clones recomendados para o plantio em larga escala no Estado de São Paulo visando à avaliação e certificação da qualidade deste produto.

Neste contexto, o presente trabalho tem o objetivo de estudar e avaliar as variações intra e inter clonais, a influência do tipo de porta-enxerto e o efeito do período de estocagem e tipo de coagulação nas propriedades da borracha natural. Para isso a borracha natural foi estudada através de ensaios padrões como \% de borracha seca ( $\%$ DRC), $\%$ de nitrogênio ( $\% \mathrm{~N}), \%$ de cinzas, Plasticidade Wallace $\left(\mathrm{P}_{0}\right)$, Viscosidade Mooney $\left(\mathrm{V}_{0}\right)$ e índice de retenção de plasticidade $(\mathrm{PRI})$ e técnicas de espectroscopia de infravermelho, calorimetria diferencial de varredura (DSC), análise termogravimétrica (TG), análise termo dinâmico-mecânica (DMTA) e técnica de nanoindentação. Além disso, foi investigada a utilização da técnica de nanoindentação para o estudo e avaliação das propriedades nanomecânicas da borracha natural, visando a melhor compreensão da sua estrutura polimérica. 


\section{REVISÃO BIBLIOGRÁFICA}

Atualmente, existem poucos trabalhos na literatura voltados a estudar e avaliar a qualidade da borracha no Brasil. Em trabalho realizado em seringais na região de Presidente Prudente [12] a borracha dos clones RRIM 600, IAN 873, GT1 e PB 235 foi estudada em função dos meses de coleta, por um período de seis meses, e de diferentes freqüências de sangria. A borracha destes clones foi caracterizada através de ensaios padrões como o conteúdo de borracha seca (DRC), \% de cinzas, \% de nitrogênio, plasticidade Wallace $\left(\mathrm{P}_{0}\right)$ e viscosidade Mooney $\left(\mathrm{V}_{0}\right)$. Análises estas, em geral, utilizadas pela indústria pneumática para a avaliação da qualidade da borracha. Os resultados mostraram que as propriedades do látex e da borracha variam consideravelmente em função do tipo de clone e período de coleta. Observou-se que os valores de DRC tendem a diminuir no início da estação seca e fria (meses de maio e junho), enquanto que para a \% de nitrogênio e \% de cinzas observou-se um aumento neste mesmo período. A hipótese utilizada para explicar estes comportamentos é o fato das condições climáticas favorecerem a queda das folhas das árvores e a diminuição da fotossíntese, fazendo com que os nutrientes da planta sejam direcionados para o látex. A investigação do efeito da freqüência de sangria nas propriedades do látex foi feita através da análise dos parâmetros fisiológicos do látex, método este proposto por Jacob et al. [13, 14]. Neste estudo, observou-se que cada tipo de clone responde de uma forma diferente ao tipo de sangria e estimulação. Em trabalho realizado na região de Votuporanga-SP os clones RRIM 600, IAN 873, GT 1 e PB 235 foram estudados sistematicamente por dois anos, visando à investigação da influência das condições climáticas e sazonais (temperatura e precipitações pluviométricas) na qualidade e produtividade da borracha [15]. A qualidade da borracha natural foi avaliada pela técnica de análise termo dinâmicomecânica (DMTA) e pelos ensaios padrões. Os resultados dos ensaios padrões apresentaram variações altamente significativas entre as coletas. Já os resultados da análise de regressão múltipla mostraram que os quatro clones estudados respondem de maneira distinta, frente às variações ambientais. Oliveira et al. [6] estudaram a estabilidade térmica da borracha natural de clones de origem asiática, como o RRIM 600 e o GT 1, e de origem brasileira como o IAC 40, IAC 300 e IAC 301. O estudo foi feito através de técnicas de TG e DSC e os resultados mostraram que as borrachas 
provenientes de clones da série IAC têm estabilidade térmica similar às borrachas provenientes dos clones asiáticos.

\subsection{Aspectos Gerais e Importância da Borracha Natural}

A borracha natural tem sido utilizada a mais de 200 anos em inúmeros produtos, porém tornou-se um material tecnicamente importante após a descoberta da vulcanização por Charles Goodyear em 1839. Depois disso, ela foi gradualmente sendo introduzida em todos os campos da atividade humana oferecendo novas possibilidades de aplicação. $O$ maior efeito no desenvolvimento da indústria de borracha foi exercido pela rápida formação e desenvolvimento da indústria automobilística, impossível sem pneus de borracha. Hoje, a variedade dos produtos que contêm borracha excede a 50.000 itens e a borracha é material indispensável no desenvolvimento da tecnologia e muitas realizações da vida moderna $[2,16]$.

Antes da segunda guerra mundial, em 1938, a produção e consumo mundial da borracha natural eram de 1.400 .000 toneladas; em comparação, a produção de borracha sintética era desprezível. Durante a guerra aconteceram grandes desenvolvimentos na produção de borracha sintética devido à queda de suprimento de borracha natural no mundo [17]. O aumento do preço do petróleo em 1973, combinado ao aumento do consumo de pneu radial levou a retomada do interesse na borracha natural. Atualmente, a borracha natural está entre os elastômeros mais consumidos no mundo como mostra a Figura 1. 


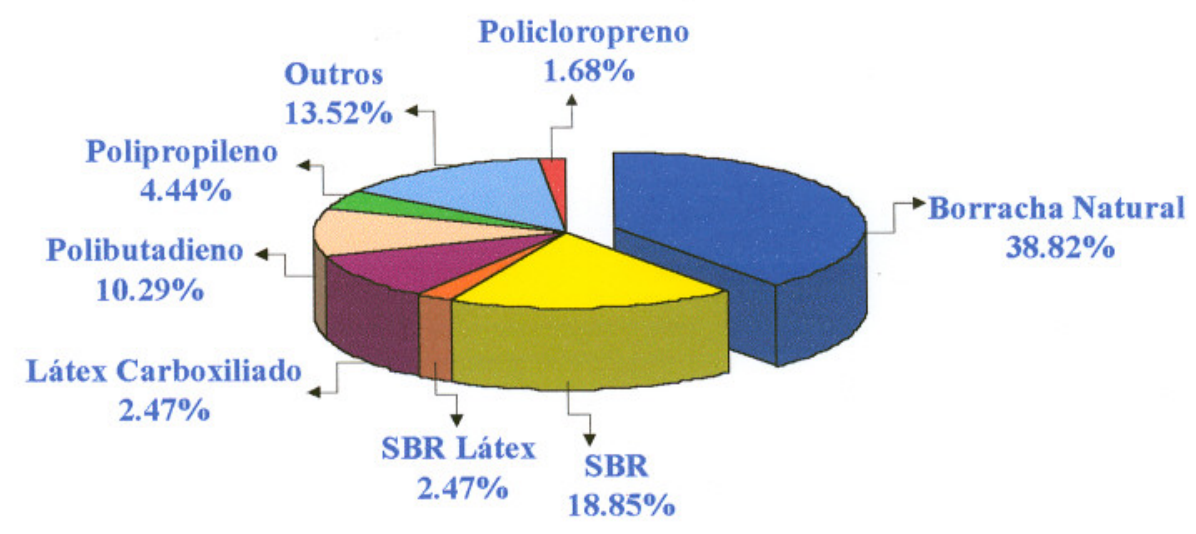

Fonte: ERJ, 1996.

Figura 1. Consumo de Borracha Natural e Sintética no mundo no ano de 1996

Além do mais, a seringueira, da qual é extraída a borracha natural, possui uma grande importância ambiental quando comparada à borracha sintética, porque utiliza o mínimo de recursos não renováveis na sua produção, não polui a água nem a atmosfera, além de funcionar como fonte de madeira e auxiliar no processo de renovação do solo.

Além das vantagens para o meio ambiente, a borracha natural possui uma série de vantagens em relação à sintética, principalmente em termos de resistência mecânica, elasticidade, propriedades de coesão, força e resistência a abrasivos e ao impacto. Ainda, na indústria pneumática a borracha natural é imprescindível na manufaturação de pneus radial e para caminhão [5]. A Figura 2 mostra a composição da borracha natural presente em pneus radial, de automóveis e de caminhões. 


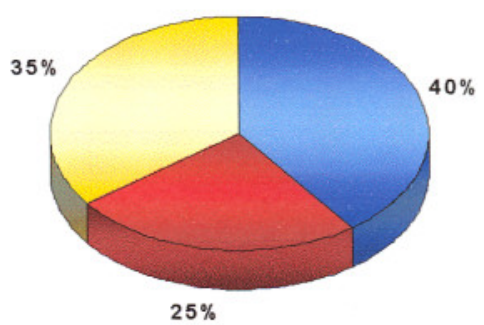

Pneu radial

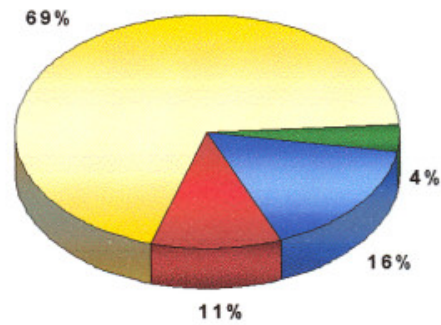

Automóveis

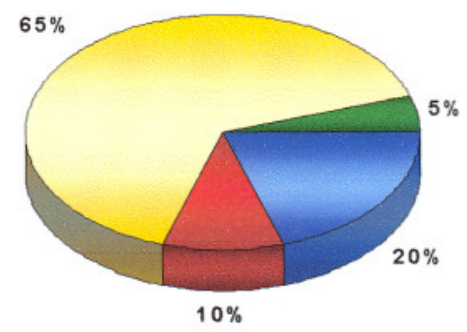

Caminhões
Borracha Natural

$\square$ Material Metálico
Borracha Sintética

Material Textil

Fonte: ANIP, 1998

Figura 2. Composição de borracha presente em pneus radial, de caminhão e de automóveis.

Apesar das excelentes propriedades, a variabilidade da qualidade da borracha natural é um problema sério que atrapalha a sua expansão comercial. Atualmente, os setores de transformação de matéria-prima estão cada vez mais exigentes em relação à qualidade e a uniformidade do material que é recebido, em busca de um produto com melhor qualidade, menor preço e visando a competição no mercado. $\mathrm{O}$ fato de a borracha natural provir de usinas e plantações diferentes, dos coágulos serem obtidos espontaneamente no campo sem nenhum tipo de cuidado e por não terem nenhum tipo de padronização em relação ao processamento, tipo de coagulação e estocagem, tornam as propriedades da borracha aleatórias. Esta falta de controle afeta principalmente as propriedades do polímero, diminuindo a sua aceitação, principalmente pelas indústrias pneumáticas, principais consumidoras.

Em 1877 sementes da Hevea brasiliensis foram levadas das florestas brasileiras, por ingleses, e plantadas na Malásia que na época era colônia inglesa. Nos seringais de cultivo, as árvores eram plantadas próximas umas das outras, o que facilitava e barateava a extração do látex permitindo o aumento da produção. Com o passar do tempo os plantadores, auxiliados pela pesquisa, aprenderam a selecionar clones altamente produtivos e propagá-los através de mudas. Em adição a isto, os produtores asiáticos investiram em pesquisas relacionadas à melhoria da qualidade $\mathrm{e}$ uniformidade da borracha natural. Estes fatos foram os responsáveis pelo êxito dos 
seringais de cultivo da Malásia e o declínio dos seringais nativos da Amazônia. Os seringais nativos brasileiros não suportaram a concorrência da borracha de cultivo asiática e entraram em declínio [18]. Devido ao expressivo interesse pela cultura por volta de 1910, os países do Império Britânico da Ásia iniciaram a suas exportações. Nesta fase, o Brasil atingiu o seu maior volume de exportação 31.1 mil toneladas oriundas do extrativismo. A última remessa de exportação expressiva no Brasil ocorreu em 1947, quando foram exportadas somente 7000 toneladas de borracha [19].

A introdução da seringueira no Estado de São Paulo aconteceu em 1916 em Gavião Peixoto/SP. Em 1942, o Instituto Agronômico de Campinas efetuou o plantio de progênie de sementes originadas de Gavião Peixoto, em diversas estações experimentais. Com a criação do PRÓ-BORRACHA, um programa estadual de borracha natural coordenado pela Coordenadoria de Assistência Técnica Integrada (CATI), os seringais implantados no Estado de São Paulo cresceram de forma significativa. Hoje o Estado de São Paulo é o principal estado produtor de borracha natural no Brasil, mas o país ainda necessita importar borracha para atender a demanda interna.

A borracha natural é uma matéria-prima agrícola, importante para a manufatura de uma grande quantidade de produtos, considerada estratégica ao lado de produtos como aço e petróleo, sendo indispensável na produção de artigos essenciais para a humanidade. $\mathrm{Na}$ indústria de artefatos leves de borracha, por exemplo, é enorme a diversidade de bens produzidos a partir de látex centrifugado, como: luvas cirúrgicas, preservativos, chupetas, etc e artefatos que utilizam borracha sólida como coxins, solados, etc. Atualmente, novas aplicações da borracha natural têm contribuído para aumentar a sua expansão. Como exemplo, pode-se citar a utilização do látex de seringueira na confecção de um biomaterial inovador e capaz de cicatrizar feridas e reconstituir esôfagos e tímpanos perfurados [20]. Outra recente aplicação é a utilização da borracha natural para fabricar o couro vegetal, que vem sendo utilizado na confecção de bolsas e sapatos. Outro ramo onde a borracha natural é muito utilizada é na indústria de transporte e produtos bélicos, por ser um material com boas propriedades isolantes e impermeabilidade tanto ao ar quanto à água [2]. A indústria de pneumáticos é a maior consumidora de borracha natural, onde cerca de $85 \%$ da produção mundial é utilizada. No contexto mundial, projeções indicam que o 
consumo crescerá mais que a produção. Burger \& Smit [21] estimam que no ano 2020 o consumo de borracha natural será de 9,71 milhões de toneladas comparadas com uma produção de 7,06 milhões de toneladas, Figura 3.

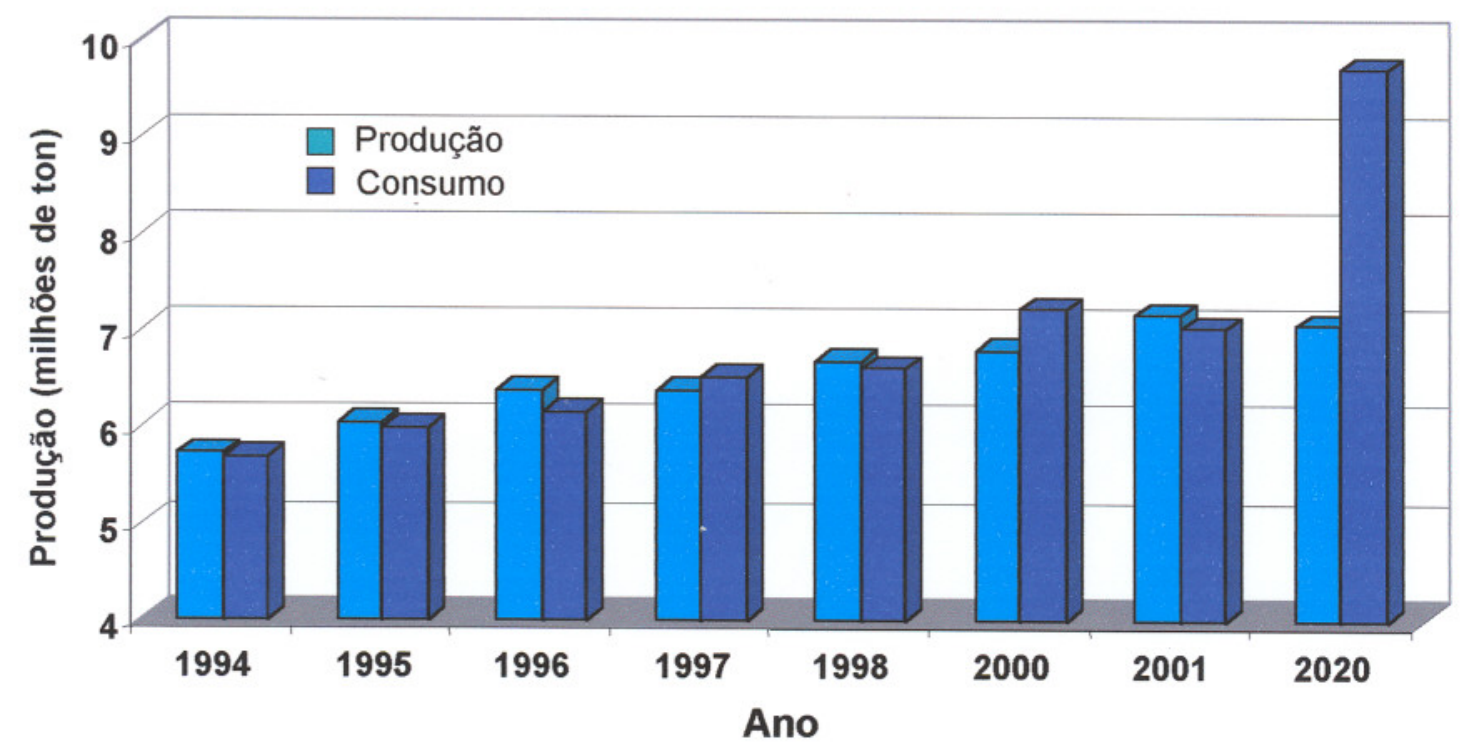

Figura 3. Projeções de Consumo Mundial para o ano de 2020 [21]

A Figura 4 mostra a distribuição da produção e consumo mundial de borracha natural em 2001 com uma produção total de 7,170 milhões de toneladas, para um consumo de 6,030 milhões de toneladas. O Brasil contribui com 1,0\% dessa produção para um consumo de 3,0\% o que mostra que a sua produção é insuficiente para o consumo interno. Por outro lado, observamos que os valores totais de produção e consumo estão bem próximos, chamando atenção para uma possível falta de borracha natural para atender a demanda mundial. 


\section{Produção}

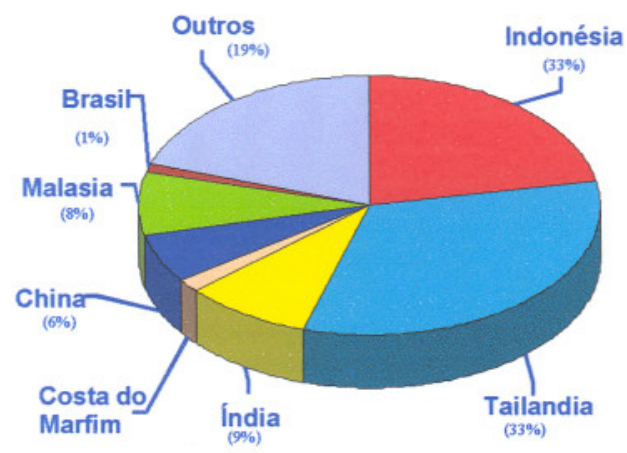

Total: 7.170 milhões ton

\section{Consumo}

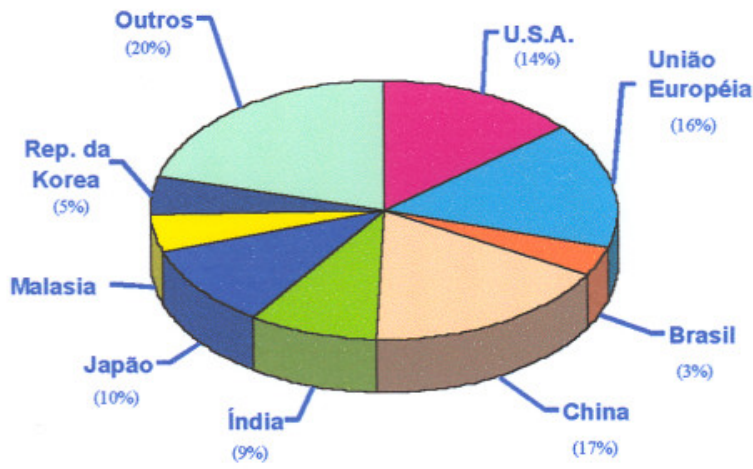

Total: 7.030 milhões ton

Figura 4. Produção e Consumo de Borracha Natural no ano 2001 [22].

Em 2001, segundo dados oficiais do Instituto Brasileiro do Meio Ambiente (IBAMA), para um consumo de 245.000 toneladas, foram importadas 149.000 toneladas. Nesse mesmo ano, o Brasil atingiu a produção recorde de 95.000 toneladas. A Figura 5 mostra a evolução da produção, importação e consumo para a borracha natural no Brasil. Deste total, os seringais paulistas participaram com $47 \%$ da borracha para a indústria nacional, Figura 6 . 


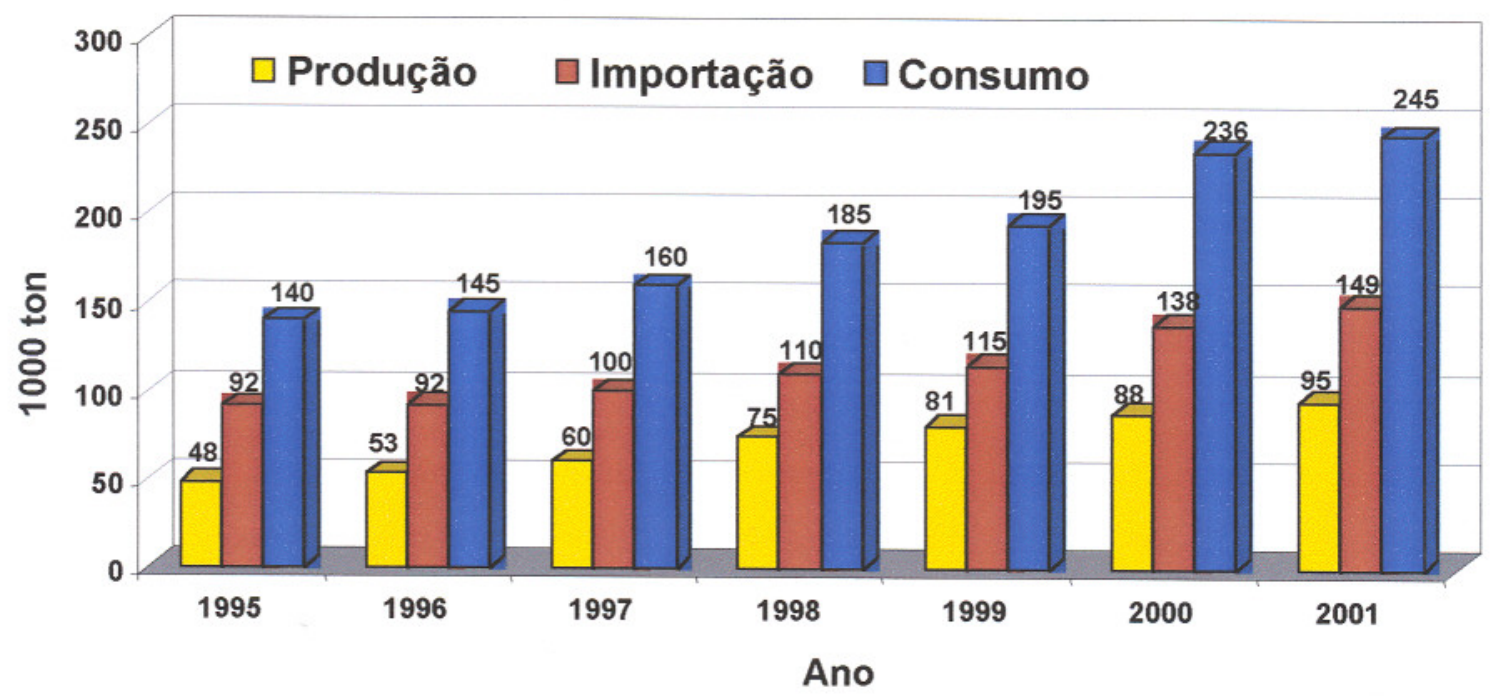

Figura 5. Evolução da produção, consumo e importação da borracha natural no Brasil no período de 1995-2001.

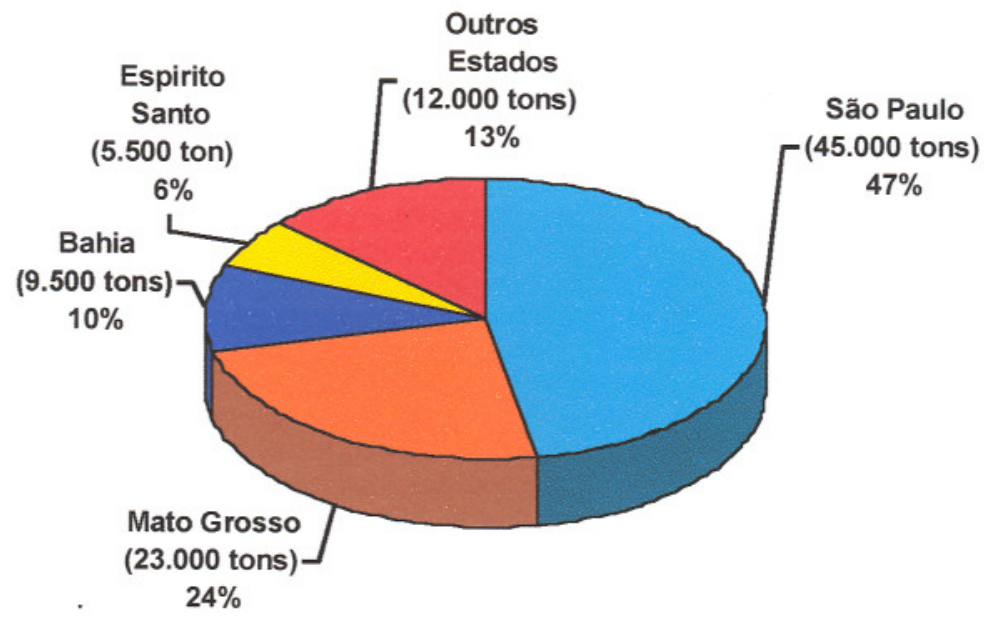

Producão: 95.000 tons

Source: Conab/MA, 2002

Figura 6. Principais Estados produtores de Borracha Natural no Brasil

Como mostrado anteriormente, as projeções indicam um aumento do consumo da borracha natural no mundo e no Brasil e uma deficiência para atender essa demanda. Observamos que em longo prazo, haverá uma tendência de aumento gradativo da produção nacional, mas que ainda será insuficiente para atender ao crescente aumento de consumo, a menos que, investimentos no setor incluindo medidas governamentais sejam tomados visando revitalizar o setor e fomentar o plantio de novas áreas potenciais. Neste contexto, se encaixa a importância de 
projetos de melhoramento da seringueira, desenvolvidos pelo IAC que tem como objetivo produzir clones mais produtivos e aptos para o plantio em larga escala no Estado de São Paulo. Com a colaboração do IAC, a Embrapa Instrumentação Agropecuária vem desenvolvendo projetos que são inéditos na literatura brasileira que buscam estudar, avaliar e caracterizar as propriedades da borracha natural póscolheita dos clones recomendados pelo IAC para o plantio em larga escala no Estado de São Paulo.

Atualmente, além da proliferação de seringais de cultivo em Estados como São Paulo e Mato Grosso, alguns programas de apoio ao extrativismo da seringueira têm sido criados e financiados tanto pelo governo de alguns estados brasileiros quanto pela iniciativa privada [23]. A idéia é resgatar a exploração sustentável dos recursos naturais da floresta Amazônica, neste caso o extrativismo da borracha natural, incentivar a organização dos seringueiros por meio de treinamentos e cooperativas visando à melhoria da qualidade da borracha natural e preservar o meio ambiente através de um programa adequado de uso da floresta. Entre estes programas está uma parceria entre os seringueiros do Acre, o governo do estado e a empresa Italiana Pirelli que irá proporcionar a fabricação do pneu Xapuri 100\% nacional. Toda a borracha utilizada neste pneu será extraída e beneficiada no Brasil. Com o lançamento do Xapuri, a Pirelli pretende consumir toda a extração do estado estimada em cerca de 2000 ton. A princípio, a produção do Xapuri garantirá trabalho e renda para 300 famílias de seringueiros na região e estima-se que até 2003 , seis mil acreanos estarão trabalhando na extração [23]. Segundo a responsável pelo desenvolvimento de materiais da Pirelli, equipes de treinamento da Pirelli estarão acompanhando os seringueiros do Estado para aprimorar a mão de obra e melhorar os processos de extração, produção e beneficiamento da borracha e o objetivo deste projeto é o de comprovar a qualidade da borracha acreana. Por enquanto, apenas caminhões poderão utilizar o pneu que em médio prazo será exportado para Europa e EUA, podendo ficar reconhecido internacionalmente [23, 24]. Outro programa que tem buscado a melhoria da qualidade da borracha natural no norte do país é o da secretaria de Estado da Ciência e Tecnologia do Estado do Amapá denominado "Ciência e Tecnologia para o Desenvolvimento Sustentável no Amapá" [25]. Este programa inclui um projeto que busca tecnologias limpas para a exploração sustentável dos recursos naturais da Amazônia, visando à qualidade dos itens 
produzidos e viabilizando a sua absorção pelo mercado. Este projeto tem o objetivo de difundir a Tecnologia Alternativa para a Produção de Borracha na AmazôniaTECBOR, que consiste de um conjunto de técnicas simples, que permitem ao próprio seringueiro preparar um produto de boa qualidade, coagulando o látex com o ácido pirolenhoso, um subproduto da carbonização da madeira [26].

\subsection{Borracha Natural}

A borracha natural está presente no látex em diversas espécies de plantas dentre as quais a mais importante é a seringueira [Hevea brasiliensis (Willd. Ex Adr. de Juss.) Muell. Arg.] que é responsável por cerca de $99 \%$ de toda a borracha produzida no mundo [27]. Única entre os produtos naturais, a borracha natural, extraída da Hevea brasiliensis combina elasticidade, resistência ao desgaste (fricção) a altas temperaturas, propriedades de isolamento elétrico e impermeabilidade para líquidos e gases.

A borracha natural é obtida da seringueira através do processo de sangria sendo o látex natural um líquido branco, similar ao leite, cujas características serão descritas a seguir.

\section{2.a. Composição do Látex de Seringueira}

O látex natural é um sistema coloidal, ou seja, uma suspensão de partículas de borracha (fase dispersa) em um meio aquoso, também chamado soro (meio dispersivo) [28]. Uma variedade de substâncias, chamadas não-borracha, está suspensa no soro, a saber: proteínas, açúcares, álcoois, lipídios e pequenas quantidades de substâncias minerais.

A fase borracha é constituída por $96 \%$ de hidrocarboneto, $1 \%$ de proteína e $3 \%$ de lipídios e alguns traços de magnésio, potássio e cobre [17]. A fase soro também chamada de soro $\mathrm{C}$ ou fase aquosa contêm diferentes classes de compostos incluindo carboidratos, proteínas, aminoácidos, enzimas e bases nitrogenadas [29, 30]. Quando o látex é submetido à ultracentrifugação ocorre a separação do látex em quatro diferentes fases principais. A fração menos densa é constituída por partículas de borracha que são as mais numerosas e representam $25-45 \%$ do volume total do látex; são envolvidas por uma camada fosfolipoprotéica de composição complexa. $O$ 
tamanho destas partículas varia em torno de 60 angstrons a $6 \mu \mathrm{m}$ e possuem formas esféricas, ovóides ou piriformes. A fase seguinte é composta pelas partículas "Frey Wyssling" que apresentam coloração amarelada devido à presença de carotenóides. Estas partículas apresentam estrutura complexa, são limitadas por uma dupla membrana que contém um sistema de tubos ramificados e glóbulos que contêm lipídios e carotenóides. $\mathrm{O}$ papel biológico destas partículas ainda não foi totalmente esclarecido; alguns autores acreditam que elas participem da síntese do isopreno, mas até agora nada foi provado [31]. A terceira fração é a fase soro que contem proteínas, aminoácidos, carboidratos, etc. A chamada fração de fundo ou fase lutóide consiste principalmente de partículas lutóides. Estas partículas são vesículas ou vacúolos envolvidos por uma membrana frágil, semipermeável e que contêm em seu interior um liquido denominado soro $\mathrm{B}$, com $\mathrm{pH}$ em torno de 5,5 .

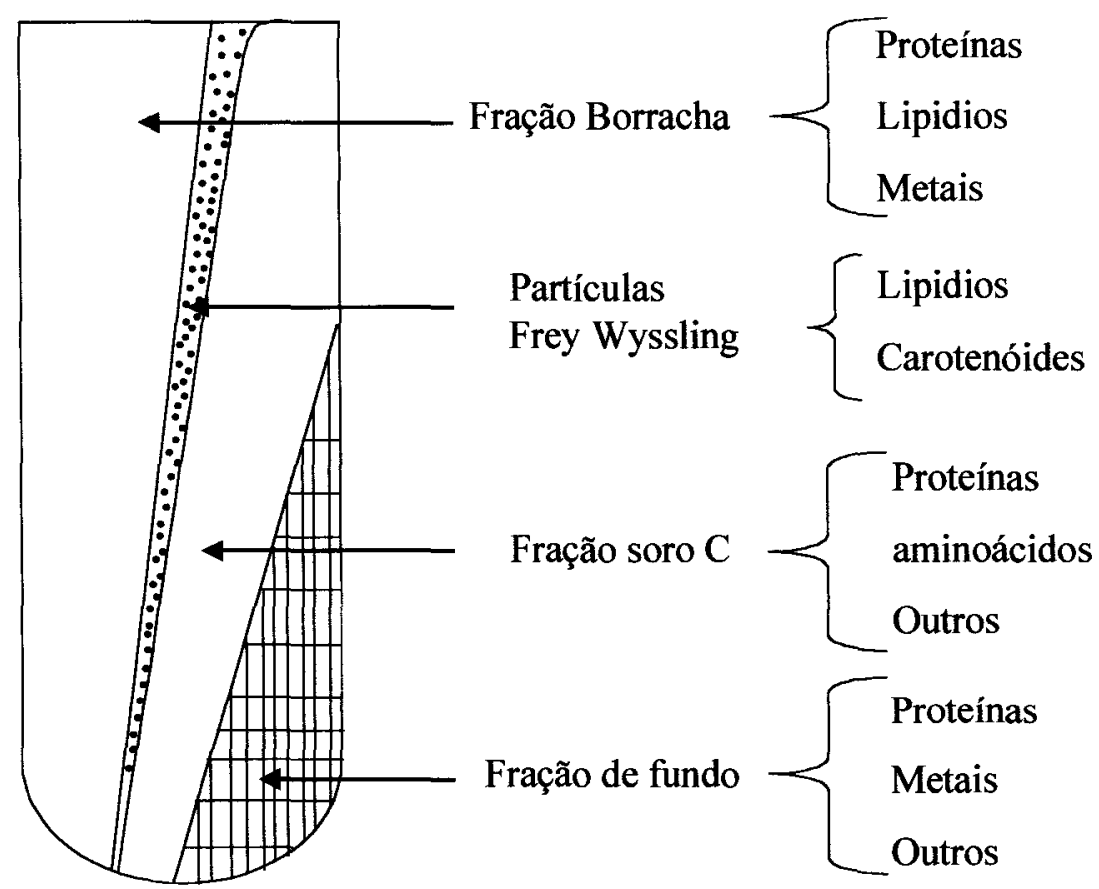

Figura 7. Frações do látex ultracentrifugado [30]

O látex é uma suspensão coloidal de partículas negativamente carregadas. A coagulação do látex ocorre após a neutralização destas cargas, o que acontece com a adição, por exemplo, de ácido acético, que reduz o $\mathrm{pH}$ do látex para próximo de seu ponto isoelétrico. No entanto, quando o látex é deixado em repouso ele coagula espontaneamente e alguns autores [32] sugerem que, as partículas lutóides são responsáveis por esta coagulação e pela parada de fluxo do látex nos vasos 
laticíferos. Vários experimentos demonstraram que quando os lutóides são, de alguma forma, removidos do látex o tempo para a coagulação é maior. Os lutóides têm influência no metabolismo do látex e na estabilidade do mesmo [33].

As proteínas, aminoácidos, carboidratos, lipídios, ácidos nucléicos e outros constituintes inorgânicos são os chamados constituintes não borracha do látex. Muitos destes estão dissolvidos no soro, enquanto outros estão associados à cadeia de hidrocarbonetos [34]. A quantidade destes constituintes varia de acordo com o tipo de clone, época do ano, sistema de sangria e tipo de processamento. No decorrer da coagulação ou da crepagem, certos constituintes não borracha são eliminados com o soro e enquanto outros são retidos na fase borracha. Estes constituintes têm grande importância para a borracha, pois influenciam as propriedades físicas e mecânicas da mesma. As proteínas, por exemplo, afetam a resistência da borracha e os aminoácidos são responsáveis pelo endurecimento por tempo de estocagem, pois aumentam a quantidade de ligações cruzadas. Alguns íons metálicos como $\mathrm{Cu}, \mathrm{Mn}$ e Fe, que fazem parte dos constituintes não-borracha, agem como oxidantes, pois desempenham um papel importante nas reações de ligação cruzada e na integridade das cadeias poli-isoprênicas. Gan et al. [35] estudaram o complexo fenômeno envolvendo reações de ligações cruzadas de alguns íons metálicos com as cadeias de borracha comparando os valores de $\mathrm{P}_{0}, \mathrm{PRI}$ e \% de nitrogênio de amostras de látex padrão com aquelas tratadas com íons metálicos. Segundo os autores, cátions monovalentes como $\mathrm{Li}^{+}, \mathrm{Na}^{+}, \mathrm{K}^{+}$e $\mathrm{Cs}^{+}$, não afetam a incorporação de grupos nitrogenados na cadeia da borracha e portanto, não afetam as reações de ligação cruzada. Por outro lado, os resultados mostraram que a adição de cátions divalentes no látex, como $\mathrm{Ba}^{+2}, \mathrm{Ca}^{+2} \mathrm{e} \mathrm{Mg}^{+2}$, diminuiu a quantidade de grupos nitrogenados na borracha e conseqüentemente refletiu na diminuição do tempo de envelhecimento da borracha.

\section{2.b. Propriedades Gerais da Borracha Natural}

A borracha natural é composta principalmente por um polímero o 1,4 policis-isopreno que é uma cadeia linear que se apresenta no látex de forma heterogênea, ou seja, em diversos tamanhos. No entanto, o valor numérico da massa molecular da borracha depende da forma como ele é medido podendo ser expresso tanto como 
massa molar numérica média $\mathrm{Mn}$, tanto como a média da massa molar Mw. A relação entre Mn e Mw depende da distribuição do tamanho das cadeias poliméricas no látex. As duas medidas ( $\mathrm{Mn}$ e $\mathrm{Mw}$ ) são iguais somente quando o polímero é monodisperso, do contrário $\mathrm{Mw}$ é maior que $\mathrm{Mn}[36,37]$. Em geral, os valores de Mw estão em torno de $2 \times 10^{6}$ e Mn em torno de $5 \times 10^{5}$ como mostra a Tabela 1 abaixo.

Tabela 1. Pesos moleculares médios de borrachas crepe de alguns clones [38].

\begin{tabular}{c|c|c}
\hline Clones & Mw x 10 $^{6}$ & Mn x 10 \\
\hline Tjir 1 & 2.26 & 4.76 \\
PB 5/51 & 2.18 & 5.21 \\
PB 86 & 2.04 & 3.61 \\
RRIM 600 & 1.93 & 2.58 \\
GT 1 & 1.85 & 2.65 \\
RRIM 703 & 1.72 & 2.03 \\
RRIM 501 & 1.71 & 1.95 \\
\hline \hline
\end{tabular}

Uma outra forma de caracterizar um polímero como a borracha natural é analisar a sua distribuição de massa molar. Esta forma de caracterização, medida em geral pela técnica de permeação em gel, pode ser bimodal e unimodal. A Figura 8 apresenta os três tipos de distribuição da massa molecular da borracha natural. A curva de Tipo 1 mostra distribuição bimodal com picos de maior e menor massa molecular praticamente na mesma altura, o Tipo 2 também apresenta a forma bimodal, mas com o pico de maior massa molecular mais alto do que o pico de menor massa molecular já a curva representada pelo Tipo 3 é unimodal [37, 39]. 


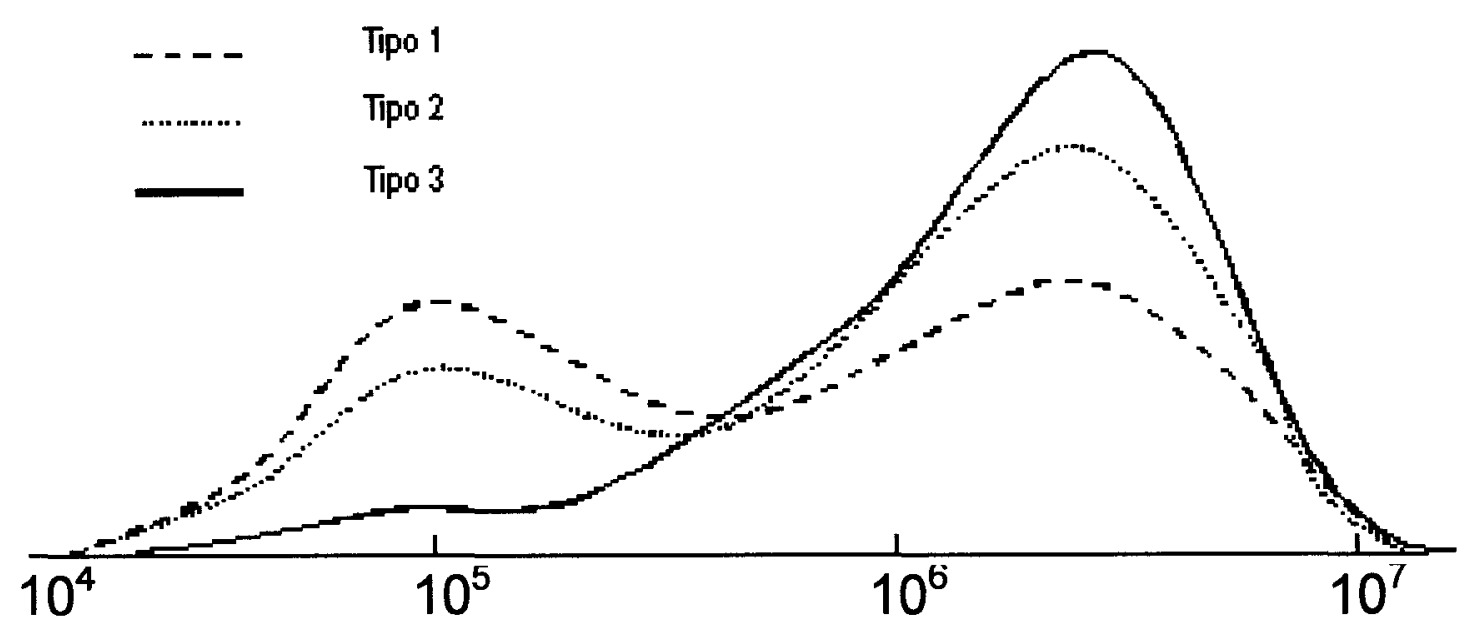

Figura 8. Tipos de curvas de distribuição de massa molecular da borracha natural [39].

Tipo 1: Distribuição bimodal onde os picos estão quase à mesma altura. Tipo 2: Distribuição bimodal onde o pico na região de baixo peso molecular é menor. Tipo 3: Distribuição unimodal com um "ombro" ou "platô" na região de baixo peso molar.

Algumas propriedades da borracha mudam consideravelmente com a variação da temperatura. Quando a borracha é excessivamente resfriada para valores próximos da $T_{g}$ (temperatura de transição vítrea) ela torna-se quebradiça. No entanto, quando ela é resfriada, sem que mudanças irreversíveis ocorram, a borracha pode retornar ao seu estado original através do aquecimento e recuperar as suas propriedades. $O$ polímero em questão, quando em uso deve estar em torno de $50{ }^{\circ} \mathrm{C}$ acima de sua temperatura de transição vítrea $\left(\mathrm{T}_{\mathrm{g}}\right)$, considerando que a $\mathrm{T}_{\mathrm{g}}$ das borrachas está dentro de um intervalo de temperatura de -50 a $-80{ }^{\circ} \mathrm{C}$ [40], o que permite alta mobilidade de segmentos da cadeia. Esta mobilidade significa facilidade nas mudanças de conformação das cadeias poliméricas. Muitos polímeros, tais como a borracha, são flexíveis devido facilidade à rotação das ligações simples $\mathrm{C}-\mathrm{C}$, o que permite a formação de diferentes conformações. A rotação de átomos ligados covalentemente é também impedida pela presença de duplas ligações. Assim são possíveis configurações cis e trans dos poli-isoprenos que são conhecidos como borracha Hevea flexível e como plástico duro Gutta percha, respectivamente. A Figura 9 mostra a fórmula estrutural do poli (cis - 1,4 - isopreno) não vulcanizado. 


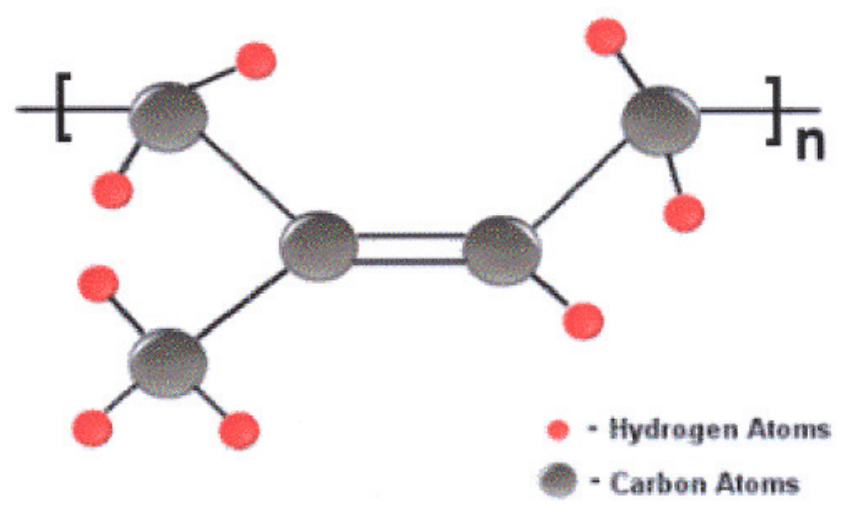

Figura 9. Fórmula estrutural do 1,4 poli-cis-isopreno

Quando aquecidas às borrachas amolecem, tornando-se pegajosas e em temperaturas acima de $200{ }^{\circ} \mathrm{C}$ inicia-se a degradação térmica. Alguns elastômeros, quando aquecidos por um longo tempo (em temperaturas menores do que a temperatura de degradação) formam ligações cruzadas e tornam-se duros, como por exemplo, a borracha de butadieno - estireno.

Para que um polímero se comporte como borracha ele deve estar no estado amorfo, já que a cristalinidade restringe os movimentos moleculares necessários para a ocorrência da elasticidade.

Somente quando as ligações químicas são introduzidas entre moléculas vizinhas através da vulcanização, é que a borracha é convertida em material tecnicamente utilizável. As borrachas vulcanizadas devem conter uma "rede" de ligações cruzadas (baixa densidade de ligações cruzadas) para restringir os escoamentos relativos entre as cadeias poliméricas, já que estas poderiam deslizar umas sobre as outras quando aplicada uma tensão externa, e a recuperação seria incompleta. As ligações devem ser relativamente em pequeno número, isto é, sem impedir a mobilidade dos segmentos de cadeia, e consideravelmente de forma que o estiramento até grandes extensões possa ser possível sem a ruptura de ligações primárias [40]. Esta habilidade de formar ligações cruzadas é tecnicamente a propriedade mais importante da borracha. A formação das ligações cruzadas é um processo aleatório, com uma ligação sendo formada, em geral, a cada 100-200 unidades monoméricas, sendo que o principal agente de vulcanização é o enxofre. 


\subsection{Estudo e Avaliação da Variação Intra e Interclonal nas Propriedades da Borracha Natural.}

A seringueira pertence à família das Euforbiáceas e é uma dicotiledônea monóica, pois possui flores masculinas e femininas em um mesmo individuo. As flores são unissexuadas, pequenas e amareladas e as folhas longamente pecioladas e repartidas em três folíolos. O fruto é uma cápsula grande que geralmente apresenta três sementes. As Figuras 10, 11 e 12 mostram a seringueira, o fruto e as sementes extraídas do fruto. Tradicionalmente, a seringueira tem sido cultivada na região equatorial onde encontra as condições ideais para o seu desenvolvimento podendo atingir até 50 metros [41]. Entretanto, o aumento da demanda da borracha natural fez com que várias regiões do mundo, fora da zona convencional, iniciassem seu cultivo [42]. No estabelecimento de um seringal, a muda deve ser considerada como insumo básico para o sucesso do empreendimento. Dada a alta variabilidade genética da espécie, quando propagada por via sexuada, a muda deve ser produzida por via assexuada utilizando-se, neste caso, a enxertia por borbulha. Em geral, as sementes híbridas utilizadas no processo de enxertia são de clones altamente produtivos e recomendados para o plantio devido à alta produtividade, baixa suscetibilidade à quebra pelo vento e resistência a pragas.

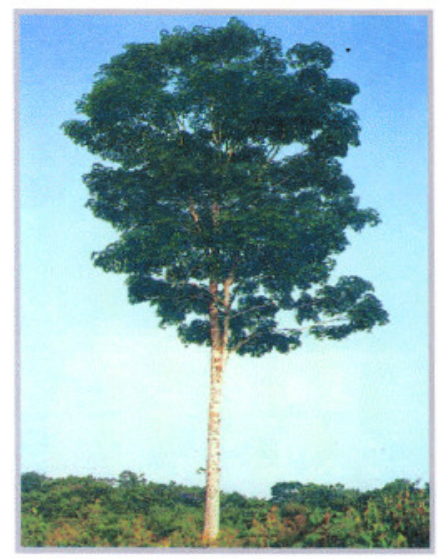

Figura 10. Hevea brasilienses

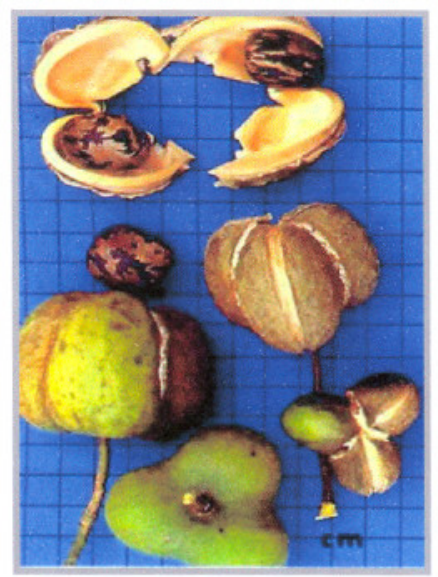

Figura 11. Fruto da Hevea

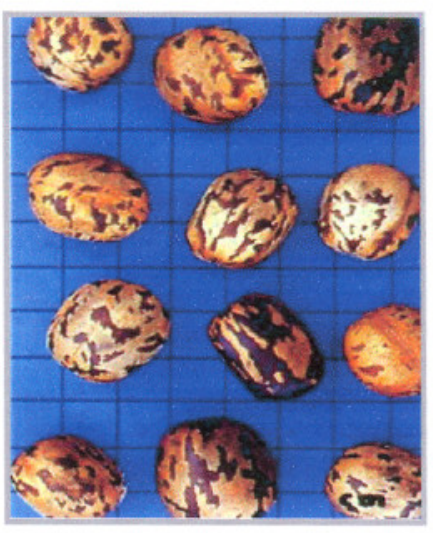

Figura 12. Sementes da Hevea 
Um clone é formado por um grupo de plantas obtidas através da propagação vegetativa de uma planta matriz. Todas as árvores de um clone possuem a mesma constituição genética, responsável pela uniformidade existente entre elas [41, 42]. Os clones, como material para o estabelecimento de um seringal, apresentam várias vantagens e a mais importante é a uniformidade exibida pelos seus indivíduos. Todas as árvores de um mesmo clone, sob as mesmas condições ambientais, apresentam baixa variabilidade em relação a diferentes caracteres como: vigor, espessura de casca, produção, senescência anual das folhas, nutrição e tolerância a pragas e doenças. De certa forma, isso possibilita ao heveicultor adotar um manejo fácil e econômico. Com crescimento uniforme, o número de árvores de um seringal, que necessita ser descartado, é sempre menor. Outro ponto importante a considerar no clone é a uniformidade das propriedades do látex. Para propósitos industriais específicos, ele é mais bem apreciado, considerando essa uniformidade essencial. Através de clones possuidores de caracteres específicos diferenciados, é possível a seleção de material para as mais diversas situações exigidas para enxertos [41, 43].

Com base nos parentais utilizados nos cruzamentos para obtenção da árvore matriz, os clones costumam ser classificados como primários, secundários $\mathrm{e}$ terciários. Clones oriundos de parentais desconhecidos são chamados clones primários. Em geral, essas árvores matrizes possuem caracteres desejáveis, sendo portanto, multiplicadas vegetativamente para dar origem ao clone. Em clones secundários, as árvores matrizes são obtidas através de cruzamentos controlados entre dois clones primários. As árvores matrizes são então multiplicadas vegetativamente, do mesmo modo que os clones primários. Clones terciários são obtidos de cruzamento em que pelo menos um dos paternais é secundário [41, 43]. A Tabela 2 mostra a origem e parentais dos clones GT 1, RRIM 600 e PB 235 estudados no presente trabalho. 
Tabela 2. Origem e parentais dos clones GT 1, RRIM 600 e PB 235

\begin{tabular}{ccc}
\hline Clones $^{1}$ & Parental & Origem \\
\hline GT 1 & Clone Primário & Indonésia \\
PB 235 & PB 5/51 x PBS 78 & Malásia \\
RRIM 600 & Tjir 1 x PB 69 & Malásia \\
\hline
\end{tabular}

${ }^{1}$ GT - Godang Tapen; RRIM - Rubber Research Institute of Malaysia; PB - Prang Vesar; Tjir - Tjirandji.

A seguir serão apresentadas as características agronômicas dos clones de importância comercial que foram estudados neste trabalho.

\section{Clone GT 1}

Clone primário desenvolvido no seringal Gondang Tapen, na Indonésia. A árvore, de caule bem vertical, pode apresentar irregularidades, tais como estrias ou torções na região do enxerto. A abertura da copa é bem tardia e de hábito variável, pois algumas árvores não apresentam galhos líderes, enquanto outras possuem vários. As árvores jovens são altas e tendem a entortar quando a formação dos galhos é tardia. Durante o período de imaturidade, as folhas são grandes, verde-escuras e brilhantes, e menores quando a árvore atinge a fase adulta. A casca virgem é média, muito tenra, e se renova imediatamente, não apresentando problemas à sangria. Na Costa do Marfim, o vigor, expresso pelo crescimento da circunferência do caule até a abertura do painel de sangria, é razoável, tornando-se lento após a sangria normal, mas em compensação, é um clone muito homogêneo. É considerado de excelente produção, tanto que na Malásia a sua média nos primeiros dez anos foi de $1723 \mathrm{Kg} / \mathrm{ha} / \mathrm{ano}$; na Costa do Marfim nos primeiros cinco anos de $1728 \mathrm{Kg} / \mathrm{ha} /$ ano e no Estado de São Paulo foi de $1810 \mathrm{Kg} / \mathrm{ha} /$ ano, no sistema $1 / 2 \mathrm{~S} \mathrm{~d} / 26 \mathrm{~d} / 7$. A produção tem um pequeno declínio durante a senescência. Apresenta caracteres secundários desejáveis, pois a resistência à quebra pelo vento é de média para boa e a ocorrência de seca do painel, é pouco notada, salvo quando submetido à sangria intensiva. Demonstra uma tendência de aumentar a produção de látex com o passar do tempo. $\mathrm{O}$ látex é branco e adequado para todos os processos de produtos manufaturados. $\mathrm{Na}$ 
China, revelou-se tolerante às geadas e ao vento. Por ser precoce e pela sua rusticidade e qualidades agronômicas, deve ser recomendado para pequenos heveicultores do Planalto Paulista $[41,43]$.

\section{Clone PB 235}

Clone secundário resultante do cruzamento dos clones primários PB $5 / 51$ x PBS /72, originários da Malásia. A árvore possui caule muito reto, regular, e boa compatibilidade com relação ao enxerto e porta-enxerto. Quando jovem, possui, na base, muitos galhos pequenos, dispostos horizontalmente. As árvores adultas revelam uma formação de galhos bem homogênea, mas entre os seis e os dez anos, ocorre um desbaste natural, proporcionando o aparecimento de novos ramos mestres muito altos e com ângulo bem definido. As folhas são de coloração verde bem acentuada. Na Costa do Marfim, apresenta senescência parcial, pois não ocorre praticamente o desfolhamento total e a queda das folhas dentro da própria estação é muito lenta. A casca virgem é lisa, espessa, tenra, sem problemas na sangria. É considerado muito vigoroso, pois o início da sangria se dá por volta de cinco anos e meio, é altamente produtivo. Na Malásia observou-se que a média de produção, nos 5 primeiros anos, foi de $2273 \mathrm{Kg} / \mathrm{ha} /$ ano no sistema $1 / 2 \mathrm{~S} \mathrm{~d} / 26 \mathrm{~d} / 7$ enquanto que no Estado de São Paulo no mesmo sistema de sangria observou-se média de $2000 \mathrm{Kg} / \mathrm{ha} / \mathrm{ano}$. Em função do número de árvores comumente afetadas por esse problema, nos sistemas normais de sangria, e da susceptibilidade ao oídio, o plantio deve ser aconselhado com a devida reserva.

\section{Clone RRIM 600}

Clone secundário desenvolvido pelo Rubber Research Institute of Malaysia, cujos parentais são os clones primários Tjir 1 e PB 86. As suas árvores são altas, com caule vertical e de rápido crescimento quando jovem. Os ramos aparecem tardiamente e formam grossas bifurcações que acarretam grande peso para a base das plantas e, em caso de problemas ocasionados pelo vento, haverá quebra, podendo provocar o aparecimento de clareiras no seringal. No Estado de São Paulo, esse clone é considerado suscetível ao vento. A copa é estreita e a folhagem esparsa, apresentando folhas pequenas verde-claras. $\mathrm{O}$ vigor, se comparando antes e após a 
entrada em sangria, é considerado médio. A casca por ser fina, torna-o um pouco delicado à prática de sangria; em compensação, a renovação é boa. Em plantios comerciais da Malásia, sua média de produção nos primeiros 5 anos foi de 1540 $\mathrm{Kg} /$ ha/ano $(1 / 2 \mathrm{~S} \mathrm{~d} / 2)$. O clone exibe tendência de produção crescente porque, em geral, a produção inicial é média e as subseqüentes são muito mais altas. A produção durante o estágio de senescência também é alta. $O$ látex é branco e impróprio para concentração, devido à baixa estabilidade. É altamente suscetível ao cancro do tronco (Phytophthora spp.) na Costa do Marfim e considerado pouco tolerante ao frio na China. É o clone mais plantado na região do Planalto Paulista por apresentar bom desempenho no que tange a produção e vigor $[42,43]$.

Os clones apresentados anteriormente são clones desenvolvidos na Ásia para atingir características agronômicas ideais (como alta produtividade, boa resistência a pragas e doenças etc). No Brasil, através do programa de melhoramento genético da seringueira, em andamento no IAC, foi obtida uma série de novos clones que, em conjunto com asiáticos são de grande potencial de produção, e encontram-se em fase de avaliação com vistas de recomendação para o plantio em larga escala no Estado.

Sabe-se que apesar das boas características técnicas da borracha natural, as suas propriedades apresentam grande variabilidade e falta de uniformidade. Poucos são os trabalhos na literatura voltados para o estudo e avaliação dessas propriedades buscando em função do tipo de clone, tipo de processamento e influência do solo na qualidade do produto pós-colheita. Neste contexto, o estudo da variação intra e interclonal nas propriedades da borracha natural busca avaliar se as diferenças nestas propriedades são estatisticamente relevantes para a indústria consumidora da borracha natural. Até agora, não há na literatura nenhum trabalho que avalie, de forma sistemática, as variações das propriedades da borracha natural dentro de um mesmo clone e entre clones. Portanto, na primeira etapa do trabalho, as propriedades DRC, \% de nitrogênio, plasticidade Wallace, viscosidade Mooney, PRI e extrato acetônico foram estudadas para os clones PB 235, GT 1 e RRIM 600 e as diferenças intra e interclonais puderam ser avaliadas. 


\subsection{Avaliação da influência do tipo de porta-enxerto nas propriedades da Borracha Natural}

Com a "domesticação" da cultura facilitada pelo uso da técnica de enxertia, como método de propagação, aumentaram-se as possibilidades de obtenção de plantas mais homogêneas e produtivas no seringal. Uma vez que a seringueira é uma planta alógama com alto grau de segregação, a propagação vegetativa é a mais recomendada e visa assegurar a integridade genotípica dos clones estabelecidos. $\mathrm{O}$ método mais empregado é o da enxertia por borbulha em porta-enxertos provenientes de sementes. Sendo assim, em plantações comerciais, os clones são escolhidos em função da sua adaptabilidade local e da sua produtividade; já os porta-enxertos, desde que preencham as condições ideais de enxertia, pouca importância lhes é dada quanto a sua procedência ou descendência.

A seleção do material a ser enxertado levou a um aumento da produtividade e resistência a doenças. No entanto, nunca houve uma preocupação com o tipo de porta-enxerto selecionado até que alguns pesquisadores [44] mostraram a influência deste no crescimento e na produção do enxerto. Dentre as principais influências causadas pelo porta-enxerto em relação ao enxerto evidenciou-se a existência de grande variabilidade intra-clonal para vigor e produção [45].

Geralmente as sementes utilizadas nos viveiros não possuem nenhum rigor de coleta, empregando-se sementes das mais variadas origens e procedências, o que influencia as variáveis de crescimento e produção em um seringal. Assim, o uso de sementes capazes de produzir porta-enxertos homogêneos, vigorosos e de alta produtividade é indispensável para realçar o potencial dos clones empregados.

Nos países asiáticos, onde a cultura da seringueira é tecnicamente mais avançada, já são conhecidas as melhores combinações entre enxertos e portaenxertos. Este fato tem proporcionado um melhor desempenho no plantio de seringais comerciais e conseqüentemente um maior sucesso no empreendimento. No Brasil porém, pouco são os resultados de pesquisa sobre a interação de clones com porta-enxertos obtidos a partir de sementes clonais. Recentemente nos estado de São Paulo, Gonçalves et al. [44, 45] avaliaram o vigor de seis populações de portaenxertos anteriores ao processo de enxertia. Na avaliação foram utilizadas variáveis 
de crescimento mostrando, inclusive, a existência de diferenças significativas entre os porta-enxertos para quaisquer das variáveis estudadas. Não foram encontradas, até agora, na literatura referências sobre a influência de porta-enxertos nas propriedades técnicas da borracha como plasticidade, viscosidade, PRI, etc. Neste sentido, essa etapa do trabalho visa avaliar, através de um estudo sistemático, se as propriedades da borracha natural como \% de DRC, \% de nitrogênio, \% de cinzas, viscosidade Mooney, plasticidade Wallace e PRI variam em função do porta-enxerto. O objetivo é o de mostrar se existem ou não diferenças nas propriedades da borracha natural dos diferentes clones dependendo do tipo de porta-enxerto que foi utilizado no momento da plantação e se essas diferenças são estatisticamente importantes. 


\subsection{Efeito dos Tratamentos de Estabilização, Coagulação e Estocagem nas Propriedades da Borracha Natural.}

A borracha natural, apresenta uma variação nas suas propriedades na medida em que fica estocada [30, 35]. Este fenômeno é chamado de envelhecimento por estocagem e tem sido muito estudado, pois afeta as propriedades e conseqüentemente o processamento e a homogeneidade da borracha. A estocagem da borracha natural é muito comum nas fazendas produtoras e pequenos seringais que estocam a sua borracha para aguardar a coleta feita pelos caminhões da empresas compradoras. Durante a estocagem, a borracha torna-se mais dura e os valores de plasticidade Wallace e viscosidade Mooney tornam-se mais altos em função do aumento do período de dias de estocagem. Acredita-se que esse endurecimento se dá devido ao aumento do número de ligações cruzadas na borracha. $O$ endurecimento por estocagem não é simplesmente um subproduto de degradação oxidativa, mas envolve grupos adjacentes presentes na cadeia isoprênica como, por exemplo, grupos aldeído, epóxi e aminoácidos [30]. Sekhar et al. [46] propuseram a presença de grupos aldeído adjacentes à cadeia isoprênica através da observação de que certas monoaminas, como a hidroxilamina, inibiam o processo de endurecimento por estocagem na borracha.

Muitos trabalhos na literatura $[47,48,49,50]$ vêm propondo mecanismos de formação de ligações cruzadas envolvendo grupos aldeído e epóxi adjacentes à cadeia isoprênica. Segundo os autores, os aminoácidos presentes na borracha natural quebram os anéis epóxi dando origem a uma amina substituída, essa pode interagir com outros grupos epóxi adjacentes à cadeia isoprênica formando as ligações cruzadas. A Figura 13 mostra o mecanismo de reação de poli-cis-isopreno com aminoácidos presentes na borracha que foi proposto por Burfield [51]. 

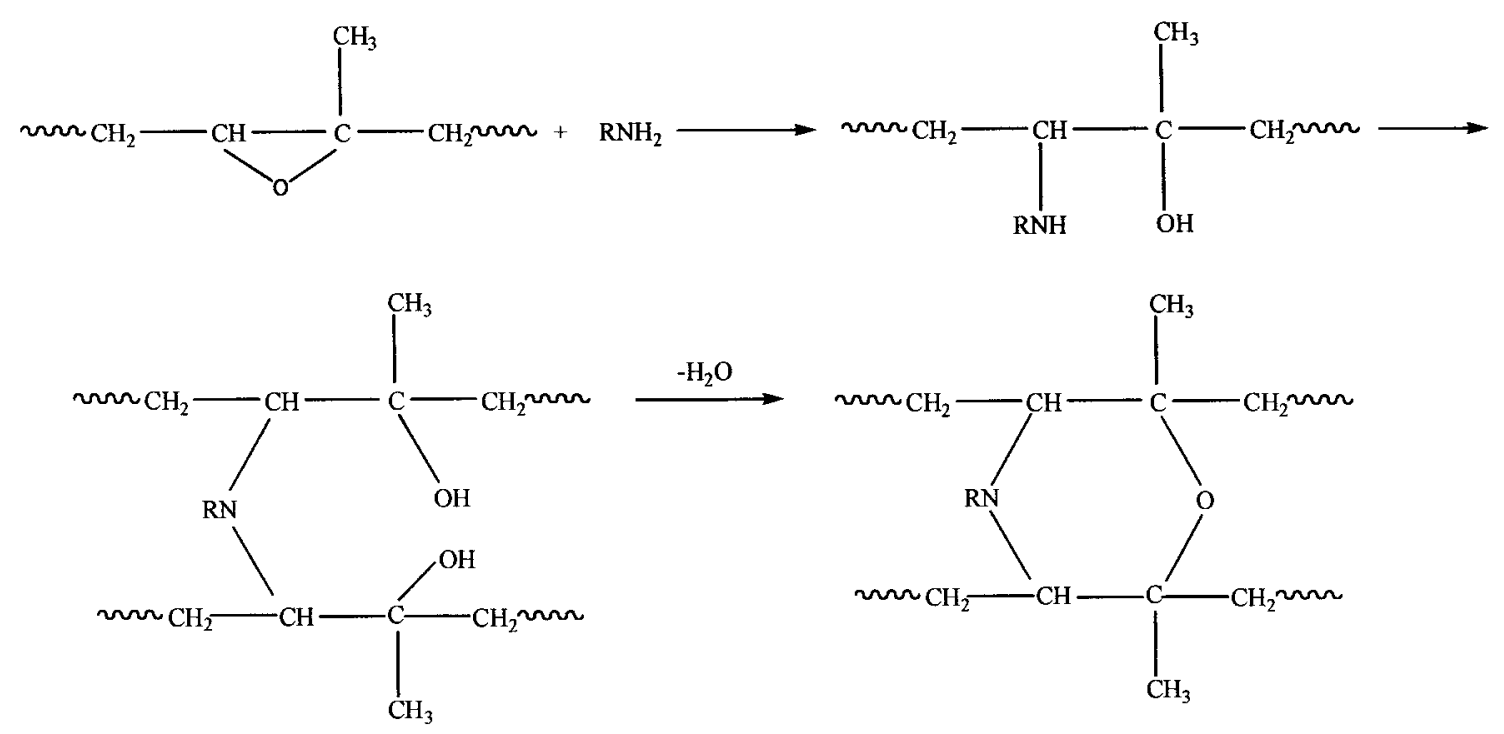

Figura 13. Esquema de reação do grupo epóxi adjacente à cadeia isoprênica reagindo com o aminoácido presente no soro da borracha natural [51].

As reações acima citadas são aceleradas em condições de baixa umidade e inibidas com a remoção das proteínas e aminoácidos, que pode ser feita através da centrifugação ou adição de hidroxilamina [52]. Li et al. [53] estudaram a variação da estrutura e propriedade da borracha natural durante o envelhecimento acelerado. Segundo este estudo, à medida que a amostra é envelhecida a distribuição da massa molar é modificada e passa de bimodal para unimodal. O conteúdo de gel aumenta e a densidade de ligações cruzadas flutua em um determinado intervalo. As variações na estrutura da cadeia refletem nos valores de $P_{0}, V_{0}$ e PRI. A investigação das propriedades físicas da borracha, assim como seu processo de degradação têm sido amplamente estudados. $O$ intuito dos pesquisadores é compreender melhor este fenômeno e, desta forma, manipular os parâmetros físico-químicos da borracha natural para obter propriedades mais homogêneas para o polímero natural, satisfazendo os consumidores e otimizando os seus processos de fabricação. Até agora não existe na literatura brasileira nenhum trabalho que mostre como as condições e o processo de estocagem feito no campo afetam as propriedades mecânicas da borracha natural.

Nesta etapa do trabalho, a borracha do clone RRIM 600 foi estocada por diferentes períodos de tempo e caracterizada. $\mathrm{O}$ estudo foi feito através de ensaios padrões de DRC, \% de nitrogênio, plasticidade Wallace, Viscosidade Mooney e PRI, medidas de Calorimetria Diferencial de Varredura (DSC), análise termogravimétrica 
(TG), análise termo dinâmico-mecânica (DMTA) e espectroscopia de infravermelho (FTIR). 


\subsection{Estudo das Propriedades nanomecânicas da borracha} natural via técnica de nanoindentação

A investigação das propriedades mecânicas de polímeros pode ser estudada em três diferentes dimensões: a macroscópica $(\mathrm{mm})$, microscópica $(\mu \mathrm{m})$ e molecular $(\mathrm{nm})$, sendo que as duas primeiras estão sendo investigadas há mais de 60 anos. Para um maior entendimento e controle da relação estrutura-propriedade do material é importante entender e correlacionar o comportamento mecânico da cadeia polimérica nestas três dimensões. Recentemente, a invenção de instrumentos como microscópio de força atômica (AFM), microscópio de força magnética (MLFM) e nanoindentadores têm facilitado o estudo das propriedades físicas de materiais em escala molecular e ampliado novos campos como o da nanomecânica. As técnicas de microscopia de força atômica AFM, Figura 14, permitem o estudo da imagem topográfica da superfície de vários materiais como polímeros, elastômeros e materiais biológicos como DNA (Figura 15) hemoglobina (Figura 16) e colágeno, (Figura 17).

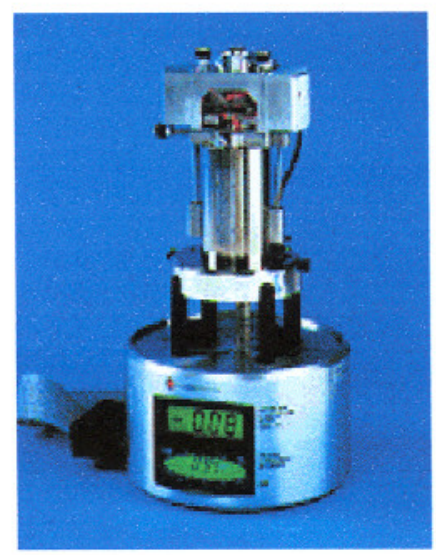

Figura 14. Foto de aparelho de AFM [54]. 


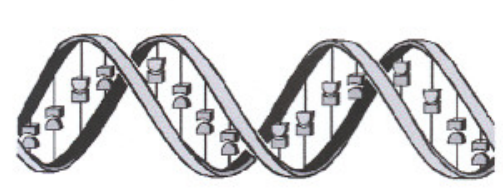

Figura 15. Representação esquemática do DNA

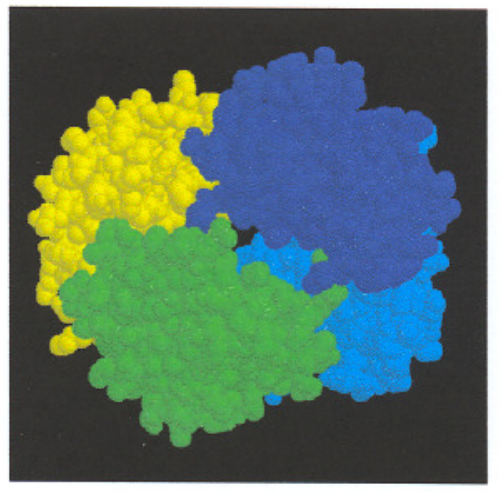

Figura 16. Representação esquemática da Hemoglobina

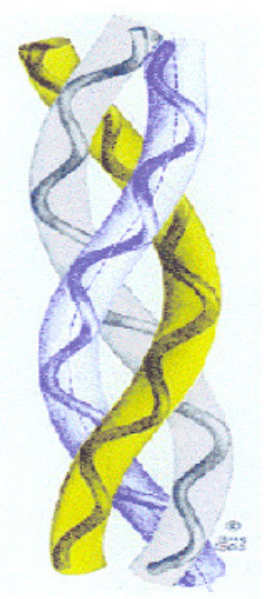

Figura 17. Representação esquemática do Colágeno

Na Figura 18, está representado um esquema simplificado de medida de microscopia de força atômica, em que um cantiléver, fabricado geralmente com nitreto de silício, possui uma sonda em uma das suas pontas e o sistema cantiléversonda percorre a superfície do material produzindo uma imagem topográfica do mesmo. A deflexão sofrida pelo cantiléver é transmitida para um fotodetector, através de um feixe de raio laser, o sinal obtido é transmitido para um computador onde os dados são coletados e posteriormente tratados, Figura 18. Uma imagem da altura da amostra versus a posição horizontal da sonda pode então ser obtida, Figura 19. 


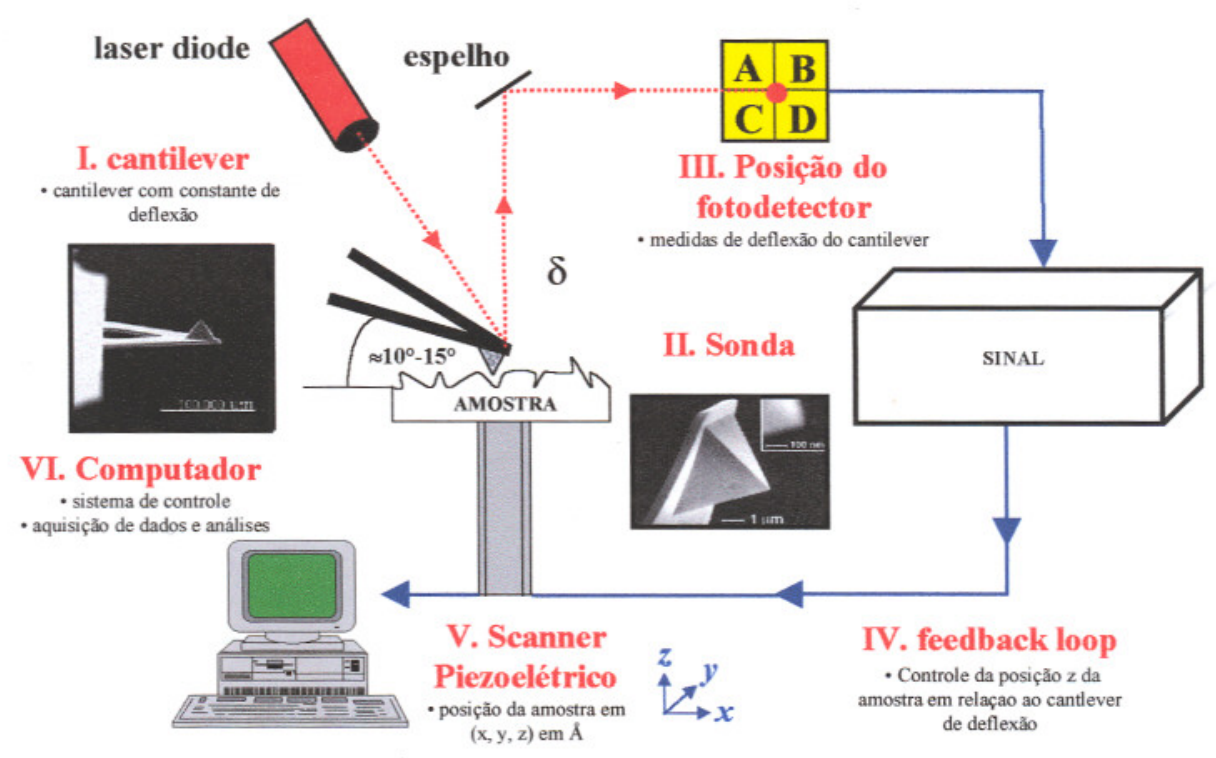

Figura 18. Esquema simplificado de um aparelho de Microscopia de Força Atômica.

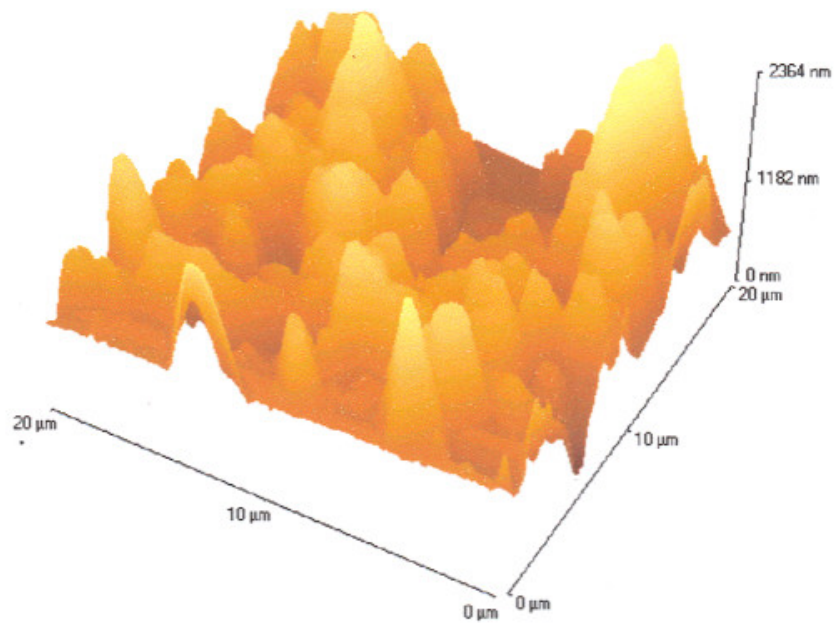

Figura 19. Imagem de Microscopia de Força Atômica (AFM) feita em amostra de látex diluído em água a $30 \%$. A deposição foi feita em superfície de quartzo através de técnica de "self-assembly" com 30 min de imersão.

Em medidas de AFM no modo contato convencional, a sonda é arrastada na superfície da amostra determinando a imagem topográfica do material a partir da oscilação sofrida pelo cantiléver. Este método é bastante utilizado em muitos materiais, com excelentes resultados mas, tem muitos inconvenientes como a adesão da amostra na sonda. Nestes casos, além da medida ser prejudicada, devido a uma menor resolução da imagem, muitas vezes o cantiléver e sonda sofrem danos 
irreparáveis não permitindo a reutilização dos mesmos. A Figura 20 mostra um esquema convencional de medida de AFM no modo contato.

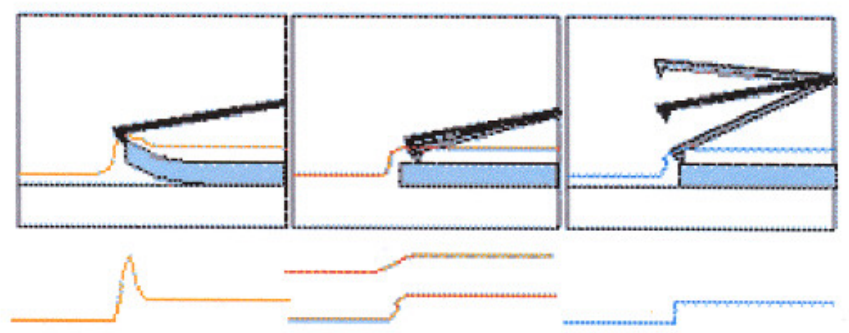

Figura 20. Esquema de medida de AFM no modo contato conventional. Exemplo de adesão da amostra na sonda [54].

Nas análises realizadas em condição ambiente, a superfície do material estudado apresenta uma fina camada de vapor de água adsorvida e isto pode interferir nas medidas devido às interações eletrostáticas da sonda em relação à amostra. Vários estudos têm sido realizados para tentar diminuir este tipo de interação, Weisenhorm et al. [55] descobriram que a força de adesão entre uma sonda de nitreto de silício e a mica pode ser reduzida cem vezes quando o sistema é imerso em água.

Outro modo utilizado na realização de medidas de AFM é o chamado não contato. Neste método a sonda é mantida a uma certa distância acima da amostra e os dados obtidos correspondem a uma medida da interação entre a sonda e amostra devido a presença das forças de van der Walls, que são mais fracas do que aquelas forças medidas no modo contato. Apesar de importante na análise de vários tipos de materiais, o modo não contato restringe a análise de amostras que possuem baixa densidade deste tipo de ligação. Nestes casos, a resolução se torna muito baixa comprometendo a qualidade das imagens obtidas.

Em adição a estes dois métodos de análises de amostras por AFM existe um terceiro, chamado de "Tapping Mode", onde o cantiléver fica oscilando em uma freqüência constante de 50 a 500.000 ciclos por segundo, tocando eventualmente na amostra e evitando que ela arraste a superfície. Quando a sonda toca a superfície da amostra, a amplitude de oscilação do cantiléver é reduzida, devido à perda de energia ocasionada pelo contato da sonda com a amostra. Da mesma forma, se a sonda passa por um "obstáculo" esta amplitude diminui ainda mais. Ao contrário, quando a sonda varre uma depressão na superfície o cantiléver tem mais espaço para oscilar e a 
amplitude aumenta. A Figura 21 mostra o esquema de medida em "tapping mode" em microscopia de força atômica. A amplitude de oscilação do cantiléver é medida por um detector e informações como elasticidade, deformação plástica, dureza e força de adesão podem ser obtidas.

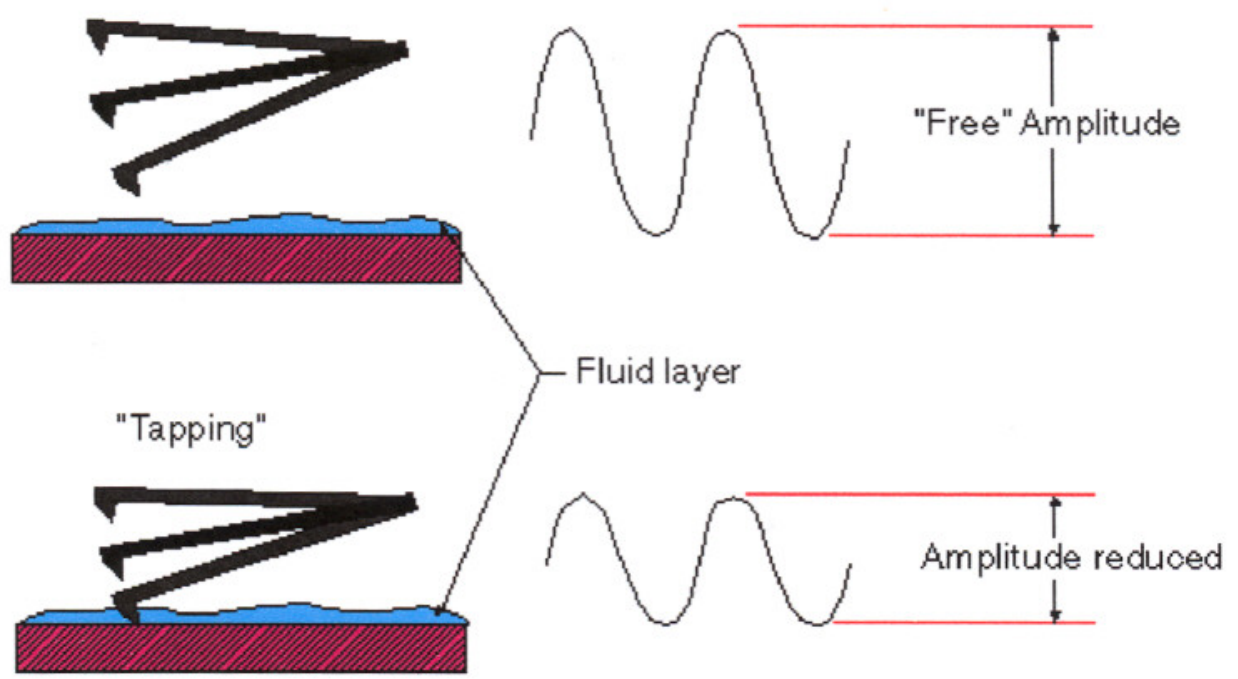

Figura 21. Esquema de medida em "tapping mode" em microscopia de força atômica [54].

O AFM permite a realização da nanoindentação nas amostras de diversos materiais tanto na área de engenharia de materiais [56, 57] como na de polímeros, filmes finos [58], cristais, biomateriais [59, 60]: proteínas, DNA e células do sangue. Nesta técnica, uma sonda, montada na ponta de um cantiléver flexível, Figura 22, é indentada a uma razão constante na superfície do material a ser estudado e em seguida é retraída. 


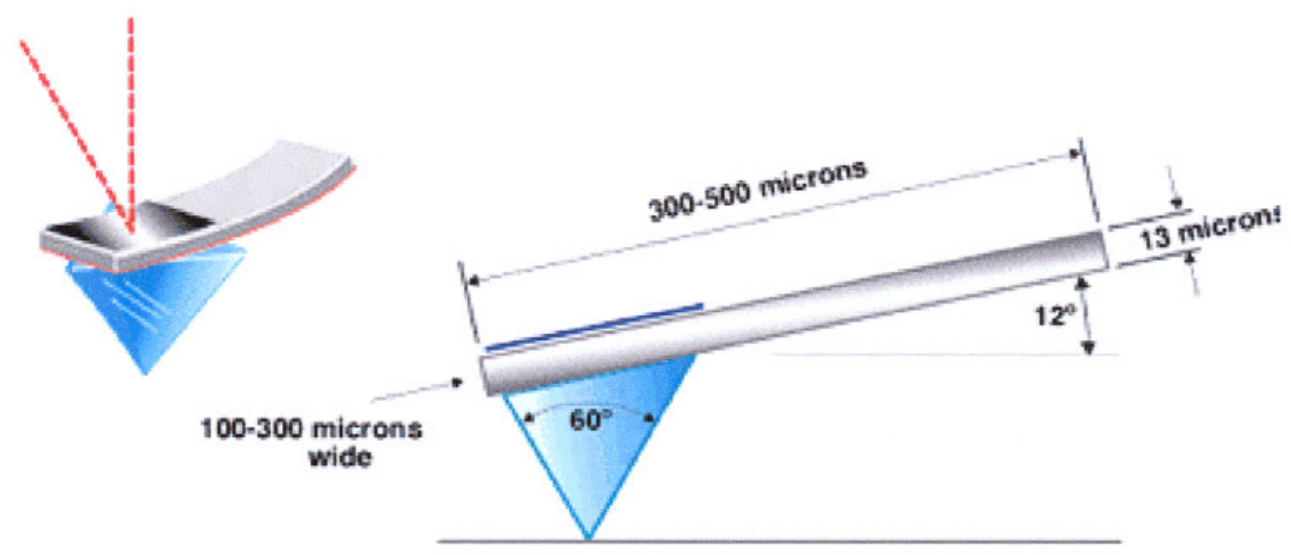

Figura 22. Cantiléver com dimensões [54].

As Figuras 23 e 24 esquematizam uma medida de força versus distância realizada com técnica de AFM. Na primeira etapa -aproximação- observamos que na região A a sonda ainda não toca a superfície da amostra e o cantiléver praticamente não sente as forças atrativas (ou repulsivas) do material analisado, portanto, não sofre deflexão. Na região B, a sonda se aproxima e toca o material passando a sentir as forças atrativas da amostra e na medida que essas forças aumentam o cantiléver passa a sofrer deflexão, região $\mathbf{C}$. Essa deflexão $D$ é proporcional à força aplicada e pode ser determinada a partir da relação $\mathrm{F}=k D$ (onde k é a constante de mola da ponta e $D$ é a deflexão sofrida pelo cantiléver) para casos onde não há deformação na superfície da amostra. Para amostras duras, a dureza do material deve ser muito maior do que a constante de mola da ponta ( $\mathrm{S}>>$ ). Essa situação é representada, na curva de força versus distância por uma linha reta, Figura 24. Por outro lado, se o cantiléver for suficientemente forte (dureza do material $\mathrm{S}<<k$ ) ele pode indentar a superfície da amostra e a curva de força em $\mathrm{nN}$ versus deslocamento do piezo em $\mathrm{nm}$ obtida muda de forma. Nesse caso, não ocorre a deflexão no cantiléver mas sim, uma deformação na superfície da amostra ou seja, a indentação, o que resulta em uma linha com a característica de uma curva. 

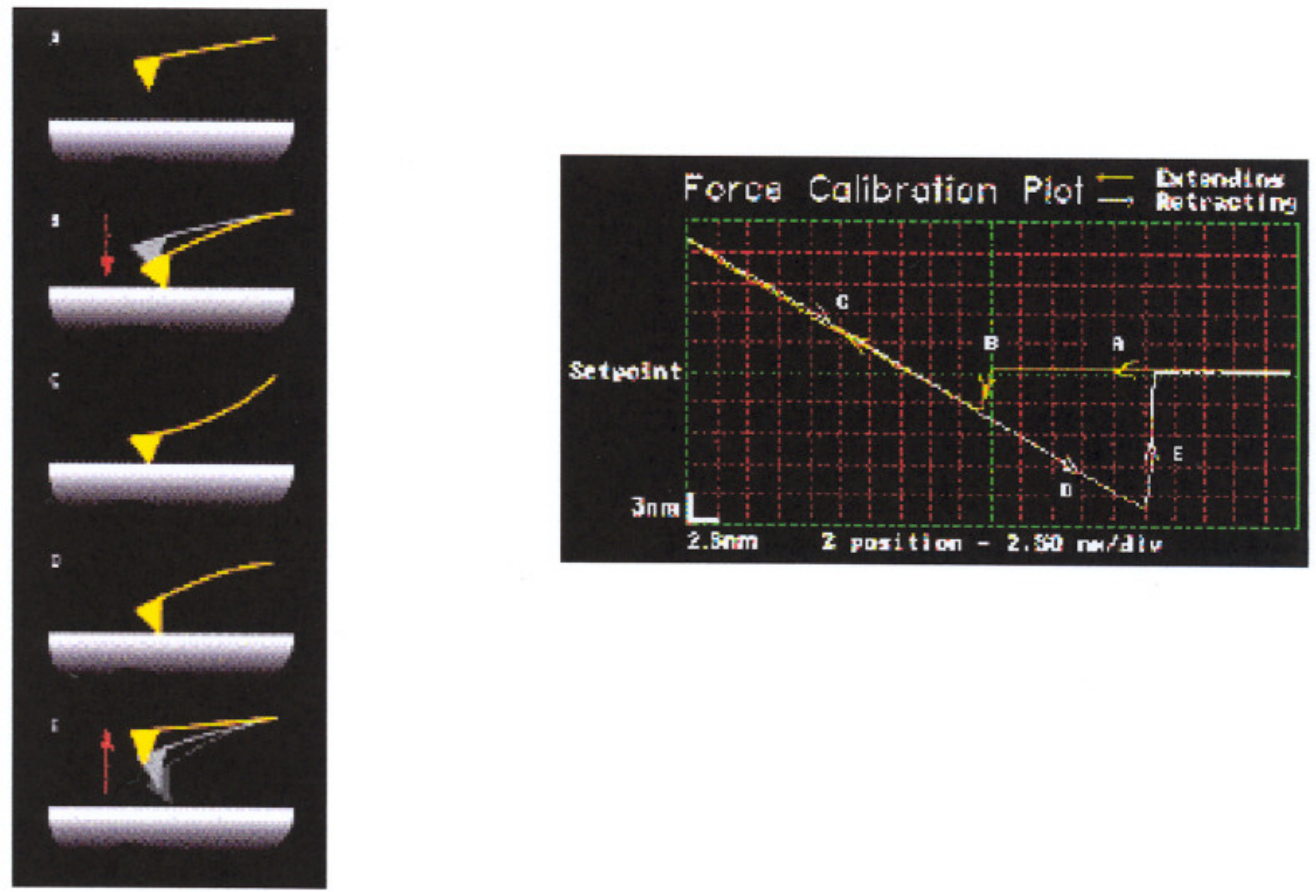

Figura 23. Esquema de uma medida de força versus distância realizada com técnica de AFM [54].

Figura 24. Curva força versus deslocamento determinada a partir de técnica de AFM.

Para se obter uma curva de força versus distância de indentação a partir da curva de força versus deslocamento de piezo é necessário que a curva experimental obtida no ensaio de nanoindentação seja subtraída da curva obtida para o substrato rígido. Após esses tratamentos, os dados obtidos são apresentados em uma curva de força versus $(\mathrm{nN})$ versus a profundidade de indentação em (nm), Figura 25. Utilizando-se os modelos clássicos de contato e as teorias de contato de Hertz e Sneddon, várias informações podem ser extraídas destas curvas como: elasticidade, plasticidade (no caso do material apresentar deformação plástica), histerese, adesão, etc. Na Figura 25, o traço azul representa a ponta se aproximando da superfície da amostra "approach" e o traço vermelho representa a ponta se afastando da amostra "unloading curve". A linha tracejada representa a curva teórica para uma ponta em contato com um material rígido onde não ocorre indentação. Os círculos representam esquematicamente a posição da ponta em relação à amostra. No caso de materiais elastoméricos como a borracha natural, no momento de retração da ponta em relação à superfície da amostra ocorre uma forte adesão das cadeias poliméricas nessa ponta. Representada pela região de instabilidade do cantiléver na Figura 25. 


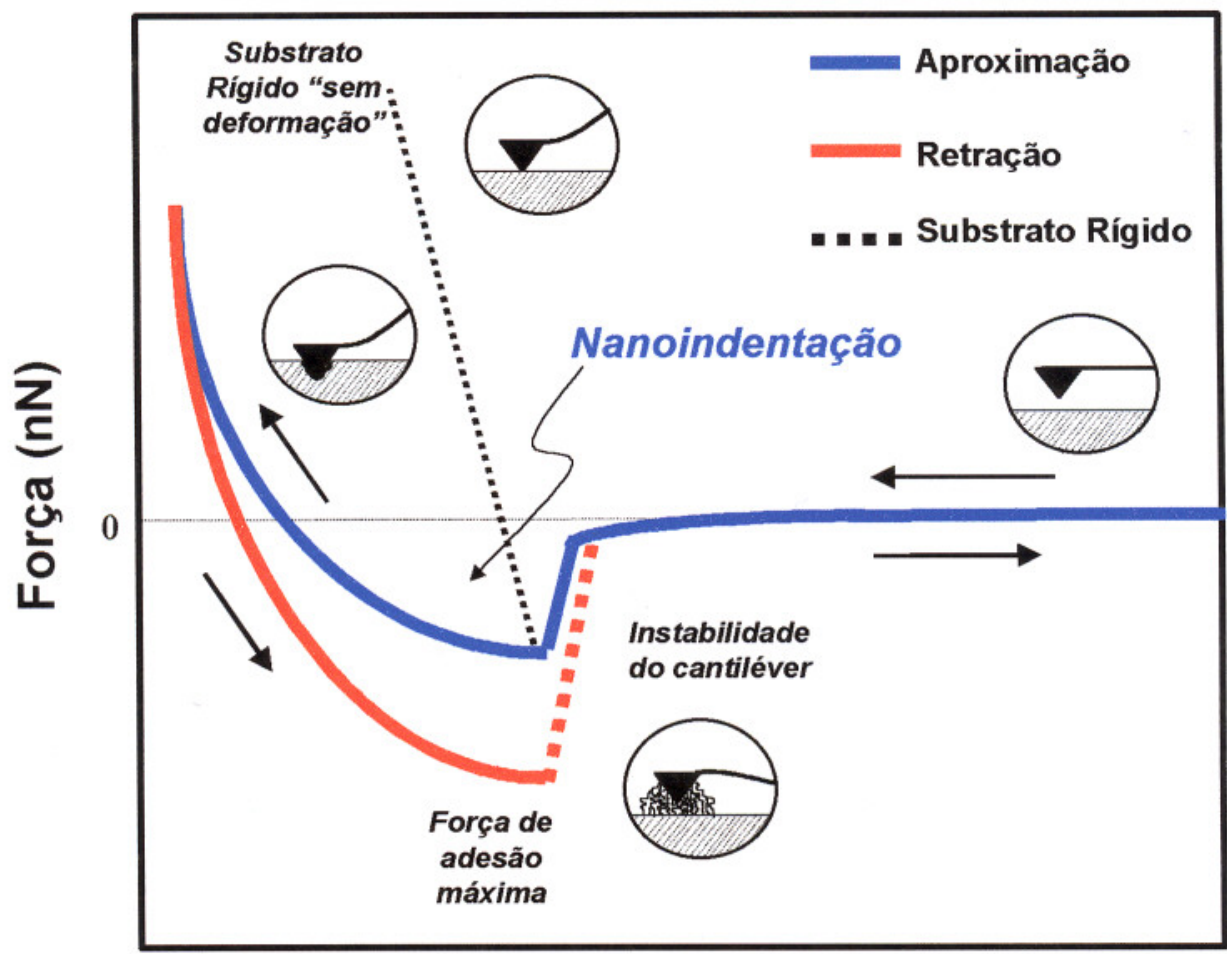

Distância de Indentação (nm)

Figura 25. Curva de força versus distância de indentação, obtida através de medida de nanoindentação via técnica de microscopia de força atômica AFM.

\subsubsection{Medidas de Elasticidade através de técnica de nanoindentação.}

A determinação das propriedades mecânicas de materiais poliméricos é uma área que tem sido bastante estudada devido a sua importância no campo da medicina, tecnologia e biomateriais [61-63]. A procura de novos materiais na área ortopédica (implantes) e cardiọvascular (cateteres) exige a investigação da superfície química e da biocompatibilidade como fatores de grande importância para a adaptação destes materiais no corpo humano. A boa performance destes materiais em macroescala e o futuro da área biomédica dependem do comportamento destes materiais em nano e microescalas, portanto, o estudo de propriedades como elasticidade, dureza, fratura e adesão, por meio técnicas de nanoindentação são bastante relevantes. Apesar desta técnica ser bastante utilizada para medir propriedades de materiais duros como cerâmicas e cristais, a determinação de propriedades mecânicas de filmes finos de polímeros e elastômeros é recente. Strongny et al. [64] usaram técnicas de nanoindentação para avaliar a elasticidade do polimetilmetacrilato (PMMA) e do poliuretano. Ele encontrou que através destas técnicas é possível determinar a 
diferença entre estes materiais de acordo com a quantidade de aditivos adicionados. Em outro trabalho, Strongny e Gerber [63] investigaram a resiliência do (PMMA) e do polidimetilsiloxano para determinar as constantes viscoelásticas destes materiais. Os dados foram comparados com três modelos clássicos da teoria da elasticidade e os resultados foram satisfatórios. Drechsler et al. [65] usaram sondas de silicone e diamante para indentar polimetilmetacrilato (PMMA), policarbonato (PC) e blendas destes dois polímeros. Os dados foram analisados a partir da área da curva Força (nN) versus distância de indentação. Os resultados mostraram que o PMMA é mais rígido do que o PC como era de se esperar. Os dados de rigidez foram correlacionados com a quantidade de PMMA e PC nas blendas poliméricas e uma boa correlação foi obtida. Briscoe et al. [66, 67] determinaram módulo de elasticidade e dureza de materiais a partir dos resultados obtidos na fase do experimento, onde a sonda está se afastando da superfície da amostra. Esta parte da curva força versus deslocamento é denominada porção "unloading". Neste tipo de estudo, os resultados obtidos são analisados usando os modelos de elasticidade clássicos e a partir daí, as propriedades dos materiais podem ser determinadas. Estes autores conduziram experimentos de indentação em polietileno (PE), polimetilmetacrilato (PMMA), policarbonato (PC) e polidimetilsiloxano e encontraram diferenças entre o módulo de elasticidade, dureza e índice de plasticidade para diferentes materiais e a ocorrência de histerese. Efeitos de adesão foram observados no final do ciclo "unloading" mas, não foram explorados com detalhes.

Klapperich et al. [68] estudaram as propriedades nanomecânicas de vários polímeros de uso em engenharia como polietileno de baixa e alta densidade (LDPE) e (HDPE), policarbonato (PC) e polimetilmetacrilato (PMMA). As propriedades estudadas foram módulo de elasticidade e dureza. Os resultados foram analisados em termos de microestrutura, massa molecular e temperatura de transição vítrea $\left(T_{g}\right)$. Os autores encontraram que, enquanto o módulo de elasticidade diminui com o aumento da profundidade de indentação, a dureza do polímero, especialmente aqueles que possuem microestruturas amorfas ou pouca cristalinidade, tende a aumentar. As diferenças das propriedades do material como superficie de adesão e $o$ comportamento da curva tensão versus profundidade de indentação foram interpretados de acordo com a microestrutura, cristalinidade e estrutura química da 
superfície dos materiais. O PMMA praticamente não apresentou forças de adesão entre a sonda e a amostra. O PC exibiu baixas forças de adesão (aproximadamente $1.32 \mu \mathrm{N})$, já os polímeros semicristalinos apresentaram forças de adesão entre 5 e 13 $\mu \mathrm{N}$. Esta diferença de comportamento pode, segundo os autores, estar associada com diferenças na microestrutura e estrutura química de superfície dos polímeros. Por exemplo, um polímero mais cristalino como o HDPE produz uma força de adesão menor do que aqueles menos cristalinos como o LDPE e UHMWPE. A superfície química é importante desde que, maiores forças adesivas ocorrem em superfícies semelhantes. No caso da sonda de diamante, Figura 26, utilizada na maioria dos experimentos de nanoindentação, ocorre o predomínio de ligações C-C e devido ao processo de fabricação, essa sonda contém também impurezas de hidrocarbonetos. $\mathrm{O}$ polietileno assim como a sonda de diamante, possui ligações C-C e C-H portanto, estrutura similar à da sonda de diamante. Consequentemente, segundo os autores, estes dois materiais têm a propensão para aderir aumentando portanto, a intensidade da força de adesão. Já os materiais de PMMA e PC possuem predominantemente ligações C-O, diferentes da estrutura química da sonda, o que reduz a intensidade das forças de adesão.

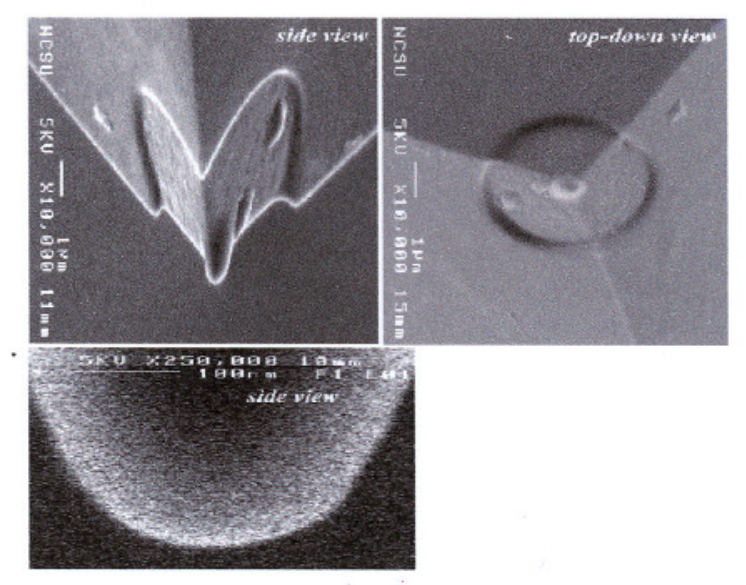

Figura 26. Exemplo de sonda de diamante utilizada para medidas de nanoindentação [54].

Chizhik et al. [69] estudaram as propriedades de materiais poliméricos que apresentam propriedades elásticas. Modelos clássicos como os de Sneddons, Hertzian e Jonson-Kendall-Roberts (JKR) foram testados em várias profundidades de indentação para materiais poliméricos como policloreto de vinila (PVC), 
poliestireno, poliuretano (PU) e poli-isopreno com módulo de Young variando entre $1 \mathrm{MPa}$ até $5 \mathrm{GPa}$. Os experimentos foram realizados em "tapping mode" no ar, utilizando uma sonda de nitreto de silício com constantes de $0.25,0.5,0.6,0.7$ e 0.21 $\mathrm{N} / \mathrm{m}$. Os resultados mostraram que, para a amostra de poliisopreno, o módulo de Young é relativamente independente da profundidade de contato para os três modelos de elasticidade estudados. A exceção foi para valores de profundidade abaixo de $30 \mathrm{~nm}$, neste intervalo, os resultados apresentaram muitas variações para as cinco diferentes regiões da amostra nas quais as medidas foram realizadas. Um comportamento semelhante foi observado para amostras de poliuretano (PU). Já o estudo do poliestireno mostrou grande dependência dos valores de módulo de Young com a profundidade de indentação. Os valores de módulo de Young determinados estavam bem próximos dos valores da literatura mostrando que a combinação dos parâmetros adequados de medida, e a escolha da sonda ideal são fatores que merecem uma atenção especial nas medidas de elasticidade via AFM.

\subsubsection{Metodologia de aquisição das propriedades mecânicas de materiais} via técnica de indentação

Como mostrado anteriormente, o objetivo das medidas de nanoindentação é extrair valores de módulo de Young e dureza do material a partir de curvas de força versus indentação. A metodologia usualmente utilizada para determinar essas propriedades dos materiais, a partir do teste de nanoindentação, baseia- se nas teorias de contato entre dois corpos elásticos desenvolvidas por Hertz [70]. Nesse método, a curva que representa o processo de retração do indentador "unloading curve" é analisada de acordo com o modelo de deformação de dois corpos elásticos (nesse caso a amostra e o indentador) e relaciona a área projetada no ponto máximo de força e indentação com a propriedade do material. A área projetada pode ser determinada por diferentes métodos, utilizando medidas de microscopia eletrônica ou de calibração da ponta em um material com propriedades conhecidas. No caso da calibração da ponta, encontra-se o valor da área de contato $\mathrm{A}$ (hc) em função da distância de indentação.

O problema do contato elástico entre dois corpos foi primeiramente estudado no século 19 por Boussinesq [71] e Hertz [70]. O primeiro desenvolveu um método 
baseado na teoria potencial para calcular a tensão e a deformação em um corpo elástico quando pressionado por um indentador. $\mathrm{O}$ segundo estudou o problema do contato elástico entre dois corpos esféricos com diferentes raios e constantes elásticas e seu trabalho foi de fundamental importância para trabalhos na área de contato mecânico. Outra importante contribuição para a área foi a de Sneddon [72] que derivou equações que relacionam a força aplicada, deslocamento e a área de contato entre uma superfície plana e um sólido de revolução. A Equação 2.6.1 mostra a relação obtida por Sneddon que pode ser aplicada para indentadores com diferentes geometrias.

$$
P=\alpha h^{m}
$$

Na Equação 2.6.1 $P$ representa a força do indentador aplicada na amostra, $h$ é o deslocamento do indentador, e $\alpha$ e m são constantes que incluem a geometria do indentador e as propriedades elásticas do material. Os valores de $m$ dependem da geometria do indentador e possuem valores iguais a 1 para cilindros, 2 para cones e 1,5 para esfera de revolução.

Tabor et al. [73, 74] realizaram medidas de indentação utilizando um indentador esférico e amostras de diferentes metais. Eles observaram o efeito da plasticidade em amostras de metais através da análise da forma geométrica do indentador que ficava impressa no metal. Os autores sugeriram que a melhor forma de considerar o efeito da plasticidade nos cálculos das propriedades mecânicas seria considerar a área de contato nas análises das propriedades elásticas. Outra importante observação feita pelos autores foi que as propriedades elásticas do indentador e do material indentado podem ser efetivamente relacionadas através da equação de módulo relativo, Equação 2.6.2.

$$
\frac{1}{E_{r}}=\frac{\left(1-v_{s}^{2}\right)}{E_{s}}+\frac{\left(1-v_{i}^{2}\right)}{E_{i}}
$$

em que $E_{s}$ e $v_{i}$ são respectivamente o módulo de Young e constante de Poisson da amostra estudada e $E_{i}$ e $v_{i}$ são os mesmos parâmetros para o indentador. 
O interesse na técnica de indentação como uma ferramenta para determinar as propriedades elásticas de materiais começou no início dos anos 70 com importantes trabalhos feitos por Bulychev, Alekin, Shorshov e colaboradores [75]. Eles usaram instrumentos de microdureza para obter dados de força versus distância de indentação do tipo do diagrama da Figura 27. Os dados foram analisados de acordo com a Equação 2.6.3 que relaciona a dureza do material, $\mathrm{S}$, com a área de contato, $\mathrm{A}$.

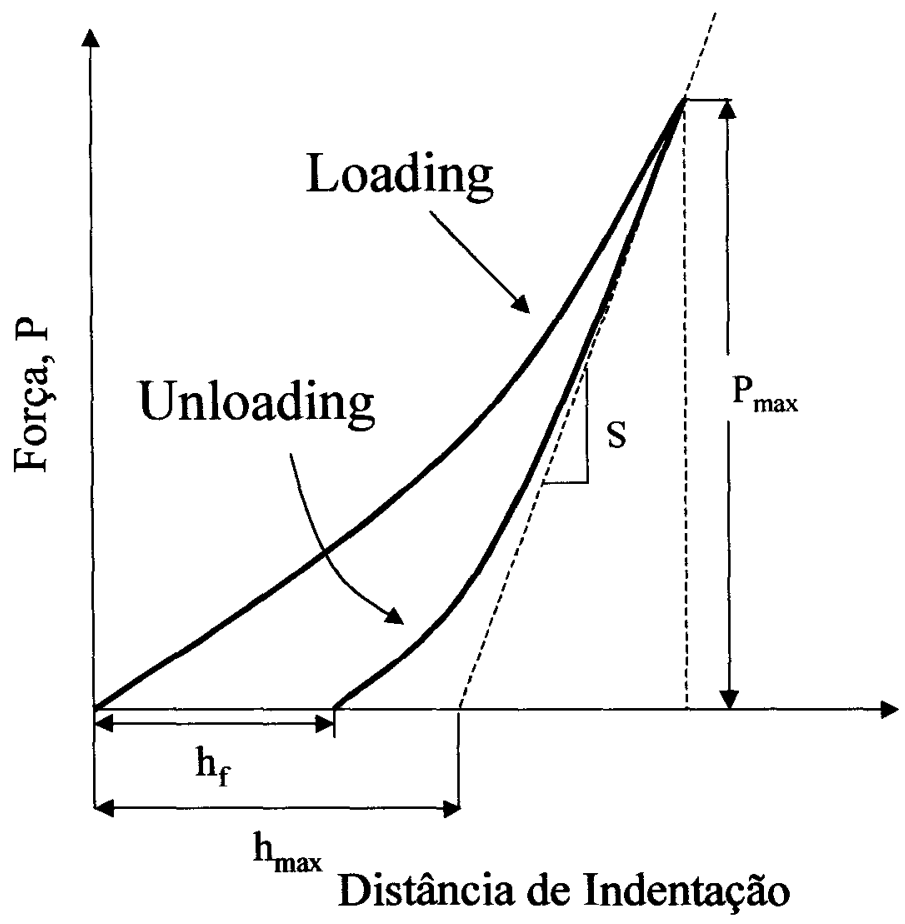

Figura 27. Esquema de uma curva de força versus distância de indentação.

$$
S=\frac{d P}{d h}=\frac{2}{\sqrt{\pi}} E_{r} \sqrt{A}
$$

Na Equação 2.6.3, $\mathrm{S}=\mathrm{dP} / \mathrm{dh}$ é a medida experimental da dureza na porção mais alta da curva, $\mathrm{E}_{\mathrm{r}}$ é o módulo relativo e $\mathrm{A}$ é a área projetada. A Equação 2.6.3 foi derivada da teoria do contato elástico sendo originariamente derivada para indentador do tipo parabólico mas, Pharr, Oliver e Brotzen [76] mostraram que ela pode ser utilizada para todos os tipos de indentadores descritos, como um sólido de revolução, independente da sua geometria.

Com o crescente interesse em usar a técnica da indentação para medir propriedades elásticas de filmes finos, muitos pesquisadores têm trabalhado para desenvolver e produzir indentações em escala micrométrica $[77,78]$. Doerner e Nix 
[79] estudaram e analisaram muitos trabalhos anteriormente feitos com o objetivo de desenvolver um método para determinação da dureza e elasticidade de materiais. Os autores observaram que nas medidas de indentação, durante os estágios iniciais da retração, a área de contato permanece constante. A justificativa foi que, para determinados materiais, a porção inicial da curva de retração é linear. Os autores propuseram um método empírico para determinar a área de contato extrapolando-se a linha da parte inicial da curva de retração até o eixo $x$ onde a força é zero, Figura 27. Nesse método, o valor de distância obtido na extrapolação foi usado para calcular a área de contato do indentador na amostra. Calculando-se essa área, o valor da dureza do material pôde ser estimado a partir da Equação 2.6.3. Em outras palavras, o método proposto por Doerner e Nix sugeriu que a dureza do material poderia ser calculada a partir do ajuste linear da porção mais alta da curva de retração.

De acordo com Oliver e Pharr [80,81], o erro da metodologia proposta acima foi o fato de não levar em consideração a mudança de área na superfície da amostra durante a indentação. Os autores realizaram uma série de testes, utilizando uma técnica para medir continuamente a dureza do material quando o indentador está saindo da amostra. Eles observaram que as curvas de retração quase nunca são lineares, a dureza do material muda constantemente durante o ensaio e portanto, é de se esperar que haja uma mudança na área de contato. Os autores concluíram que o fato de considerar a porção mais alta da curva de retração como constante, não representa corretamente o comportamento físico do material.

\subsubsection{Metodologia de Oliver e Pharr}

Oliver e Pharr $[80,81]$ realizaram um trabalho pioneiro e estabeleceram uma metodologia para determinar o módulo de elasticidade e a dureza de materiais via técnica de nanoindentação. Os autores realizaram experimentos de nanoindentação para diversos materiais como, sílica, alumínio, quartzo e safira e reportaram que a maioria dos materiais não apresentaram curva de retração linear. Eles propuseram uma metodologia que leva em consideração a curvatura da curva de retração, ou seja a mudança de área, obtida experimentalmente para determinar a profundidade de indentação e estabelecer a área de contato. De acordo com a metodologia proposta por Oliver e Pharr, a dureza do material $\left(S_{\max }\right)$ pode ser obtida de uma forma mais 
adequada se determinada através da derivada, no ponto máximo, da curva tangente à curva de retração. É importante colocar que, nessa metodologia, a dureza do material é determinada no ponto de força máxima e portando, não há restrições em relação à curva ser linear ou não. Os parâmetros necessários para medir dureza e módulo de elasticidade na metodologia de Oliver e Pharr são apresentados na Figura 28.

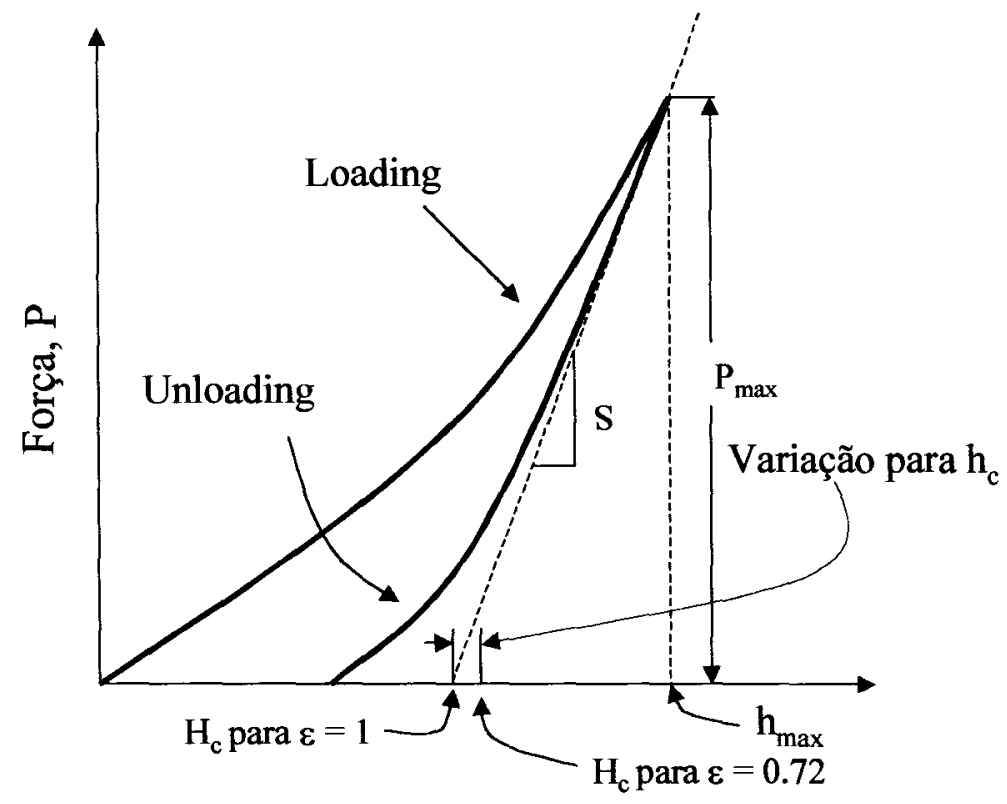

Distância de Indentação

Figura 28. Esquema de curva de força versus distância de indentação e os parâmetros usados na metodologia de Oliver Pharr [80].

Após a determinação de S no ponto máximo, calculado independentemente da linearidade da curva de retração, o passo seguinte foi determinar a altura de contato $h_{c}$ e em seguida a área de contato em função dessa altura A (hc). A Figura 29 mostra uma seç̧ão transversal do indentador penetrando na superfície da amostra. Para qualquer valor de força, o deslocamento total $h_{\max }$ pode ser escrito como:

$$
h=h_{c}+h_{s}
$$

onde $h_{c}$ é a distância de contato e $h_{s}$ é a porção do material que não está em contato com o indentador. Quando a retração se inicia, e o deslocamento ocasionado pela elasticidade do material volta a sua posição normal e no momento que o indentador 
sai da superfície do material, é observada uma impressão residual $h_{f}$ na superfície da amostra.

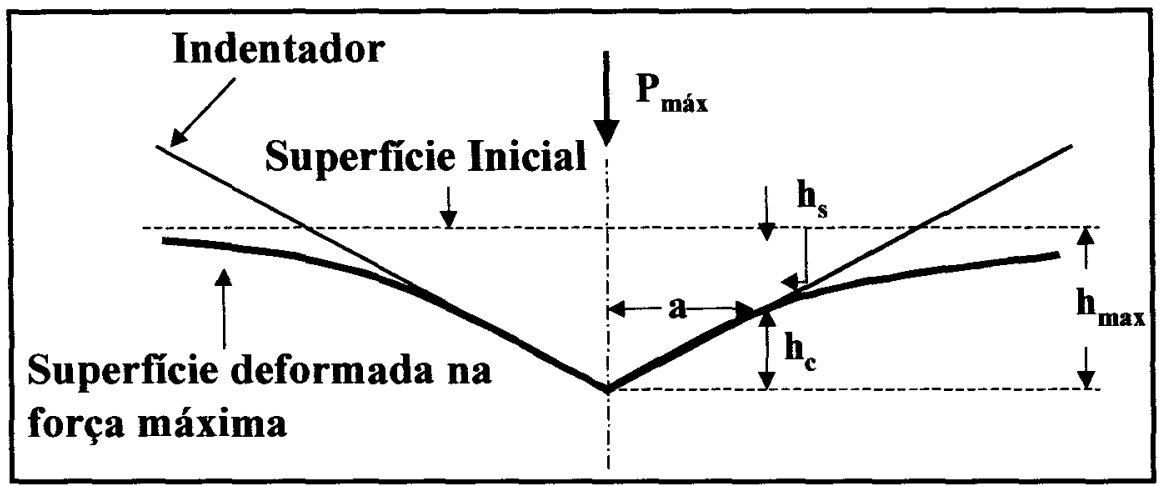

Figura 29. Figura esquemática da área de contato projetada na superficie da amostra no ponto $\mathrm{F}_{\max }, \mathrm{D}_{\max }$ segundo a metodologia de Oliver Pharr.

$\mathrm{O}$ valor $h_{\mathrm{c}}$ foi determinado a partir de dados experimentais usando e Equação 2.6.5 que foi derivada a partir da Equação 2.6.4:

$$
h_{c}=h_{\max }-h_{s}
$$

Como $h_{\max }$ pode ser medido experimentalmente, precisamos obter o valor de $h_{s}$ que é a altura do indentador que não está em contato com o material. A equação para cálculo desse valor foi determinada por Sneddon [72] e depende da geometria do indentador. Para um indentador com a geometria semelhante à de um cone de revolução $h_{s}$ é dado pela Equação 2.6.6:

$$
h_{s}=\frac{(\pi-2)}{\pi}\left(h-h_{f}\right)
$$

Outra importante equação derivada por Sneddon é a que relaciona a profundidade de indentação $\mathrm{h}$ com a força ,P, e a dureza do material, S, Equação 2.6.7:

$$
\left(h-h_{f}\right)=2 \frac{P}{S}
$$


Substituindo-se a Equação 2.6.7 na Equação 2.6.6 obtém-se a Equação 2.6.8 para $\mathrm{h}_{\mathrm{s}}$

$$
h_{s}=\varepsilon \frac{P_{\max }}{S}
$$

e para o indentador cônico o valor da constante $\varepsilon$ é dado pela equação 9 ou $\varepsilon=0.72$ A Tabela 3 mostra os valores da constante $\varepsilon$ para diferentes geometrias do indentador.

$$
\varepsilon=\frac{2}{\pi}(\pi-2)
$$

Tabela 3. Valores da constante $\varepsilon$ para diferentes geometrias do indentador.

\begin{tabular}{c|c}
\hline Geometria do indentador & $\varepsilon$ \\
\hline Cilíndrica & 1 \\
Parábola & 0.75 \\
Cone & $2(\pi-2) / \pi$ \\
\hline
\end{tabular}

A interpretação gráfica da Equação 2.6.8 aparece na Figura 28. Para $\varepsilon=1$ o valor de $h_{s}$ e a profundidade de contato $h_{c}$ são dados pela linha tangente a parte inicial da curva de retração e que intercepta o eixo $x$ onde a força é igual a zero. Esse valor é o mesmo usado nas análises feitas por Doerner e Nix. Para indentadores com geometria do tipo cone e parábola de revolução as profundidades de contato são maiores e a metodologia proposta por Oliver e Pharr permite uma avaliação mais acurada desses valores.

Outra importante questão prática levantada por Oliver e Pharr foi o método para calcular a dureza do material. Uma forma simples de determinar esse parâmetro foi discutido anteriormente e consiste em traçar uma linha reta na porção mais alta da curva de retração e depois usar a derivada dessa curva para determinar a dureza. $\mathrm{O}$ problema desse método é que o valor de $\mathrm{S}$ pode variar dependendo da porção da curva utilizada no cálculo e do número de pontos escolhidos na análise. Os autores estudaram a dureza do tungstênio em função da fração da curva de retração utilizada 
no cálculo e observaram uma grande variação nesses valores. Segundo eles, a razão para essa variação é porque existe uma quantidade grande de fluência do material no início da porção de retração fazendo com que a derivada dessa curva tenha altos valores. Os autores sugeriram um procedimento alternativo adotado com base na observação da curva de retração. Eles estudaram cuidadosamente a forma da curva de retração para seis diferentes materiais e observaram que curva pode ser descrita pela relação mostrada na Equação 2.6.10:

$$
P=A\left(h-h_{f}\right)^{m}
$$

em que A e m são constantes do material e $h_{f}$ é a altura no final da indentação.

Para comparar as curvas de retração do material, os autores propuseram subtrair $h_{f}$ da profundidade total $h$ para colocar as curvas no mesmo ponto de origem. Uma análise detalhada das curvas mostrou que elas são ligeiramente côncavas e que podem ser descritas pela relação acima que é a mesma da Equação 2.6.1. A dureza pode ser corretamente determinada ajustando-se a Equação 2.6.10 na curva de retração obtida experimentalmente e calculando-se a derivada no ponto máximo.

A metodologia de Oliver e Pharr tem sido muito utilizada para determinar propriedades mecânicas de materiais a partir da técnica de nanoindentação. Os autores sugeriram que a metodologia anteriormente utilizada na literatura, na qual as propriedades mecânicas de materiais são obtidas supondo a linearidade da curva de retração, não estava correta. Eles examinaram detalhadamente o comportamento de curvas de seis diferentes materiais obtidos em testes de nanoindentação e propuseram que as curvas podem ser descritas através da Equação 2.6.10 Eles também determinaram um método para levar em consideração a curvatura da força de retração e determinar a altura de contato $h_{c}$ do indentador na amostra. Dessa forma, o método proposto leva em consideração importantes fenômenos da mecânica de contato e portanto, permite uma avaliação mais correta das propriedades mecânicas dos materiais.

VanLandigham et al. aplicaram a metodologia acima para estudo de indentação em materiais poliméricos $[82,83]$ e sugeriram o uso de uma rotina para 
ajustar a equação que relaciona força versus distância de indentação. Segundo o autor, materiais poliméricos apresentam um comportamento viscoelástico bastante acentuado quando submetido a uma força P. Esse comportamento pode afetar drasticamente a determinação da derivada da curva e o cálculo da dureza do material. VanLandigham sugeriu o uso de uma rotina chamada "spline smooth" para ajustar a curva experimental e a partir deste ajuste determinar a dureza do material e o módulo de Young. A metodologia de Oliver Pharr associada à de VanLandhingam vem sendo muito utilizada para determinar as propriedades mecânicas de polímeros a partir da técnica de nanoindentação pelo fato de considerar em seus cálculos as mudanças no comportamento físico do material durante o ensaio de nanoindentação. A primeira leva em consideração mudanças na área de contato no decorrer do teste e a segunda consideram a viscoelasticidade dos materiais poliméricos.

\subsubsection{Energia de adesão $W_{\text {ads }}$ em experimentos de nanoindentação.}

A determinação dos valores de adesão de materiais poliméricos é uma área de grande interesse técnico e científico. Em geral, os materiais adesivos podem ser classificados de acordo com seus valores de módulo. Adesivos rígidos, como os epóxis, possuem módulo em torno de $10^{9} \mathrm{~Pa}$ e são mais apropriados para aplicações que requerem alta tensão de ruptura. Por outro lado, adesivos feitos à base de elastômeros e polímeros fundidos, possuem módulo em torno de $10^{6} \mathrm{~Pa}$ e $10^{4} \mathrm{~Pa}$ respectivamente. A adesão de dois materiais pode ser quantificada pela energia por unidade de área necessária para separá-los. De um modo geral, para um elastômero aderido a uma superfície sólida a energia de adesão é determinada pelas forças moleculares (interações de van der Walls e ligações covalentes) que mantêm os dois materiais unidos, assim como, pela energia gasta em processos dissipativos no interior do elastômero.

A quantidade de energia específica, de interesse e relevância nos processos de adesão de dois materiais, é a taxa de energia, $G$, definida como a força energética dirigida para propagar uma falha quando duas superficies anteriormente aderidas estão sendo separadas. Para melhor compreender o significado dessa quantidade, Shull et al. [84] propuseram usar a Figura esquemática 30 como forma de pensar no modo o que torna possível determinar o parâmetro $G$ experimentalmente. 


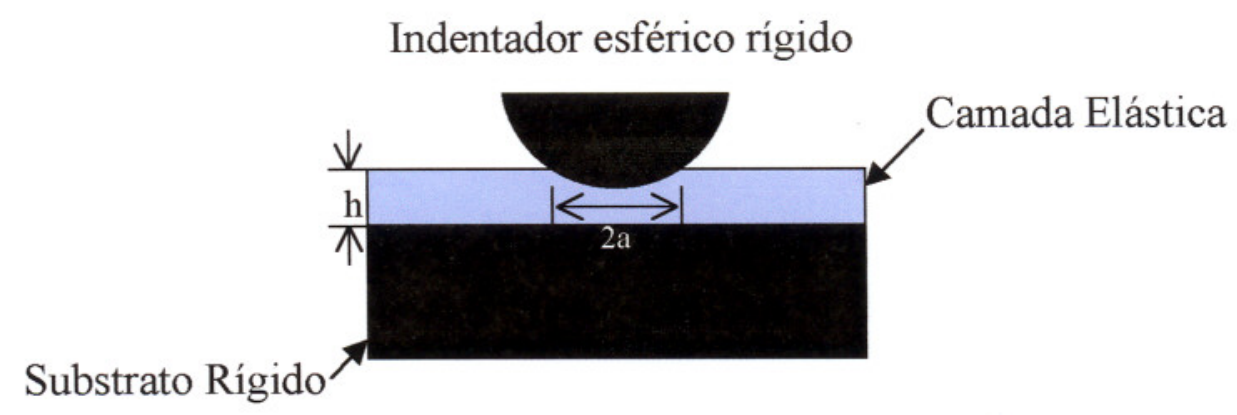

Figura 30. Figura esquemática de um teste típico de adesão [84]

$\mathrm{Na}$ Figura 30, a camada elástica está confinada entre duas superfícies e a interface entre ela e a superfície de interesse (o topo da superfície) é definida como área de contato circular. Pelo fato da camada elástica e da superfície rígida estarem aderidas, a força $\mathrm{P}$ aplicada na superfície será transferida para a camada elástica. Para um material elástico, a energia elástica estocada, $\mathrm{U}_{\mathrm{E}}$, é igual ao trabalho feito no sistema durante a deformação:

$$
U_{E}=\int_{0}^{\delta_{0}} P d \delta
$$

em que $\delta_{0}$ é o valor final de deslocamento, $\delta$, em direção da força aplicada. A relação entre $\mathrm{P}$ e $\delta$ depende da geometria da amostra o que inclui a geometria da falha. Considerando a geometria da falha como fixa, a energia elástica estocada pode ser determinada experimentalmente através da relação entre a força e o deslocamento.

Supondo-se que a geometria da falha, responsável pela separação das duas superfícies aumente em tamanho, então a área de contato entre as duas regiões diminui de A para A-dA. A força P requerida para manter um deslocamento fixo diminui assim como a energia de tensão na amostra. Nesse caso temos a taxa de energia, $G$, que relaciona a mudança na energia elástica estocada com o aumento da área A. Em termos práticos, em um experimento de indentação, a energia de adesão $\mathrm{U}_{\mathrm{E}}$ pode ser determinada a partir da curva de força versus indentação calculando-se a área entre as curvas de aproximação e retração: 


$$
G=\left.\frac{\partial U_{E}}{\partial A}\right|_{\delta}
$$

Paiva et al. estudaram $[85,86]$ as propriedades de adesão de filmes adesivos e caracterizaram a superfície dos mesmos usando técnica de micro e nanoindentação. Os autores também investigaram a variação das propriedades dos polímeros em função da quantidade de carga adicionada e do envelhecimento dos filmes. Os resultados mostraram diferença de comportamento entre as regiões de domínio com grande concentração de carga adicionada e a região de matriz polimérica. No domínio, os autores observaram comportamento viscoelástico e na região de matriz polimérica, um comportamento viscoso caracterizado por alta dissipação de energia. Os autores calcularam, a partir das curvas de força versus distância de indentação, o trabalho de adesão, $\mathrm{W}_{\mathrm{ads}}$, para diferentes composições da blenda polimérica e observaram que o $\mathrm{W}_{\text {ads }}$ diminui com o aumento da concentração da carga. Eles concluíram que a microindentação fornece medidas quantitativas de adesão e dureza do material como um todo e a nanoindentação fornece medidas pontuais da amostra, já que o volume analisado em um ensaio de nanoindentação é muito menor do que o volume estudado na microindentação.

Nesta etapa do trabalho, a borracha natural dos clones RRIM 600, PB 235, IAN 873 e GT 1 foi estudada via técnica de nanoindentação e as propriedades nanomecânicas como dureza, módulo de elasticidade e trabalho de adesão foram determinadas e avaliadas. Também foram realizados para estes clones ensaios através da técnica de DMTA. Os resultados de módulo obtidos através das técnicas de DMTA e nanoindentação foram comparados permitindo uma melhor avaliação do método de nanoindentação aqui proposto para avaliação de propriedades da borracha natural em nanoescala. 


\section{EXPERIMENTAL}

\subsection{Estudo e Avaliação da Variação Intra e Interclonal nas Propriedades da Borracha Natural}

Para o estudo da variação intra e interclonal foram utilizadas amostras de látex de borracha natural de três clones recomendados para o plantio em larga escala no estado de São Paulo (PB 235, GT 1, RRIM 600). As amostras de látex foram coletadas de árvores plantadas em uma fazenda experimental (Fazenda Indiana) instalada no município de Indiana, região de Presidente Prudente-SP. Essa fazenda experimental faz parte de um projeto do IAC (Instituto Agronômico de Campinas) que vem estudando as características agronômicas (fisiologia, fitotecnia e genética) da seringueira. $O$ programa de cultivo e aperfeiçoamento genético da seringueira, coordenado pelo Dr. Paulo Gonçalves, vem buscando a obtenção de clones altamente produtivos e tolerantes à principal doença da seringueira, que é o mal das folhas causado pelo Microcyclus ulei. O Oeste Paulista não tem apresentado problemas de ataques epidêmicos de M.ulei e é a melhor região do estado para a produção de borracha natural. Atualmente, o parque heveícola com mais de 2000 produtores está estimado em 40000 hectares, principal fator que elevou o Estado à condição de primeiro produtor nacional de borracha natural com uma produção de borracha seca anual variando de 2.000 para 45.000 toneladas no período de 1985-2001 [87]. O planalto ocidental do Estado engloba $90 \%$ da área plantada onde se situa a região mais importante do cultivo com $42 \%$ da área com seringueiras, demostrando grande potencial de cultivo notadamente pelas condições climáticas.

As fazendas experimentais do IAC, que vêm sendo utilizadas no estudo das propriedades da borracha natural, são experimentos estatisticamente planejados e montados para que os resultados obtidos, sofram o mínimo de interferência das variações do solo. Para isso as árvores são plantadas utilizando-se um delineamento experimental de blocos ao acaso, com parcelas divididas. Dessa forma, as árvores dos clones são plantadas em parcelas do experimento e em diferentes blocos. As repetições são estatisticamente importantes para que se possam considerar valores médios dos resultados obtidos e que se faça uma estimativa do erro experimental. A casualização é a aplicação dos tratamentos às unidades experimentais de modo que 
todas as unidades tenham chance de receber um determinado tratamento. Sua função é assegurar estimativas não tendenciosas do erro experimental e do efeito dos tratamentos. No delineamento do tipo "Blocos ao Acaso" os tratamentos são agrupados em blocos, permitindo que o efeito da variação relativo a eles seja excluído da variação total do ensaio. Além do mais, eles permitem a obtenção de estimativas não tendenciosas do efeito dos tratamentos. $\mathrm{O}$ delineamento experimental utilizado nesses experimentos possui bordaduras que são as linhas mais externas da parcela. As linhas de bordadura, em geral, encontram-se adjacentes aos caminhos entre as parcelas, portanto, nos locais onde a competição por água luz, $\mathrm{CO}_{2}$, etc., é unilateral. Em outras palavras, essas linhas são favorecidas. As árvores da bordadura não devem ser utilizadas na aquisição dos resultados pois podem sofrer os efeitos das variáveis do clima, níveis de fertilizante etc, [88].

Após o experimento ter sido instalado, passa-se a avaliar anualmente o perímetro e incremento do caule. Em uma média de cinco anos após a plantação das árvores, ou quando o caule atinge um perímetro ideal de $45 \mathrm{~cm}$, dá-se inicio à abertura dos painéis de sangria a aproximadamente $1,20 \mathrm{~cm}$ do calo de enxertia. A partir daí as árvores começam a ser sangradas semanalmente, o látex coletado e a produção registrada.

\subsubsection{Descrição do Experimento instalado em Indiana - SP (região de Presidente Prudente)}

O experimento foi instalado em Outubro de 1993, na Fazenda Indiana, no município de Indiana, região de Presidente Prudente, SP, localizada na latitude de $22^{\circ} 7^{\prime} \mathrm{S}$, longitude $51^{\circ} 16^{\prime} \mathrm{W}$ e altitude de $460 \mathrm{~m}$, em solo Podzólico VermelhoAmarelo eutrófico, textura arenosa [89].

A temperatura média anual é de $22,2{ }^{\circ} \mathrm{C}$, oscilando entre valores médios mensais de $18,0^{\circ} \mathrm{C}$ a $24,1^{\circ} \mathrm{C}$. A média anual das precipitações pluviais é de 1370 $\mathrm{mm}$, que se concentra nas estações de primavera e verão (outubro-março). No período mais seco, que vai de abril a setembro, as chuvas totalizam $399 \mathrm{~mm}$. O clima situa-se no limite entre o regime de distribuição tropical e subtropical.

Foi utilizado o delineamento experimental de blocos ao acaso com parcelas divididas. Os clones (total de sete clones) foram plantados distribuídos em três 
repetições com 30 plantas por parcelas. $\mathrm{O}$ espaçamento foi de 7,0 $\mathrm{m}$ entre as linhas e 3,0 m entre plantas. A Figura 31 mostra esquema do delineamento experimental do experimento utilizado.

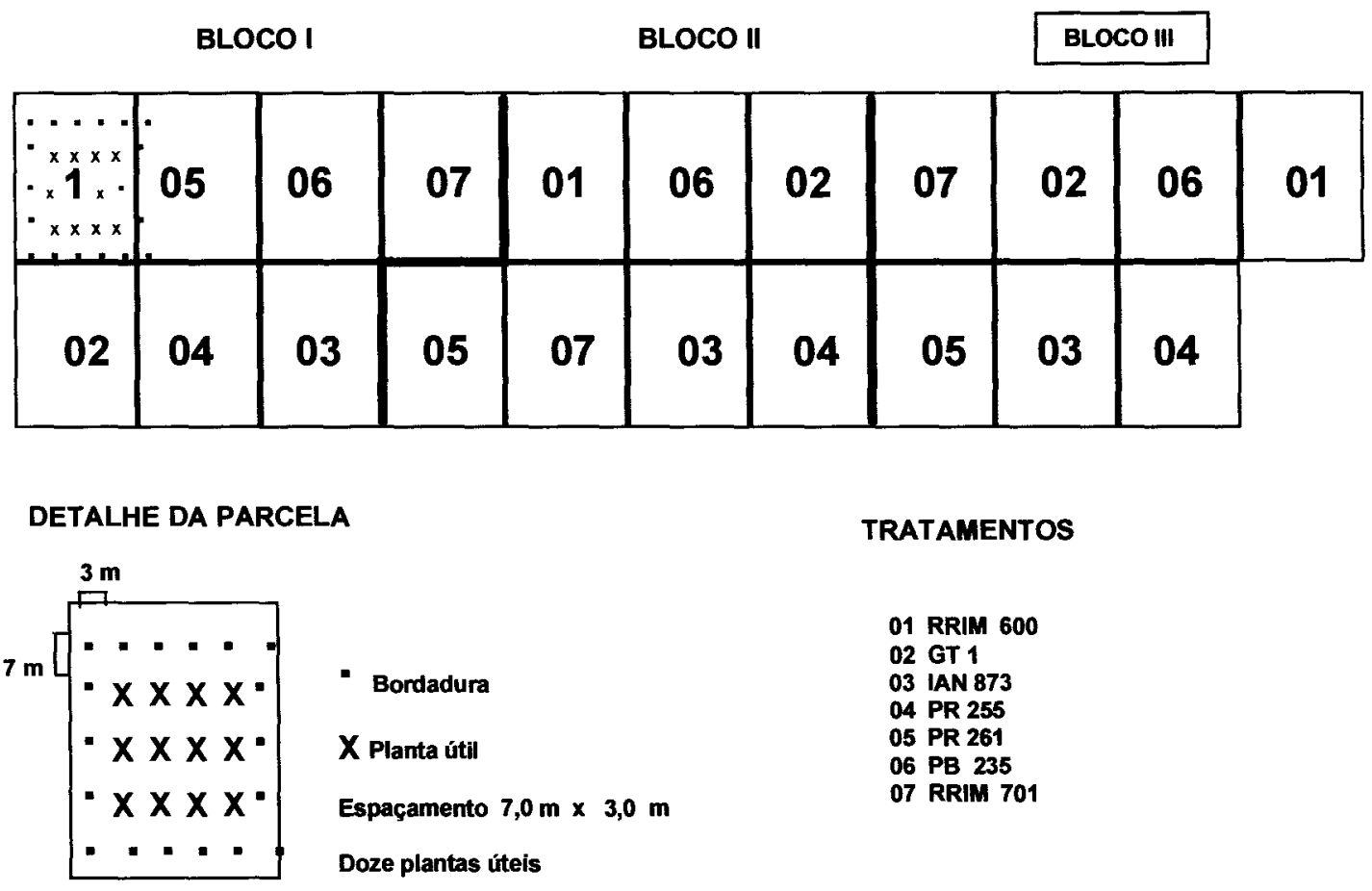

Figura 31. Figura esquemática do delineamento experimental do seringal de Indiana SP (região de Presidente Prudente - SP)

\subsubsection{Coleta do látex}

Para avaliar a variação intraclonal das propriedades da borracha, foram coletadas amostras de látex de dez árvores em cada bloco. $O$ látex dessas dez árvores foi misturado para se ter uma amostra representativa daquela repetição. Foram coletadas amostras dos clones RRIM 600, PB 235 e GT 1 em três blocos distintos. Dessa forma, as amostras foram chamadas de (RRIM 600 I (amostra representativa do clone RRIM 600 para o bloco I) RRIM 600 II (amostra representativa do clone RRIM 600 coletado no bloco II) e RRIM 600 III (amostra representativa do clone RRIM 600 coletado no bloco III)). O látex foi coletado em recipiente limpo, e logo em seguida estabilizado. $O$ agente utilizado para a estabilização foi uma solução de hidróxido de amônio na quantidade suficiente para elevar o pH do látex a 10,2 [28]. Esta estabilização é feita para que não haja coagulação do látex após a colheita do mesmo permitindo assim que ele possa ser levado ao laboratório para ser analisado. 
A coagulação do látex foi feita em laboratório utilizando-se ácido acético $6 \mathrm{~N}$. O coágulo foi laminado em calandra à temperatura ambiente e colocado para secar em estufa à temperatura de aproximadamente $50{ }^{0} \mathrm{C}$. As datas de coleta foram: 10/05/2000 (coleta 1), 30/06/2000 (coleta 2), 05/10/2000 (coleta 3) e 01/12/2000 (coleta 4). O sistema de sangria foi o S/2 d/4 ET 2,5,\% (sangria em meia espiral $(\mathrm{S} / 2)$, realizada em intervalos de 4 dias $(\mathrm{d} / 4)$, sendo a sangria realizada no primeiro painel, com estimulação feita com Ethrel a 2,5 \% de ingrediente ativo (ET 2,5\%)). A aplicação de Ethrel foi feita uma vez ao mês, dez vezes ao ano, com exceção dos meses de agosto e setembro, período de descanso das árvores. A Figura 32 mostra a foto da coleta do látex.

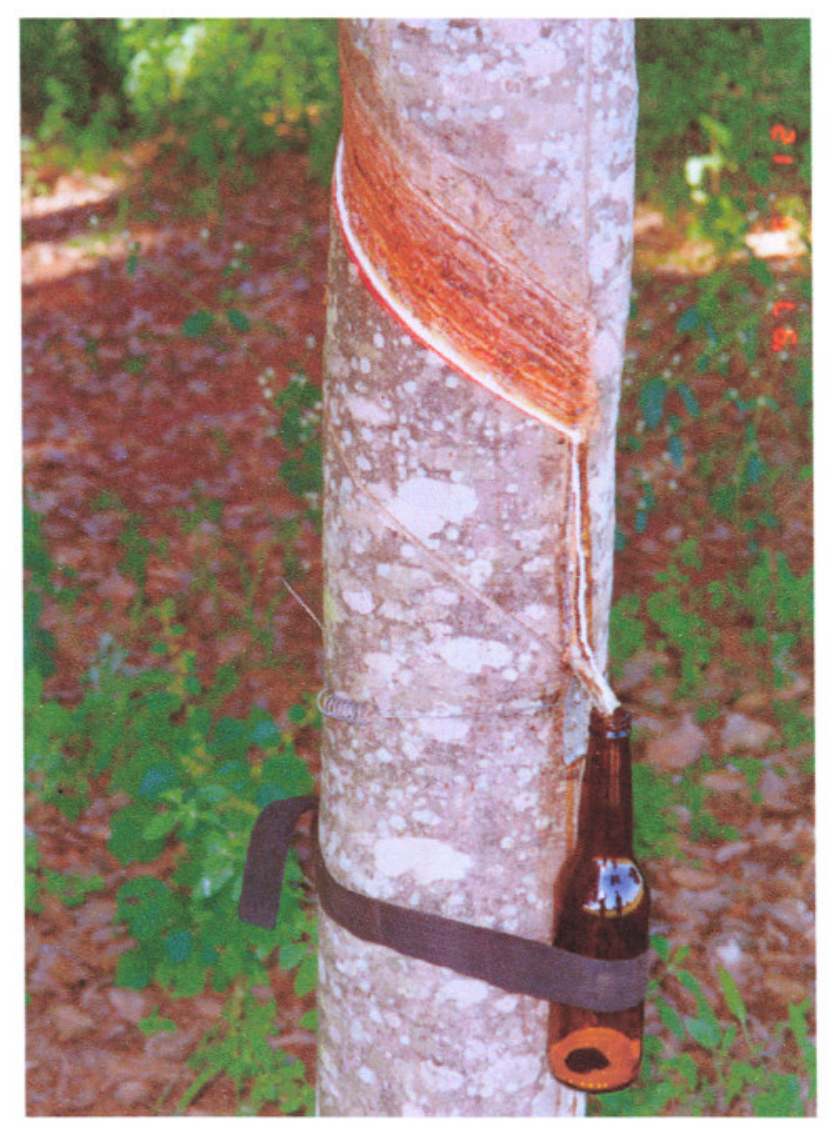

Figura 32. Foto da coleta do látex

\subsubsection{Descrição das Técnicas}

No estudo da variação intra e interclonal a borracha natural foi avaliada através de ensaios padrões de DRC, \% de nitrogênio, \% de extrato acetônico, viscosidade Mooney, Plasticidade Wallace e PRI. Essas análises são chamadas de “ensaios padrões” porque são, em geral, utilizadas pelas indústrias pneumáticas para 
avaliar a qualidade da borracha comprada. Em seguida é apresentada uma descrição dos ensaios padrões.

\subsection{3.a) Determinação do DRC (Conteúdo de Borracha Seca)}

A determinação do conteúdo de borracha seca foi feita no látex. Para a determinação do DRC uma alíquota de aproximadamente $20 \mathrm{~g}$ de látex natural foi coagulada com ácido acético. A coagulação ocorre em um $\mathrm{pH}$ de aproximadamente 5. Em seguida o coágulo foi laminado em calandra e seco em estufa a temperatura de aproximadamente $60^{\circ} \mathrm{C}$ por $48 \mathrm{~h}$ e pesado até que se obtivesse uma massa constante.

\subsection{3.b) Determinação da Porcentagem de Nitrogênio (método semi-micro} Kjeldahal)

A análise de nitrogênio foi realizada no laboratório de química do CPPSE/ Embrapa, de acordo com a norma da ABNT [90].

Cerca de $200 \mathrm{mg}$ de borracha seca foram pesados e misturados com mistura catalítica para digestão (1:10 $\mathrm{K}_{2} \mathrm{SO}_{4}$ ou $\mathrm{Na}_{2} \mathrm{SO}_{4}+\mathrm{H}_{2} \mathrm{SO}_{4}$ concentrado). Após a obtenção da digestão da borracha, o digerido foi levado ao equipamento Kjeltec auto $1035 / 38$ e iniciou-se a destilação, feita por arraste de vapor. $\mathrm{O}\left(\mathrm{NH}_{4}\right)_{2} \mathrm{SO}_{4}$ foi tratado com solução de $\mathrm{NaOH} 40 \%$ em excesso, e ocorreu a liberação de $\mathrm{NH}_{3}$. A amônia recebida reagiu com $\mathrm{o}_{3} \mathrm{BO}_{3}+$ indicador. $\mathrm{O}$ borato ácido de amônio foi titulado com solução de $\mathrm{H}_{2} \mathrm{SO}_{4} 0.1 \mathrm{~N}$. A porcentagem de proteína bruta (PB) que forneceu a \% de nitrogênio, foi calculada a partir da expressão:

\section{\% de Nitrogênio $=\%$ de proteína bruta $/ 6.25$}

O resultado é expresso em peso de nitrogênio sobre $100 \mathrm{~g}$ de amostra de borracha, que será de boa qualidade, segundo as normas, se exibir teores de nitrogênio entre 0,2 e $0,6 \%$. 


\subsection{3.c) Determinação da porcentagem de extrato acetônico}

O extrato acetônico (EA) é representado pela fração não-borracha solúvel em acetona, tendo como principais componentes os ácidos graxos, ésteres de esteróis, em adição a um número de outras substâncias de menor importância, sendo que os altos valores de extrato acetônico influenciam negativamente nas características físicas de um produto acabado. Uma massa de borracha de cerca de 2,0000 $\pm 0,0001$ $\mathrm{g}$ foi adicionada em um extrator tipo Soxhlet e a extração foi feita com acetona por $16 \mathrm{~h}$ seguidas. A acetona foi removida por evaporação em banho-Maria e o extrato seco foi pesado para a determinação da porcentagem EA em borracha seca.

\subsection{3.d) Viscosidade Mooney (Vo)}

A viscosidade Mooney $\left(\mathrm{V}_{0}\right)$ foi medida através de um disco metálico envolto por uma amostra de borracha, contido numa câmara rígida e mantidos à temperatura constante de $100,0 \pm 0,5{ }^{\circ} \mathrm{C}$. O disco foi então girado lentamente em uma direção, pelo viscosímetro, por $4 \mathrm{~min}$. A resistência que foi oferecida pela borracha a esta rotação, medida em uma escala convencionada, foi definida como a viscosidade Mooney do corpo de prova. Para cada determinação foram preparados dois corpos de prova com cerca de $50 \mathrm{~mm}$ de diâmetro, $6 \mathrm{~mm}$ de espessura e com um furo central de $8 \mathrm{~mm}$. Essas análises foram realizadas no IPT (Instituto de Pesquisas Tecnológicas).

\subsection{3.e) Plasticidade Wallace $\left(P_{0}\right)$}

O plastímetro Wallace de pratos paralelos mede a plasticidade através do achatamento de um corpo de prova submetido a uma compressão constante em condições padrão de temperatura, tempo de ação da força de compressão, forma e peso do corpo de prova. Foram pesadas cerca de $30 \mathrm{~g}$ de borracha seca, passadas na calandra até que ficassem homogeneizadas e obtivéssemos um filme de aproximadamente 1,7 $\mathrm{mm}$ de espessura. Esta homogeneização foi realizada segundo normas da ABNT [90]. Preparou-se 10 corpos de prova que foram divididos, ao acaso, em dois grupos de cinco cada um. A plasticidade $\left(\mathrm{P}_{0}\right)$ foi determinada em 5 corpos de prova não degradados e em 5 termodegradados $\left(140{ }^{\circ} \mathrm{C}\right.$ por $\left.30 \mathrm{~min}\right)$ usando um plastímetro Wallace. O PRI é expresso em porcentagem e calculado por: 


$$
P R I=\left(P_{30} P_{o}\right) \times 100
$$

sendo $\mathrm{P}_{0}=$ plasticidade e $\mathrm{P}_{30}=$ plasticidade após degradação térmica dos corpos de prova.

As análises de DRC, \% de nitrogênio, \% de extrato acetônico e viscosidade foram realizadas em duplicata e as análises de plasticidade e PRI em triplicata. As análises de nitrogênio, extrato acetônico, viscosidade, plasticidade e PRI foram realizadas seguindo-se as normas da ABNT (Associação Brasileira de Normas Técnicas) [90].

\subsection{Avaliação da influência do tipo de porta-enxerto nas propriedades da Borracha Natural}

Neste trabalho foram utilizadas amostras de borracha natural de dois clones recomendados para o plantio em larga escala no estado de São Paulo (PB 235 e RRIM 600) enxertados em cinco diferentes porta-enxertos (RRIM 600, PB 235, IAN 873, SNS (sementes não selecionadas) e GT 1). O experimento instalado na Estação Experimental do IAC em Pindorama foi montado com o objetivo de avaliar a interação de enxerto versus porta-enxerto nas características agronômicas da borracha natural [44] e determinar a melhor combinação de enxerto versus portaenxerto em relação ao vigor. Este experimento teve início em 1992 e teve como coordenadores o Dr. Paulo de Souza Gonçalves (IAC/Embrapa) e o Engenheiro Agr. Antonio Lúcio Mello Martins.

\footnotetext{
3.2.1. Descrição do Experimento instalado em Pindorama - SP (região de São José do Rio Preto)

O experimento foi instalado na estação experimental de Agronomia de Pindorama, pertencente ao IAC, localizada a $21^{\circ} 13^{\prime} \mathrm{S}$ de latitude e $48^{\circ} 56^{\prime} \mathrm{W}$ de longitude, com $560 \mathrm{~m}$ de altitude, em solo Podzólico Vermelho-Amarelo eutrófico, de textura média, profundo abrupto e bem drenado. Predomina nesta região o clima com estação seca definida, amplitude média de 23.8 a $19.3{ }^{\circ} \mathrm{C}$ e precipitação média
} 
anual de $1258 \mathrm{~mm}$. As deficiências hídricas e os baixos níveis térmicos ocorrem de junho ao início de setembro, com um período favorável ao crescimento da seringueira nos meses de outubro a março [44].

Foi utilizado o delineamento de blocos ao acaso com parcelas subdivididas em seis tratamentos (porta-enxertos) e seis subtratamentos (enxertos), com quatro repetições. Cada parcela constou de vinte plantas, sendo seis úteis, no espaçamento de 7,0 m entre linhas e 3,0 m entre plantas distribuidas em 6,0 ha. A Figura 33, mostra esquema do delineamento experimental para experimento utilizado no estudo da influência do porta-enxerto nas propriedades da borracha natural dos clones PB 235 e RRIM 600. 
1

\begin{tabular}{|c|c|c|}
\hline $\begin{array}{l}\text { RRMTOI } \\
\text { RRMGOI } \\
\text { RRMAOI } \\
\text { RRMGOO }\end{array}$ & $\begin{array}{l}17235 \\
\text { RRRMan } \\
\text { GII } \\
\text { RRMMGOD }\end{array}$ & $\begin{array}{l}\text { [R HOT } \\
\text { RRMGOO } \\
\text { AN8B3 } \\
\text { RROMGO }\end{array}$ \\
\hline $\begin{array}{l}\text { W } 235 \\
\text { WN87 } \\
\text { WN8m } \\
\text { AN873 }\end{array}$ & $\begin{array}{l}\text { RRMADD } \\
\text { UN87 } \\
\text { IR 107 } \\
\text { LN873 } \\
\end{array}$ & $\begin{array}{l}\text { ROAM701 } \\
\text { AN873 } \\
\text { FoMGOO } \\
\text { IAN8B }\end{array}$ \\
\hline $\begin{array}{l}\text { AN873 } \\
\text { NS } \\
\text { RKMinol } \\
\text { SNS }\end{array}$ & $\begin{array}{l}\text { (iTl } \\
\text { NNS } \\
\text { ikio' } \\
\text { SNS }\end{array}$ & 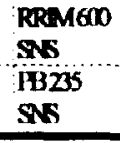 \\
\hline $\begin{array}{l}\text { IN83 } \\
\text { I14235 } \\
\text { (iT) } \\
143235\end{array}$ & 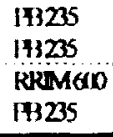 & 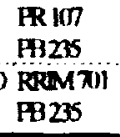 \\
\hline 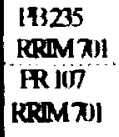 & $\begin{array}{l}\text { RRMT)I } \\
\text { RRM } 70 ! \\
\text { (ITI } \\
\text { RRM } 70 !\end{array}$ & 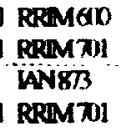 \\
\hline $\begin{array}{l}\text { RRM } 711 \\
\text { (IT) } \\
\text { III235 } \\
\text { (T) } 1\end{array}$ & $\begin{array}{l}\text { AN8T } \\
\text { (iT) } \\
\text { IR in } \\
\text { (iT) }\end{array}$ & $\begin{array}{l}\text { PRAMGO } \\
\text { GT1 } \\
\text { [AN\&B3 } \\
\text { (IT) }\end{array}$ \\
\hline
\end{tabular}

II

\begin{tabular}{|c|c|c|}
\hline $\begin{array}{l}173235 \\
\text { AN873 } \\
\text { PCOMT1 } \\
\text { AN873 }\end{array}$ & $\begin{array}{l}\text { IR107 } \\
\text { MN873 } \\
\text { RRM MO00 } \\
\text { LN87 }\end{array}$ & $\begin{array}{l}\text { AN87 } \\
\text { AN8B } \\
\text { GT1 } \\
\text { AN8B }\end{array}$ \\
\hline 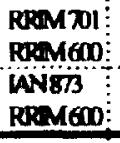 & 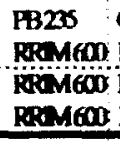 & $\begin{array}{l}\text { Gli } \\
\text { RPM } \\
\text { PRió } \\
\text { ReM }\end{array}$ \\
\hline 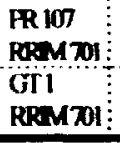 & 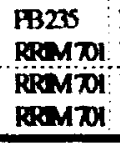 & 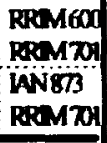 \\
\hline $\begin{array}{l}\text { PRIOT } \\
\text { GTI } \\
\text { His235 } \\
\text { GT1 }\end{array}$ & $\begin{array}{l}\text { RRM XI } \\
\text { GTI } \\
\text { WNBS } \\
\text { GT I }\end{array}$ & $\begin{array}{l}\text { RRM MoOd } \\
\text { GT } 1 \\
\text { GT } 1 \\
\text { GT 1 }\end{array}$ \\
\hline \begin{tabular}{l} 
H3235 \\
SNS \\
\hdashline PHaM701 \\
SNS
\end{tabular} & $\begin{array}{l}\text { IANB } \\
\text { SNS } \\
\text { IRIOT } \\
\text { SNS }\end{array}$ & $\begin{array}{l}\text { Gil } \\
\text { SNs } \\
\text { Rivino } \\
\text { SNS }\end{array}$ \\
\hline $\begin{array}{l}\text { FR NO7 } \\
\text { PB235 } \\
\text { WN833 } \\
\text { FA235 }\end{array}$ & $\begin{array}{l}\text { FB235 } \\
\text { PB225 } \\
\text { FRMT1 } \\
\text { F1225 }\end{array}$ & $\begin{array}{l}\text { GT 1 } \\
\text { PB225 } \\
\text { RREM } 600 \\
\text { FH225 }\end{array}$ \\
\hline
\end{tabular}

III

\begin{tabular}{|c|c|c|}
\hline 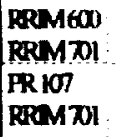 & 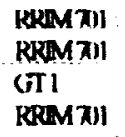 & $\begin{array}{l}\text { LAN8B } \\
\text { RRMT01 } \\
\text { H(3235 } \\
\text { RRM X01 }\end{array}$ \\
\hline $\begin{array}{l}\text { PB22 } \\
\text { SNS } \\
\text { PRio } \\
\text { SNS }\end{array}$ & $\begin{array}{l}\text { ROMTII } \\
\text { NS } \\
\text { ROM610 } \\
\text { SNS }\end{array}$ & $\begin{array}{l}\text { LN\&73 } \\
\text { SN } \\
\text { GII } \\
\text { SN }\end{array}$ \\
\hline $\begin{array}{l}\text { FB225 } \\
\text { GT1 } \\
\text { RRAMO0 } \\
\text { GT1 }\end{array}$ & $\begin{array}{l}\text { AN873 } \\
\text { GT1 } \\
\text { BR ion } \\
\text { GT1 }\end{array}$ & $\begin{array}{l}\text { RRM } 7 \text { II } \\
\text { GI! } \\
\text { GII } \\
\text { GII }\end{array}$ \\
\hline 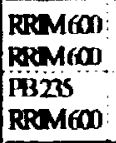 & $\begin{array}{l}\text { PRIOT } \\
\text { RRMGIN } \\
\text { GTi } \\
\text { RPMGOO }\end{array}$ & $\begin{array}{l}\text { AN\&B } \\
\text { RRM600 } \\
\text { RRMT01 } \\
\text { RRMGOD }\end{array}$ \\
\hline $\begin{array}{l}\text { PRIOT } \\
\text { WN873 } \\
\text { PB21 } \\
\text { AN873 }\end{array}$ & $\begin{array}{l}\text { lH3235 } \\
\text { WN873 } \\
\text { GI1 } \\
\text { AN873 }\end{array}$ & $\begin{array}{l}\text { RRM600 } \\
\text { WN873 } \\
\text { RPM Moi } \\
\text { WN\&73 }\end{array}$ \\
\hline $\begin{array}{l}\text { RRAM600 } \\
\text { PB225 } \\
\text { RRAT21 } \\
\text { PB225 }\end{array}$ & $\begin{array}{l}\text { FH235 } \\
\text { HH235 } \\
\text { GF1 } \\
\text { PH235 }\end{array}$ & $\begin{array}{l}\text { AN873 } \\
\text { IH3235 } \\
\text { RR } 107 \\
\text { P3235 }\end{array}$ \\
\hline
\end{tabular}

IV

\begin{tabular}{|c|c|c|}
\hline 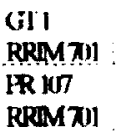 & $\begin{array}{l}\text { IH2S } \\
\text { RRMMT)! } \\
\text { WN8T3 } \\
\text { RRMN1 }\end{array}$ & $\begin{array}{l}\text { RRM TOI } \\
\text { RRMTKO] } \\
\text { RRM600 } \\
\text { RRMXI }\end{array}$ \\
\hline 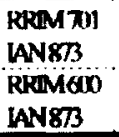 & $\begin{array}{l}\text { (iil } \\
\text { WN873 } \\
\text { Wi236 } \\
\text { WN873 }\end{array}$ & $\begin{array}{l}\text { PR K7 } \\
\text { WN873 } \\
\text { WN87 } \\
\text { WN873 }\end{array}$ \\
\hline $\begin{array}{l}\text { RRAMTII } \\
\text { SNS } \\
\text { LRMMAO } \\
\text { SNS }\end{array}$ & $\begin{array}{l}143235 \\
\text { SN } \\
\text { (151 } \\
\text { SN }\end{array}$ & $\begin{array}{l}\text { PR IO } \\
\text { SN } \\
\text { WNRn } \\
\text { SNS }\end{array}$ \\
\hline $\begin{array}{l}\text { WN873 } \\
\text { (iTl } \\
\text { IR ind } \\
\text { GT1 }\end{array}$ & $\begin{array}{l}\text { REM(O) } \\
\text { (it) } \\
\text { IB225 } \\
\text { GiT1 }\end{array}$ & 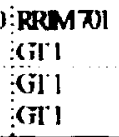 \\
\hline $\begin{array}{l}\text { WN873 } \\
\text { H1225 } \\
\text { RPMiGio } \\
\text { H1225 }\end{array}$ & $\begin{array}{l}\text { PRPMTDI } \\
\text { M1275 } \\
\text { Gil 1 } \\
\text { PH3275 }\end{array}$ & 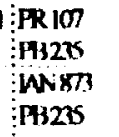 \\
\hline $\begin{array}{l}\text { GT I } \\
\text { RRMGOD } \\
\text { RPMGOD } \\
\text { RPMG10 }\end{array}$ & 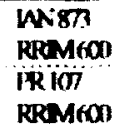 & 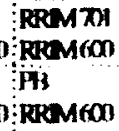 \\
\hline
\end{tabular}

\section{Detrlede Subparoch}

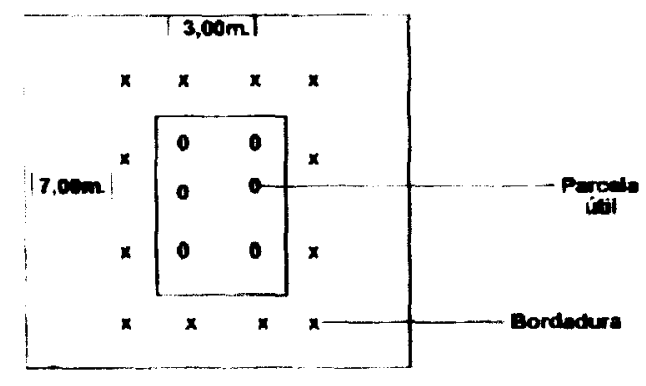

Figura 33. Figura esquemática do delineamento experimental do seringal de Pindorama - SP

\subsubsection{Coleta do Látex}

A coleta do látex para o estudo da influência de porta-enxertos nas propriedades da borracha natural seguiu o mesmo procedimento descrito no item 3.1.b. As datas da coleta foram 10/04/2000, 12/06/2000, 19/09/2000 e 19/12/2000. 


\subsubsection{Descrição das Técnicas}

No estudo e avaliação da influência do porta-enxerto nas propriedades da borracha natural dos clones RRIM 600 e PB 235 as amostras foram analisadas através dos ensaios padrões descritos no item 3.1.3.

\subsection{Análise Estatística}

Os resultados obtidos no estudo da variação intra e interclonal nas propriedades da borracha natural e na avaliação da influência do porta-enxerto foram analisados através de análises de variância com as médias das propriedades dos clones. Em seguida, foram conduzidas análises combinadas de cada variável, utilizando-se o delineamento de blocos ao acaso, com parcelas subdivididas. As análises foram feitas no IAC em Campinas em colaboração com o Dr. Paulo Gonçalves, utilizando-se o software SANEST (Sistema de Análise Estatística) desenvolvido no próprio Instituto Agronômico de Campinas.

\subsection{Avaliação do Efeito dos Tratamentos de Estabilização, Coagulação e Estocagem nas Propriedades da Borracha Natural.}

Nesta etapa do trabalho, foram utilizadas amostras de látex de borracha natural do clone RRIM 600 coletado na fazenda comercial do grupo Hevea Tech na região de São José do Rio Preto. A necessidade de se obter uma quantidade suficiente de borracha natural para o preparo das amostras, nos obrigou a realizar a coleta em uma fazenda comercial onde o número de árvores de cada clone é bem maior do que em um seringal experimental.

\subsection{Coleta do Látex}

O látex foi coletado em recipiente limpo, e logo em seguida submetido a sete diferentes tratamentos citados abaixo. Para se obter uma quantidade suficiente de borracha para que fossem realizadas todas as análises, o látex foi coletado de 10 árvores distintas para cada tipo de tratamento realizado totalizando 70 árvores. 
1. Borracha natural estabilizada com amônia e coagulada, em laboratório, com ácido acético $6 \mathrm{~N}$.

2. Borracha natural coagulada logo após a coleta, no campo, com ácido acético $6 \mathrm{~N}$.

3. "Borracha natural coagulada logo após a coleta, no campo, com ácido acético $3 \mathrm{~N}$.

4. Borracha natural coagulada naturalmente à temperatura ambiente, na sombra, durante 7 dias.

5. Borracha natural coagulada naturalmente à temperatura ambiente, na sombra, durante 14 dias.

6. Borracha natural coagulada naturalmente à temperatura ambiente, na sombra, durante 30 dias.

7. Borracha natural coagulada naturalmente à temperatura ambiente, na sombra, durante 60 dias.

As amostras, depois de submetidas aos tratamentos acima, foram então laminadas em calandra e secas em estufa a $50{ }^{\circ} \mathrm{C}$ por aproximadamente $72 \mathrm{~h}$.

O sistema de sangria utilizado no experimento foi o S/2 d/4 ET 2,5\%, sendo a sangria realizada no primeiro painel. A aplicação de Ethrel® foi realizada quinze dias antes da data da coleta. Esta aplicação é feita uma vez ao mês, dez vezes ao ano, com exceção dos meses de agosto e setembro, período de descanso das árvores.

${ }^{*} \mathrm{~A}$ borracha natural coagulada no campo com ácido acético $3 \mathrm{~N}$ apresentou alguns problemas relacionados à coagulação. A coagulação no campo não foi obtida pelo fato de não haver separação da fase borracha (coagulada) e a fase soro. Esta amostra precisou ser trazida ao laboratório onde foi submetida à agitação mecânica durante $24 \mathrm{~h}$ para promover a separação das duas fases e permitir a extração da borracha.

\subsubsection{Descrição das Técnicas}

$\mathrm{Na}$ avaliação do efeito dos tratamentos de estabilização, coagulação e estocagem nas propriedades da borracha natural as amostras de borracha natural foram analisadas através das técnicas de viscosidade Mooney, plasticidade Wallace, PRI, \% de nitrogênio, Calorimetria Diferencial de Varredura (DSC), análise 
termogravimétrica (TG), análise termo dinâmico-mecânica (DMTA) e espectroscopia de infravermelho. As análises de viscosidade Mooney, plasticidade Wallace, PRI e \% de nitrogênio foram descritas no item 3.1.3. As demais técnicas estão descritas a seguir.

\subsection{2.a Medidas de DSC}

As medidas de Calorimetria Diferencial de Varredura (DSC) foram realizadas em aparelho da marca NETZSCH, modelo 204. A taxa de aquecimento foi de $10{ }^{\circ} \mathrm{C} / \mathrm{min}$, em atmosfera de nitrogênio como gás de arraste. A faixa de temperatura analisada foi de -100 a $200{ }^{\circ} \mathrm{C}$.

\subsection{2.b Medidas de TG}

As medidas de análise termogravimétrica (TGA) foram realizadas em equipamento da marca NETZSCH modelo 209. A taxa de aquecimento foi de $10{ }^{\circ} \mathrm{C} /$ min e varredura de 25 a $700{ }^{\circ} \mathrm{C}$.

\subsection{2.c Medidas de DMTA}

As análises termo dinâmico-mecânica (DMTA) foram realizadas em aparelho da NETZSCH modelo 242C. A freqüência foi de $10 \mathrm{~Hz}$ e a temperatura varrida foi -110 a $100^{\circ} \mathrm{C}$. A taxa de aquecimento foi de $10^{\circ} \mathrm{C} / \mathrm{min}$. As dimensões do corpo de prova foram $10 \mathrm{~mm}$ de comprimento, $5 \mathrm{~mm}$ de largura e $1,8 \mathrm{~mm}$ de espessura.

As medidas acima foram realizadas no Departamento de Química, Física e Biologia na UNESP de Presidente Prudente-SP com a colaboração do Dr. Aldo Job.

\subsection{2.d Medidas de espectroscopia na região do infravermelho} (FTIR)

Os espectros na região do infravermelho da borracha natural foram obtidos no Laboratório de Polímeros do Instituto de Física da USP de São Carlos (IFSC) com a colaboração da Dr (a) Débora Terezia Balogh. O equipamento utilizado o Nexus 470 FTIR equipado com acessório HATR (Horizontal Attenuated 
Total Reflectance). Esse acessório permitiu que os espectros fossem obtidos analisando-se diretamente os filmes de borracha com espessura de aproximadamente $0,3 \mathrm{~cm}$ utilizando-se como porta-amostra o cristal de seleneto de zinco ( $\mathrm{ZnSe}$ ). Os espectros foram obtidos na região de $4000-650 \mathrm{~cm}^{-1}$.

\subsection{Estudo das Propriedades nanomecânicas da borracha natural via técnica de nanoindentação}

Nesta etapa do trabalho, foram realizadas medidas de nanoindentação em filmes finos de borracha natural para determinação das propriedades nanomecânicas da borracha. A investigação das propriedades elásticas da borracha natural em nanoescala foi feita no departamento de engenharia de materiais do Massachusetts Institute of Technology no Ortiz Polymer Mechanics Laboratory (OPML) sob a supervisão da Prof (a) Dr (a). Christine Ortiz.

\subsubsection{Coleta do Látex}

Nesse trabalho foram utilizadas amostras dos clones comerciais RRIM 600, IAN 873, PB 235 a GT 1. A coleta foi realizada em dez diferentes árvores de um mesmo clone e o látex dessas árvores foi misturado para que os resultados apresentados pudessem ser mais significativos e para obter uma quantidade suficiente de amostra para realizar todas as análises. $\mathrm{O}$ látex foi coletado em recipiente limpo, e logo estabilizado com solução de hidróxido de amônia. A coleta foi realizada na fazenda experimental do IAC em Votuporanga - SP.

\subsubsection{Preparação dos filmes de borracha}

Para a preparação dos filmes finos, a borracha natural foi cortada em pedaços com cerca de $2 \mathrm{~mm}$, e colocada em álcool etílico P.A sob agitação em ultra-som durante 10 min para que fossem removidas as impurezas. Depois de seca, a borracha foi dissolvida em tolueno sob agitação em $48 \mathrm{~h}$. A concentração da solução de borracha natural foi de aproximadamente $0,02 \mathrm{~g} / \mathrm{mL}$. Os filmes foram preparados através de técnica de "spin coating" com velocidade de $1500 \mathrm{rps}$ durante $30 \mathrm{~s}$. A solução foi depositada em substrato de vidro, Figura 34. A espessura do filme foi 
determinada via técnica de Microscopia de Força Atômica AFM em água e em ar. Para isso, foi feito um rasgo no filme de borracha e a uma imagem do relevo da superfície foi obtida. A espessura determinada foi de $2.5 \mu \mathrm{m}$.

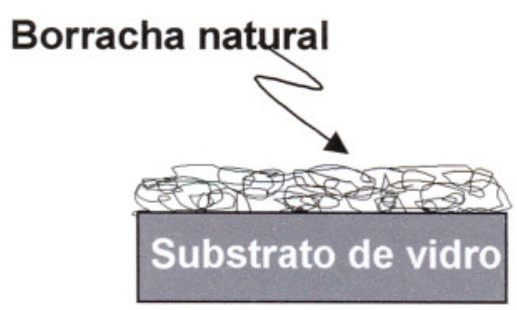

Figura 34. Figura esquemática do filme de borracha depositado em substrato de vidro via técnica de "spin coating".

\subsubsection{Descrição da Técnica de Espectroscopia de Força de alta resolução}

\section{HRFS}

A técnica utilizada para realização das medidas de nanoindentação nos filmes de borracha foi a técnica de espectroscopia de força de alta resolução. O equipamento utilizado foi o Molecular Force Probe MFP produzido pela Asylum Research INC Santa Barbara Califórnia, Figura 35. O MFP possui o mesmo princípio de funcionamento do AFM, em que um cantiléver macio e flexível funciona como um transdutor de força e deflete em resposta às pequenas forças entre o ele e a superfície do material. Um laser focado na ponta desse cantiléver envia sinal para um fototransdutor através de um espelho. Ao contrário do AFM, o MFP, não realiza imagens da superfície da amostra e foi projetado para obter medidas de força $(\mathrm{nN})$ versus distância $(\mathrm{nm})$ da ponta em relação à amostra. Além do mais, o MFP tem algumas vantagens quando comparado com o AFM o que possibilita a realização de medidas de nanoindentação com uma precisão maior. Entre essas vantagens estão: a) o equipamento possui uma geometria dos feixes de laser que minimiza o espalhamento de luz e minimiza interferências; b) possui célula projetada para facilitar o uso e manipulação de amostras poliméricas e biológicas em meio fluído; c) o equipamento possui um sensor (Linear Variable Differential Transformer-LVDT) que quantifica diretamente à distância percorrida pelo piezo minimizando perdas por histereses do equipamento e aumentando a resolução. O MFP mostrado na Figura 35 pode detectar forças de até $5 \mathrm{pN}$ em fluído e distâncias de até 3 angstrons. 


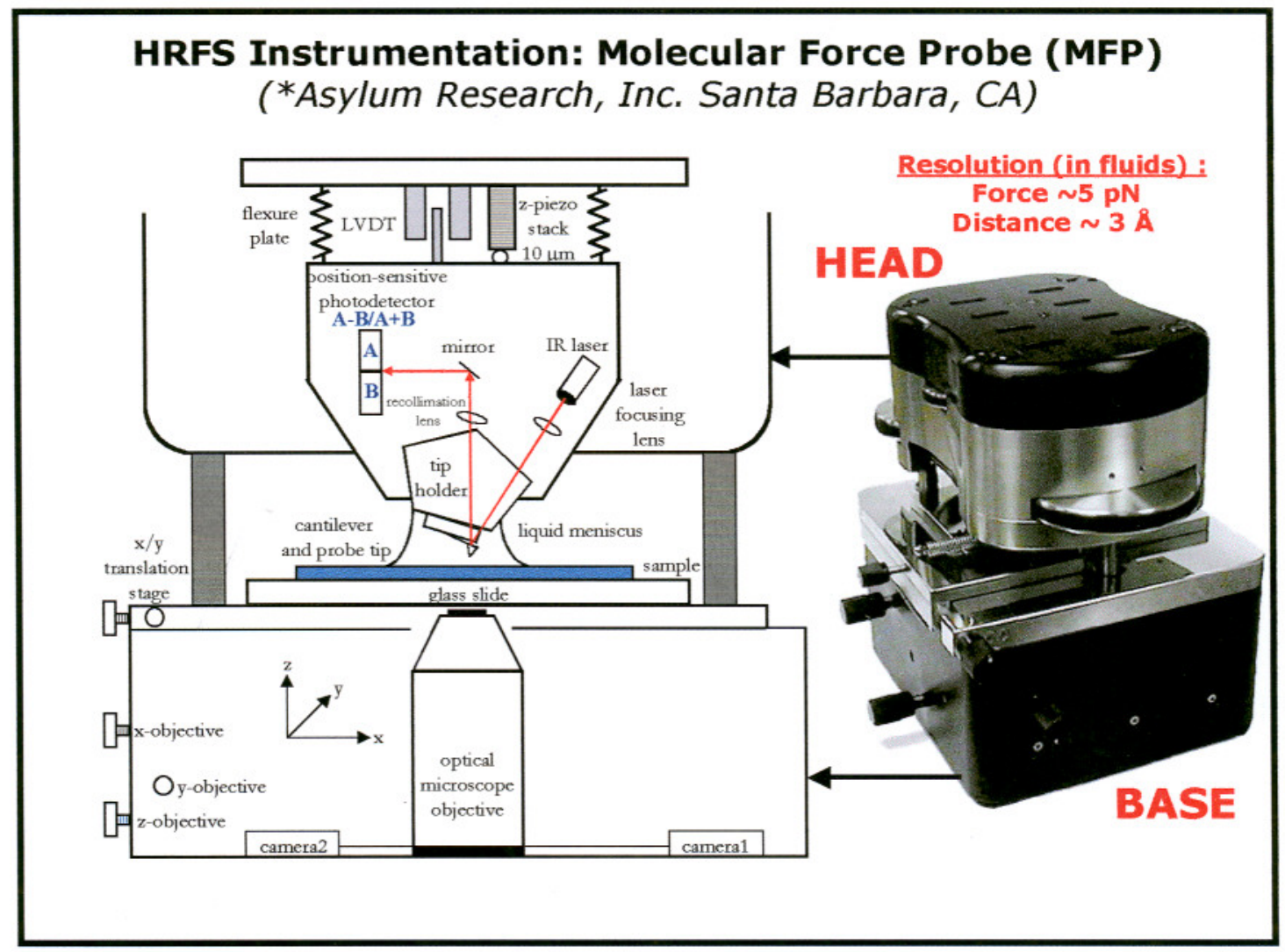

Figura 35. Esquema do equipamento de MFP usado no experimento de nanoindentação.

O cantiléver utilizado nas medidas de nanoindentação corresponde a um cantiléver de nitreto de silício da Digital Instruments Inc com constante de mola de $0,2 \mathrm{~N} / \mathrm{m}$, Figura 36. O cantiléver foi o mesmo para as todas as medidas realizadas. Em um primeiro momento, as medidas de nanoindentação foram realizadas em ar mas, devido às forças de interação, como forças de van der Walls, entre a superfície do filme de borracha e a ponta, observou-se uma certa dificuldade na determinação do ponto de contato inicial. Portanto, optou-se pela realização das medidas em meio aquoso. 


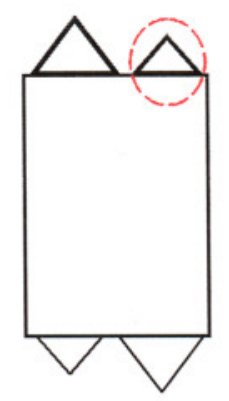

Digital Instruments, Inc.

Figura 36. Esquema do cantiléver de nitreto de silício utilizado nas medidas de nanoindentação.

Para realização das medidas de nanoindentação, o equipamento foi colocado em uma bancada com sistema de isolamento de vibração.

As medidas de indentação foram realizadas em cinco diferentes posições no filme de borracha, para se obter um valor representativo de módulo elástico para o filme todo.

\subsubsection{Determinação da área da ponta utilizada}

Os parâmetros (raio e ângulo da ponta), necessários para a determinação da área da ponta utilizada nas medidas de nanoindentação, foram determinados através de técnica de microscopia de eletrônica de varredura (MEV). O equipamento utilizado foi o JEOL $6320 \mathrm{FV}$ de alta resolução. O ângulo da ponta foi determinado a partir da imagem obtida em MEV com auxílio de um esquadro. 


\section{RESULTADOS E DISCUSSÕES}

\subsection{Estudo e Avaliação da Variação Intra e Interclonal nas Propriedades da Borracha Natural}

No estudo da variação intraclonal das propriedades da borracha natural foi verificada a variação das propriedades $\mathrm{DRC}, \%$ de nitrogênio, \% de extrato acetônico, plasticidade, viscosidade e PRI para os clones GT 1, RRIM 600 e PB 235 plantados em três blocos distintos de uma plantação experimental na cidade de Indiana região de Presidente Prudente - SP. Os valores das propriedades dos clones em blocos distintos são mostrados nas Tabelas 4-24.

\subsubsection{Variação do Conteúdo de Borracha Seca}

O DRC representa a quantidade de borracha seca existente no látex e reflete a regeneração do mesmo no interior dos laticíferos, sendo que sua composição contém mais de $90 \%$ de poli (cis - 1,4 - isopreno). O DRC está relacionado com a quantidade de borracha produzida pelas árvores, portanto, se as árvores de um mesmo clone produzem borracha de forma homogênea, isso terá uma resposta positiva na produtividade. A capacidade de um clone produzir borracha ou seja, a sua produtividade, é um dos principais aspectos agronômicos levado em consideração no planejamento de um seringal. As Tabelas 4, 5 e 6 mostram a variação dos valores de DRC para os clones GT 1, RRIM 600 e PB 235 em três blocos distintos (I, II e III) para quatro coletas realizadas. Como pode se observar pelos valores de desvio padrão (dp) os valores de DRC variam pouco dentro de uma mesma coleta podendo-se concluir que existe uma pequena variação intraclonal para a \% de DRC. Na Tabela 4, que mostra a variação dos valores de \% DRC para o clone GT 1, observamos os valores de 32, 29 e 29 para os blocos (I), (II) e (III) respectivamente dentro da coleta número 1. Já entre as coletas observa-se uma variação maior. Em geral, nota-se uma tendência de aumento dos valores de DRC da primeira para a quarta coleta para todos os clones estudados. Isso se dá devido à influência do clima nas propriedades da borracha. Os valores de DRC tendem a cair nos meses de maio e junho, devido ao 
período de senescência das árvores (queda das folhas) e da ausência de chuvas, característica marcante do inverno na região do Estado de São Paulo [15].

Tabela 4.Variação dos valores de DRC para o clone GT 1 em três blocos distintos (I, II e III) para quatro coletas realizadas.

\begin{tabular}{ccccc}
\hline Número da Coleta & \multicolumn{4}{c}{ DRC (\%) } \\
\hline & GT 1 (I) & GT 1 (II) & GT 1 (III) & média \pm dp \\
\hline 1 & 32 & 29 & 29 & $30 \pm 1$ \\
2 & 27 & 28 & 29 & $28 \pm 1$ \\
3 & 35 & 35 & 37 & $36 \pm 1$ \\
4 & 33, & 36 & 34 & $34 \pm 2$ \\
\hline média+dp & $32 \pm 3$ & $32 \pm 4$ & $32 \pm 4$ & \\
\hline
\end{tabular}

Tabela 5. Variação dos valores de DRC para o clone RRIM 600 em três blocos distintos (I, II e III) para quatro coletas realizadas.

\begin{tabular}{ccccc}
\hline Número da Coleta & \multicolumn{4}{c}{ DRC (\%) } \\
\hline & RRIM (I) & RRIM 600 (II) & RRIM 600 (III) & média \pm dp \\
\hline 1 & 29 & 28 & 30 & $29 \pm 1$ \\
2 & 30 & 27 & 30 & $29 \pm 2$ \\
3 & 36 & 32 & 39 & $36 \pm 3$ \\
4 & 35 & 34 & 36 & $35 \pm 1$ \\
\hline média+dp & $32 \pm 3$ & $30 \pm 3$ & $34 \pm 4$ & \\
\hline
\end{tabular}


Tabela 6.Variação dos valores de DRC para o clone PB 235 em três blocos distintos (I, II e III) para quatro coletas realizadas.

\begin{tabular}{ccccc}
\hline Número da Coleta & \multicolumn{4}{c}{ DRC (\%) } \\
\hline & PB 235 I & PB 235 II & PB 235 III & média $\pm d p$ \\
\hline 1 & 27 & 34 & 30 & $30 \pm 3$ \\
2 & 31 & 32 & 31 & $31 \pm 1$ \\
3 & 36 & 37 & 36 & $36 \pm 1$ \\
4 & 42 & 40 & 46 & $43 \pm 3$ \\
\hline média+dp & $34 \pm 7$ & $36 \pm 4$ & $36 \pm 7$ & \\
\hline
\end{tabular}

Yip [91] classificou 43 clones, da região da Malásia, de acordo com o seu valor de DRC e segundo esta classificação os clones com DRC variando de 31-34\% estão abaixo da média; valores entre $34-38 \%$ estão dentro da média; aqueles entre $38-41 \%$ são considerados acima da média e clones com valores maiores de $41 \%$ são considerados com alto DRC.

Neste trabalho, a média dos valores de DRC encontrados para os clones GT 1 (aproximadamente 32\%) e RRIM 600 (entre 30-34 \%) estão abaixo da média dos valores observados na literatura para a região da Malásia [91]. Já, se forem comparados os valores de DRC obtidos neste trabalho com os valores de DRC obtidos em estudo realizado na região de Votuporanga-SP [15] para os clones GT 1 e RRIM 600, observa-se que na média os valores são similares nos dois estudos. Já o clone PB 235 apresentou valores de DRC dentro da média e próximos dos valores de DRC obtidos em estudo realizado na Malásia [91] e no Estado de São Paulo, Brasil [15]. Estudos realizados na região de Votuporanga - SP no período de Janeiro de 2000 - Dezembro de 2002 investigaram as propriedades da borracha natural dos clones GT 1, PB 235, IAN 873 e RRIM 600 indicados para o plantio em larga escala nessa região, visando a investigação da influência do efeito das condições climáticas (temperatura e índice pluviométrico) na qualidade e produtividade da borracha. A qualidade do látex de borracha natural foi avaliada pelos ensaios padrões de conteúdo de borracha seca no látex, percentagem de cinzas, percentagem de extrato acetônico, percentagem de nitrogênio, plasticidade Wallace, índice de retenção de plasticidade e viscosidade Mooney e correlacionada com a produtividade e condições climáticas. 
Os resultados mostraram variações altamente significativas entre clones e coletas e grande influência do clima nas propriedades das borrachas.

\subsubsection{Variação Intraclonal da Porcentagem de Nitrogênio}

As substâncias nitrogenadas são compostas de proteínas, aminoácidos e bases nitrogenadas e estão presentes na borracha natural, tanto na fase borracha como na fase soro do látex. A porcentagem de nitrogênio é uma característica muito importante do látex, porque se houver excesso ou falta destas substâncias a borracha apresentará, depois de processada e vulcanizada, propriedades de resistência insatisfatórias. As proteínas da borracha natural exercem influência especial sobre suas propriedades físicas e mecânicas [92]. Othman et al. [93], mostraram que alguns aminoácidos favorecem o aumento de ligações cruzadas e aumentam o módulo de elasticidade. A desproteinização do látex de campo reduz o conteúdo de gel da borracha de 2,6 a 1,5\%, o que demonstra que as proteínas são responsáveis pela formação do gel, o que por sua vez está relacionado com o aumento das ligações cruzadas na borracha natural.

Através dos dados contidos nas Tabelas 7, 8 e 9, observa-se que existe pouca variação intraclonal para a \% de nitrogênio o que pôde ser comprovado pelos baixos valores de dp dentro de uma mesma coleta. Assim como para a \% de DRC, a borracha dos clones apresentou homogeneidade intraclonal quanto à \% de nitrogênio. O fato de não haver variação da \% de nitrogênio, dentro de um mesmo clone, é um aspecto positivo porque as substâncias nitrogenadas afetam o desempenho da borracha natural depois de processada e vulcanizada. Alguns autores [51, 92, 93] têm reportado que a presença de proteínas e aminoácidos catalisa reações que provocam o endurecimento da borracha natural. Portanto, a verificação de que a borracha proveniente de um mesmo clone não possui variação quanto à quantidade de nitrogênio, é um indicativo de que após ser submetida a um determinado tipo de processamento esse material vai apresentar um comportamento com poucas variações.

No geral, a média dos valores encontrados para o conteúdo de nitrogênio dos três clones estudados está dentro dos padrões requisitados para as borrachas brasileiras das normas da ABNT (Associação Brasileira de Normas Técnicas), que 
especifica valores máximos de $\%$ de nitrogênio de até $0,6 \%$. O clone PB 235 apresentou os valores menores de \% de nitrogênio (aproximadamente $0,4 \%$ ) quando comparado com os demais clones. Observa-se que no geral, há uma tendência de queda dos valores de \% de nitrogênio da primeira para a quarta coleta para os três clones estudados. Assim como para a propriedade DRC, a propriedade \% de nitrogênio também é influenciada pelo clima $[15,94]$ como pode ser observado pela variação dos valores de \% de nitrogênio entre as coletas. Quando comparamos os valores médios de \% de nitrogênio obtidos neste trabalho com os valores obtidos em trabalho realizado na região de Votuporanga - SP, observa-se que os valores são próximos o que indica que a média de \% de nitrogênio para clones de borracha natural plantados no Estado de São Paulo está variando de 0,4-0,6 \%.

Tabela 7. Variação dos valores de \% de Nitrogênio para o clone GT 1 em três blocos distintos (I, II e III) para quatro coletas realizadas.

\begin{tabular}{ccccc}
\hline Número da Coleta & \multicolumn{4}{c}{ Nitrogênio (\%) } \\
\hline & GT 1 (I) & GT 1 (II) & GT 1 (III) & média $\pm d p$ \\
\hline 1 & 0,50 & 0,60 & 0,70 & $0,60 \pm 0,10$ \\
2 & 0,70 & 0,70 & 0,70 & $0,70 \pm 0,00$ \\
3 & 0,50 & 0,50 & 0,50 & $0,50 \pm 0,00$ \\
4 & 0,60 & 0,50 & 0,60 & $0,60 \pm 0,05$ \\
\hline média+dp & $0,60 \pm 0,10$ & $0,60 \pm 0,10$ & $0,60 \pm 0,10$ & \\
\hline
\end{tabular}

Tabela 8.Variação dos valores de \% de Nitrogênio para o clone RRIM 600 em três blocos distintos (I, II e III) para quatro coletas realizadas.

\begin{tabular}{ccccc}
\hline \multicolumn{2}{c}{ Número da Coleta } & \multicolumn{4}{c}{ Nitrogênio (\%) } \\
\hline & RRIM 600 (I) & RRIM 600 (II) & RRIM 600 (III) & média \pm dp \\
\hline 1 & 0,60 & 0,60 & 0,60 & $0,60 \pm 0$ \\
2 & 0,60 & 0,70 & 0,70 & $0,60 \pm 0,06$ \\
3 & 0,50 & 0,50 & 0,40 & $0,50 \pm 0,06$ \\
4 & 0,50 & 0,50 & 0,50 & $0,50 \pm 0$ \\
\hline média + dp & $0,55 \pm 0,06$ & $0,60 \pm 0,10$ & $0,52 \pm 0,10$ \\
\hline
\end{tabular}


Tabela 9.Variação dos valores de \% de Nitrogênio para o clone PB 235 em três blocos distintos (I, II e III) para quatro coletas realizadas.

\begin{tabular}{ccccc}
\hline Número da Coleta & \multicolumn{4}{c}{ Nitrogênio (\%) } \\
\hline & PB 235 (I) & PB 235 (II) & PB 235 (III) & média \pm dp \\
\hline 1 & 0,50 & 0,40 & 0,50 & $0,50 \pm 0,06$ \\
2 & 0,50 & 0,50 & 0,50 & $0,50 \pm 0$ \\
3 & 0,30 & 0,30 & 0,30 & $0,30 \pm 0$ \\
4 & 0,30 & 0,40 & 0,30 & $0,30 \pm 0,06$ \\
\hline média+dp & $0,40 \pm 0,1$ & $0,40 \pm 0,10$ & $0,40 \pm 0,10$ & \\
\hline
\end{tabular}

\subsubsection{Variação da Viscosidade Mooney, Plasticidade Wallace e PRI}

A viscosidade Mooney é um parâmetro largamente usado pelos países consumidores de borracha. Uma borracha com alta viscosidade Mooney requer longos tempos de premastigação ou a adição de agentes caros para tornar o produto processável. Por outro lado, borrachas muito moles com baixa viscosidade Mooney, praticamente não requerem mastigação, mas não podem ser submetidas a certos tipos de processamento. $\mathrm{O}$ valor da viscosidade Mooney muda com o tempo de estocagem, condições de temperatura e umidade, fazendo com que a borracha possa tornar-se mais dura sob certas condições. O processo de endurecimento da borracha é acelerado em temperaturas elevadas e em ambiente seco. Alguns autores $[47,95]$ têm postulado que este endurecimento se dá devido a reações de ligação cruzada entre moléculas de borracha as quais envolvem grupos aldeídos presentes na cadeia isoprênica. Essas reações são favorecidas pelos aminoácidos presentes na fase nãoborracha do látex, que mesmo após a coagulação e descarte do soro, ficam presos na rede polimérica. A adição de reagentes, como a hidroxilamina, ao látex, antes da coagulação, inibe estas reações dando origem ao látex com viscosidade estabilizada conhecido como "CV rubbers" (constant viscosity) [91].

As Tabelas 10, 11 e 12 mostram a variação dos valores de viscosidade Mooney para os clones GT 1, RRIM 600 e PB 235 em três blocos distintos. Ao contrário do observado para DRC e \% de nitrogênio, os valores de viscosidade Mooney apresentam uma certa variação intraclonal para os clones estudados. Com 
destaque para o clone RRIM 600 na segunda e terceira coleta que apresentou variação de 25 unidades Mooney entre os blocos RRIM 600 I e RRIM 600 II e 19 unidades Mooney entre os blocos RRIM 600 II e RRIM 600 III, respectivamente. O clone PB 235 apresentou variação de 15 unidades Mooney para a segunda coleta entre os blocos PB 235 I e PB 235 III. Já clone GT 1 apresentou variação de 10 unidades Mooney na segunda e terceira coleta para os blocos GT 1 I e GT 1 III. Observa-se altos valores de dp dentro de uma mesma coleta principalmente para 0 clone RRIM 600. No entanto, é importante observar que na média entre as coletas, o efeito da variação intraclonal é minimizado. Portanto, observa-se que, no geral, a viscosidade Mooney não apresentou uma tendência clara de comportamento em função dos meses de coleta.

Tabela 10. Variação dos valores de Viscosidade Mooney para o clone GT 1 em três blocos distintos (I, II e III) para quatro coletas realizadas.

\begin{tabular}{ccccc}
\hline Número da Coleta & \multicolumn{4}{c}{ Viscosidade Mooney $\left(\mathbf{V}_{0}\right)$} \\
\hline 1 & GT 1 (I) & GT 1 (II) & GT 1 (III) & média \pm dp \\
\hline 2 & 113 & 109 & 108 & $110 \pm 3$ \\
3 & 99 & 101 & 109 & $103 \pm 5$ \\
4 & 97 & 100 & 108 & $102 \pm 6$ \\
\hline média+dp & 106 & 105 & 108 & $106 \pm 2$ \\
\hline
\end{tabular}

Tabela 11. Variação dos valores de Viscosidade Mooney para o clone RRIM 600 em três blocos distintos (I, II e III) para quatro coletas realizadas.

\begin{tabular}{ccccc}
\hline \multicolumn{2}{c}{ Número da Coleta } & \multicolumn{4}{c}{ Viscosidade Mooney (V) } \\
\hline & RRIM 600 (I) & RRIM 600 (II) & RRIM 600(III) & média \pm dp \\
\hline 1 & 127,0 & 105,0 & 119,0 & $117 \pm 11$ \\
2 & 124,0 & 99,0 & 123,0 & $115 \pm 14$ \\
3 & 95,4 & 80,8 & 99,7 & $92 \pm 10$ \\
4 & 111,0 & 113,4 & 110,3 & $112 \pm 2$ \\
\hline média+dp & $114 \pm 14$ & $100 \pm 14$ & $113 \pm 10$ & \\
\hline
\end{tabular}


Tabela 12. Variação dos valores de Viscosidade Mooney para o clone PB 235 em três blocos distintos (I, II e III) para quatro coletas realizadas.

\begin{tabular}{ccccc}
\hline Número da Coleta & \multicolumn{4}{c}{ Viscosidade Mooney $\left(\mathbf{V}_{\mathbf{0}}\right)$} \\
\hline & PB 235 (I) & PB 235 (II) & PB 235 (III) & média \pm dp \\
\hline 1 & 100 & 92 & 102 & $98 \pm 6$ \\
3 & 95 & 88 & 80 & $88 \pm 7$ \\
4 & 105 & 101 & 103 & $103 \pm 2$ \\
\hline média+dp & 104 & 101 & 93 & $99 \pm 6$ \\
\hline
\end{tabular}

Yip [91] estudou a viscosidade Mooney para 43 clones e encontrou valores de viscosidade média entre 55-83 unidades para clones da Classe I como GT 1, RRIM 600, e entre 46 e 78 unidades para clones da Classe II como IAN 873 e PB 235. Quando se comparam os valores de viscosidade Mooney obtidos para as borrachas da Malásia [91] com os obtidos neste trabalho, que variam de em média de 95-114, observa-se as borrachas estudadas possuem altos valores de $\mathrm{V}_{0}$. Portanto, as amostras de borracha estudadas aqui podem ser classificadas como duras. No estudo da variação da Viscosidade Mooney para os clones GT 1, RRIM 600 e PB 235 em três blocos distintos, o clone RRIM 600 apresentou os maiores valores médios de viscosidade Mooney, o que indica que este necessitará de maior trabalho e energia no seu processamento, quando comparado com o clone PB 235, que possui os menores valores de viscosidade Mooney. O clone RRIM 600 também apresentou maiores valores de desvio padrão, quando comparado com os clones GT 1 e PB 235. Isto sugere que o clone RRIM 600 é mais susceptível as variações climáticas do que os demais. Comparando-se os resultados de viscosidade Mooney obtidos neste estudo, com os resultados obtidos em estudo realizado em Votuporanga, SP [15] que variam de 95-120, podemos observar que os valores são próximos. Portanto, podemos concluir que os valores de viscosidade Mooney obtidos neste estudo estão dentro dos valores encontrados para os clones de borracha natural plantados no Estado de São Paulo.

A plasticidade Wallace e a viscosidade Mooney são propriedades que estão relacionadas com a viscosidade da borracha. Os testes para a determinação da 
plasticidade Wallace e da viscosidade Mooney baseiam-se em princípios diferentes, embora exista uma correlação entre as mesmas. O plastímetro Wallace de pratos paralelos mede a plasticidade com base no achatamento de um corpo de prova submetido a uma compressão constante em condições padrão de temperatura, tempo de ação da força de compressão, forma e peso do corpo de prova, e a leitura é feita em unidades na escala Wallace. Já a viscosidade Mooney é medida pelo torque requerido para girar um disco no interior de uma câmara cilíndrica cheia de borracha. A leitura direta é feita em unidades Mooney que são, em cada caso, uma função do valor do torque tomado como índice de viscosidade.

As Tabelas 13, 14 e 15 mostram a variação dos valores de plasticidade Wallace para os clones GT 1, RRIM 600 e PB 235 em três blocos distintos. Observase que a variação intraclonal para Plasticidade Wallace é menor do que a observada para a viscosidade Mooney no entanto, maior quando comparamos com a variação intraclonal para as propriedades \%DRC e \% de nitrogênio. O clone RRIM 600, apresentou, na segunda coleta, variação de 22 unidades na escala Wallace entre os blocos RRIM 600 II e RRIM III e na terceira coleta esse clone apresentou 10 unidades na escala Wallace entre os blocos RRIM 600 I e RRIM II.

Observa-se que não há uma tendência clara de comportamento para essa propriedade e as maiores variações foram para o clone RRIM 600 na segunda e terceira coleta. Os valores médios de $\mathrm{P}_{0}$ encontrados neste estudo variam de 66-78 e estão, em geral, dentro dos valores estipulados pelas normas da ABNT, que é de no mínimo 30 unidades para esta propriedade, caso contrário, a borracha é considerada muito mole. No entanto, quando comparamos os valores de plasticidade obtidos neste trabalho com os da literatura que variam de 42-55 observamos que a borracha dos clones brasileiros possui valor de $\mathrm{P}_{0}$ acima dos valores reportados [91] e podem ser consideradas duras. O clone PB 235 apresentou os menores valores médios de plasticidade quando comparado com os demais clones estudados mas ainda assim acima dos valores da literatura internacional. Por outro lado, os valores de plasticidade para a borracha natural encontrados nesse estudo estão de acordo com os valores médios obtidos em trabalho realizado em Votuporanga, SP [15] que variam de 65-85. 
Tabela 13. Variação dos valores de Plasticidade Wallace para o clone GT 1em três blocos distintos (I, II e III) para quatro coletas realizadas.

\begin{tabular}{ccccc}
\hline Número da Coleta & \multicolumn{4}{c}{ Plasticidade Wallace (P) } \\
\hline & GT 1 (I) & GT 1 (II) & GT (III) & Média \pm dp \\
\hline 1 & 73 & 76 & 73 & $74 \pm 2$ \\
2 & 77 & 80 & 82 & $80 \pm 3$ \\
3 & 76 & 76 & 81 & $78 \pm 3$ \\
4 & 76 & 66 & 77 & $73 \pm 6$ \\
\hline média+dp & $76 \pm 2$ & $75 \pm 6$ & $78 \pm 4$ &
\end{tabular}

Tabela 14. Variação dos valores de Plasticidade Wallace para o clone RRIM $600 \mathrm{em}$ três blocos distintos (I, II e III) para quatro coletas realizadas.

\begin{tabular}{ccccc}
\hline Número da Coleta & \multicolumn{4}{c}{ Plasticidade Wallace (P) } \\
\hline & RRIM 600 (I) & RRIM 600 (II) & RRIM 600(III) & Média \pm dp \\
\hline 1 & 75 & 70 & 78 & $74 \pm 4$ \\
2 & 78 & 67 & 89 & $78 \pm 11$ \\
3 & 76 & 66 & 74 & $72 \pm 5$ \\
4 & 76 & 75 & 73 & $75 \pm 2$ \\
\hline média+dp & $76 \pm 1$ & $69 \pm 4$ & $79 \pm 5$ & \\
\hline
\end{tabular}

Tabela 15. Variação dos valores de Plasticidade Wallace para o clone PB 235 em três blocos distintos (I, II e III) para quatro coletas realizadas.

\begin{tabular}{|c|c|c|c|c|}
\hline \multirow[t]{2}{*}{ Número da Coleta } & \multicolumn{4}{|c|}{ Plasticidade Wallace $\left(\mathbf{P}_{0}\right)$} \\
\hline & PB 235 (I) & PB 235 (II) & PB 235 (III) & Média $t$ dp \\
\hline 1 & 56 & 66 & 63 & $62 \pm 5$ \\
\hline 2 & 71 & 71 & 64 & $69 \pm 4$ \\
\hline 3 & 70 & 73 & 73 & $72 \pm 2$ \\
\hline 4 & 65 & 72 & 66 & $68 \pm 4$ \\
\hline média $+\mathrm{dp}$ & $67 \pm 7$ & $71 \pm 3$ & $67 \pm 5$ & \\
\hline
\end{tabular}


Os valores de PRI (Índice de Retenção de Plasticidade) fornecem uma estimativa da resistência à degradação termo-oxidativa [39, 96-100]. Altos valores de PRI correspondem a uma boa resistência ao aquecimento e a uma menor degradação termo-oxidativa.

As Tabelas 16, 17 e 18 mostram a variação dos valores de PRI para os clones GT 1, RRIM 600 e PB 235 em três blocos distintos. Essa propriedade foi a que apresentou os maiores valores de variação intraclonal como mostra os altos valores de dp principalmente para os clones RRIM 600 na primeira e segunda coleta e para o clone PB 235 na primeira coleta. O clone RRIM 600 apresentou variação de 21 unidades de PRI entre os blocos I e II e 18 unidades entre blocos II e III dentro primeira coleta. O clone PB 235 apresentou variação de 38 unidades de PRI entre os blocos II e III e 14 unidades de PRI entre os blocos I e II também para a primeira coleta. O clone GT 1 apresentou variação intraclonal de 18 unidades de PRI entre os blocos GT 1 I e GT 1 III para a terceira coleta realizada. O PRI foi a propriedade que mais apresentou variação entre as coletas como pode ser observada pelos altos valores de dp. O clone PB 235 foi o que apresentou as maiores variações entre as coletas. As variações observadas entre as coletas provavelmente se dão devido a uma maior ou menor quantidade de constituintes não borracha que influenciarão nas características da borracha, como por exemplo na formação de ligações cruzadas, e variações na massa molecular e sua distribuição [39, 91, 101]. Segundo a literatura $[38,48]$ essas borrachas quando estocadas em condições de temperatura e umidade ambientes tenderão a aumentar a quantidade de ligações cruzadas ocasionando um aumento adicional da $V_{0}$, devido às reações entre as moléculas de poli-isopreno envolvendo grupos aldeído ou carbonila adjacentes a cadeia isoprênica e a condensação de grupos aldeído presentes na fase não borracha como alguns aminoácidos $[51,102]$. 
Tabela 16. Variação dos valores de PRI para o clone GT 1 em três blocos distintos (I, II e III) para quatro coletas realizadas.

\begin{tabular}{ccccc}
\hline Número da Coleta & \multicolumn{5}{c}{ PRI } \\
\hline & GT 1 (I) & GT 1 (II) & GT (III) & média \pm dp \\
\hline 1 & 70 & 65 & 67,0 & $67 \pm 3$ \\
2 & 64 & 69 & 74,0 & $69 \pm 5$ \\
3 & 47 & 60 & 65,0 & $57 \pm 9$ \\
4 & 67 & 70 & 69,0 & $69 \pm 2$ \\
\hline média + dp & $62 \pm 10$ & $66 \pm 5$ & $69 \pm 4$ & \\
\hline
\end{tabular}

Tabela 17. Variação dos valores de PRI para o clone RRIM 600 em três blocos distintos (I, II e III) para quatro coletas realizadas.

\begin{tabular}{ccccc}
\hline Número da Coleta & \multicolumn{5}{c}{ PRI } \\
\hline & RRIM 600 (I) & RRIM 600 (II) & RRIM 600(III) & média \pm dp \\
\hline 1 & 61 & 40 & 58 & $53 \pm 11$ \\
2 & 64 & 46 & 58 & $56 \pm 9$ \\
3 & 47 & 37 & 48 & $44 \pm 6$ \\
4 & 68 & 69 & 60 & $66 \pm 5$ \\
\hline média+dp & $60 \pm 9$ & $48 \pm 15$ & $56 \pm 5$ & \\
\hline
\end{tabular}

Tabela 18. Variação dos valores de PRI para o clone PB 235 em três blocos distintos (I, II e III) para quatro coletas realizadas.

\begin{tabular}{ccccc}
\hline Número da Coleta & \multicolumn{5}{c}{ PRI } \\
\hline & PB 235 (I) & PB 235 (II) & PB 235 (III) & média \pm dp \\
\hline 1 & 50,0 & 30,0 & 68,0 & $49 \pm 20$ \\
2 & 45,0 & 31,0 & 34,0 & $37 \pm 7$ \\
3 & 57,0 & 60,0 & 49,0 & $55 \pm 6$ \\
4 & 69,0 & 68,0 & 60,0 & $66 \pm 5$ \\
\hline média + dp & $55 \pm 10$ & $47 \pm 20$ & $53 \pm 15$ & \\
\hline
\end{tabular}

As especificações do SMR (Standard Malaysian Rubber) [103] padronizam o valor de PRI de no mínimo de 60 para todas as classes de borrachas. Portanto, os 
valores médios de PRI para o clone GT $1(62-69)$ podem ser considerados bons para os três blocos (GT 1 blocos I, II e III) estudados. Já os valores de PRI para os clones RRIM 600 e PB 235 estão abaixo dos padrões especificados pela norma para a maioria dos blocos. No entanto, quando os valores de PRI (obtidos nesse trabalho) são comparados com os valores encontrados na literatura (que encontrou, para borracha de clones na Malásia, valores entre 85-90 para o clone GT 1, e RRIM 600 e 80-85 para o clone PB 235) pode-se concluir que os valores de PRI encontrados para os clones plantados no estado de São Paulo estão bem abaixo dos valores citados na literatura. Comparando-se os valores médios de PRI obtidos nesse trabalho que variam de 47-69 com aqueles obtidos em estudo realizado em Votuporanga, SP [15] que variam de 56-66, observa-se que os valores obtidos neste trabalho estão próximos dos valores médios previamente estudados para outras regiões do Estado de São Paulo.

\subsubsection{Variação da \% Extrato Acetônico}

$\mathrm{O}$ extrato acetônico é uma medida da quantidade de lipídios na fração dos constituintes não-borracha. No látex, esses lipídeos estão localizados ao redor das partículas de borracha, exercendo certa influência na estabilidade mecânica do látex estocado com amônia, embora existam também outros fatores [104]. Uma composição típica de lipídios no látex de borracha natural consiste de $54 \%$ em lipídios neutros, $33 \%$ em glicolipídios e $14 \%$ em fosfolipídios [92].

As Tabelas 19, 20 e 21 mostram a variação dos valores de extrato acetônico para os clones GT 1, RRIM 600 e PB 235 em três blocos distintos. Assim como para a \% de DRC e \% de nitrogênio observa-se que os valores de EA variam pouco em função dos blocos estudados como mostram os valores de dp dentro de uma mesma coleta. No entanto, maiores variações são observadas em função das coletas comportamento este já observado na literatura. 
Tabela 19. Variação dos valores extrato acetônico para o clone GT 1 em três blocos distintos (I, II e III) para quatro coletas realizadas.

\begin{tabular}{ccccc}
\hline Número da Coleta & \multicolumn{4}{c}{ Extrato Acetônico (\%) } \\
\hline & GT 1 (I) & GT 1 (II) & GT 1 (III) & média + dp \\
\hline 1 & 2,6 & 2,7 & 2,5 & $2,6 \pm 0,1$ \\
2 & 2,6 & 2,7 & 2,9 & $2,7 \pm 0,2$ \\
3 & 1,9 & 1,4 & 2,0 & $1,8 \pm 0,3$ \\
4 & 2,1 & 2,1 & 1,5 & $1,9 \pm 0,3$ \\
\hline média+dp & $2,3 \pm 0,4$ & $2,2 \pm 0.6$ & $2,2 \pm 0,6$ &
\end{tabular}

Tabela 20. Variação dos valores extrato acetônico para o clone RRIM 600 em três blocos distintos (I, II e III) para quatro coletas realizadas.

\begin{tabular}{ccccc}
\hline Número da Coleta & \multicolumn{4}{c}{ Extrato Acetônico (\%) } \\
\hline & RRIM 600 (I) & RRIM 600 (II) & RRIM 600 (III) & média \pm dp \\
\hline 1 & 2,4 & 2,4 & 2,4 & $2,4 \pm 0$ \\
2 & 2,0 & 2,0 & 2,1 & $2,0 \pm 0,1$ \\
3 & 2,3 & 2,4 & 2,2 & $2,3 \pm 0,1$ \\
4 & 1,4 & 1,8 & 1,4 & $1,7 \pm 0,2$ \\
\hline média+dp & $2,0 \pm 0,5$ & $2,2 \pm 0,3$ & $2,0 \pm 0,4$ & \\
\hline
\end{tabular}

Tabela 21. Variação dos valores extrato acetônico para o clone PB 235 em três blocos distintos (I, II e III) para quatro coletas realizadas.

\begin{tabular}{ccccc}
\hline Número da Coleta & \multicolumn{4}{c}{ Extrato Acetônico (\%) } \\
\hline & PB 235 (I) & PB 235 (II) & PB 235 (III) & média \pm dp \\
\hline 1 & 3,3 & 3,5 & 3,7 & $3,5 \pm 0,2$ \\
3 & 3,4 & 3,6 & 3,7 & $3,6 \pm 0,2$ \\
4 & 3,4 & 3,3 & 3,3 & $3,3 \pm 0,1$ \\
& 2,3 & 2,0 & 1,8 & $2,0 \pm 0,3$ \\
\hline média+dp & $3,1 \pm 0,5$ & $3,1 \pm 0,7$ & $3,1 \pm 0,9$ & \\
\hline
\end{tabular}


Em geral, não é observada uma tendência clara de comportamento da propriedade extrato acetônico em função do número de coleta. Os valores médios de $\%$ extrato acetônico obtidos neste estudo estão abaixo dos valores encontrados na literatura. Yip [91] encontrou em seu trabalho de avaliação das propriedades de 49 clones diferentes, o valor de extrato acetônico de aproximadamente 4,0, 3,9 e 5,0 para os clones GT 1, RRIM 600 e PB 235, respectivamente. Por outro lado, o clone PB 235 apresentou os maiores valores médios de extrato acetônico quando comparado com os clones GT 1 e RRIM 600 estando, portanto, de acordo com o obtido por Yip [91].

No estudo da variação intraclonal, foram investigados os clones GT 1, RRIM 600 e PB 235 em três diferentes blocos I, II e III, com o objetivo de avaliar se existe variação das propriedades da borracha natural dentro de um mesmo clone, plantado em um mesmo local. No geral, observou-se que para as propriedades \% de DRC, \% de nitrogênio e \% de EA as variações intraclonais são menores. No entanto, para as propriedades viscosidade Mooney, plasticidade Wallace e principalmente PRI as variações intraclonais observadas são maiores.

No geral, os valores de \% de nitrogênio, extrato acetônico e PRI estão abaixo dos valores reportados na literatura [91], o que indica que a borracha desses clones pode apresentar baixa resistência à degradação térmica. A Tabela 25 mostra os valores das propriedades dos clones RRIM 600, GT 1 e PB 235 para os clones cultivados na Malásia. As borrachas dos clones estudados nesse trabalho possuem altos valores de viscosidade e plasticidade quando comparadas com os valores apresentados na literatura e portanto, podem ser classificadas como duras. Apesar da borracha natural estudada nesse trabalho apresentar valores diferentes dos reportados na literatura internacional (borrachas cultivadas na Malásia), essas mesmas borrachas podem ser classificadas como dentro dos padrões nacionais e satisfazendo os limites estabelecidos pelas normas da ABNT. 
Tabela 22. Propriedades da borracha natural dos clones RRIM 600, GT 1 e PB 235 cultivados na Malásia [91].

\begin{tabular}{cccccc}
\hline Clone & $\% \mathrm{~N}$ & $\% \mathrm{EA}$ & $\mathrm{P}_{0}$ & $\mathrm{~V}_{0}$ & PRI \\
\hline RRIM600 & 0,75 & 4,0 & 42 & 55 & 91 \\
GT 1 & 0,8 & 4,2 & 45 & 58 & 90 \\
PB 235 & 0,5 & 5,0 & 55 & 76 & 85 \\
\hline
\end{tabular}

Os resultados apresentados nas Tabelas 4-21 foram analisados estatisticamente para avaliar a variação das propriedades da borracha dentro de um mesmo clone, entre as coletas e entre os clones e dessa forma estabelecer se as diferenças discutidas anteriormente são estatisticamente significantes ou não.

O procedimento estatístico para se comparar médias de mais de duas populações é a aplicação do teste F. Esse teste é feito através da análise de variância, que compara a variabilidade devido aos tratamentos, ou seja, pelo fato das amostras provirem de populações diferentes $[88,105]$. No presente trabalho, esses tratamentos correspondem as propriedades da borracha natural que são estudadas em diferentes repetições ou seja, entre blocos (I, II e III) e quatro diferentes coletas. Para aplicar o teste $\mathrm{F}$ é necessário que seja feito uma série de cálculos e no final, determina-se um valor calculado da razão F. Em seguida, compara-se o valor calculado de F com o valor dado em uma tabela, no nível de significância estabelecido, e com (k-1) graus de liberdade no numerador e (n-k) graus de liberdade no denominador. Toda vez que o valor calculado de $\mathrm{F}$ for igual ou maior que o da tabela conclui-se que, no nível de significância estabelecido, as médias dos tratamentos não são iguais. Os cálculos utilizados na análise de variância são mostrados no ANEXO I. Para entender como se procura o valor de F na tabela, observe a Tabela 23, que reproduz parte da tabela de valores de $\mathrm{F}$. $\mathrm{O}$ valor de $\mathrm{F}$ no nível de significância de $5 \%$, com 3 graus de liberdade para tratamentos (numerador) e 5 graus de liberdade para o resíduo (denominador) está sombreado. A tabela completa com os valores de $\mathrm{F}$ ao nível de significância de 5\% e $1 \%$ está no ANEXO II. 
Tabela 23 Valor de $\mathrm{F}$ ao nível de significância de 5\%, com 3 e 5 graus de liberdade [105].

\begin{tabular}{cccc} 
& $\mathbf{1}$ & $\mathbf{2}$ & $\mathbf{3}$ \\
\hline $\mathbf{1}$ & 161 & 200 & 216 \\
$\mathbf{2}$ & 18,5 & 19 & 19,2 \\
$\mathbf{3}$ & 10,1 & 9,55 & 9,28 \\
$\mathbf{4}$ & 7,71 & 6,94 & 6,59 \\
$\mathbf{5}$ & 6,61 & 5,79 & \\
\hline
\end{tabular}

A Tabela 24 mostra os resultados da análise de variância individual feita para avaliar como as propriedades da borracha natural variam em função do tipo de clone, diferentes repetições e entre as coletas. A tabela mostra os quadrados médios (QM) e coeficientes de variação experimental (CV \%) obtidos para a as propriedades da borracha natural dos clones RRIM 600, GT 1 e PB 235. Os valores da razão F calculada não aparecem na Tabela 24 porque ela já apresenta os resultados finais da análise através dos sufixos ns (não significativo), $\left(^{*}\right)$ significativo a 0,05 de probabilidade e $\left(^{* *}\right)$ significativo a 0,01 de probabilidade. Para se calcular o valor de $\mathrm{F}$ devemos dividir o valor de $\mathrm{QM}$ do tratamento pelo $\mathrm{QM}$ do resíduo e o valor obtido deve ser comparado com o valor tabelado. Por exemplo, se pegarmos o valor de 40,8333 que é o valor de quadrado médio obtido para a propriedade DRC dentro do clone RRIM 600 para as quatro coletas e dividirmos este valor pelo quadrado médio do resíduo obteremos o valor $F=35,4$. Quando consultamos os valores de $F$ na tabela de valores de $\mathrm{F}$ ao nível de $1 \%$ de probabilidade com 3 graus de liberdade no numerador e 5 graus de liberdade no denominador obtemos um valor tabelado de $\mathrm{F}=$ 12,06. Como o valor calculado de $\mathrm{F}$ é maior do que o valor tabelado conclui-se que existem variações altamente significativas para a \% de DRC entre as quatro coletas. Podemos observar que para clone RRIM 600 a \% de DRC não varia dentro de uma mesma repetição (blocos) como mostra o sufixo ns que segue o valor do quadrado médio. Portanto, podemos concluir que o clone RRIM 600 não apresenta diferença intraclonal para a \% de DRC. O mesmo comportamento pôde ser observado para as outras propriedades nos três clones estudados. Já quando avaliamos as diferenças das propriedades da borracha natural entre as coletas observamos que existem diferenças altamente significativas $(\mathrm{P} \leq 0,01)$ para a $\%$ de $\mathrm{DRC}, \%$ de nitrogênio e \% de EA 
para todos os clones estudados. A variação não foi significativa para o PRI dentro do clone GT 1 e PB 235, plasticidade Wallace dentro dos clones RRIM 600 e GT 1 e viscosidade Mooney para o clone GT 1. O clone GT 1 não apresentou diferenças significativas entre as coletas para as propriedades PRI, Plasticidade Wallace e Viscosidade Mooney. Os coeficientes de variação experimental variaram de 3,29\% a $7,14 \%$ para a $\%$ de DRC, $6,76 \%$ a $11,77 \%$ para a $\%$ de $\mathrm{N}, 5,98 \%$ a $12,80 \%$ para $\%$ de EA $7,56 \%$ a $22,46 \%$ para PRI, $4,77 \%$ a $6,90 \%$ para a plasticidade Wallace e $3.51 \%$ a $6,64 \%$ para a viscosidade Mooney. O coeficiente de variação experimental, CV \%, é definido como a razão entre o desvio padrão de uma amostra e a sua média, em porcentagem. Esse parâmetro fornece uma medida de dispersão relativa e permite que a variação entre as características expressas em unidades diferentes seja comparada. O coeficiente de variação dá uma idéia da precisão do experimento. Tendo em vista os coeficientes de variação obtidos comumente nos ensaios agrícolas de campo podemos considerá-los baixos quando inferiores a $10 \%$, médios, quando de $10-20 \%$, altos quando de 20 a $30 \%$ e muito altos quando superiores a $30 \%$.

Os resultados obtidos na análise de variância para o estudo da variação intraclonal dos os clones RRIM 600, PB 235 e GT 1 mostraram que as propriedades da borracha natural não variam dentro de um mesmo clone. A homogeneidade intraclonal observada nesse trabalho é de extrema importância para a indústria beneficiadora que poderá manipular e padronizar misturas de borracha natural desde que ela esteja separada por borrachas de um mesmo clone. As variações observadas para as propriedades da borracha natural entre as coletas eram esperadas uma vez que existem trabalhos na literatura $[9,11,94]$ que mostram a grande influência do clima nas propriedades da borracha natural. 
Tabela 24. Valores dos quadrados médios e coeficientes de variação experimental (CV\%) obtidos para as propriedades do látex e da borracha dos clones RRIM 600, GT 1 e PB 235.

\begin{tabular}{|c|c|c|c|c|c|c|}
\hline \multirow{2}{*}{ Propriedades } & \multirow[b]{2}{*}{ Clone } & \multicolumn{3}{|c|}{ Fontes de Variação } & \multirow{2}{*}{ CV\% } & \multirow[b]{2}{*}{ Média } \\
\hline & & Repetição (Blocos) & Coletas & Resíduo & & \\
\hline \multirow{3}{*}{$\operatorname{DRC}(\%)$} & RRIM 600 & $13,0108 \mathrm{~ns}$ & $40,8333^{* *}$ & 1,1308 & 3,2990 & 32,2333 \\
\hline & GT 1 & $0,4258 \mathrm{~ns}$ & $36,1719^{* *}$ & 2,2436 & 4,6675 & 32,0916 \\
\hline & PB 235 & $2,6133 \mathrm{~ns}$ & $96,6866^{* *}$ & 6,2966 & 7,1423 & 35,1333 \\
\hline \multirow{3}{*}{$\mathrm{N}(\%)$} & RRIM 600 & $0,0025 \mathrm{~ns}$ & $0,0189^{* *}$ & 0,0014 & 6,7624 & 0,5500 \\
\hline & GT 1 & $0,0033 \mathrm{~ns}$ & $0,0208^{* *}$ & 0,0033 & 9,7580 & 0,5917 \\
\hline & PB 235 & $0,00 \mathrm{~ns}$ & $0,0289^{* *}$ & 0,0022 & 11,7704 & 0,5000 \\
\hline \multirow{3}{*}{ EA (\%) } & RRIM 600 & $0,0208 \mathrm{~ns}$ & $0,4511^{* *}$ & 0,0153 & 5,9819 & 2,0667 \\
\hline & GT 1 & $0,0075 \mathrm{~ns}$ & $0,7122^{* *}$ & 0,0830 & 12,8082 & 2,2500 \\
\hline & PB 235 & $0,0008 \mathrm{~ns}$ & $1,5697^{* *}$ & 0,0431 & 6,6751 & 3,1083 \\
\hline \multirow{3}{*}{ PRI } & RRIM 600 & $149,3333 n s$ & $239,3393^{*}$ & 41,6667 & 11,8079 & 54,6667 \\
\hline & GT 1 & $46,0833 \mathrm{~ns}$ & $92,3055 \mathrm{~ns}$ & 24,6338 & 7,5686 & 65,5833 \\
\hline & PB 235 & $67,0000 \mathrm{~ns}$ & $439,861 \mathrm{lns}$ & 135,1111 & 22,4613 & 51,7500 \\
\hline \multirow{3}{*}{$\begin{array}{l}\text { Plasticidade } \\
\text { Wallace }\end{array}$} & RRIM 600 & $87,7500 \mathrm{~ns}$ & $18,3056 \mathrm{~ns}$ & 26,6388 & 6,9047 & 74,7500 \\
\hline & GT 1 & $15,0833 \mathrm{~ns}$ & $29,1944 \mathrm{~ns}$ & 13,1944 & 4,7742 & 76,0833 \\
\hline & PB 235 & $28,0000 \mathrm{~ns}$ & $55,6667^{*}$ & 10,6667 & 4,8384 & 67,5000 \\
\hline \multirow{3}{*}{$\begin{array}{l}\text { Viscosidade } \\
\text { Mooney }\end{array}$} & RRIM 600 & $267,8733 \mathrm{~ns}$ & $400,8289 *$ & 52,4255 & 6,6447 & 127,0000 \\
\hline & GT 1 & $27,3108 \mathrm{~ns}$ & $42,003 \mathrm{lns}$ & 13,6797 & 3,5122 & 105,3083 \\
\hline & PB 235 & $45,7108 \mathrm{~ns}$ & $147,2100^{*}$ & 26,2408 & 5,8801 & 97,0167 \\
\hline
\end{tabular}

Os graus de liberdade para as fontes de variação, repetição, coletas e resíduo foram 2,3 e 6 respectivamente.

${ }^{*} \mathrm{e}^{* *}$, significativos a 0.05 e 0.01 de probabilidade respectivamente.

n.s., não significativo.

Para avaliarmos a variação interclonal e a existência de interações entre clones e coletas utilizou-se uma análise de variância chamada de "análise de variância conjunta" que permite avaliar a interação de dois fatores. Na Tabela 25 é avaliada a interação clones e coletas. Essa análise foi feita utilizando o delineamento de blocos ao acaso com parcelas subdivididas no tempo, uma vez que foram efetuadas medidas sucessivas numa mesma parcela, durante um certo período de 
tempo. Nos cálculos foram considerados como blocos os blocos I, II e III dentro dos quais os clones foram estudados. Os clones foram considerados como tratamentos e as coletas como subtratamento. A Tabela 25 mostra os valores de quadrados médios das análises de variância conjunta para as propriedades da borracha natural. 
Tabela 25. Quadrados médios (QM) das análises de variância para as propriedades da borracha dos clones RRIM 600, GT 1 e PB 235.

\begin{tabular}{|c|c|c|c|c|c|c|c|}
\hline Fontes de variação & g.l. & DRC \% & Nitrogênio \% & Visc. Mooney & Plást. Wallace & Extrato acetônico & PRI \\
\hline Repetição (Blocos) & 2 & 5,2386n.s. & 0,0002 n.s. & 154,2369 n.s. & 26,6944 n.s. & 0,0033 n.s. & 115,5833 \\
\hline Clones & 2 & $35,3636 * *$ & $0,1219^{* *}$ & $449,8753^{* *}$ & $256,0277^{* *}$ & $3,7108 * *$ & $638,0833^{* *}$ \\
\hline Erro A & 4 & 5,4057 & 0,0278 & 93,3140 & 52,0694 & 0,0129 & 73,4166 \\
\hline Coletas & 3 & $148,2603^{* *}$ & $0,0655^{* *}$ & $152,6921^{* *}$ & 51,1852 n.s. & $1,9388^{* *}$ & $377,1111 * *$ \\
\hline Clones $\times$ Coletas & 6 & $12,7158^{* *}$ & 0,0016 n.s. & $208,6749^{* *}$ & 25,9907 n.s. & $0,3971^{* *}$ & $197,1944^{*}$ \\
\hline Error B & 18 & 3,2237 & 0,0023 & 30,7820 & 16,8333 & 0,0471 & 67,1389 \\
\hline $\mathrm{CV}_{\mathrm{A}} \%$ & & 7,0130 & 10,2560 & 9,3095 & 9,9150 & 4,5920 & 14,9448 \\
\hline $\mathrm{CV}_{\mathrm{B}} \%$ & & 5,4157 & 9,3624 & 5,3469 & 5,6375 & 8,7715 & 14,2916 \\
\hline Média & & 33,1527 & 0,5189 & 103,7639 & 72,7778 & 2,4750 & 57,3333 \\
\hline
\end{tabular}


A primeira linha da Tabela 25 mostra que não existem variações altamente significativas para as propriedades da borracha natural dentro dos blocos estudados. Esse resultado está de acordo com a análise de variância apresentada na Tabela 24 onde também se verificou que as propriedades da borracha natural não variam dentro dos blocos. A segunda linha da Tabela 25 mostra a variação das propriedades da borracha dentro do fator clone. Verificam-se diferenças altamente significativas $(\mathrm{P}<$ 0,01) para as todas as propriedades da borracha natural. Portanto, as diferenças interclonais são significativas e as propriedades da borracha natural mudam dependendo do tipo de clone. Essa verificação é importante porque quando na usina beneficiadora, borrachas de diferentes clones são misturadas, essa diferença significativa do índice de retenção de plasticidade pode afetar a uniformidade da borracha natural e portanto, esse é um fator que deve ser considerado com cuidado na elaboração de blendas de diferentes clones. A interação clones versus coletas significa que os clones apresentaram diferentes desempenhos ao longo das coletas como é o caso das propriedades \% de DRC, viscosidade Mooney e extrato acetônico no nível de $1 \%$. Para PRI a variação foi significativa a $5 \%$ e o efeito da interação clone coleta não foi significativo para plasticidade Wallace. Os coeficientes de variação experimental dentro dos clones variaram de 4,59 a $14,94 \%$ e dentro das coletas variaram de 5,35 a $14,29 \%$. 


\subsection{Avaliação da influência do tipo de porta-enxerto nas propriedades da Borracha Natural}

As tabelas 26 e 27 mostram a variação das propriedades de \% DRC, \% de nitrogênio, \% de extrato acetônico, viscosidade Mooney, plasticidade Wallace e PRI para os clones RRIM 600 e PB 235 em cinco diferentes porta-enxertos. Assim como o observado no estudo da variação intra e interclonal em geral, as propriedades da borracha natural variam pouco dentro de uma mesma coleta. $\mathrm{Na}$ tabela 26, que mostra a variação das propriedades da borracha para o clone RRIM 600 em cinco diferentes porta-enxertos, observamos, dentro da primeira coleta, valores de $\%$ de DRC de 26, 28, 28, 27 e $28 \%$ para os porta-enxertos RRIM 600, PB 235, SNS, GT 1 e IAN 873 respectivamente. Também para o clone RRIM 600 na primeira coleta, não houve diferença entre os porta-enxertos para as propriedades \% de nitrogênio e \% EA. As maiores variações são observadas entre as coletas por causa da influência do clima.

Os valores para DRC obtidos, para os cinco porta-enxertos estudados, podem ser classificados como abaixo da média segundo a literatura que classifica os clones com DRC variando de 31-34\% como abaixo da média; valores entre 34-38\% estão dentro da média e aqueles entre 38-41\% acima da média [91]. A média dos valores de \% de nitrogênio para os clones RRIM 600 e PB 235 nos cinco porta-enxertos estudados estão dentro dos valores da literatura (aproximadamente 0,6 e 0,5 para os clones RRIM 600 e PB 235 respectivamente). Assim como para DRC os valores de EA obtidos neste estudo estão abaixo dos valores da literatura que sugere valores de aproximadamente 4.0 e $5.0 \%$ para o clone RRIM 600 e PB 235 respectivamente. Os valores médios de $\mathrm{V}_{0}$ e $\mathrm{P}_{0}$ encontrados nesta etapa do estudo podem ser considerados altos quando comparados com os valores da literatura o que mostra que tanto as borrachas provenientes do clone RRIM 600 quanto as do clone PB 235 podem ser consideradas duras e portanto, requerem maior energia no processamento. Os valores de PRI estão acima daqueles especificados pelo SMR (60 unidades de PRI). No entanto, quando comparamos os valores médios mostrados na literatura (91 unidades de PRI para o clone RRIM 600 e 85 para o clone PB 235) com os obtidos em nosso estudo (72 unidades de PRI para o clone RRIM 600 e 66 para o clone PB 235) estes podem ser considerados abaixo da média. 
Tabela 26. Variação das propriedades de \% DRC, \% de nitrogênio, \% de extrato acetônico, viscosidade mooney, plasticidade Wallace e PRI para o clone RRIM 600 em cinco diferentes porta-enxertos e para quatro coletas.

\section{Clone RRIM 600}

\begin{tabular}{|c|c|c|c|c|c|c|}
\hline Porta-Enxerto & $\%$ DRC & $\% \mathbf{N}$ & $\%$ EA & $\mathbf{V}_{\mathbf{0}}$ & $\mathbf{P}_{\mathbf{0}}$ & PRI \\
\hline \multicolumn{7}{|l|}{$R R I M 600$} \\
\hline 1 & 26 & 0,8 & 3,0 & 128 & 79 & 71 \\
\hline 2 & 25 & 0,8 & 3,0 & 98 & 77 & 70 \\
\hline 3 & 30 & 0,6 & 2,7 & 87 & 70 & 57 \\
\hline 4 & 40 & 0,4 & 2,0 & 81 & 60 & 78 \\
\hline Média $\pm d p$ & $30 \pm 6$ & $0,6 \pm 0,2$ & $2,7 \pm 0,5$ & $98 \pm 20$ & $72 \pm 9$ & $69 \pm 9$ \\
\hline \multicolumn{7}{|l|}{ PB 235} \\
\hline 1 & 28 & 0,8 & 2,5 & 133 & 74 & 70 \\
\hline 2 & 28 & 0,7 & 3,3 & 123 & 80 & 80 \\
\hline 3 & 34 & 0,5 & 2,4 & 95 & 70 & 58 \\
\hline 4 & 42 & 0,4 & 2,3 & 98 & 69 & 72 \\
\hline Média $\pm d p$ & $33 \pm 7$ & $0,6 \pm 0,2$ & $2,6 \pm 0,5$ & $112 \pm 18$ & $73 \pm 5$ & $70 \pm 9$ \\
\hline \multicolumn{7}{|l|}{ SNS } \\
\hline 1 & 28 & 0,8 & 2,9 & 135 & 73 & 71 \\
\hline 2 & 27 & 0,7 & 3,0 & 124 & 79 & 76 \\
\hline 3 & 28 & 0,6 & 2,6 & 85 & 58 & 74 \\
\hline 4 & 38 & 0,5 & 2,4 & 110 & 71 & 68 \\
\hline Média $\pm d p$ & $30 \pm 5$ & $0,6 \pm 0,2$ & $2,8 \pm 0,3$ & $113 \pm 22$ & $70 \pm 9$ & $72 \pm 3$ \\
\hline \multicolumn{7}{|l|}{ GT 1} \\
\hline 1 & 27 & 0,8 & 2,8 & 127,5 & 69 & 71 \\
\hline 2 & 25 & 0,7 & 3,3 & 112,0 & 79 & 77 \\
\hline 3 & 29 & 0,6 & 2,2 & 87,6 & 71 & 65 \\
\hline 4 & 47 & 0,5 & 2,0 & 92,0 & 63 & 77 \\
\hline Média $\pm d p$ & $32 \pm 10$ & $0,6 \pm 0,1$ & $2,5 \pm 0,6$ & $105 \pm 19$ & $70 \pm 7$ & $72 \pm 6$ \\
\hline \multicolumn{7}{|l|}{ LAN 877} \\
\hline 1 & 28,0 & 0,8 & 3,0 & 126,1 & 74 & 81 \\
\hline 2 & 25,3 & 0,8 & 3,0 & 118,0 & 80 & 79 \\
\hline 3 & 30,5 & 0,5 & 2,3 & 91,0 & 73 & 66 \\
\hline 4 & 35,5 & 0,5 & 3,1 & 82,0 & 60 & 75 \\
\hline Média $\pm d p$ & $30 \pm 4$ & $0,6 \pm 0,2$ & $2,9 \pm 0,4$ & $104 \pm 21$ & $72 \pm 8$ & $75 \pm 7$ \\
\hline
\end{tabular}


Tabela 27. Variação das propriedades de \% DRC, \% de nitrogênio, \% de extrato acetônico, viscosidade mooney, plasticidade Wallace e PRI para o clone PB 235 em cinco diferentes porta-enxertos.

\section{Clone PB 235}

\begin{tabular}{ccccccc} 
Porta-Enxerto & \% DRC & \% N & \% EA & V & P & PR \\
\hline RRIM 600 & 29 & 0,6 & 3,5 & 110 & 65 & 34 \\
1 & 27 & 0,7 & 3,8 & 101 & 75 & 69 \\
2 & 38 & 0,4 & 2,7 & 98 & 74 & 65 \\
3 & 41 & 0,3 & 2,6 & 96 & 66 & 72
\end{tabular}

$\begin{array}{lllllll}\text { Média } \pm d p & 34 \pm 7 & 0,5 \pm 0,2 & 3,2 \pm 0,6 & 101 \pm 6 & 70 \pm 5 & 60 \pm 18\end{array}$

PB 235

$\begin{array}{llllcll}1 & 28 & 0,6 & 4,2 & 99 & 59 & 64 \\ 2 & 28 & 0,6 & 4,2 & 104 & 74 & 77 \\ 3 & 33 & 0,5 & 4,3 & 93 & 70 & 69 \\ 4 & 49 & 0,3 & 2,7 & 98 & 67 & 72\end{array}$

$\begin{array}{lllllll}\text { Média } \pm d p & 35 \pm 10 & \mathbf{0 , 5} \pm 0,2 & 3,8 \pm 0,8 & 98 \pm 5 & 67 \pm 6 & 70 \pm 5\end{array}$

SNS

$\begin{array}{lllllll}1 & 30 & 0,6 & 0,8 & 107 & 58 & 50 \\ 2 & 26 & 0,7 & 0,7 & 110 & 78 & 76 \\ 3 & 34 & 0,5 & 2,9 & 107 & 79 & 72 \\ 4 & 36 & 0,4 & 3,2 & 104 & 75 & 72\end{array}$

$\begin{array}{lllllll}\text { Média } \pm d p & 31 \pm 4 & 0,5 \pm 0,2 & 1,9 \pm 1,3 & 107 \pm 2 & 72 \pm 10 & 67 \pm 12\end{array}$

$\begin{array}{ccccccc}\boldsymbol{G T} \boldsymbol{I} & & & & & & \\ 1 & 29 & 0,6 & 3,0 & 115 & 58 & 66 \\ 2 & 25 & 0,6 & 3,3 & 104 & 71 & 70 \\ 3 & 35 & 0,4 & 3,0 & 104 & 79 & 70 \\ 4 & 47 & 0,3 & 2,0 & 100 & 71 & 70\end{array}$

$\begin{array}{lllllll}\text { Média } \pm d p & 34 \pm 9 & 0,5 \pm 0,2 & 2,8 \pm 0,6 & 106 \pm 6 & 70 \pm 9 & 69 \pm 2\end{array}$

IAN 877

$\begin{array}{lcccccc}1 & 31 & 0,5 & 3,5 & 117 & 72 & 64 \\ 2 & 28 & 0,6 & 3,3 & 107 & 78 & 75 \\ 3 & 34 & 0,5 & 3,1 & 106 & 81 & 60 \\ 4 & 38 & 0,4 & 3,1 & 99 & 69 & 67\end{array}$

\begin{tabular}{lllllll} 
Média $\pm d p$ & $33 \pm 4$ & $0,5 \pm 0,1$ & $3,0 \pm 0,5$ & $107 \pm 8$ & $75 \pm 6$ & $66 \pm 6$ \\
\hline
\end{tabular}


A análise estatística foi utilizada, similarmente ao feito no estudo da variação intra e interclonal, para avaliar de forma mais precisa e quantitativa o efeito do portaenxerto nas propriedades da borracha.

A Tabela 28 mostra os resultados da análise de variância conjunta para avaliar a interação clone e porta-enxerto para as propriedades da borracha natural. A primeira linha da tabela mostra como as propriedades da borracha variam em função das coletas. Como podemos observar, existem diferenças altamente significativas $(\mathrm{P}<0,01)$ para as propriedades \% de DRC, \% de nitrogênio, viscosidade Mooney e plasticidade Wallace. Para PRI as diferenças são significativas a 0,05 de probabilidade e não significativas para a \% de EA. No geral, as propriedades da borracha natural não variam em função do porta-enxerto como mostra a segunda linha da Tabela 28. As interações não significativas para clones versus porta-enxerto evidenciam que os clones não apresentam diferenças significativas em relação ao porta-enxerto utilizado. A exceção foi para a interação clone versus porta-enxerto para propriedade viscosidade Mooney a 0,05 de probabilidade. A interação clone $x$ coleta para as propriedades viscosidade Mooney e plasticidade Wallace $(\mathrm{P}<0,01)$ e $\%$ de nitrogênio, $P R I(P<0,05)$ mostram mais uma vez que as propriedades da borracha natural variam em função do clima.

Os coeficientes de variação para porta-enxerto $\left(\mathrm{CV}_{\mathrm{A}} \%\right)$ variaram de $4,03 \%$ $20,25 \%$ e para coletas $\left(\mathrm{CV}_{\mathrm{B}} \%\right)$ variaram de $4,70 \%-25,72 \%$ e encontram-se dentro do esperado. 
Tabela 28. Quadrados médios (QM) das análises de variância relativas ao estudo da influência do porta-enxerto nas propriedades da borracha e látex do clone.

\begin{tabular}{|c|c|c|c|c|c|c|c|}
\hline Fontes de variação & g.l. & DRC \% & Nitrogênio \% & Visc. Mooney & Plást. Wallace & Extrato acetônico \% & PRI \\
\hline Repetições (coleta) & 3 & $429,7329^{* *}$ & $0,2003^{* *}$ & $1389,3859^{* *}$ & $209,7333^{* *}$ & $0,0582 \mathrm{~ns}$ & $266,8333^{*}$ \\
\hline Porta-enxerto & 4 & $12,2685 \mathrm{~ns}$ & $0,0027 \mathrm{~ns}$ & $107,9166 \mathrm{~ns}$ & $13,6000 \mathrm{~ns}$ & $0,9909 \mathrm{~ns}$ & 57,6875 \\
\hline Erro A & 12 & 13,0633 & 0,0023 & 36,0407 & 26,9833 & 0,5747 & 47,7708 \\
\hline Clones & 1 & $51,3022^{* *}$ & $0,1904^{* *}$ & $70,2270 \mathrm{~ns}$ & $2,5000 \mathrm{~ns}$ & $0,0723 \mathrm{~ns}$ & $260,1000^{*}$ \\
\hline Clones x Porta-enxerto & 4 & $2,1709 \mathrm{~ns}$ & $0,0025 \mathrm{~ns}$ & $106,5506^{*}$ & $25,1250 \mathrm{~ns}$ & $0,809 \operatorname{lns}$ & $31,2875 \mathrm{~ns}$ \\
\hline Clone $x$ repetição (coleta) & 3 & 5,7916 ns & $0,0084^{*}$ & $559,1297^{* *}$ & $196,3667^{* *}$ & $1,0509 \mathrm{~ns}$ & $185,5000^{*}$ \\
\hline Error B & 12 & 3,6678 & 0,0023 & 24,5144 & 11,7417 & 0,4636 & 31,9375 \\
\hline $\mathrm{CV}_{\mathrm{A}} \%$ & & 7,939 & 5,9200 & 4,0320 & 5,1590 & 20,2480 & 7,057 \\
\hline $\mathrm{CV}_{\mathrm{B}} \%$ & & 5,949 & 8,3100 & 4,7030 & 4,8130 & 25,7190 & 8,161 \\
\hline Média & & 32,1925 & 0,5710 & 105,2799 & 71,1999 & 2,6475 & 69,2500 \\
\hline
\end{tabular}


As análises estatísticas para a avaliação influência do porta-enxerto nas propriedades da borracha natural para diferentes clones mostraram que no geral, não há influência do porta-enxerto para as propriedades estudadas. Portanto, as propriedades da borracha natural podem ser consideradas uniformes, independentemente do tipo de porta-enxerto onde os clones são enxertados, o que pode ser considerado um fator positivo para a aplicação técnica e industrial da borracha natural. Para a indústria pneumática, a principal consumidora da matériaprima em questão, a variabilidade das propriedades da borracha se reflete nos custos do processamento, que se tornam mais elevados. Em geral, os trabalhos da literatura mostram que ocorre influência do porta-enxerto nas características agronômicas da seringueira. Gonçalves et al. $[44,45]$ realizaram uma avaliação da influência de seis porta-enxertos no crescimento de seis clones de seringueira. Os autores encontraram que o porta-enxerto IAN 873 foi o que produziu as melhores plantas dos clones enxertados. Comparado com o porta-enxerto RRIM 600, o IAN 873 produziu um aumento médio de 10 e $12 \%$ na circunferência do caule e altura dos enxertos, respectivamente. O porta-enxerto de pior desempenho, o PB 235, apresentou circunferência média dos enxertos $11 \%$ inferior em relação ao IAN 873. Portaenxertos dos clones RRIM 600 e RRIM 701 produziram enxertos menos vigorosos. Não foi encontrado na literatura nenhum estudo sobre a influência dos porta-enxertos nas propriedades da borracha natural. Assim é extremamente importante observar que o porta-enxerto não influi nas propriedades da borracha, para clones e condições estudadas.

No estudo da variação intraclonal das propriedades da borracha natural observou-se que um mesmo clone plantado em blocos distintos de uma mesma plantação não apresenta diferenças significativas entre as suas propriedades. Ou seja, a importância deste estudo é mostrar que borrachas de um mesmo clone possuem propriedades técnicas uniformes o que é desejado quando se requer borrachas com propriedades específicas e constantes para o processamento e formulação de pneus entre outras aplicações. Já o estudo da variação interclonal, que avaliou se há diferenças nas propriedades da borracha em função do tipo de clone mostrou diferenças altamente significativas $(\mathrm{P}<0,01)$ entre as borrachas dos clones estudados. Quando na usina beneficiadora, a borracha de diferentes clones é misturada, essa diferença significativa das propriedades da borracha pode afetar a uniformidade do 
produto final. Portanto, esse é um fator que deve ser considerado com cuidado na elaboração de blendas de diferentes clones. 


\subsection{Avaliação do Efeito dos Tratamentos de Estabilização, Coagulação e Estocagem nas Propriedades da Borracha Natural}

Nesta etapa do estudo foi realizada uma avaliação dos efeitos de tratamentos de coagulação e do tempo de estocagem nas propriedades da borracha natural do clone RRIM 600. O objetivo do trabalho foi o de simular o processo de estocagem que ocorre nas fazendas produtoras e pequenos seringais que costumam coagular a borracha espontaneamente e estocá-la durante o período de espera dos caminhões das empresas compradoras que recolhem a borracha. Nessas fazendas, quando chove após a sangria das árvores, utiliza-se o procedimento de adicionar ácido acético para que ocorra a rápida coagulação do látex e dessa forma não haja perda do material.

A Tabela 29 mostra os valores de viscosidade, plasticidade, PRI e \% de nitrogênio para amostras do clone RRIM 600 submetido a sete diferentes tratamentos: três de coagulação e quatro de estocagem.

Tabela 29. Valores de viscosidade, plasticidade e PRI para amostras do clone RRIM 600 submetido a sete diferentes tratamentos: três de coagulação e quatro de estocagem.

\begin{tabular}{ccccc}
\hline Tipo de Tratamento & Viscosidade & Plasticidade & PRI & $\%$ N \\
\hline & Efeito do Tipo de & Coagulação & & \\
\hline BN-Amônia +Ac. 6N & 116 & 79 & 76 & 0,54 \\
BN-Coág Campo + Ac. 6N & 114 & 76 & 80 & 0,53 \\
BN-Coág Campo + Ac. 3N & 65 & 50 & 90 & 0,62 \\
\hline \multicolumn{6}{c}{ Efeito do Tempo de Estocagem } & & \\
\hline BN-Coág. Natural-7dias & 85 & 65 & 90 & 0,35 \\
BN-Coág. Natural-14 dias & 105 & 71 & 70 & 0,38 \\
BN-Coág. Natural-30 dias & 100 & 56 & 73 & 0,57 \\
BN-Coág. Natural-60 dias & 107 & 75 & 71 & 0,45 \\
\hline
\end{tabular}

Como se pode observar através dos dados da Tabela 29 para amostras coaguladas com diferentes concentrações de ácido acético, a amostra estabilizada com amônia e coagulada com ácido acético $6 \mathrm{~N}$ apresenta maiores valores de 
viscosidade, plasticidade e menores valores de PRI. A amostra coagulada em campo com ácido $6 \mathrm{~N}$ também apresentou valores altos de $\mathrm{P}_{0}$ e $\mathrm{V}_{0}$. Os valores de viscosidade Mooney encontrados para estas amostras $\left(\mathrm{V}_{0}=116\right.$-amostra estabilizada com amônia e coagulada com ácido acético $6 \mathrm{~N})$ e $\left(\mathrm{V}_{0}=114\right.$-amostra coagulada em campo com ácido acético $6 \mathrm{~N}$ ) estão acima dos valores encontrados na literatura [91] podendo ser classificadas como duras. A amostra coagulada em campo, com ácido acético $3 \mathrm{~N}$ e sem adição de amônia como estabilizante, apresentou um valor de viscosidade Mooney mais baixo (65) e mais próximo dos valores encontrados na literatura [91]. Isto sugere que a adição de ácido na concentração de $6 \mathrm{~N}$ pode influenciar no aumento dos valores de viscosidade Mooney. Por outro lado, acreditase que os problemas obtidos com a coagulação da amostra com ácido acético $3 \mathrm{~N}$, em campo, que resultou na perda parcial de material, possa ter influenciado os valores de viscosidade Mooney e plasticidade Wallace obtidos para essas amostras.

A queda nos valores de plasticidade Wallace e viscosidade Mooney era um comportamento esperado, haja vista vários trabalhos na literatura mostrarem uma boa correlação entre estas duas propriedades $[9,11,38,91]$. Por outro lado, quando se comparam os valores de PRI entre as amostras coaguladas com diferentes tratamentos, observa-se que a amostra coagulada no campo com ácido acético $3 \mathrm{~N}$ possui o maior valor de PRI, indicando que para esse tipo de tratamento, a borracha apresenta melhor resistência à degradação térmica. Por outro lado, a amostra estabilizada com amônia e coagulada com ácido acético $6 \mathrm{~N}$ apresentou um valor de PRI menor do que as outras amostras e abaixo dos valores estipulados na literatura [91]. Isto sugere que a adição de amônia e a posterior coagulação com ácido acético $6 \mathrm{~N}$ podem reduzir a resistência da borracha natural contra a termo-oxidação.

Quando analisamos os valores de viscosidade Mooney e plasticidade Wallace das amostras coaguladas naturalmente (sem adição de amônia e/ou ácido acético) em diferentes tempos de estocagem $(7,14,30$ e 60 dias após a coleta) observa-se uma certa tendência de aumento destes valores em relação às amostras coaguladas quimicamente. Na Figura 37 se observa que o aumento nos valores de viscosidade Mooney dá-se de forma mais acentuada nos primeiros quinze dias de estocagem, tendendo a estabilizar nos próximos dias. Os valores de plasticidade não apresentaram um comportamento claro de aumento dos valores em função do período de estocagem. Apesar de não haver um comportamento de aumento nos 
valores de plasticidade, as curvas de tendência para viscosidade e plasticidade mostradas no gráfico da Figura 37 seguem uma tendência similar. A curva de tendência para valores de PRI mostra uma queda nos valores para os primeiros quinze dias de estocagem tendendo a estabilizar após esse período. Os valores de PRI estão associados com a estabilidade da borracha natural em relação à degradação termo-oxidativa. Isso sugere que, períodos de estocagem superiores a quinze dias podem não ser convenientes para a aplicação da borracha que requeira utilização em altas temperaturas. Na-Ranong et al. [98] observaram queda nos valores de PRI para tempos de estocagem superiores a 30 dias. Entre as amostras submetidas a diferentes tipos de estocagem observa-se que a amostra estocada por 7 dias apresenta os melhores resultados de $\mathrm{V}_{0}, \mathrm{P}_{0}$ e PRI (menores valores de $\mathrm{V}_{0}, \mathrm{P}_{0}$ e maiores valores de PRI) do que as demais amostras. Isto sugere que esse método de coagulação pode ser indicado como um bom método de coagulação para se obter borrachas com melhores propriedades técnicas para a indústria de beneficiamento.

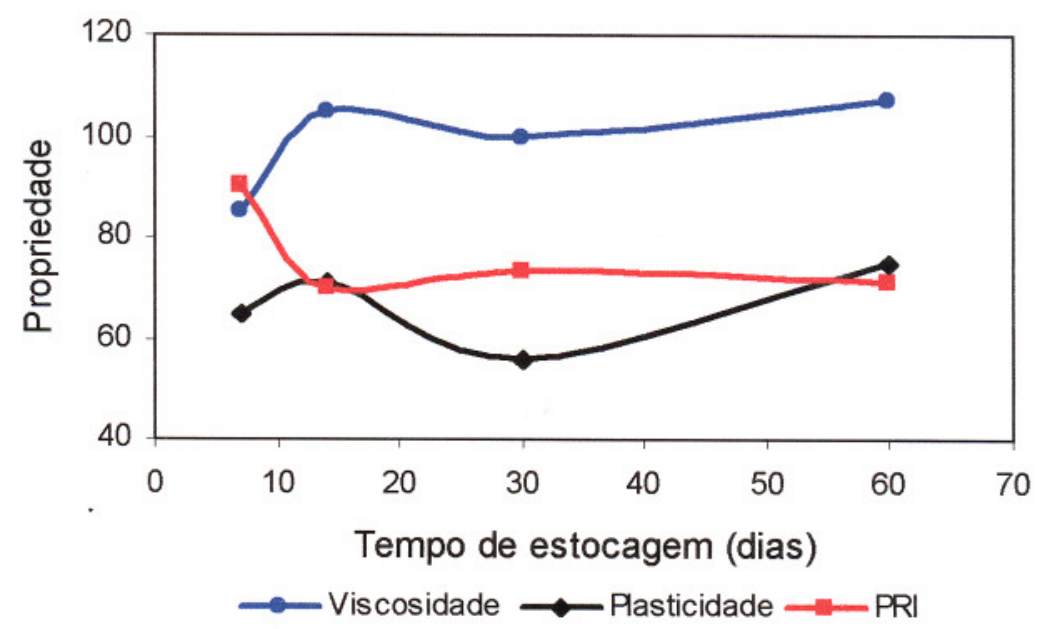

Figura 37. Curva de tendência para os valores de viscosidade, plasticidade e PRI em função dos dias de estocagem.

A Figura 38 abaixo mostra a correlação entre os valores de plasticidade e viscosidade para as amostras do clone RRIM 600 nos sete diferentes tratamentos. Pode-se observar uma boa correlação $(r=0.87)$ entre os valores das duas propriedades, o que está consistente com os comportamentos observados na literatura [91]. 


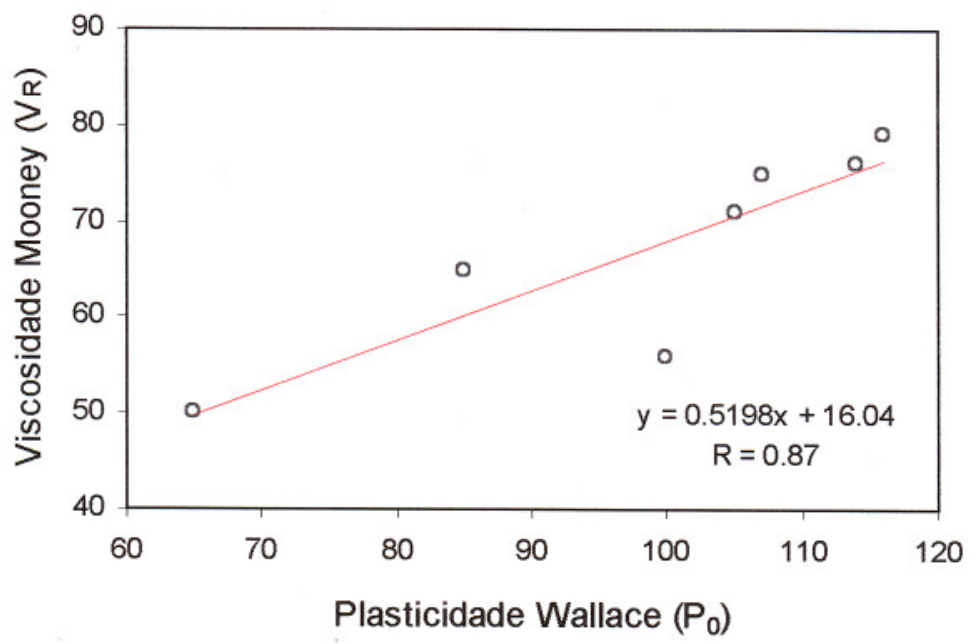

Figura 38. Correlação entre os valores de viscosidade Mooney e plasticidade Wallace para as amostras do clone RRIM 600 submetidas a sete diferentes tratamentos.

Os resultados de viscosidade Mooney e plasticidade Wallace mostraram que, em geral, as borrachas coaguladas quimicamente são mais duras que as borrachas coaguladas espontaneamente. De acordo com a literatura $[97,106]$, o tipo de coagulação (com adição de reagentes químicos ou coagulação espontânea) influencia a quantidade de constituintes não-borracha retidos na borracha natural afetando portanto, o balanço de substâncias oxidantes e antioxidantes. Na-Ranong et al. [98] mostraram que algumas substâncias não-borracha como aminas e aminoácidos agem como antioxidantes enquanto outras, como uréia e ácidos graxos atuam como oxidantes da borracha. Knight et al. [106], quantificaram os conteúdos de \% de nitrogênio, \% de cinzas, \% de extrato acetônico e \% de ácido graxo para amostras de borracha coaguladas por diferentes métodos. Eles observaram que para a \% de extrato acetônico os valores variaram de 3.9 \% a $3.5 \%$ para as borrachas coaguladas pela adição de ácido e as coaguladas naturalmente respectivamente. Já para o conteúdo de ácidos graxos os valores variaram de $0,15 \%$ a $0,19 \%$, respectivamente, para borrachas coaguladas pela a adição de ácido e as coaguladas naturalmente. Os autores observaram também que o conteúdo de gel em (\%) variou de 4,7 a 5,7 respectivamente para as amostras coaguladas com ácido e as coaguladas espontaneamente. A fase gel é composta por sítios que constituem pontos de ligação cruzada entre as cadeias da borracha. Quanto maior a quantidade da fração gel maiores os valores de plasticidade e viscosidade da borracha e mais difícil é a sua 
dissolução em solventes apolares como o tolueno [107]. Tanaka [107] observou que a fase gel que varia, em geral, de 3-5\% aproximadamente, aumenta para $70 \%$ ou mais dependendo do tempo de estocagem. Este efeito foi observado para as borrachas provenientes de látex estabilizados com amônia. Por outro lado, o conteúdo de gel varia pouco para as borrachas obtidas a partir do látex previamente desproteinizado. $\mathrm{O}$ autor propôs que a fase gel é composta por dois tipos de ligação cruzada; uma delas é feita principalmente por ligações hidrogênio de proteínas e a outra acontece devido à presença de fosfolipídios. A primeira pode ser evitada ou controlada através da desproteinização do látex, enquanto que a segunda pode ter seus pontos quebrados através de reações de transesterificação. Essas reações diminuem os pontos de ligação cruzada na borracha natural diminuindo portanto, a viscosidade e plasticidade da borracha natural. Esses resultados indicam que as ligações cruzadas existentes na borracha natural ou a fração gel estão relacionadas com a quantidade de constituintes não-borracha (proteína, lipídeos) presentes na mesma. Por sua vez, a quantidade de gel influencia diretamente os valores de viscosidade e plasticidade. De acordo com os resultados apresentados na Tabela 29 os valores de \% de nitrogênio são, no geral, maiores para as amostras coaguladas quimicamente. Isto sugere que o fato de possuir maior quantidade de substâncias nitrogenadas pode ter contribuído para um aumento no conteúdo de gel o que possui relação com aumento nos valores de viscosidade e plasticidade. Como discutido anteriormente, quantidade de substâncias não borracha variam dependendo do tipo de coagulação.

Quando comparamos os valores de PRI das amostras coaguladas quimicamente e das amostras estocadas por períodos superiores a 14 dias observamos que as amostras coaguladas com ácido possuem maiores valores de PRI e portanto maior resistência a degradação térmica. A borracha coagulada em campo com ácido $6 \mathrm{~N}$ possui valor de PRI igual a 80 e a amostra coagulada espontaneamente e estocada por 60 dias possui valor de PRI igual a 71. Segundo Na-Ranong et al. [98], borrachas produzidas através da coagulação imediata do látex em geral, possuem maiores valores de PRI exceto quando são submetidas à secagem em altas temperaturas. Além disso, para borrachas coaguladas espontaneamente o valor de PRI cai com o aumento do tempo de estocagem. Segundo os autores [98], as partículas de látex quando estão ainda em fase coloidal, estão dispersas no meio 
líquido e são envolvidas por uma membrana fosfolipoglicoprotéica, cuja superficie é carregada negativamente e contribui para a estabilidade do meio coloidal. Os lipídios neutros estão entre os constituintes destas membranas e desempenham um papel muito importante de proteção das partículas de borracha contra a termo-oxidação. Os autores acreditam que após a rápida coagulação do látex, através da adição de ácido, essa camada protetora é preservada protegendo a cadeia isoprênica contra a oxidação. No entanto, quando a borracha é submetida à coagulação espontânea e à maturação por longos períodos de tempo, a membrana que protege as partículas de borracha é destruída através de reações enzimáticas. Segundo eles, o ataque de enzimas a essa membrana pode envolver a hidrolise da flora microbial a qual ocorre durante a maturação da borracha. Portanto, além de perderem a camada protetora que representa uma resistência inicial à termo-degradação, as cadeias do polímero ficariam susceptíveis a oxidação por estarem mais expostas a ação de outras substâncias oxidantes presentes na borracha natural. Dessa forma, os resultados mostrados neste trabalho de valores maiores de PRI para as amostras coaguladas quimicamente, em relação às amostras coaguladas espontaneamente, pode ser explicado pelo fato de que a coagulação espontânea associada a longos períodos de estocagem pode comprometer a integridade da membrana fosfolipoglicoprotêica. Essa membrana desempenha papel importante na preservação das cadeias isoprênicas quanto a termo-oxidação. A Figura 39 mostra esquema de degradação da borracha natural durante envelhecimento por estocagem segundo esquema proposto por $\mathrm{Na}$ Narong et al. [98]. 
$\longrightarrow$ Agente oxidante

〜 Cadeia isoprênica
- Membrana

- Antioxidante natural

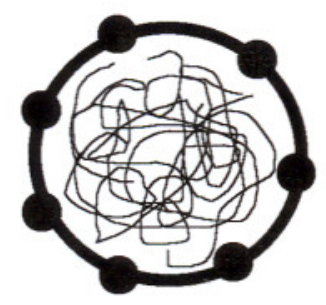

1

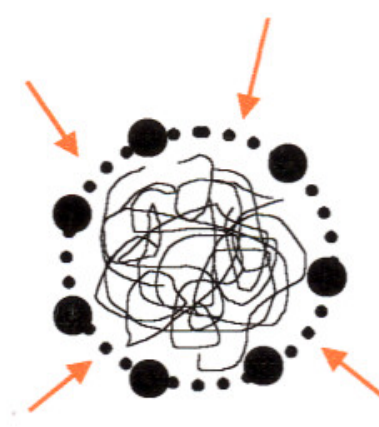

2

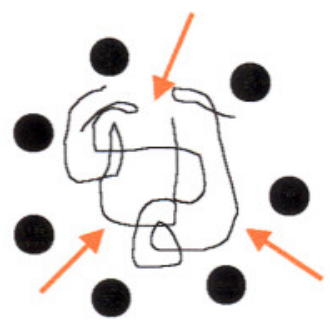

3

Figura 39. Esquema da degradação da membrana fosfolipoprotéica presente na borracha natural [98]. 1-Partícula de borracha presente no látex intacta; 2-Partícula de borracha cuja membrana foi atacada por agentes de oxidação. Observa-se a degradação da membrana fosfolipoprotéica; 3-Partícula de borracha cuja membrana foi degradada. As setas mostram as cadeias isoprênicas susceptíveis aos agentes oxidantes.

A Figura 40 mostra os espectros na região do infravermelho da borracha natural para diferentes tipos de coagulação química. 
BN Amônia Ac. 6N

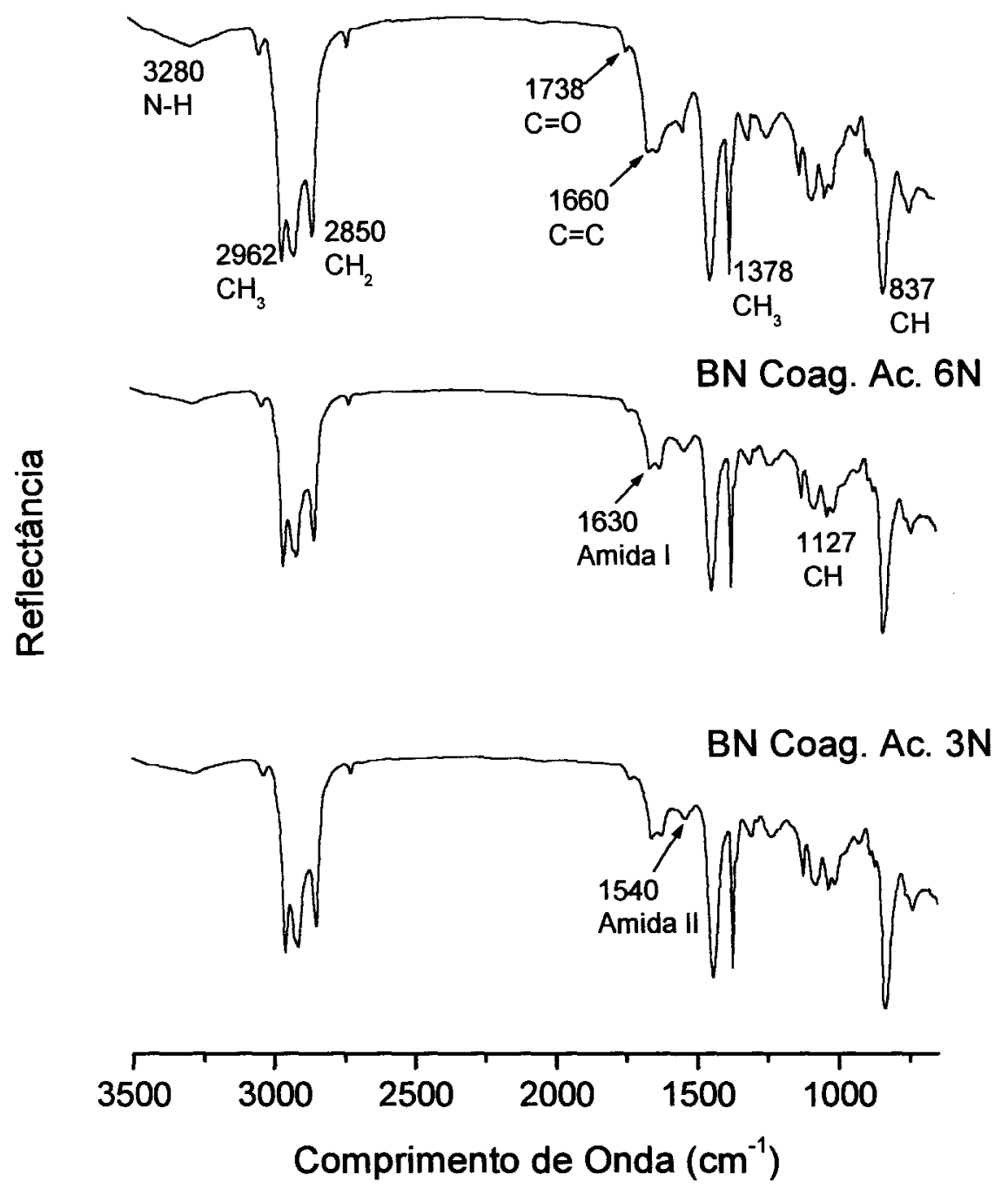

Figura 40. Espectros na região do infravermelho da borracha natural submetida a diferentes tratamentos de coagulação.

Como podemos observar na Figura 40, os espectros na região do infravermelho para as amostras coaguladas quimicamente não apresentam diferenças significativas entre si. $\mathrm{O}$ espectro da borracha coagulada em campo com ácido acético $6 \mathrm{~N}$ mostra absorção em $3280 \mathrm{~cm}^{-1}$, devido à deformação axial da ligação $\mathrm{N}$ $\mathrm{H}$ das proteinas e aminoácidos presentes na borracha natural. Neste espectro observam-se também as bandas de amida I e II (região de 1630 e $1540 \mathrm{~cm}^{-1}$ ) características de proteínas presentes na fração não borracha. No espectro da região do infravermelho da borracha natural estabilizada com amônia e coagulada com ácido acético $6 \mathrm{~N}$, nota-se que a banda em $3280 \mathrm{~cm}^{-1}$ possui uma intensidade maior quando comparada com o espectro anterior. Neste caso, o estabilizante amônia 
adicionado pode ter sido o responsável por esse aumento. Observa-se também absorção típica de grupo carbonila $(\mathrm{C}=0)$ na região de $1738 \mathrm{~cm}^{-1}$. Em relação às bandas da cadeia isoprênica, não se observa mudanças significativas comparando-se os espectros da borracha natural (BN) coagulada com ácido no campo e a estabilizada com amônia e coagulada no laboratório. Como características da cadeia isoprênica observam-se as bandas de estiramento $\mathrm{CH}_{3} \mathrm{em} 2962 \mathrm{~cm}^{-1}$, bandas de estiramento $\mathrm{CH}_{2} \mathrm{em} 2850 \mathrm{~cm}^{-1}$, estiramento $\mathrm{C}=\mathrm{C}$ em $1660 \mathrm{~cm}^{-1}$, deformação $\mathrm{CH}_{2} \mathrm{em}$ $1450 \mathrm{~cm}^{-1}$, deformação $\mathrm{CH}_{3} \mathrm{em} 1378 \mathrm{~cm}^{-1}$, C-H no plano cis $1,4 \mathrm{em} 1127 \mathrm{~cm}^{-1}$ e C-H fora do plano em $837 \mathrm{~cm}^{-1}$. Os resultados mostraram-se semelhantes com a literatura [108].

A Figura 41 mostra os espectros na região do infravermelho da borracha natural coagulada espontaneamente e estocada em diferentes tempos. 
BN Coag. 60 dias

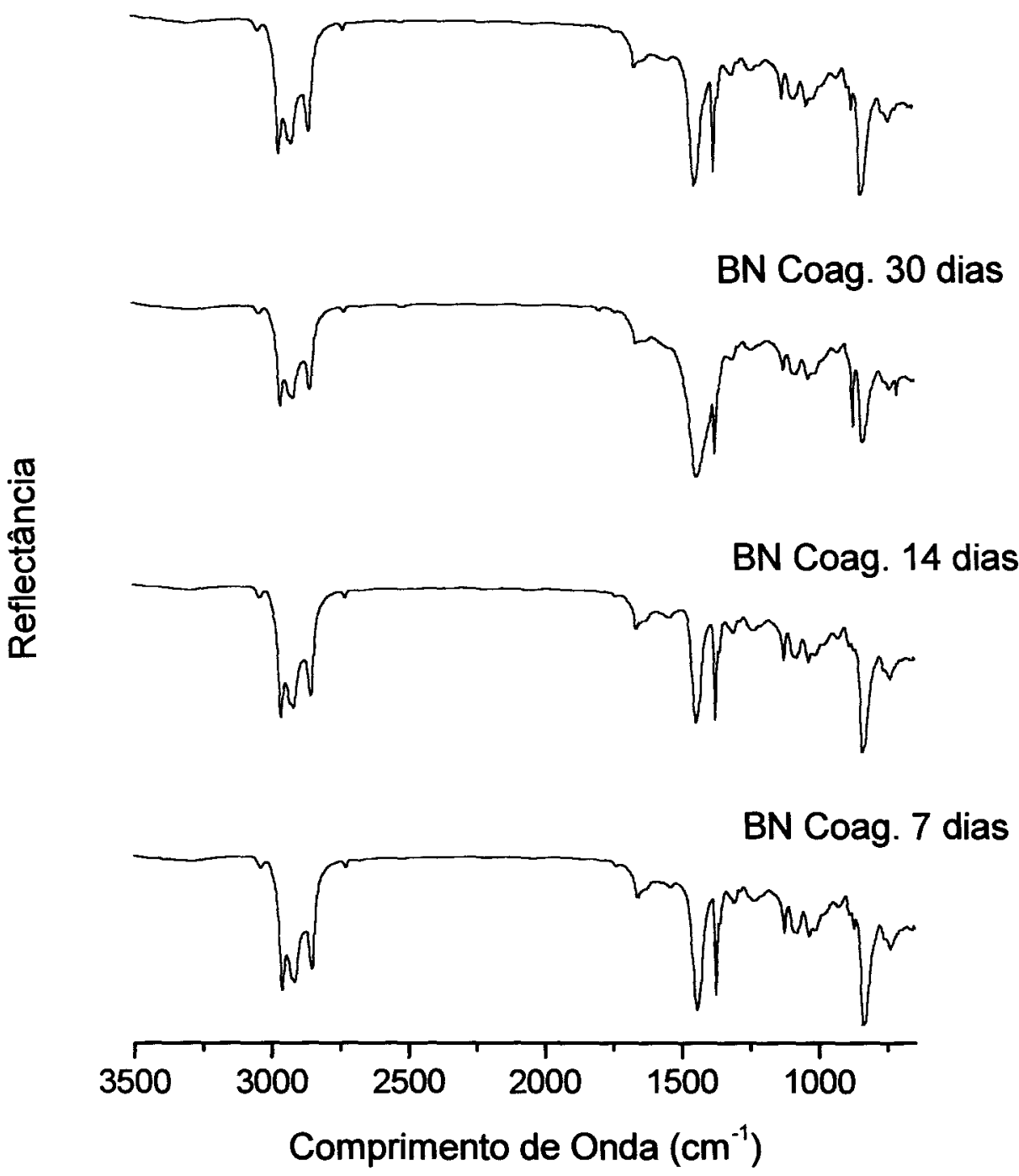

Figura 41. Espectro na região do infravermelho da borracha natural submetida a diferentes tempos de estocagem.

Os espectros na região do infravermelho para a borracha natural em diferentes tempos de estocagem são bastante similares. A principal diferença está na região de 1630 e $1540 \mathrm{~cm}^{-1}$, onde vemos as bandas características das amidas I e II respectivamente. Todas as amidas mostram uma banda de absorção de carbonila conhecida como banda de amida I, que absorve na região de $1630 \mathrm{~cm}^{-1}$ [109]. A banda na região de $1540 \mathrm{~cm}^{-1}$ é devida à deformação angular N-H e é chamada de amida II $\left(1540 \mathrm{~cm}^{-1}\right)$. As amidas são grupos característicos das proteínas que estão presentes na borracha natural. Observa-se através dos espectros que, de certa forma, está havendo uma modificação no arranjo dessas proteínas que, de acordo com a 
literatura [34, 110], desempenham um papel importante no endurecimento da borracha por estocagem. No entanto, os dados obtidos via espectro na região do infravermelho não são suficientes para avaliar a influência das amidas no endurecimento da borracha natural. A semelhança entre os espectros anteriores mostra que as características principais da cadeia polimérica não foram alteradas com o processo de estocagem.

Outro aspecto importante do endurecimento por estocagem é a presença de grupos aldeído adjacentes à borracha natural. $\mathrm{O}$ grupo carbonila desses aldeídos tem o potencial de formar ligações cruzadas na presença de aminoácidos e são os principais responsáveis pelo endurecimento da borracha com o tempo de estocagem. A carbonila deste grupo absorve na região de $1740 \mathrm{~cm}^{-1}$. Nos espectros de infravermelho para as amostras de borracha envelhecidas observa-se que a banda característica da carbonila aparece em todos os espectros de infravermelho das amostras independente do tratamento.

Para melhor avaliar as mudanças ocorridas nas amostras estocadas por diferentes períodos, as amostras foram submetidas a condições de maiores tempos de envelhecimento $(30,60$ e $120 \mathrm{~min})$ em estufa à temperatura de $140{ }^{\circ} \mathrm{C}$. Apesar das amostras apresentarem diferença aparente no seu aspecto físico, não foram observadas mudanças significativas nas bandas características da cadeia isoprênica nos espectros de infravermelho. Os espectros de infravermelho das amostras estocadas por 7 e 60 dias submetidas a diferentes tempos de envelhecimento são mostrados nas Figuras 41 e 42 . Assim como discutido anteriormente, as principais mudanças observadas nos espectros de infravermelho para borracha natural submetida a condições extremas de envelhecimento são nas bandas das amidas (região de 1630 e $1540 \mathrm{~cm}^{-1}$ ). Para o espectro de infravermelho da amostra estocada por 7 dias não se observa mudanças nas bandas dessa região. No entanto, para a amostra estocada por 60 dias observa-se uma mudança nas bandas na região de 1630$1540 \mathrm{~cm}^{-1}$. 


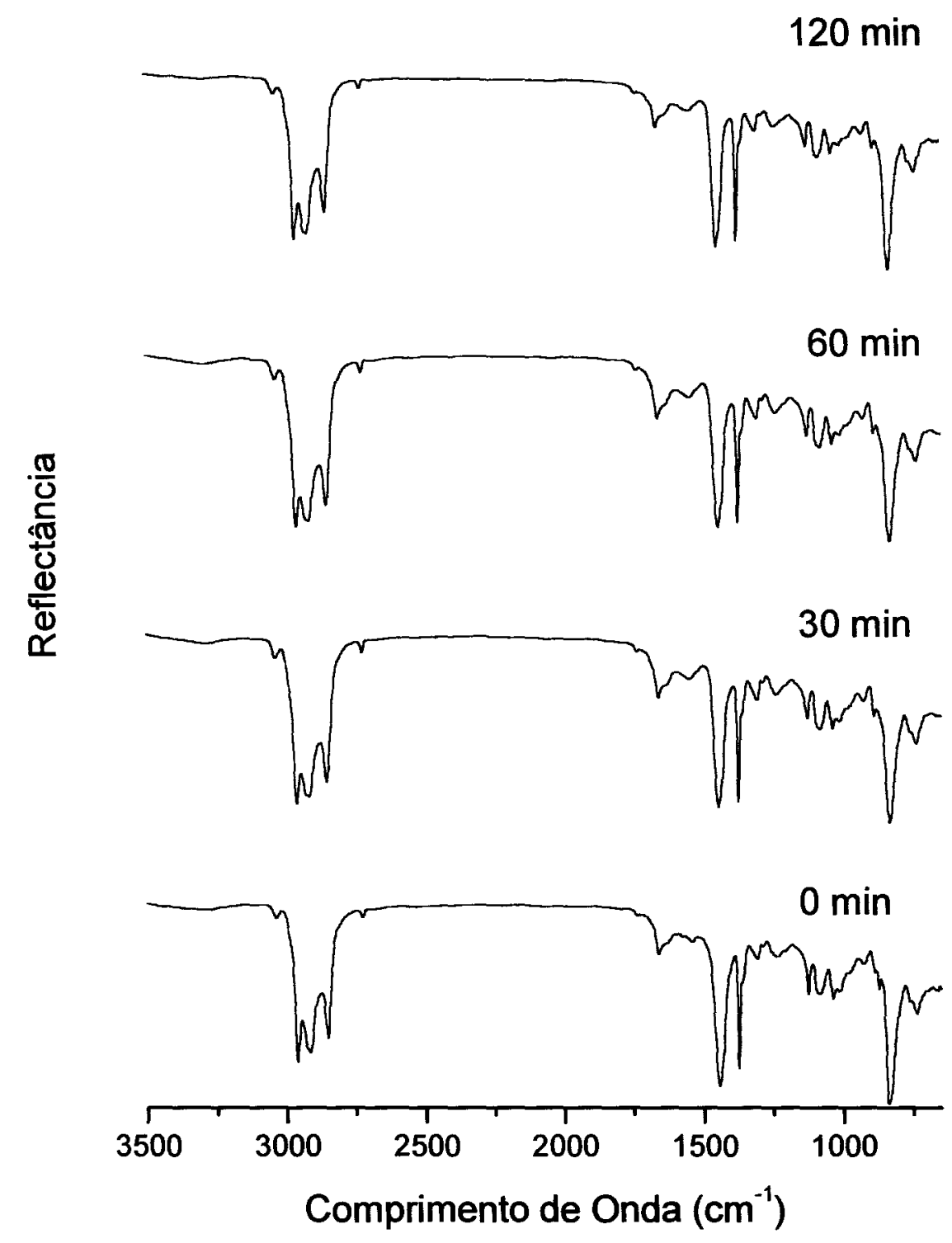

Figura 42. Espectro na região do infravermelho da amostra estocada por 7 dias e envelhecida a $140^{\circ} \mathrm{C}$ por 30,60 e $120 \mathrm{~min}$. 

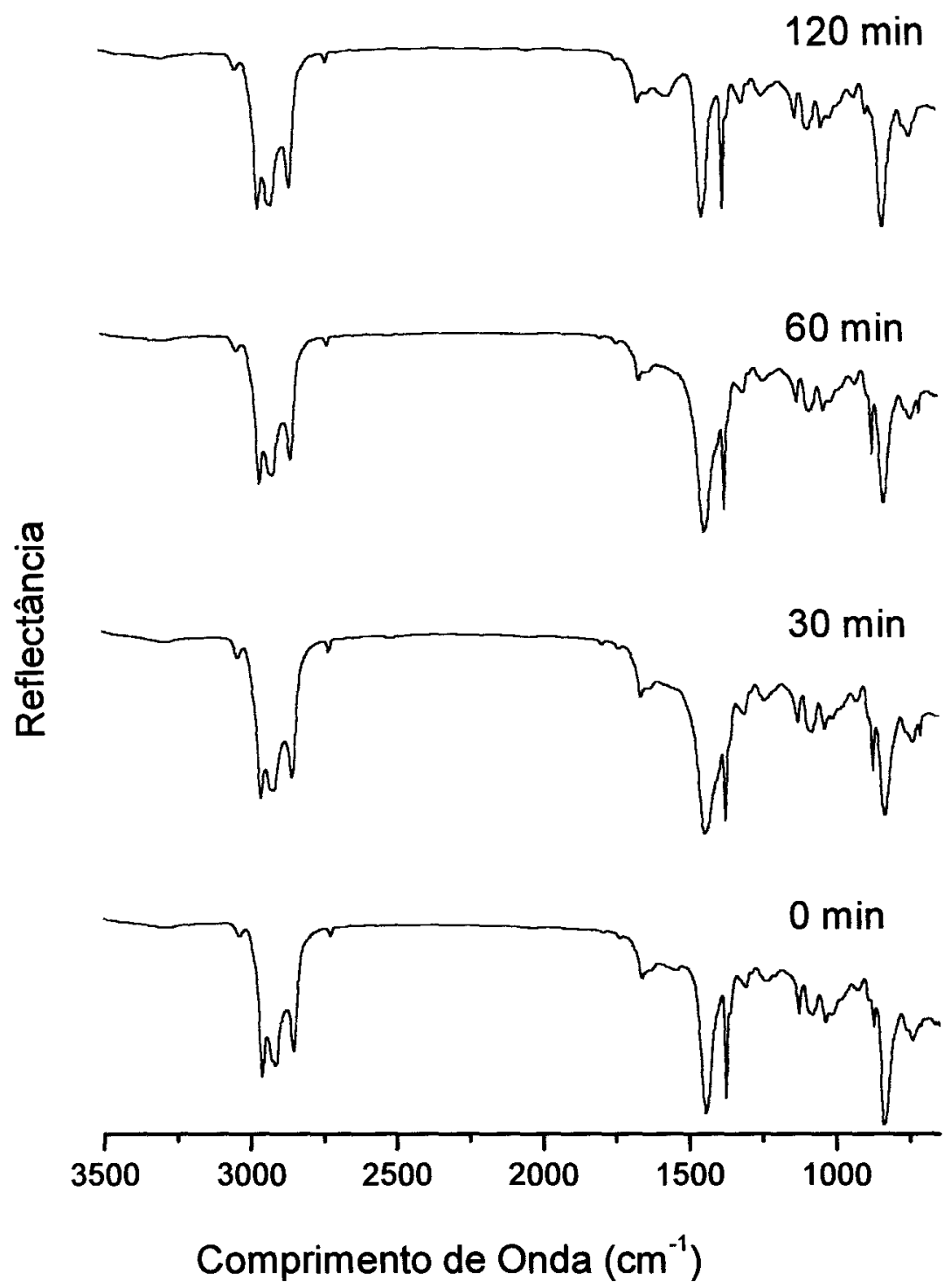

Figura 43. Espectro na região do infravermelho da amostra estocada por 60 dias e envelhecida a $140^{\circ} \mathrm{C}$ por 30,60 e $120 \mathrm{~min}$.

As medidas de DSC, TG e DMTA foram realizadas buscando uma maior compreensão do comportamento térmico e dinâmico da borracha obtida após os sete diferentes tratamentos aos quais as amostras de látex foram submetidas.

A Figura 44 mostra as curvas de DSC obtidas para as amostras do clone RRIM 600 submetidas a diferentes tratamentos referentes à coagulação e tempo de estocagem. Observa-se que a temperatura de transição vítrea $T_{g}$ encontrada foi de aproximadamente $-63{ }^{\circ} \mathrm{C}$ e que não há variação significativa nos valores de $T_{g}$ entre as amostras submetidas a estes tratamentos. Os valores são mostrados na Tabela 30 e estão acima dos valores observados na literatura para a borracha natural não 
vulcanizada (-74 $\left.-79{ }^{0} \mathrm{C}\right)$ [111] porém, estão próximos dos encontrado para a borracha vulcanizada $\left(-72-61^{0} \mathrm{C}\right)$.

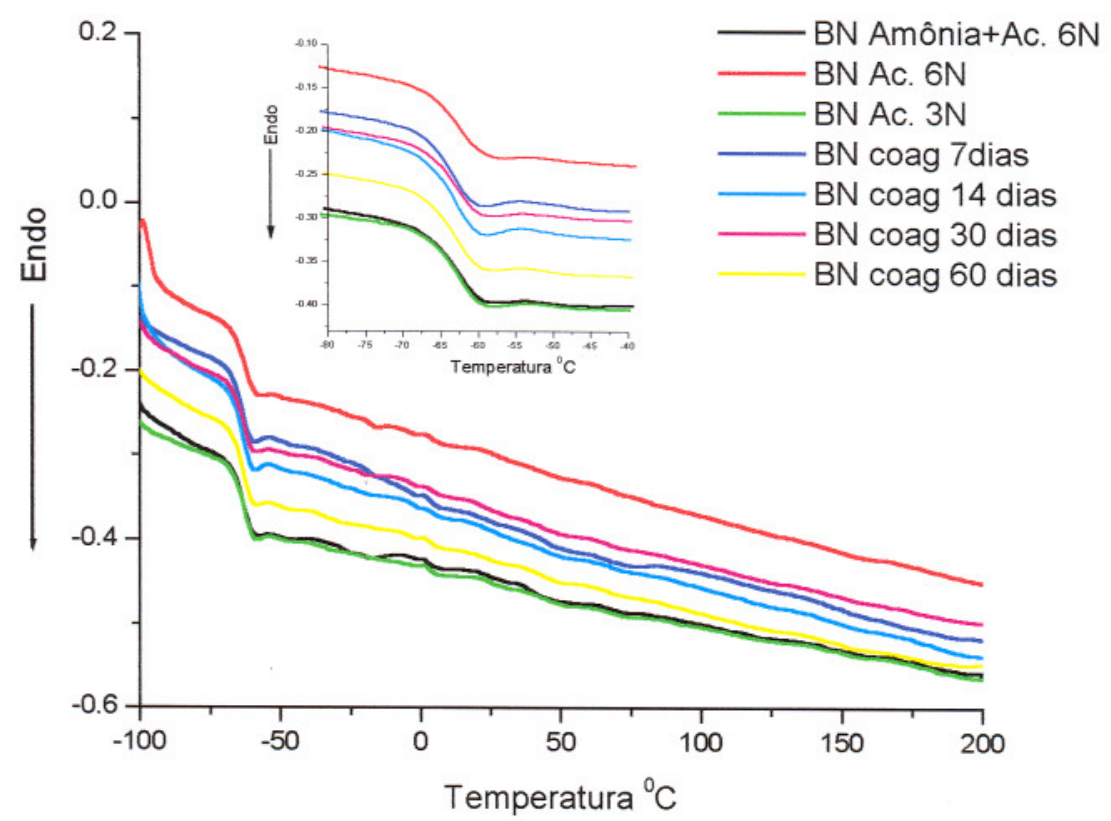

Figura 44. Curvas de DSC para amostras do clone RRIM 600 submetidas a sete diferentes tratamentos.

Tabela 30. Valores de Tg obtidos através de medidas de DSC para amostras de borracha natural do clone RRIM 600 submetidas a diferentes tratamentos.

\begin{tabular}{cc}
\hline Amostras & Tg $\left({ }^{\circ} \mathbf{C}\right)$ \\
\hline BN Amônia + Ac. 6N & $-63,4$ \\
BN Ac. 6N & $-63,3$ \\
BN Ac 3N & $-63,3$ \\
BN Coag. 7dias & $-63,5$ \\
BN Coag. 14 dias & $-63,4$ \\
BN Coag. 30 dias & $-63,8$ \\
BN Coag 60 dias & $-63,3$ \\
\hline
\end{tabular}

A Figura 45 mostra as curvas de TG obtidas para as amostras do clone RRIM 600 submetidas a diferentes tratamentos de coagulação e tempo de estocagem. Através das medidas de TG observa-se que a partir de aproximadamente $300{ }^{\circ} \mathrm{C}$ a borracha inicia seu processo de degradação onde há uma diminuição significativa da 
$\%$ de massa. A perda total de massa ocorreu a aproximadamente $600{ }^{0} \mathrm{C}$. Quando se observa o gráfico da Figura 46, o qual mostra um detalhe da perda de massa (\%) em função da temperatura no intervalo de $30-300{ }^{\circ} \mathrm{C}$, nota-se que a amostra estocada por trinta dias começa a perder massa em temperaturas ligeiramente menores do que as amostras estocadas por 7 e 14 dias. Comparando-se a temperatura de perda de massa, em aproximadamente $97 \%$ vê-se que a amostra estocada por 30 dias perde $3 \%$ de massa na temperatura de $140{ }^{\circ} \mathrm{C}$, enquanto que a amostra estocada por 7 dias perde 3 $\%$ de massa em aproximadamente $250{ }^{\circ} \mathrm{C}$. Este comportamento mostra que a amostra estocada por 7 dias possui melhor resistência à degradação térmica do que a amostra estocada por 30 dias. Isto está de acordo com os resultados de PRI encontrados que foram iguais a 90 e 73 para a amostra estocada por 7 e 30 dias respectivamente. A amostra de $\mathrm{BN}$ coagulada com ácido $3 \mathrm{~N}$ e a amostra $\mathrm{BN}$ coagulada espontaneamente durante 7 dias, possuem valores de PRI iguais. Assim, quando se compara o comportamento de degradação térmica para estas duas amostras (Figuras 45, 46 e 47) nota-se que esse comportamento é bastante semelhante. Para as amostras coaguladas em campo com diferentes concentrações de ácido e estabilizada com amônia não foram observadas mudanças significativas nas análises de perda de massa em função da temperatura. A Figura 48 mostra a derivada do gráfico de TG e observa-se um pico intenso de degradação por volta de $380{ }^{\circ} \mathrm{C}$. Em temperaturas menores que 300 ${ }^{0} \mathrm{C}$ observa-se uma perda pequena de massa como resultado da oxidação e volatilização de material. Após $300{ }^{\circ} \mathrm{C}$, a principal reação é a degradação oxidativa e, nesse caso, observa-se decomposição rápida do material. As curvas de TG e DTG mostram grandes similaridades entre si o que sugere que os mecanismos de decomposição são parecidos independentemente do tipo de tratamento ao qual as amostras são submetidas. O comportamento das curvas de TG apresentados neste trabalho está semelhante com o observado na literatura por Oliveira et al. [6] que estudaram o comportamento de borrachas de diferentes clones através de ensaios de técnica de DSC e TG. 


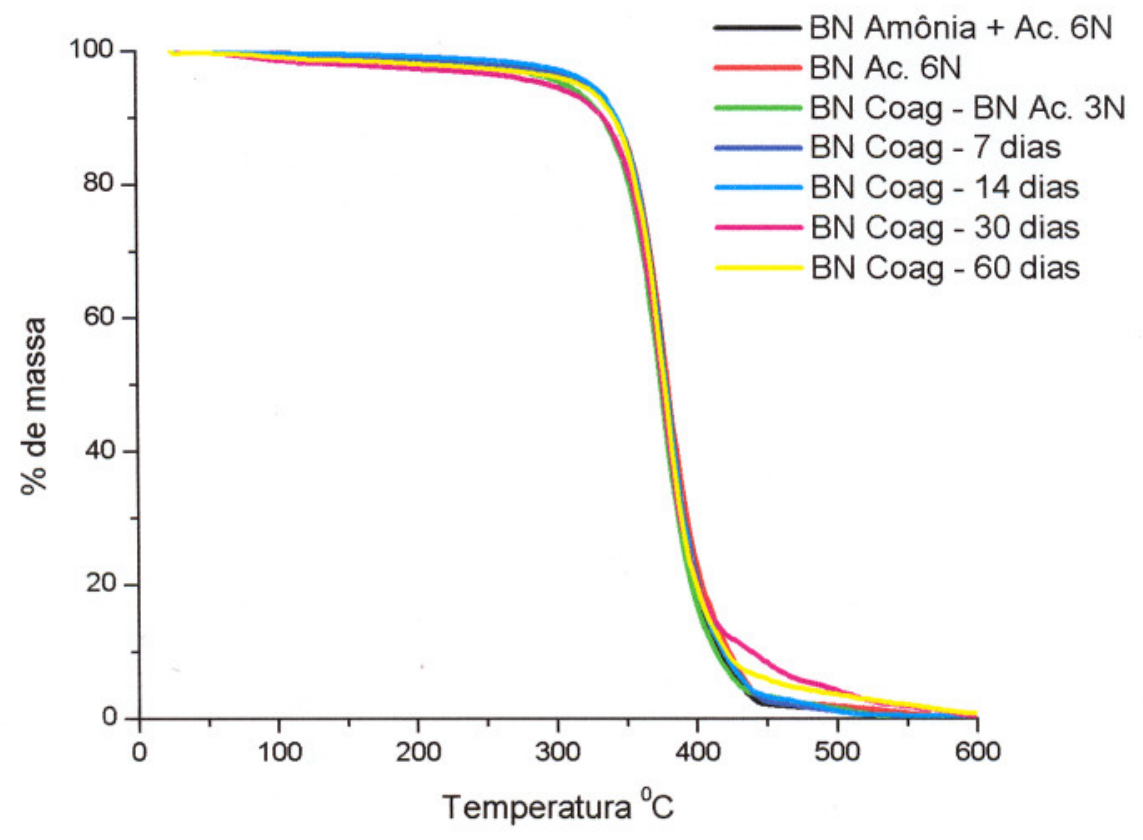

Figura 45.Curvas de TG para amostras do clone RRIM 600 submetidas a sete diferentes tratamentos.

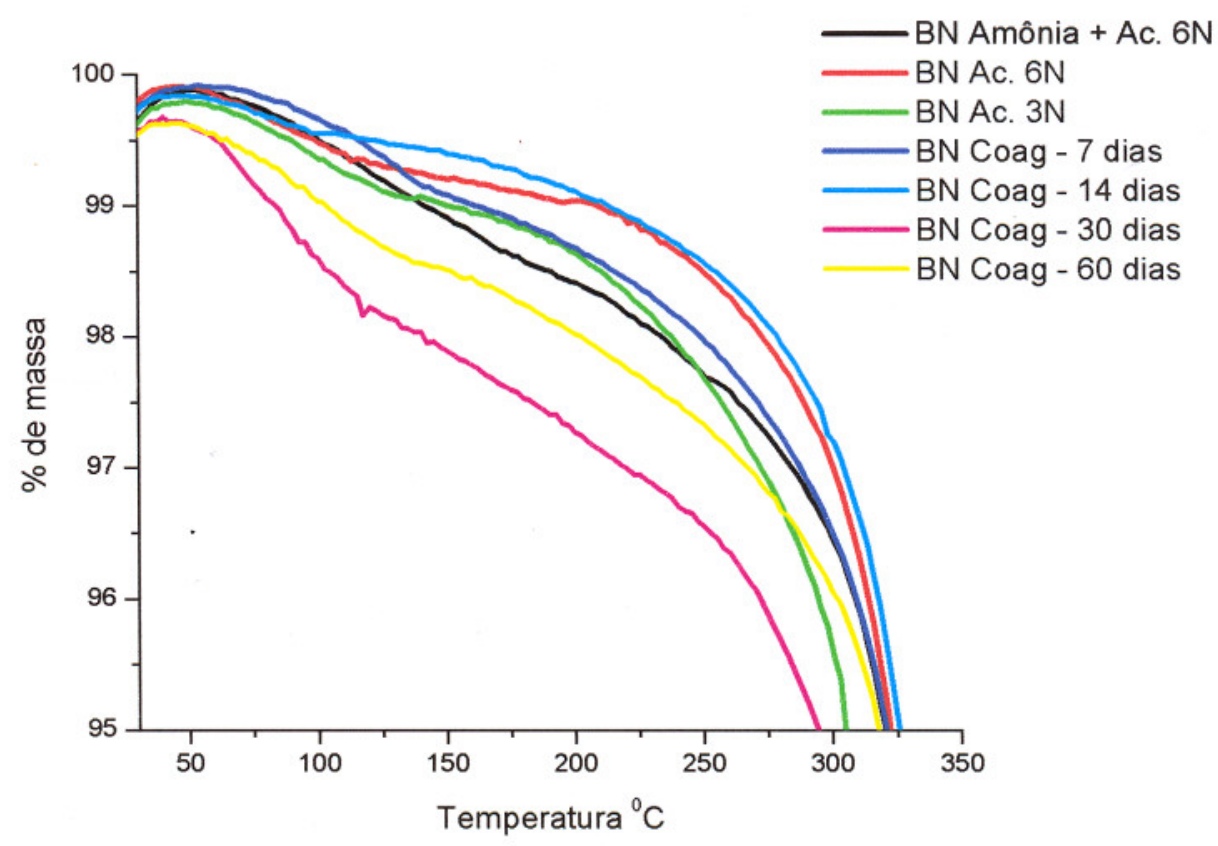

Figura 46. Detalhe das curvas de TG no intervalo de $0-300{ }^{\circ} \mathrm{C}$ 


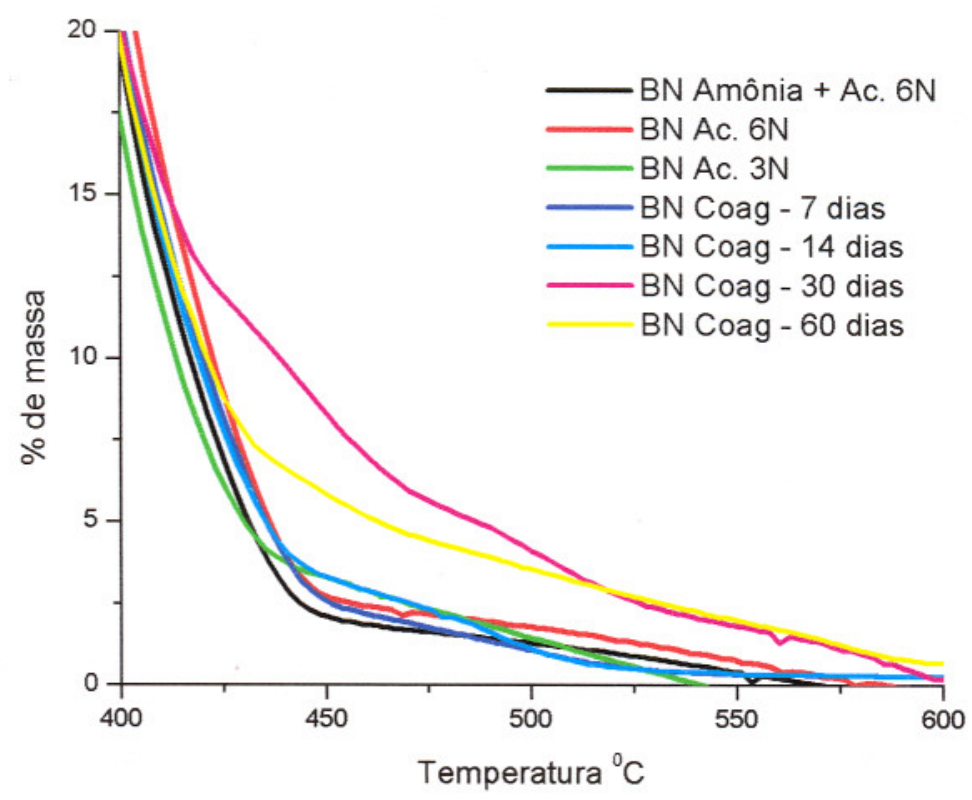

Figura 47 Detalhe das curvas de TG no intervalo de $400-600{ }^{0} \mathrm{C}$

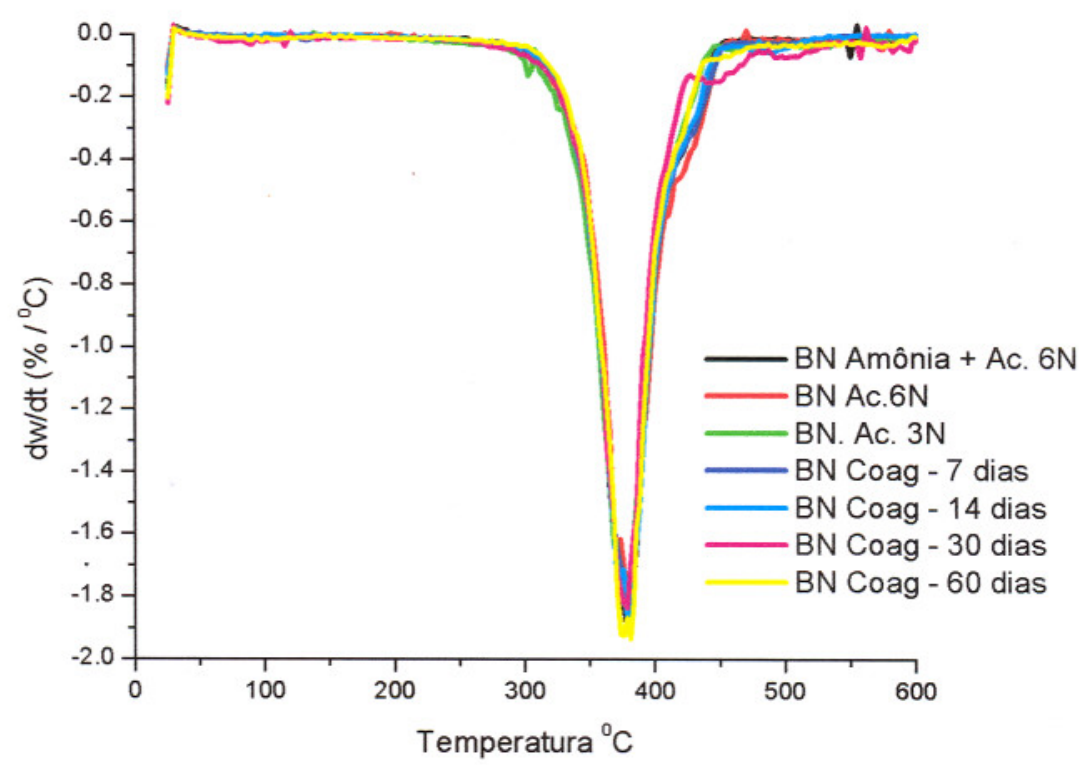

Figura 48. Derivada da curva de TG para amostras do clone RRIM 600 submetidas a sete diferentes tratamentos.

A Figura 49 mostra as curvas obtidas nas análises de DMTA da borracha natural do clone RRIM 600 em sete diferentes tratamentos. Observa-se que a amostra estocada por 60 dias apresentou maior valor de módulo dinâmico de armazenamento na temperatura de $-100{ }^{\circ} \mathrm{C}$. Considerando-se os diferentes tipos de coagulação, 
observa-se que a amostra coagulada, em campo, com ácido $6 \mathrm{~N}$, apresenta o menor valor de módulo dinâmico. Já a amostra estabilizada com amônia apresentou valor de $\mathrm{E}_{\text {max }}$ menor do que a amostra coagulada em campo com ácido $3 \mathrm{~N}$ a qual apresentou o maior valor de E' ${ }_{\max }$. Nota-se que a grande variação de E' ocorreu em temperaturas inferiores à temperatura de transição vítrea. No entanto, para temperaturas acima de $-65{ }^{0} \mathrm{C}$ o valor de módulo dinâmico apresenta menores variações de uma amostra para outra como mostra a Figura 49.

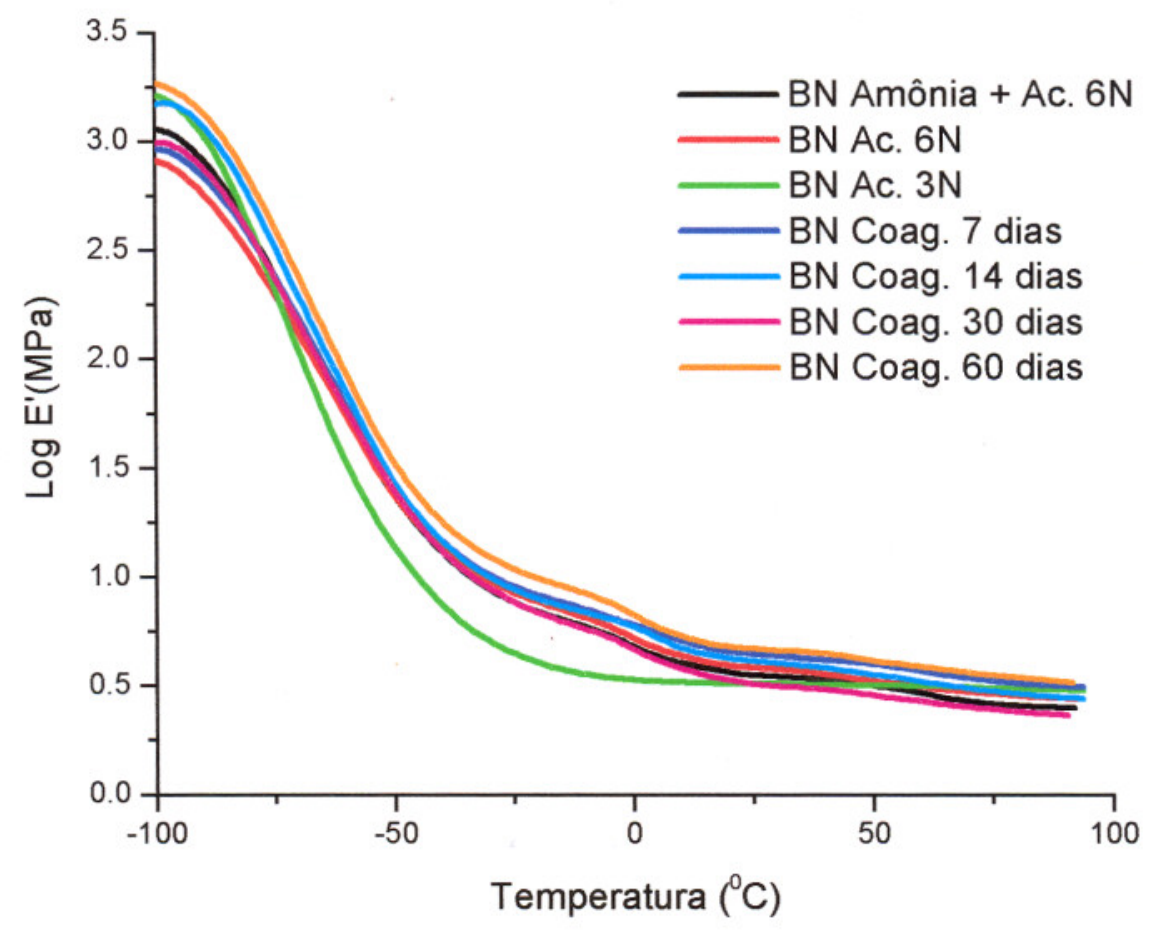

Figura 49. Curvas do logaritmo do módulo de armazenamento versus temperatura para as borrachas submetidas a diferentes tratamentos

Quando se observa a variação dos valores de E' na temperatura variando de 0-50 ${ }^{\circ} \mathrm{C}$ (Figura 50) nota-se que a amostra estocada por 60 dias possui maiores valores de E' do que as demais amostras. Já a amostra estocada por 30 dias a amostra coagulada em campo com ácido $3 \mathrm{~N}$ apresentam os menores valores de E'. A amostra coagulada com ácido $3 \mathrm{~N}$, ao contrário das outras amostras, não mostra variação de E' em função da temperatura acima de $0{ }^{\circ} \mathrm{C}$. 


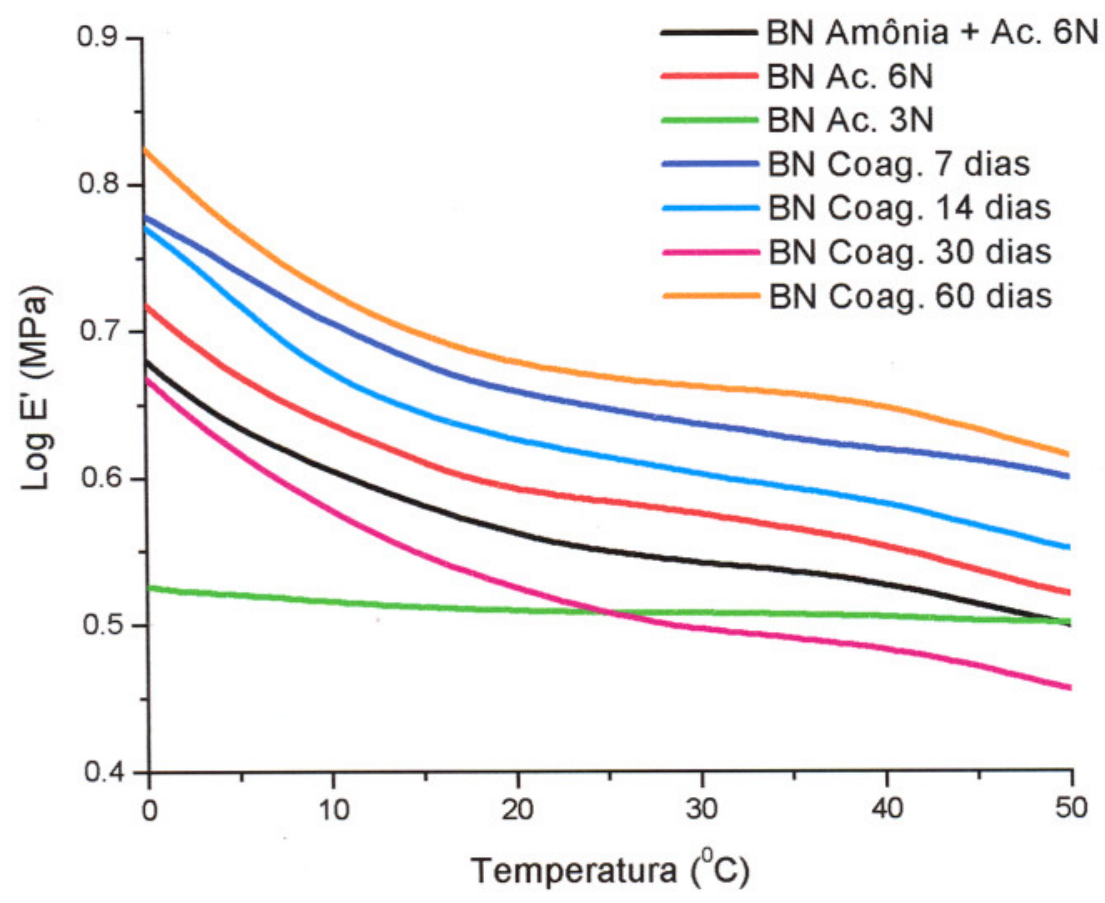

Figura 50. Variação do módulo E'em função da temperatura para o intervalo de temperatura de $0-50{ }^{\circ} \mathrm{C}$

A Figura 51 mostra a variação dos valores de E' a $25^{\circ} \mathrm{C}$ em função do tempo de estocagem em dias para amostras submetidas a diferentes tratamentos de coagulação. Observa-se que os valores de E' caem para as amostras estocadas por 14 e 30 dias voltando a subir após 30 dias de estocagem.

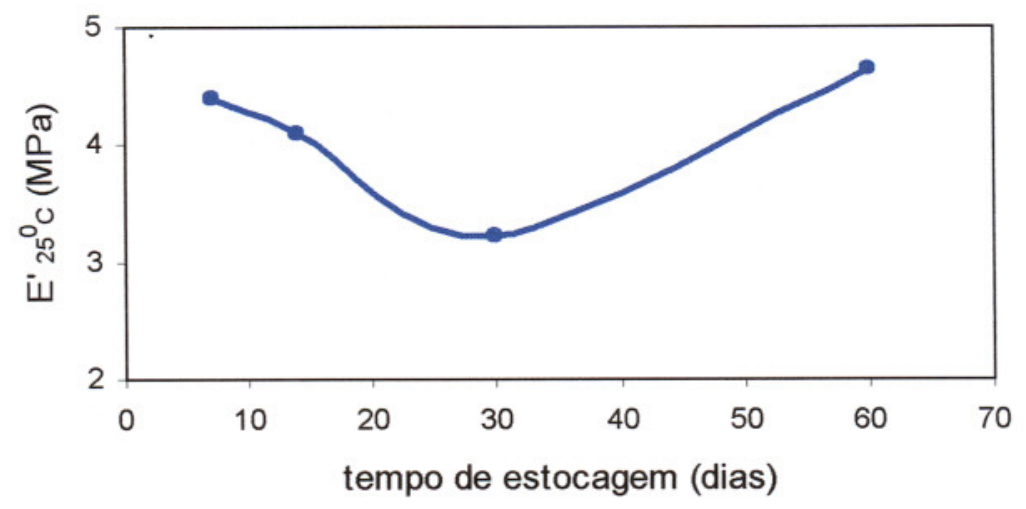

Figura 51. Curva de tendência para os valores de E'a $25^{\circ} \mathrm{C}$.

Ao se compararem os valores de $\mathrm{E}_{25}{ }^{\circ} \mathrm{C}$ obtidos via técnica de DMTA e os valores de $\mathrm{P}_{0}$ (plasticidade Wallace), observa-se que não há uma tendência clara de 
comportamento para as amostras de borracha submetidas a diferentes tratamentos. Para as amostras coaguladas quimicamente, aquela coagulada com ácido $3 \mathrm{~N}$ apresentou menor valor de $P_{0}\left(P_{0}=50\right)$ e menor valor de $E^{\prime}\left(E^{\prime}=3,2 \mathrm{MPa}\right)$ quando se compara com as outras amostras coaguladas/estabilizadas com agentes químicos. Já para as amostras coaguladas espontaneamente a amostra estocada por 30 dias apresentou o menor valor de $\mathrm{P}_{0}\left(\mathrm{P}_{0}=56\right)$ e menor valor de $\mathrm{E}^{\prime}\left(\mathrm{E}^{\prime}=3,2 \mathrm{MPa}\right)$. A amostra estocada por 60 dias apresentou o maior valor de $\mathrm{P}_{0}\left(\mathrm{P}_{0}=75\right)$ acompanhado de um aumento no valor de $E^{\prime}\left(E^{\prime}=4,7 \mathrm{MPa}\right)$. A Tabela 31 mostra os valores de E' na temperatura de $25^{\circ} \mathrm{C}$ e $\mathrm{P}_{0}$ para as amostras submetidas a diferentes tratamentos de coagulação e estocagem. 
Tabela 31 . Valores de $\mathrm{E}^{\prime}{ }_{25}^{\circ} \mathrm{C}$ e $\mathrm{P}_{0}$ para as amostras de borracha submetidas a diferentes tipos de tratamento.

\begin{tabular}{ccc}
\hline AMOSTRA & E' $^{\prime}{ }^{\circ}$ C (MPa) & Po \\
\hline Tratamento de Coagulação & & 79 \\
\hline BN Amônia + Ac. 6N & 3,5 & 76 \\
BN_Coágulo Campo c/ Ac. 6N & 3,8 & 50 \\
BN_Coágulo Campo c/ Ac. 3N & 3,2 & \\
\hline Tratamento Estocagem & & 65 \\
\hline BN_Coág. Natural-7dias & 4,4 & 71 \\
BN_Coág. Natural-14 dias & 4,1 & 56 \\
BN_Coág. Natural-30 dias & 3,2 & 75 \\
BN_Coág. Natural-60 dias & 4,7 & \\
\hline
\end{tabular}

A Figura 52 mostra a correlação obtida para os valores de $\mathrm{P}_{0}$ e E' $25{ }^{\circ} \mathrm{C}$. Observa-se uma correlação moderada entre as duas propriedades com $r=0,53$. Estes resultados não puderam ser comparados com a literatura pois não foram encontrados artigos sobre a correlação existente entre valores de E'e plasticidade Wallace para a borracha natural.

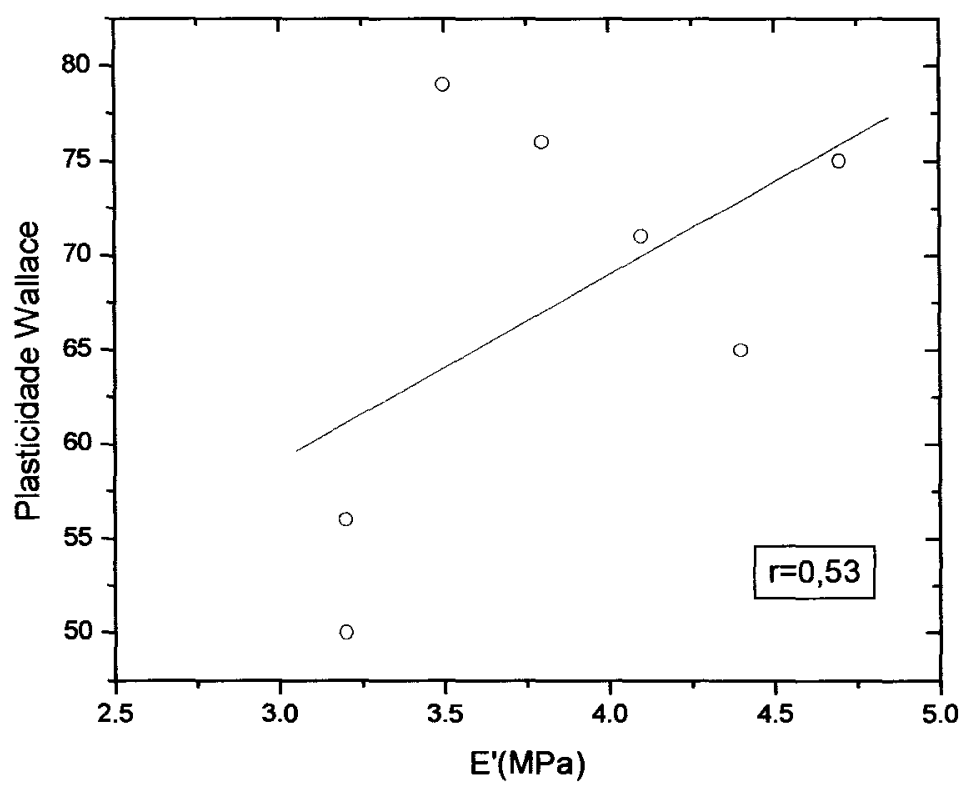

Figura 52. Relação entre os valores de $\mathrm{E}_{25}^{\prime}{ }_{\mathrm{C}}^{0}$ e $\mathrm{P}_{0}$ para as amostras de borracha submetidas a diferentes tratamentos de coagulação e estocagem. 
A baixa correlação observada entre os valores de E' obtidos via técnica de DMTA e a plasticidade Wallace pode ser explicada por um fenômeno observado por alguns autores de que amostras de borracha natural com valores idênticos de plasticidade possuem valores diferentes de massa molar ponderal média $\left(\mathrm{M}_{\mathrm{w}}\right)$ [112, 113]. A borracha natural possui diferentes distribuições de massa molar (unimodal ou bimodal) dependendo do tipo de clone e do tipo de processamento através da qual a borracha é obtida a partir do látex $[38,39]$. De acordo com Bonfils et al. $[112,113]$ a plasticidade Wallace apesar de ser um ensaio utilizado como padrão para avaliar a qualidade da borracha natural, é uma medida que está mais relacionada com a fluência do material como um todo. Segundo os autores, a microestrutura da borracha natural pode ser dividida em três partes. A primeira é a estrutura molecular que inclui a massa molar média, comprimento médio das cadeias e a distribuição dessa massa molar. A segunda parte seria a chamada macrogel que constitui a porção da borracha natural que é insolúvel em solventes. E a terceira parte, chamada de microgel corresponde a uma quantidade variável de microagregados variando de 1$15 \mu \mathrm{m}$ de diâmetro. Os autores estudaram borrachas de três clones submetidas a diferentes tipos de processamento e encontraram uma correlação moderada $(r=0,52)$ entre os valores de plasticidade e $M_{w}$. Verificou-se que amostras de borracha provenientes de clones diferentes apresentaram a mesma distribuição de massa molar, apesar dos valores de $\mathrm{P}_{0}$ variarem em 10 unidades. Por outro lado, amostras de borracha que apresentaram o mesmo valor de $\mathrm{P}_{0}$ mostraram valores de $\mathrm{Mw}$ diferentes. Uma baixa correlação entre $P_{0}$ e $M_{w}$ também foi observada por Nair [96] em estudo onde 12 clones de borracha natural foram investigados. Nestes três trabalhos $[96,112,113]$ os autores sugerem que o ensaio de plasticidade é pouco sensível a alterações da microestrutura da borracha e está relacionado com a propriedade de uma massa polimérica como um todo. Portanto, fatores importantes como a distribuição da massa molecular, a quantidade de micro-gel e ramificações da cadeia, que variam muito em função do tipo de clone e do processamento, e afetam o comportamento dinâmico-mecânico da borracha, não são evidentes nos ensaios de plasticidade.

Quando comparamos os valores de E' e plasticidade, obtidos no presente trabalho, a baixa correlação obtida entre essas duas propriedades pode ser justificada pelo fato da plasticidade não ser uma medida sensível a variações de massa molar 
entre outras características da microestrutura da borracha. $\mathrm{O}$ ensaio de DMTA por outro lado é bastante sensível a fatores como \% de gel, formação de cadeias adjacentes à cadeia isoprênica e a distribuição de massa molar (MWD). Como geralmente para a borracha natural a distribuição da massa molar é bimodal, um aumento na fração de menor massa molar pode funcionar como um plastificante interno $[112,113]$, facilitando o deslizamento das cadeias poliméricas e diminuindo

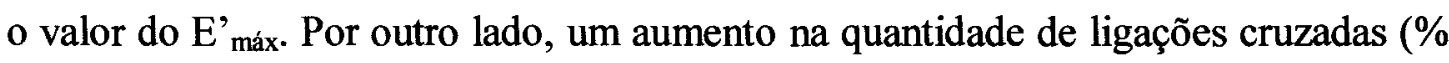
de gel e microgel) e nas ramificações de cadeia propiciaram um impedimento ao movimento de desenovelamento das cadeias poliméricas, favorecendo o aumento do E'.

A Figura 53 ilustra a dependência do fator amortecimento (tan $\delta$ ) com a temperatura para as borrachas do clone RRIM 600 submetidas a diferentes tratamentos. $O$ fator de amortecimento $\tan \delta$ é a razão (E'/E') entre a energia dissipada por ciclo e a energia potencial máxima armazenada durante o ciclo. Esta relação é útil na caracterização de sistemas poliméricos. Assim materiais mais rígidos irão apresentar valores de $\tan \delta$ menores em intensidade e do mesmo modo materiais mais flexíveis irão apresentar valores de $\tan \delta$ maiores [114]. No gráfico da Figura 54 os picos de $\tan \delta$ variam de $0,9-0,7$. Não se observou um comportamento claro nos valores de $\tan \delta$ em função do tipo de tratamento aos quais as amostras foram submetidas. Entre as amostras que variaram dentro do intervalo acima, a estocada por 14 dias apresentou maior valor de $\tan \delta$. Por outro lado a amostra coagulada quimicamente com ácido $6 \mathrm{~N}$ apresentou menor valor de $\tan \delta$. Mais uma vez, a variação dos constituintes não-borracha, efeito dos diferentes tipos de processamento, pode ter influenciado na observação deste comportamento. A amostra coagulada com ácido $3 \mathrm{~N}$ foi a que apresentou maior valor de $\tan \delta$ podendo ser considerada a amostra mais flexível de todas as outras. Esse fato pode ser observado na prática ao se manusear a amostra. No entanto, a perda de material ocorrida no momento da coagulação influenciou o valor de $\tan \delta$ obtido. 


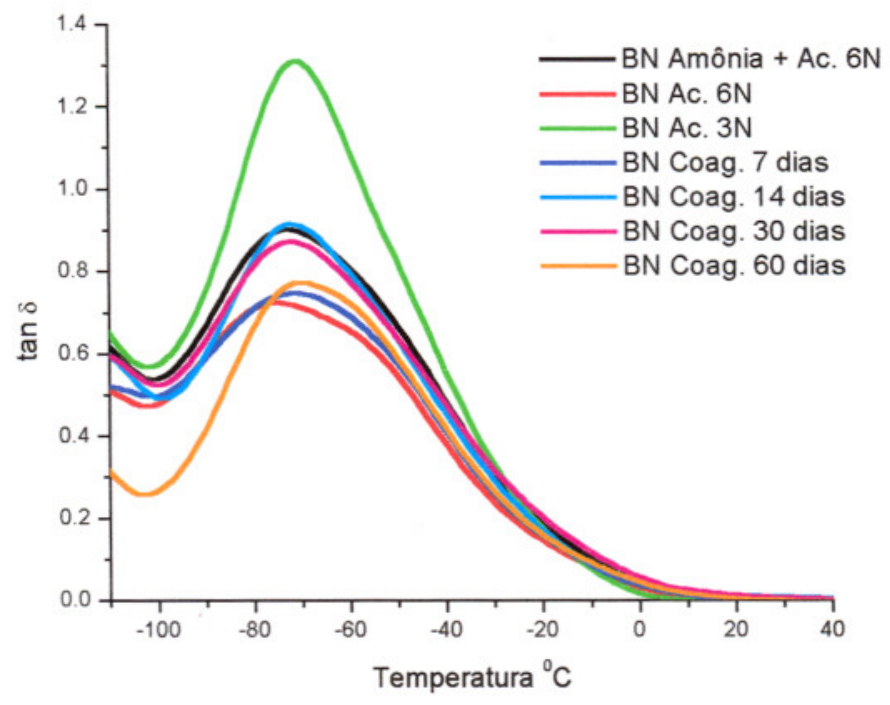

Figura 53. Curvas do fator amortecimento $(\tan \delta)$ versus temperatura para borrachas do clone RRIM 600 submetidas a diferentes tratamentos

As temperaturas de transição vítrea $\left(\mathrm{T}_{\mathrm{g}}\right)$, referentes a cada um dos diferentes tratamentos foram medidas nos pontos máximos das curvas do fator amortecimento em função da temperatura (Tabela 32). A amostra coagulada em campo com ácido $3 \mathrm{~N}$ possui o maior valor de fator de amortecimento $\tan \delta$. Valores maiores de $\tan \delta$ estão relacionados com uma maior mobilidade das cadeias poliméricas. $\mathrm{O}$ fato de a amostra ter perdido massa molar, durante o processo de coagulação, pode ter influenciado no aumento do fator de amortecimento. A amostra de borracha coagulada em campo com ácido $6 \mathrm{~N}$ apresentou menor valor de $\mathrm{T}_{\mathrm{g}}\left(-74^{\circ} \mathrm{C}\right)$, quando comparada com as outras amostras coaguladas quimicamente. A amostra coagulada com ácido $3 \mathrm{~N}$ apresentou valor de $\mathrm{T}_{\mathrm{g}}$ igual a $-71{ }^{\circ} \mathrm{C}$ e a amostra estabilizada com amônia apresentou $\mathrm{T}_{\mathrm{g}}=-73^{\circ} \mathrm{C}$. Entre as amostras coaguladas espontaneamente, os valores de $\mathrm{T}_{\mathrm{g}}$ obtidos foram $-71{ }^{\circ} \mathrm{C}$ para a amostra estocada por 7 dias, $-72{ }^{\circ} \mathrm{C}$ para a amostra estocada por 14 dias, -70 para a amostra estocada por 30 dias e $-67^{\circ} \mathrm{C}$ para a amostra estocada por 60 dias. Na literatura [111] os valores de $\mathrm{Tg}$ variam de $-74{ }^{\circ} \mathrm{C}$ até $-69{ }^{\circ} \mathrm{C}$ para a borracha natural não vulcanizada e de $-72{ }^{\circ} \mathrm{C}$ a $-61{ }^{\circ} \mathrm{C}$ para a borracha natural vulcanizada. Portanto, podemos dizer que os valores de $\mathrm{T}_{\mathrm{g}}$ obtidos nesse trabalho, via técnica de DMTA, estão dentro dos valores mostrados na literatura. A borracha estocada por um período de 60 dias apresentou valor de $\mathrm{T}_{\mathrm{g}}$ 
dentro do intervalo de valores de $\mathrm{T}_{\mathrm{g}}$ para a borracha natural vulcanizada. Isto sugere que o tempo de estocagem superior a trinta dias pode provocar um aumento de ligações cruzadas na cadeia polimérica. Apesar dos valores de $\mathrm{P}_{0}, \mathrm{~V}_{0}$ e $\mathrm{E}^{\prime}$ aumentarem em função do tempo de estocagem (Figuras 37 e 51), no geral, não houve grandes variações nos valores de $\mathrm{T}_{\mathrm{g}}$ em função do período de estocagem como mostra a Figura 54 com exceção da amostra estocada por 60 dias. Provavelmente, a quantidade de ligação cruzada, nas amostras coaguladas quimicamente e aquelas estocadas por até 30 dias, não é grande o suficiente para deslocar os valores de $T_{g}$ para temperaturas maiores.

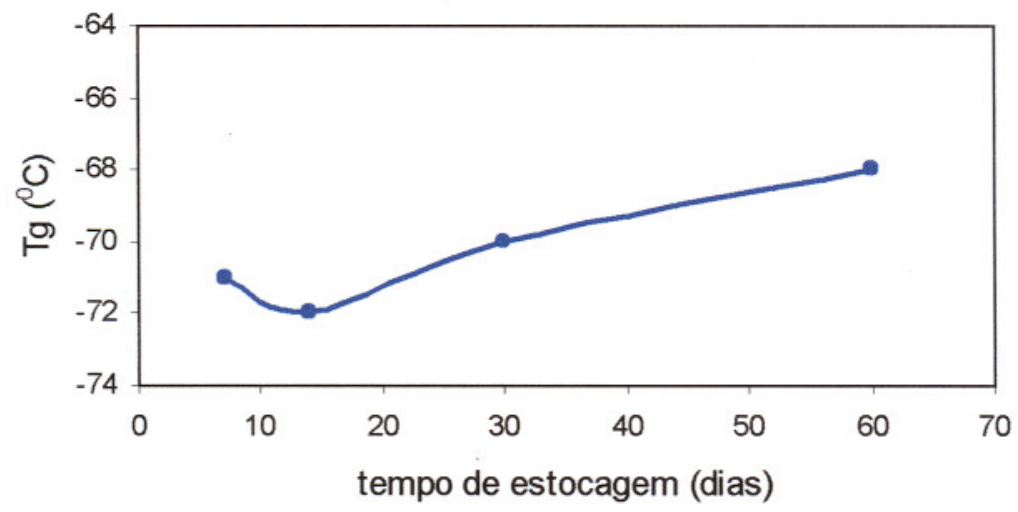

Figura 54. Variação dos valores de $\mathrm{T}_{\mathrm{g}}$ para amostras estocadas em diferentes tempos de estocagem.

Quando comparamos os valores de $\mathrm{T}_{\mathrm{g}}$ obtidos via técnica de DSC e DMTA observamos que as temperaturas de transição vítrea obtidas variam em aproximadamente $12 \%$. Isso era esperado considerando-se que a técnica de DMTA é mais sensível para a determinação de $\mathrm{T}_{\mathrm{g}}$ do que a técnica DSC [115]. Esta última técnica mede valores de $T_{g}$ através da variação de entalpia que acontece devido às transformações que a amostra sofre em função da variação de temperatura. Por outro lado, a técnica de DMTA propicia medidas mais sensíveis de transições relacionadas com as propriedades viscoelásticas do material. A Tabela 32 mostra os valores de $\mathrm{T}_{\mathrm{g}}$ obtidos via técnica de DSC e DMTA. 
Tabela 32. Valores de $\mathrm{T}_{\mathrm{g}}$ obtidos via técnica de DSC e DMTA para o clone RRIM 600 .

\begin{tabular}{ccc}
\hline AMOSTRA & $\begin{array}{c}\mathbf{T}_{\mathbf{g}}(\mathbf{C}) \\
(\mathbf{D S C})\end{array}$ & $\begin{array}{c}\left.\mathbf{T}_{\mathbf{g}} \mathbf{(}^{\circ} \mathbf{C}\right) \\
(\mathbf{D T A})\end{array}$ \\
\hline Tratamento de Coagulação & & -73 \\
\hline BN Amônia + Ac. 6N & $-63,4$ & -74 \\
BN_Coágulo Campo c/ Ac. 6N & $-63,3$ & -71 \\
BN_Coágulo Campo c/ Ac. 3N & $-63,3$ & \\
\hline Tratamento Estocagem & & -71 \\
\hline BN_Coág. Natural-7dias & $-63,5$ & -72 \\
BN_Coág. Natural-14 dias & $-63,4$ & -70 \\
BN_Coág. Natural-30 dias & $-63,8$ & -68 \\
BN_Coág. Natural-60 dias & $-63,3$ & \\
\hline
\end{tabular}

Os valores de $\mathrm{T}_{\mathrm{g}}$ obtidos através de técnica de DSC e DMTA estão de acordo com o encontrado na literatura por Dell'Antonia [116] usando também essas duas técnicas. Neste trabalho, foi estudada a influência do tipo de vulcanização nas propriedades da borracha natural de diferentes clones recomendados para o plantio no Estado de São Paulo. Para a técnica de DSC, a autora encontrou valores de $\mathrm{T}_{\mathrm{g}}$ variando de $-62,6^{\circ} \mathrm{C}$ para o clone PB 235 até $-62,0^{\circ} \mathrm{C}$ para o clone RRIM 600. Esses valores foram encontrados para a borracha não vulcanizada. Já para a técnica de DMTA os valores de $\mathrm{Tg}$ variaram de $-74,5{ }^{\circ} \mathrm{C}$ para o clone RRIM 600 até $-66,0{ }^{\circ} \mathrm{C}$ para o clone IAN 873.

Em resumo, nesta etapa do estudo foi realizada uma avaliação do efeito de tratamento de estocagem e estabilização nas propriedades da borracha natural do clone RRIM 600. Observa-se maiores valores das propriedades de viscosidade Mooney e plasticidade Wallace para as amostras coaguladas quimicamente. Entre as amostras estocadas por intervalos de 7-60 dias, observou-se que as amostras estocadas por um período maior de tempo apresentam valores maiores de plasticidade e viscosidade. Isso indica que essas borrachas são mais duras do que aquelas estocadas por um período menor de tempo. Os resultados de viscosidade e plasticidade mostraram que, em geral, as borrachas coaguladas quimicamente são 
mais duras que as borrachas coaguladas espontaneamente. Isso se dá pelo fato de que o tipo de coagulação influencia a quantidade e o tipo de substâncias não-borracha associadas às cadeias isoprênicas. A variação desses constituintes está diretamente relacionada com a \% de gel na borracha o que modifica os valores de plasticidade e viscosidade e PRI. A amostra coagulada com ácido $3 \mathrm{~N}$, representou uma exceção pois apresentou valores mais baixos de plasticidade e viscosidade e excelente valor de PRI. No entanto, nesse tipo de coagulação houve muita perda de material o que torna o método inconveniente para aplicação prática. Entre as amostras coaguladas espontaneamente, a amostra estocada por 7 dias mostrou-se com melhores propriedades (menores valores de $\mathrm{V}_{0}, \mathrm{P}_{0}$ e maiores valores de PRI) do que as demais amostras. Portanto, esse método de coagulação pode ser indicado como uma alternativa para se obter uma borracha com melhores propriedades técnicas para a indústria de beneficiamento. Os valores de PRI diminuíram com o aumento do período de estocagem o que indica menor resistência a degradação térmica. Apesar das medidas de $\mathrm{V}_{0}, \mathrm{P}_{0}$ e PRI mostrarem diferenças entre as amostras submetidas a diferentes tratamentos, tais diferenças não foram observadas nas medidas de espectroscopia na região do infravermelho, análises de DSC e TG. Essas técnicas não indicaram aumento significativo do número de ligações cruzadas ou mudanças na estrutura química do polímero para as amostras estudadas.

Observamos que, no geral, não há uma tendência clara de comportamento para os valores de módulo de elasticidade $\left(E_{\text {max }}^{\prime}\right)$. Observou-se que a amostra estocada por 60 dias possui maiores valores de $\mathrm{E}_{\text {max }}$ do que as demais amostras. $\mathrm{O}$ mesmo comportamento pôde ser observado para E' a $25^{\circ} \mathrm{C}$ (Figura 51). Mudanças nos valores de $E_{\text {max }}$ sugerem variações na massa molecular e sua distribuição. No entanto, quando relacionamos esses valores de módulo com os valores de plasticidade, observa-se uma baixa correlação $(r=0,53)$ entre essas duas propriedades. A baixa correlação observada pode ser explicada pelo fato das análises de DMTA serem mais sensíveis a pequenas alterações presentes na cadeia isoprênica como, grupos adjacentes e \% de gel, do que o ensaio de plasticidade.

No caso da necessidade de se indicar um tipo de coagulação química ou por estocagem, poderíamos indicar, com base nos resultados obtidos nesse trabalho, a coagulação espontânea do látex com períodos de estocagem não superiores a sete dias. Essas amostras apresentaram as melhores propriedades de plasticidade, 
viscosidade e PRI, de acordo com as normas da ABNT e com a literatura internacional. 


\subsection{Estudo das Propriedades nanomecânicas da borracha natural via técnica de nanoindentação}

Nesta etapa do trabalho, o objetivo foi o de avaliar as propriedades nanomecânicas da borracha natural via técnica de nanoindentação. As propriedades avaliadas foram módulo de elasticidade, dureza, força e trabalho de adesão. Para este estudo foram analisados filmes de borracha dos clones RRIM 600, PB 235, IAN 873 e GT 1.

\subsubsection{Determinação da área da ponta}

A Figura 55 mostra a imagem de microscopia eletrônica da ponta utilizada nas medidas de nanoindentação. Através desta imagem determinou-se o raio da ponta e o ângulo $\alpha$, parâmetros estes utilizados no cálculo da área. Os cálculos matemáticos para obtenção da fórmula para a determinação da área da ponta projetada na amostra foram feitos por Delphine Dean, uma matemática do grupo da Prof (a) Dr(a) Christine Ortiz. Para a obtenção da fórmula da área de contato, considerou-se a área de uma esfera inserida em um cone, na Figura 56, é apresentado um esquema da esfera dentro de um cone. Dessa forma, encontrou-se que a área da ponta A em função da altura de contato $h_{c}$ que pode ser dada pela expressão A $(h c)=2 h_{c} \tan (\alpha)^{2}$. Determinando-se $h_{c}$ pelas equações 4.4.1 e 4.4.2, de acordo com o modelo proposto por Oliver e Pharr que foi descrito anteriormente no capítulo da revisão bibliográfica, é possível encontrar a área de contato da sonda projetada na amostra. Nestas fórmulas $h_{c}$ é a distância de contato, $h_{s}$ é a porção do material que não está em contato com o indentador e $\varepsilon$ é uma valor tabelado e depende da geometria do indentador.

$$
\begin{gathered}
h_{c}=h_{\max }-h_{s} \\
h_{s}=\varepsilon \frac{P_{\max }}{S}
\end{gathered}
$$




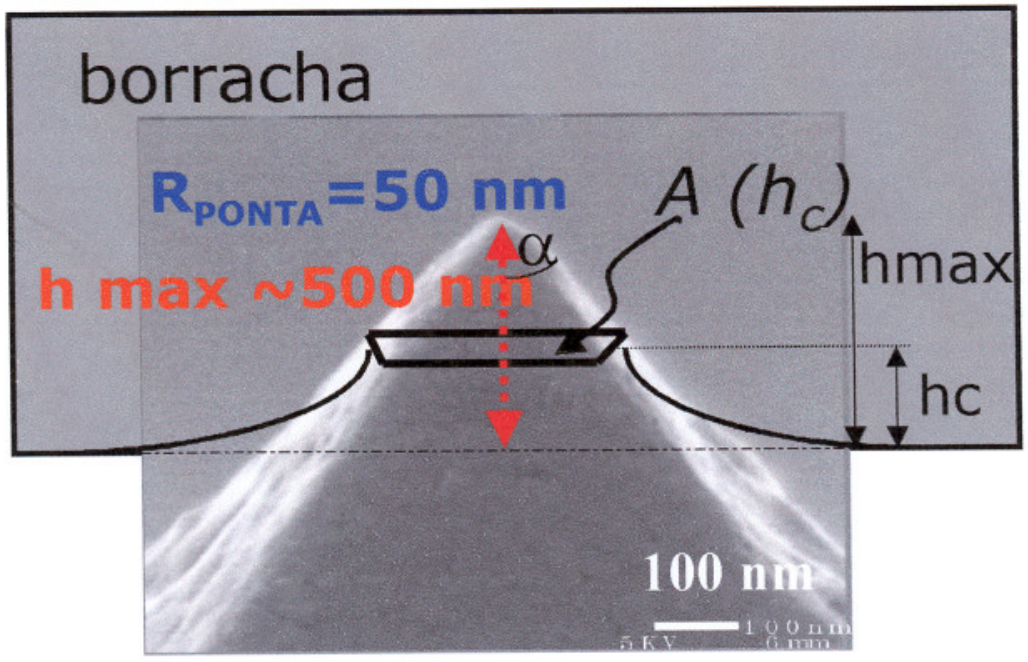

Figura 55. Imagem de MEV da sonda utilizada nas medidas de nanoindentação.

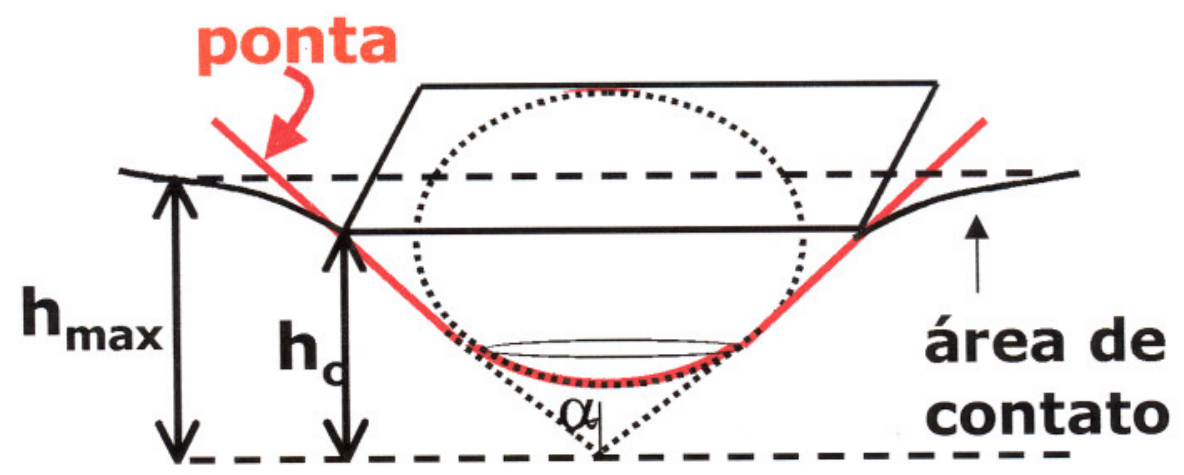

Figura 56. Desenho esquemático do modelo utilizado no cálculo da área de contato

\subsubsection{Determinação de módulo de elasticidade e dureza}

As figuras que serão discutidas a seguir são referentes às medidas feitas nos filmes de borracha do clone RRIM 600. A Figura 57 mostra um gráfico de força (nN) versus deslocamento do piezo $(\mathrm{nm})$ para uma medida de nanoindentação para o clone RRIM 600. As curvas de força versus distância de indentação para os demais clones encontram-se no ANEXO III. De acordo com a literatura [117], para transformar os valores do eixo de deslocamento do piezo, em nm, para distância de indentação devese subtrair da curva experimental uma curva teórica representativa da indentação em um substrato rígido. Essa curva pode ser obtida pela equação de uma reta do tipo $\mathrm{y}=\mathrm{mx}$, onde $\mathrm{m}$ é a constate do cantiléver. Essa subtração foi feita utilizando planilha do Excel. A curva de força versus distância de indentação para o clone RRIM 600 é mostrada na Figura 58. 


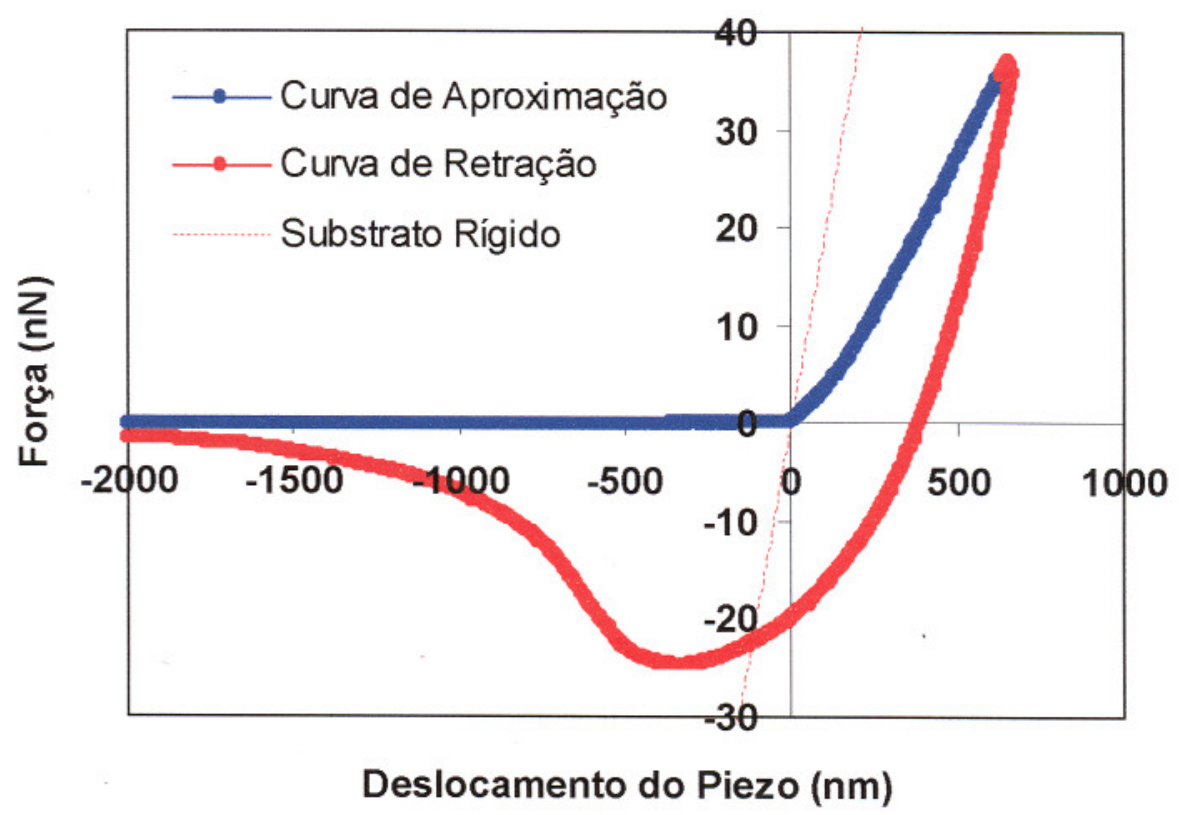

Figura 57. Gráfico de Força $(\mathrm{nN})$ versus deslocamento do piezo em $(\mathrm{nm})$ para medida de nanoindentação para clone RRIM 600.

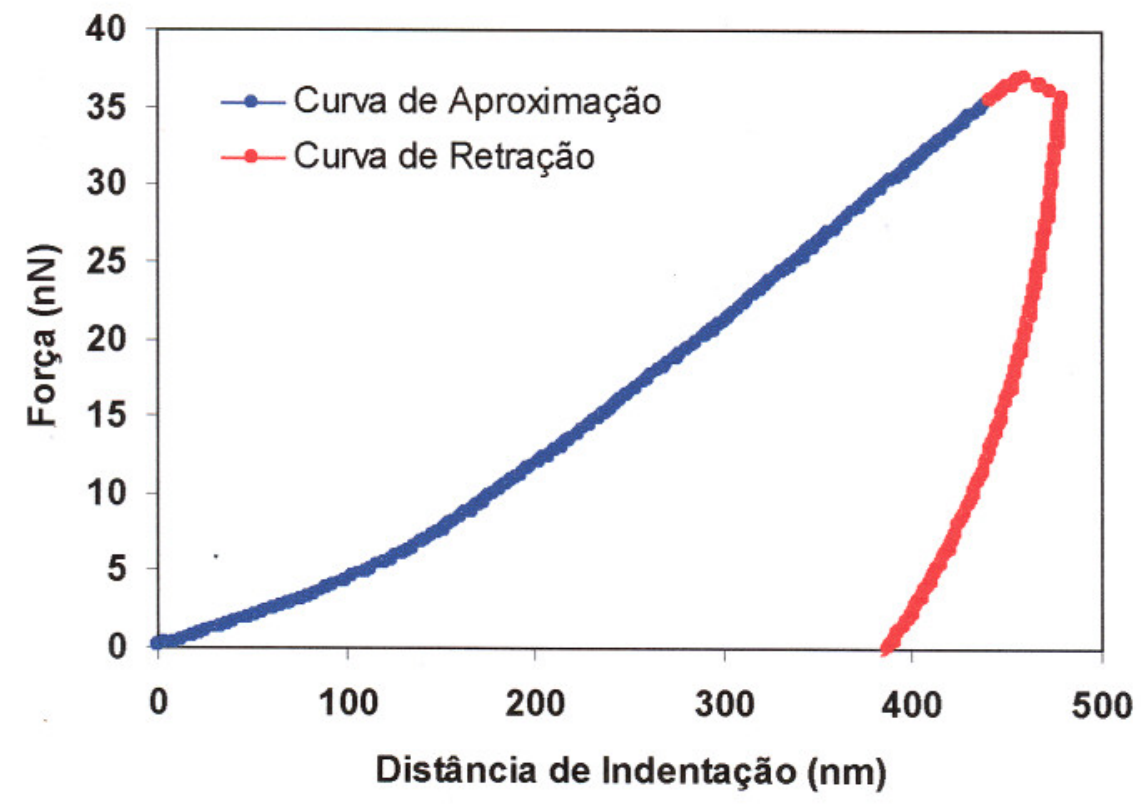

Figura 58. Gráfico de Força $(\mathrm{nN})$ versus distância de nanoindentação para medida de nanoindentação para clone RRIM 600.

Após a transformação das curvas de força $(\mathrm{nN})$ versus deslocamento do piezo em (nm) para curvas de força versus distância de indentação deve-se determinar a dureza do material. Para calcular esse parâmetro utilizou-se a metodologia de VanLandigham $[82,83]$ para ajustar os dados experimentais. O autor encontrou que 
para materiais poliméricos a melhor forma de ajustar os dados experimentais é usar a rotina "spline smooth". Neste trabalho, foi usada a rotina do "spline smooth" disponível no software da Igor Wavametrics ${ }^{\circledR}$ que realiza uma interpolação dos dados. Essa rotina ajusta uma curva nos dados experimentais através de uma interpolação de dados. Nas Figuras 59 e 60 abaixo se pode comparar as duas maneiras de ajustar os dados experimentais da curva de retração a primeira usando uma função do tipo $\mathrm{y}=\mathrm{ax}^{\mathrm{b}}$, Figura 59 e a segunda utilizando a rotina sugerida por VanLandigham [82, 83], Figura 60. Pode-se observar que na Figura 60 o ajuste da curva nos dados experimentais é mais representativo.

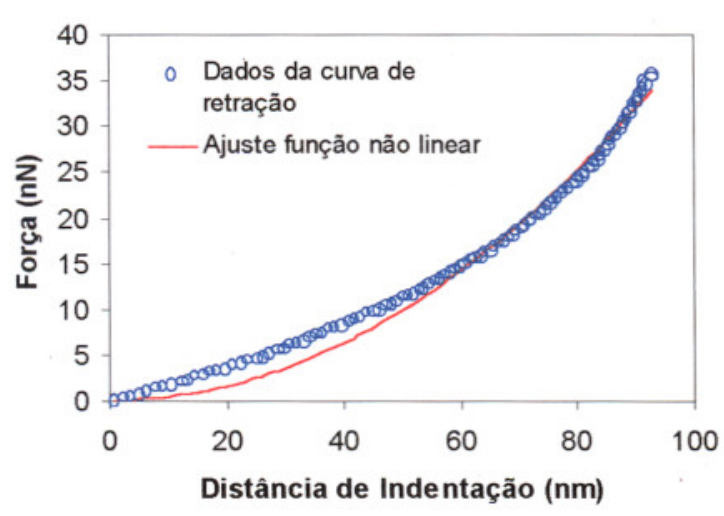

Figura 59. Ajuste dos dados experimentais Figura 60. Ajuste dos dados experimentais utilizando uma função não linear

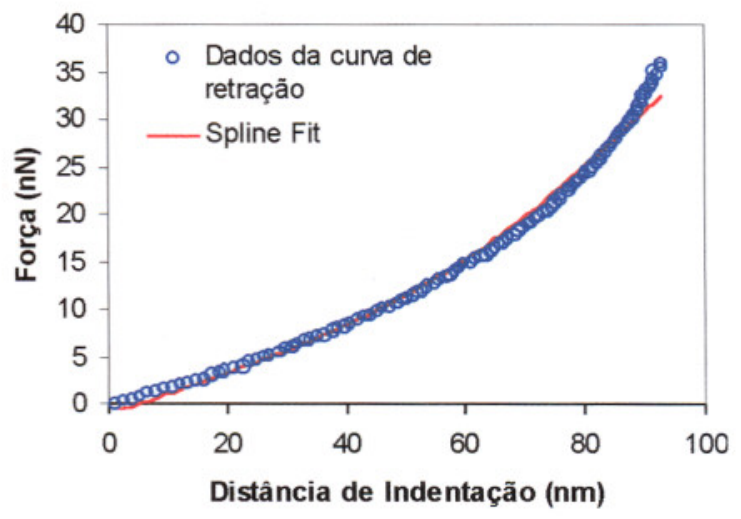

utilizando a rotina "spline smooth"

O valor da dureza pode ser determinado a partir da derivada no ponto máximo da curva ajustada nos dados experimentais. Obtendo-se o valor da dureza, o módulo elástico pode ser determinado a partir das Equações 4.4.1 e 4.4.2.

Os valores de módulo, dureza e força máxima de adesão obtidos neste estudo são mostrados na Tabela 33 . 
Tabela 33. Valores de Dureza S, módulo de Young e força de adesão máxima para diferentes clones determinados via técnica de nanoindentação.

\begin{tabular}{cccc}
\hline Clone & $\begin{array}{c}\text { Dureza } \\
(\mathrm{nN} / \mathrm{nm})\end{array}$ & $\begin{array}{c}\text { Módulo Elástico }(\mathrm{MPa}) \\
\text { RRIM 600 }\end{array}$ & $\begin{array}{c}\text { Força de máxima adesão } \\
(\mathrm{nN})\end{array}$ \\
\hline IAN 873 & $0,6 \pm 0,1$ & $1,0 \pm 0,1$ & $32,0 \pm 7,0$ \\
PB 235 & $2,1 \pm 0,3$ & $0,4 \pm 0,2$ & $32,4 \pm 7,3$ \\
GT 1 & $1,3 \pm 0,4$ & $2,4 \pm 0,2$ & $30,0 \pm 13,0$ \\
\hline
\end{tabular}

Como podemos observar nos valores mostrados na Tabela 33, o clone PB 235 possui o maior valor de dureza e módulo de elasticidade. Já o clone IAN 873 possui o menor valor de módulo. Os valores de módulo elástico variaram de 2,4-0,4 MPa. Os valores de força de adesão máxima são bastante próximos para os clones RRIM 600, IAN 873 e PB 235. O clone GT 1 apresentou maior valor de força de adesão. Os valores de módulo elástico determinados nesta etapa do trabalho via técnica de nanoindentação estão próximos dos encontrados na literatura [118]. Weisenhorm et al. [118] utilizaram a técnica de AFM para medir o módulo de elasticidade de diferentes elastômeros e outros materiais como cartilagem e células vivas. Os autores encontraram módulos variando de 0,6-2,4 MPa para amostra de borracha natural comercial. De acordo com metodologia proposta por esses autores, a curva de força versus distância de indentação, obtida experimentalmente deve ser ajustada em uma função do tipo $y=a x^{b}$. O ajuste determina o valor de $b$, o qual revela a geometria da ponta e qual a função de força versus distância de indentação deve ser utilizada no cálculo das propriedades nanomecânicas. Neste caso, os valores de b determinados a partir do ajuste da curva experimental para sete medidas de nanoindentação foram de $b=1,29 \pm 0,21$.

Para comparar os dados de módulo em nano e macroescala obtidos para os diferentes clones foram realizados ensaios em macroescala, através de ensaios de tração e DMTA. Os resultados obtidos para o ensaio de tração não serão apresentados aqui apesar de terem sido realizados, pois os valores de módulo obtidos não se mostraram confiáveis porque, no preparo das amostras para este ensaio, houve uma grande dificuldade em se obter um corpo de prova liso, homogêneo e livre de imperfeições. Esses defeitos influenciaram no ensaio afetando a medida. Além do 
mais, o ensaio de tração não se mostrou adequado para medir o módulo elástico da borracha natural crua, livre de ligações cruzadas pelo fato deste material apresentar uma alta componente viscosa e baixa elasticidade.

Os ensaios termo dinâmico-mecânico foram realizados e os resultados podem ser observados nas Figuras 61, 62, 63 e 64, as quais mostram os valores de módulo E'e $\tan \delta$ para amostras de borracha dos clones GT 1, PB 235, IAN 873 e RRIM 600.

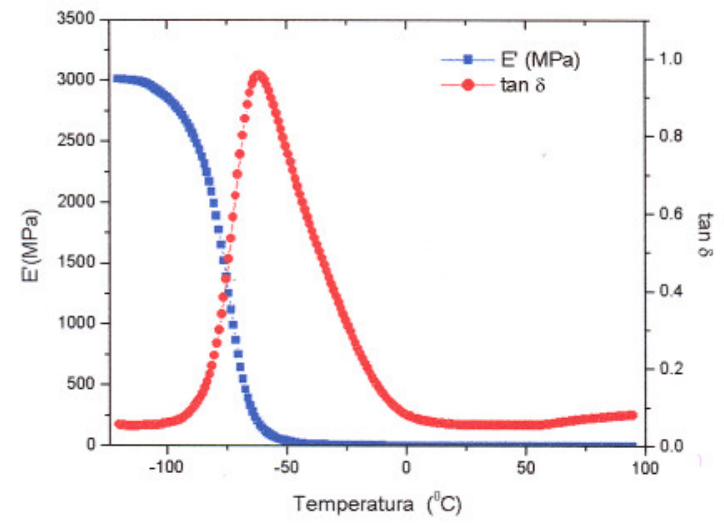

Figura 61. Curvas do E' e fator de $\tan \delta$ Figura 62. Curvas de E' e $\tan \delta$ versus versus temperatura para o clone GT 1

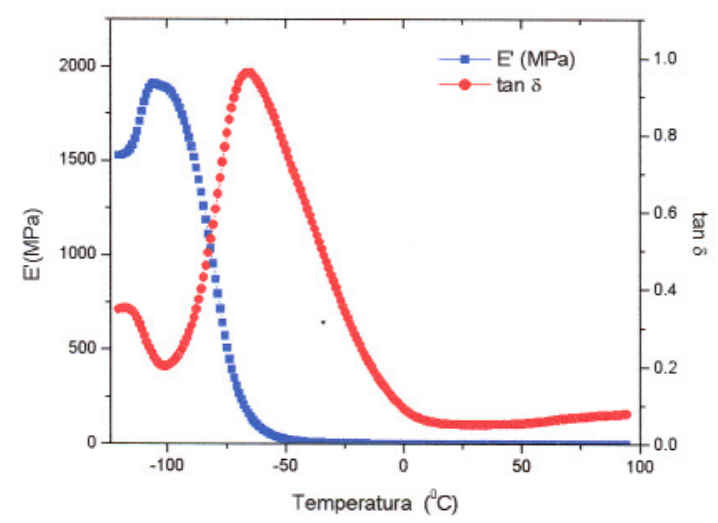

Figura 63 Curvas do $\mathrm{E}^{\prime}$ e fator de $\tan \delta$ Figura 64 Curvas do E' e fator de $\tan \delta$ versus temperatura para o clone IAN 873

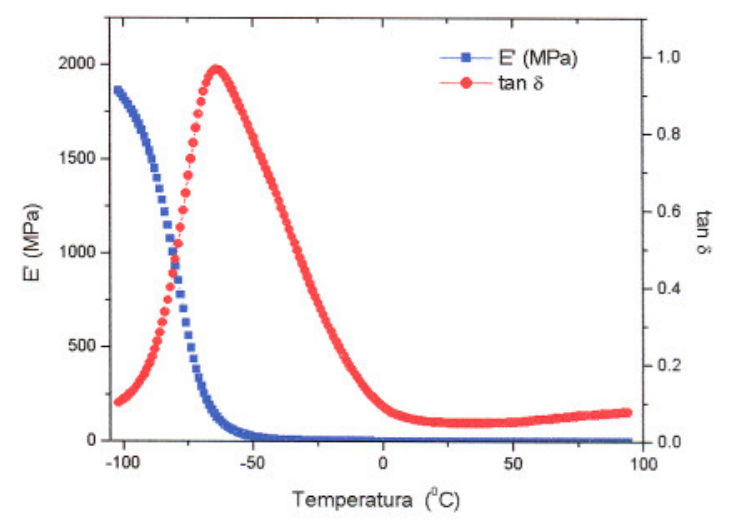
temperatura para o clone PB 235

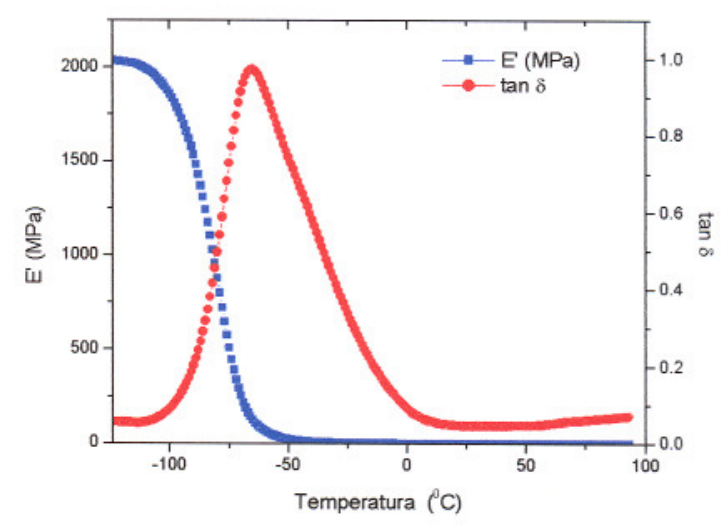
versus temperatura para o clone RRIM 600

A Tabela 34 mostra os valores de E'e tan $\delta$ retirados das curvas de ensaio de DMTA para os diferentes clones estudados. 
Tabela 34. Valores de $E_{\text {máx }}$ e temperatura de transição vítrea obtidos através de ensaio de DMTA.

\begin{tabular}{ccc}
\hline Clone & $\begin{array}{c}\text { E' }{ }_{\text {máx }} \\
(\mathbf{M P a})\end{array}$ & $\begin{array}{c}\text { Temperatura de } \\
\text { Transição Vítrea } \mathbf{T}_{\mathbf{g}}\left({ }^{\circ} \mathbf{C}\right)\end{array}$ \\
\hline RRIM 600 & 2000 & $-65,0$ \\
GT 1 & 3000 & $-62,0$ \\
IAN 873 & 1900 & $-66,0$ \\
PB 235 & 1850 & $-64,0$ \\
\hline
\end{tabular}

No geral, observa-se que não há grande variação nos valores de $E_{\text {max }}$ para os clones estudados. A exceção foi para o clone GT 1 que apresentou maior valor de E' aproximadamente $30 \%$ maior que os outros clones. Para os valores de $\mathrm{T}_{\mathrm{g}}$, obtidos no ponto máximo da curva de tan $\delta$ também não foram observadas grandes diferenças entre os clones com exceção do clone GT 1. Este ensaio também é um indicador da mobilidade das cadeias poliméricas o que é mostrado pelo deslocamento das temperaturas de transição vítrea. $O$ fato dos valores de $T_{g}$ e $E_{\text {max }}^{\prime}$ serem semelhantes para os clones estudados indica que a borracha deles não possui diferenças significativas em relação à estrutura polimérica, com exceção do clone GT 1.

A Tabela 35 mostra os valores de módulo elástico obtidos via técnica de nanoindentação e ensaio de DMTA. Os valores de módulo obtidos do ensaio de DMTA fora retirados dos gráficos da Figuras 61, 62, 63 e 64 na temperatura de 25 ${ }^{\circ} \mathrm{C}$. 
Tabela 35. Valores de módulo elástico para os diferentes clones obtidos através de técnica de nanoindentação e ensaio de DMTA.

\begin{tabular}{c|c|c}
\hline Clone & $\begin{array}{c}\text { E'(MPa) } \\
\text { nanoindentação }\end{array}$ & $\begin{array}{c}\text { E' }^{\prime 2}{ }^{\circ} \text { C (MPa) } \\
\text { DMTA }\end{array}$ \\
\hline RRIM 600 & $1,0 \pm 0,1$ & 1.8 \\
IAN 873 & $0,4 \pm 0,2$ & 2.3 \\
PB 235 & $2,4 \pm 0,2$ & 1.9 \\
GT 1 & $1,5 \pm 0,3$ & 2.3 \\
\hline
\end{tabular}

A Figura 65 mostra graficamente a comparação dos valores de módulo elástico obtidos via técnica de nanoindentação e DMTA para a borracha natural de diferentes clones estudados nesse trabalho. Como podemos observar os valores de módulo elástico obtidos via técnica de nanoindentação e DMTA estão relativamente próximos para a maioria dos clones estudados. A exceção foi para o clone IAN 873 onde os resultados de módulo obtidos através das duas técnicas foram mais distantes.

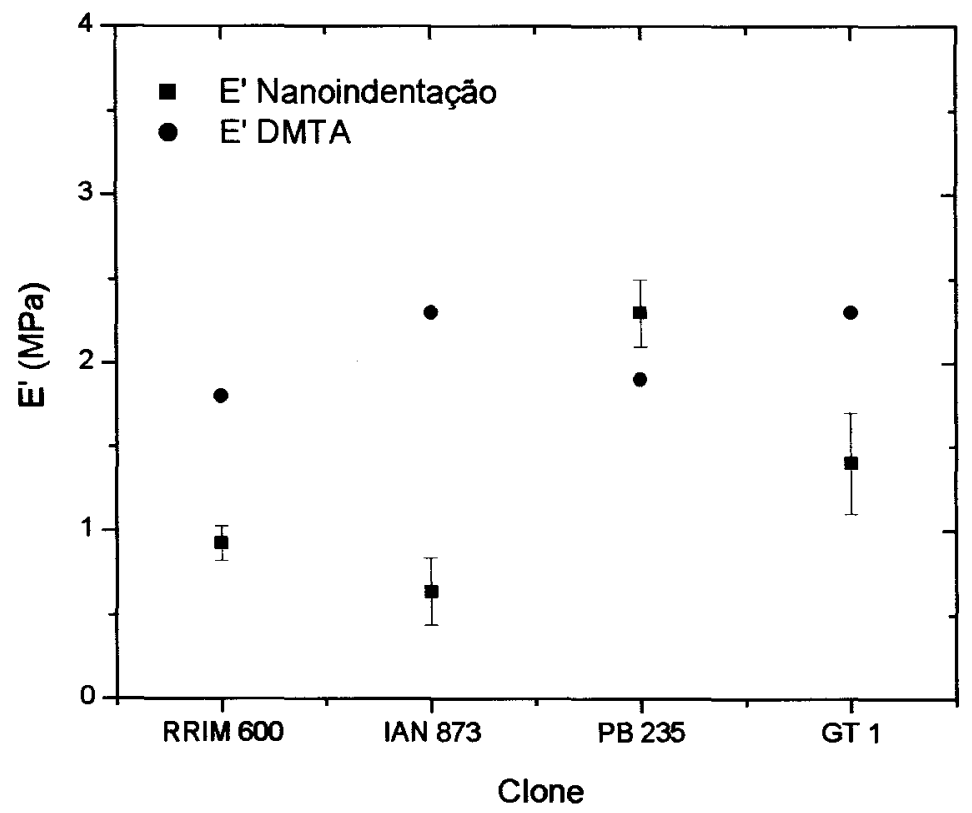

Figura 65. Valores de módulo elástico obtidos via técnica de nanoindentação e DMTA. 
Eby et al. [119] usaram a técnica de nanoindentação para avaliar o módulo elástico de elastômeros sintéticos com diferentes graus de ligação cruzada. Eles encontraram que os valores de módulo obtidos via técnica de nanoindentação possuem uma relação linear com os valores de módulo obtidos através do ensaio de DMTA. No presente, trabalho, apesar de não ter sido encontrada uma relação linear entre os módulos obtidos através da técnica de nanoindentação e DMTA pode se observar na Figura 65 que os valores são relativamente próximos entre si. Uma das causas da não linearidade é o fato do filme de borracha natural utilizado não ser totalmente homogêneo. A borracha estudada neste trabalho, apesar de não possuir ligações cruzadas pela adição de enxofre ou outros aditivos, possui ligações cruzadas de ordem física devido ao emaranhamento das cadeias. Além do mais, a borracha natural possui grupos adjacentes à cadeia polimérica que podem reagir com aminoácidos, presentes na borracha, formando ligações entre as cadeias poliméricas [46-48]. Esses fatores, que são característicos da borracha natural, dificultam a dissolução total do polímero em solventes apolares e a solução final apresenta pequenos pontos insolúveis. Esses fatores influenciaram na homogeneidade do filme o que pode justificar o fato de não ter sido observada linearidade entre valores de módulo obtidos via nanoindentação e DMTA. A heterogeneidade do filme pode também ter sido a causa da variação dos altos desvios padrões obtidos no ensaio em nanoescala.

O fato de a borracha natural possuir sítios chamados de microgel e macrogel é um fator que deve ser considerado em análises de nanoindentação onde pequenas áreas (na ordem de centena de nanometros quadrados) são estudadas. Enquanto o macrogel é responsável pelo endurecimento na estocagem da borracha, a formação do microgel no látex afeta a viscosidade do látex e consequentemente da borracha. $\mathrm{O}$ macrogel é formado na borracha seca sob estocagem, já o microgel é formado no látex presente nos vasos laticíferos da seringueira [36] e é iniciado pela condensação de grupos aldeído variando entre 100 e 420 unidades por molécula de poliisopreno. Dando-se seqüência à comparação dos resultados obtidos via técnica de nanoindentação com os de DMTA, nota-se que os testes feitos em nano escala apresentam maiores variações no valor de módulo entre os clones do que os testes feitos em macroescala. $O$ conteúdo de macro e micro gel no filme de borracha pode ter influenciado essa diferença. 


\subsubsection{Trabalho de Adesão ( $\left.W_{\text {ads }}\right)$}

Os valores de $\mathrm{W}_{\text {ads }}$ foram obtidos calculando-se primeiramente a energia de adesão $\mathrm{U}_{\mathrm{E}}=\int \mathrm{Pd} h$ e dividindo-se esse valor pela área de contato no ponto máximo. A área entre as curvas de aproximação e retração obtidas via técnica de nanoindentação foi calculada utilizando-se o programa Microcal Origin 6.0 e representa o valor de $\mathrm{U}_{\mathrm{E}}$. A área de contato máxima foi calculada segundo metodologia apresentada no item 4.1.1. (Determinação da área da ponta utilizada). A Tabela 36 mostra os valores de trabalho de adesão para os diferentes clones estudados.

Tabela 36. Valores de trabalho de adesão para diferentes clones estudados via técnica de nanoindentação.

\begin{tabular}{cc}
\hline Clones & $\mathbf{W}_{\text {ads }}\left(\mathbf{J} / \mathbf{m}^{2}\right)$ \\
\hline RRIM 600 & $0,15 \pm 0,06$ \\
IAN 873 & $0,05 \pm 0,01$ \\
PB 235 & $0,07 \pm 0,02$ \\
GT 1 & $0,07 \pm 0,01$ \\
\hline
\end{tabular}

Como pode se observar, os valores de energia de adesão encontrados para os clones IAN 873, PB 235 e GT 1 estão bastantes próximos uns dos outros. A exceção foi para o clone RRIM 600 que apresentou valor de $\mathrm{W}_{\mathrm{ads}}$ duas a três vezes maior do que os demais clones. $O$ valor representa a média das medidas feitas em quatro lugares diferentes do filme de borracha depositado em lâmina de vidro. Os resultados sugerem que para aplicações na área de adesivos, ou que precisem de maior aderência, a borracha natural do clone RRIM 600 é a mais indicada. Não foram encontrados na literatura valores de energia de adesão para borracha natural determinados a partir de medidas de nanoindentação. Paiva et al. [85, 86] determinaram o módulo de Young e o $\mathrm{W}_{\text {ads }}$ para o poliisopreno sintetizado em laboratório através de polimerização iônica e com massa molar $M_{w}$ em torno de $210.000 \mathrm{~g} / \mathrm{mol}$. $O$ valor de trabalho de adesão $W_{\text {ads }}$ reportado neste trabalho para 0 poli-isopreno em ar foi igual a $7 \mathrm{~J} / \mathrm{m}^{2}$ Comparando-se o valor de trabalho de adesão de $7 \mathrm{~J} / \mathrm{m}^{2}$ com o obtido para a borracha natural que variou de $0,15-0,05 \mathrm{~J} / \mathrm{m}^{2}$ 
observamos que os valores obtidos no presente trabalho estão muito abaixo dos valores reportados na literatura. $O$ fato dos testes de nanoindentação em borracha natural terem sido feitos em água, pode ter feito com que os valores de trabalho de adesão obtidos fossem bem menores quando comparados com aqueles reportados na literatura. De acordo com Shull et al. [84], medidas de adesão realizadas em meio líquido podem reduzir o trabalho de adesão para zero. Em estudos de biocompatibilidade, o fato de adicionar um polímero solúvel em meio aquoso na superfície a ser analisada faz com o trabalho de adesão, entre essa superficie e a proteína ou bactéria em estudo, seja reduzido. No caso da borracha natural, o fato do material conter constituintes não-borracha, os quais são solúveis em água, pode ter contribuído para que os valores de trabalho de adesão obtidos em meio líquido fossem tão baixos.

Em resumo, neste capítulo, foi realizado um estudo de nanoindentação em filmes de borracha natural para determinação das propriedades como módulo de elasticidade, dureza e trabalho de adesão da borracha natural. A metodologia proposta por Oliver e Pharr $[80,81]$ e VanLadingham $[82,83]$ foi pela primeira vez aplicada para estudo de propriedades da borracha natural em nanoescala. Os valores de módulo elasticidade determinados via técnica de nanoindentação estão próximos dos encontrados na literatura [118] para a borracha natural. Quando se comparam os resultados obtidos através das medidas feitas em escala macroscópica e em nanoescala observa-se que os obtidos via técnica de nanoindentação variam mais em função dos clones do que aqueles obtidos em macroescala. A heterogeneidade do filme associada ao fato de que a técnica de nanoindentação avalia pequenas áreas pode ter enfatizado essas diferenças. As medidas de energia de adesão mostraram que não há diferenças significativas entre a borracha obtida dos clones PB 235, GT 1 e IAN 873 com exceção do clone RRIM 600, que apresentam os maiores valores de adesão. 


\section{CONCLUSÕES}

Neste trabalho foram avaliadas as variações intra e interclonais, a influência do tipo de porta-enxerto e o efeito do tipo de coagulação e período de estocagem nas propriedades da borracha natural. Além disso, foi investigada a utilização da técnica de nanoindentação para o estudo das propriedades da borracha natural em nanoescala. Abaixo são apresentadas as principais conclusões destes estudos.

No estudo da variação intraclonal das propriedades da borracha natural observou-se que um mesmo clone plantado em blocos distintos de uma mesma plantação não apresenta diferenças significativas entre as suas propriedades. Já o estudo da variação interclonal mostrou que existem diferenças altamente significativas entre as borrachas dos clones para todas as propriedades estudadas. Quando na usina beneficiadora, a borracha de diferentes clones é misturada, a diferença interclonal pode afetar a uniformidade da borracha natural, sendo portanto, esse um fator que deve ser considerado com cuidado na elaboração de blendas de diferentes clones.

Fazendo-se uma avaliação da qualidade da borracha natural a partir dos resultados obtidos observou-se que no geral, os valores de \% de nitrogênio, extrato acetônico e PRI estão abaixo dos valores reportados na literatura [92], o que indica que a borracha desses clones pode apresentar baixa resistência à degradação térmica. As borrachas dos clones estudados nesse trabalho apresentaram altos valores de viscosidade e plasticidade, quando comparadas com os dados da literatura e, portanto, podem ser classificadas como duras. No entanto, quando os valores de \% de DRC, \% de nitrogênio, \% de EA, viscosidade Mooney, plasticidade Wallace e PRI foram comparados com os valores estipulados pela normas nacionais, observouse que as borrachas estudadas no presente trabalho estão dentro das normas da ABNT.

No estudo do efeito dos tratamentos de estocagem e coagulação, os resultados mostraram que a coagulação química do látex resulta em borrachas com altos valores de plasticidade e viscosidade. Portanto, as amostras coaguladas com adição de ácido acético $6 \mathrm{~N}$, com ou sem adição de amônia, podem ser consideradas duras. Borrachas 
com valores de plasticidade muito altos gastam mais energia e tempo no processamento. Já para as amostras coaguladas espontaneamente e estocadas por períodos de 7-60 dias, observou-se que elas tornam-se mais duras com o aumento do período de estocagem. A resistência à degradação térmica também diminuiu com aumento do tempo de estocagem, como mostram os resultados das análises de PRI. Esses resultados sugerem que a coagulação espontânea do látex, com períodos de estocagem não superiores a sete dias, podem ser indicados como um bom método de coagulação, para se obter borracha com valores mais baixos de viscosidade e plasticidade e bons valores de PRI.

No geral, não foi observada uma tendência clara de comportamento para os valores de módulo de elasticidade $\left(\mathrm{E}_{\max }^{\prime}\right)$ entre as borrachas submetidas a diferentes tipos de tratamento. A amostra estocada por 60 dias apresentou maiores valores de $E_{\text {max }}$ do que as demais amostras. Quando correlacionamos os valores de módulo a 25 ${ }^{\circ} \mathrm{C}$ com os valores de plasticidade, observou-se uma baixa correlação $(r=0,53)$ entre essas duas propriedades. A baixa correlação observada pode ser explicada pelo fato das análises de DMTA serem mais sensíveis a pequenas alterações presentes na cadeia isoprênica como, grupos adjacentes e \% de gel, do que o ensaio de plasticidade.

No estudo das propriedades nanomecânicas da borracha natural de diferentes clones a técnica de nanoindentação foi utilizada para se obter propriedades como módulo de elasticidade, dureza e trabalho de adesão a partir de curvas de força $(\mathrm{nN})$ versus distância de indentação (nm). A metodologia proposta por Oliver e Pharr [80, 81] e VanLadingham $[82,83]$ foi pela primeira vez aplicada para estudo de propriedades da borracha natural em nanoescala. Os valores de módulo elástico obtidos estão próximos dos valores citados na literatura para amostras de borracha comercial. Os valores de módulo obtidos via técnica de nanoindentação foram comparados com aqueles obtidos através de ensaios de DMTA e observou-se que no geral, estes valores são próximos. Essa técnica recente permite estudar as propriedades da borracha natural em escala nanométrica e tem o potencial de produzir resultados inovadores que permitirão ajudar na compreensão da cadeia polimérica. No entanto, o fato de a borracha natural possuir sítios chamados de microgel e macrogel que dificultam a dissolução da borracha em solvente e 
consequentemente a obtenção de filmes homogêneos, deve ser considerado nas análises de nanoindentação. Como mostraram os resultados obtidos nessa etapa do trabalho os valores de módulo e dureza apresentaram um grande desvio padrão e o fato do filme não ser completamente homogêneo pode ter influenciado os resultados. Dessa forma podemos concluir que, apesar dos resultados obtidos, a técnica de nanoindentação, aplicada ao estudo da borracha natural, deve ser aperfeiçoada em trabalhos futuros.

De uma forma geral, o trabalho desenvolvido nesta tese de doutorado apresenta resultados inéditos de um estudo sistemático sobre a variação das propriedades da borracha natural dentro de um mesmo clone, em função do tipo de clone e porta-enxerto. Os resultados mostraram que as propriedades da borracha natural são uniformes dentro de um mesmo clone mas, verificou-se que existem diferenças altamente significativas entre as borrachas dos clones estudados para todas as propriedades. $\mathrm{O}$ estudo da interação clone versus porta-enxerto mostrou que, no geral, as propriedades da borracha são uniformes independentemente do portaenxerto utilizado. Também foi feita uma avaliação de como o tipo de coagulação e estocagem afeta as propriedades da borracha natural. Além disso, foi utilizada e avaliada, pela primeira vez, uma nova técnica para estudar as propriedades da borracha natural em escala nanométrica.

Esse trabalho dá continuidade a um estudo que vem sendo feito pela Embrapa em colaboração com o IAC, de avaliação dos aspectos agronômicos da seringueira e das propriedades da borracha por elas produzida. Portanto, ele vem a contribuir com mais uma etapa dessa colaboração, que tem o objetivo de melhorar a qualidade da borracha no Estado de São Paulo. 


\section{REFERÊNCIAS BIBLIOGRÁFICAS}

[1] SEMEGEN, S.T. Natural Rubber. In: MORTON, M. Rubber Technology. 2. ed. Florida, R.E. Krieger Publ., 1978. p.152-177.

[2] IRRDB http://www.irrdb.org Acesso em:16/01/2001.

[3] SCHUH, T., GAYER, U. Automotive applications of natural fiber composites. Benefits for the environment and competitiveness with man-made materials. In LEÃO, A.L.; CARVALHO, F.X., FROLLINI, E. Lignocellulosic-Plastics Composites. São Paulo, UNESP/USP 1997. p. 181-195.

[4] GHELER, J., ROCHA, E., Aproveitamento de resíduos gerados na aglomeração da fibra de coco com látex natural In: Congresso Brasileiro de Tecnologia da Borracha São Paulo, 8 novembro 1999, Associação Brasileira de Tecnologia da Borracha, 1CD

[5] DAVIS W. O Pesadelo da Borracha. O Estado de São Paulo, São Paulo, 17 ago, 1997. p. B10.

[6] OLIVEIRA, L. C. S., GONÇALVES, P. de S., ARRUDA, E. J., COSTA, R. B., DELBEN, A. Evaluation of latex from five Hevea clones grown in São Paulo State, Brazil. Thermochimica Acta, v.398, p.259 - 263, 2003.

[7] GONÇALVES, P. de S., MARTINS, A. L. M., FURTADO, E. L., SAMBUGARO, R., OTTATTI, E. L., ORTOLANI, A. A., GODOY JUNIOR, G. Desempenho de clones de seringueira da série IAc 300 na região do planalto de São Paulo. Pesquisa Agropecuária Brasileira, v.37, n.2, p.113 - 138, 2002.

[8] GONÇALVES, P. de S., BORTOLETTO, N., ORTOLANI, A. A., BELETTI, G. O., SANTOS, W. R. Desempenho de novos clones de seringueira III. Seleções promissoras para região de Votuporanga Estado de São Paulo.. Pesquisa Agropecuária Brasileira., v.34, n.7, p.971 - 980, 1999.

[9] FERREIRA, M; MORENO, R. B.; GONÇALVES, P. S.; MATTOSO, L. H. C. Evaluation of natural rubber from clones of Hevea brasiliensis. Rubber Chemistry and Technology., v. 75, n. 1, p. 171.2002.

[10] MEDEIROS, E. S de, MORENO, R. M. B., FERREIRA, F., ALVES, N., JOB, A., GONÇALVES, P. S., MATTOSO, L. H. C., Thermogravimetric Studies of the Decomposition Kinetics of four differents Hevea rubber clones using Ozawa's Approach. Progress In Rubber Plastics And Recycling Technology, v.19, n.4, 2003.

[11] MORENO, R. M. B.; FERREIRA, M.; GONÇALVES, P. S.; MATTOSO, L. H. C. Avaliação da borracha natural crua de alguns clones de seringueira recomendados para plantio no Estado de São Paulo. Pesquisa Agropecuária Brasileira, v.38, n. 5, p.583-590, 2002. 
[12] FERREIRA, M., Caracterização do látex e da borracha natural de seringais de Presidente Prudente/SP. São Carlos, 1999. Dissertação (Mestrado) - IQSCUniversidade de São Paulo.

[13] JACOB J. L.; PRÉVÔT J. C.; LACROTTE R.; CLÉMENT A.; SERRES E.; GOHET E. Typologie clonale du fonctionnement des laticifères chez Hevea brasiliensis. Plantations, recherche développement, v.2, n.5, p.43-49, 1995.

[14] ESCHBACH. J.M; ROUSSEL.D; VAN DE SYPE. H; JACOB.J.L; d'AUZAC,J. Relationships Between Yield and Clonal Physiological Characteristics of Latex from Hevea brasiliensis. Phisiology Végétale, v.22, n.3,p. 295-304, 1984.

[15] MORENO, M. B. R., Avaliação e monitoramento das propriedades do látex e da borracha natural de clones de seringueira recomendados para o plantio no planalto do Estado de São Paulo. São Carlos 2002. Tese (Doutorado), DEMA-Universidade Federal de São Carlos.

[16] FRANTA. I. Elastomers and Rubber Compounding Materials. New YorK: Elsevier, 1989. $607 \mathrm{p}$.

[17] ENCYCLOPEDIA of Polymer Science and Engineering. New York. John Wiley, 1987. v. 8, p. 647-676.

[18] DEAN, W., A Luta pela borracha no Brasil: um estudo de história ecológica São Paulo: Nobel, 1989.

[19] GONÇALVES, P. de S.A seringueira no Estado de São Paulo. O Agronômico, v.54, n.01, p.06 - 14, 2002.

[20] ERENO, D., Curativo de Borracha. Revista Fapesp, Junho 2003.

[21] BURGER, K; SMIT,H.P. The Natural rubber Market. Review, analysis, policies and outlook. Cambridge, Woodhhead Publishing Limited, 1997. 279p.

[22] International Rubber Study Group-IRSG Rubber Statistical Bulletin, v. 56, n.8, p. 9-18, 2002.

[23] LIMA, A., SCOLESE, E., Pneu de Xapuri ajuda a preservar a floresta. Folha de São Paulo, São Paulo, 12 de dezembro, p. F 1, 2000.

[24]. ROMERO, S., Ensaios de um novo "ciclo de borracha" Gazeta Mercantil, São Paulo, 13 de dez, 2000, Relatório.

[25] Implantação da produção de borracha do tipo FDL nas comunidades de carvão e foz do Mazagão no Estado do Amapá, In: Portifólio ano 2000 Ciência e Tecnologia para o desenvolvimento sustentável do Amapá. Local: Amapá. Secretária de Estado da Ciência e Tecnologia, 2000, p. 40, p. 97. 
[26] ESTEVES, B.,L Mais qualidade para a borracha da Amazônia. Ciência Hoje, v.23, n.138, maio, 1998.

[27] SHULTES, R.E. The Odyssey of the cultivated rubber tree. Endeavour, v.1, n. $3 / 4$, p.133-138, 1977.

[28] WISNIEWSKI. A. Látex e borracha. Belém, Faculdade de Ciências Agrarias do Pará, 1983. 171p, (Informe Técnico 4).

[29] ARCHER B.L; AUDLEY B. G; McSWEENEY G. P; HONG T. C. J. Studies on composition of latex serum and "bottom fraction" particles. Rubber Research Institute of. Malaysia, v.21, n. 4, 1969, p.560.

[30] TATA S. J. Distribution of proteins between the fractions of Hevea látex separated by ultracentrifugation. Journal Rubber Research Institute of Malaysia, Kuala Lumpur, v.28, n.2, p.77-85, 1980.

[31] COMPAGNON P. Le Caoutchouc Naturel - Biologie-Culture-Production (Techniques Agricoles et Productions Tropicales), Paris, G.-P. Maisonneuve \& Larose, 1986. (série, v.35), p.77.

[32] d'AUZAC, J., PRÉVÔT, J. C., JACOB, J.L., What's new about lutoids? A vacuolar system mode from Hevea latex, Plant Physiology Biochemistry. v.33, n. 6, p.765-777, 1995.

[33] JEAN D'AUZAC; JEAN LOUIS JACOB; HERVÉ CHRESTIN. Phisiology of Rubber Tree Latex. Boca Raton, CRC Press, 1989. 469p

[34] OTHMAN, A.B; HEPBURN.C; HASMA, H. Influence of non-rubber constituents on elastic properties of natural rubber vulcanizates. Plastics, Rubber and Composites Processing and Applications, v.19, p.185-194, 1993.

[35] GAN, S.N.; TING, K.F.; Effect of treating latex with some metal ions on storage hardening of natural rubber. Polymer, v.34, n.10, p.2142-2147, 1993.

[36] SETHURAJ, M. R.; MATHEW, N. M. Natural rubber: biology, cultivation and technology. Amsterdam: ELSEVIER, 1992, 609p.

[37] DICK, J.S., HARMON, C.,VARE, A., Quality assurance of natural rubber using the rubber process analyser. Polymer Testing, v.18, p. 327-362, 1999.

[38] SUBRAMANIAN, A., Molecular weight and other properties of natural rubber: a study of clonal variation IN: International Rubber Conference., Proceedings Kuala Lumpur, Rubber Research Institute of Malaysia v. 4, p.78-85, 1975.

[39] YIP, E., SUBRAMANIAN, A - Characterization of variability in properties of clonal latex concentrates and rubbers - Jounal of Rubber Research Institute of Malaysia, v.32, n.1, p. 347-368, 1985. 
[40] AGNELLI,J.A.M.; CANEVAROLO, S.V. Físico química de polímeros. São Carlos, UFSCar Dema, 1997. p. 30 /Notas de Aula/.

[41] GONÇALVES, P. S., CARDOSO M., BOAVENTURA M.A M., COLOMBO C.A e ORTOLANI A. A. Clones de Hevea: influência dos fatores ambientais na produção e recomendação para o plantio. Campinas, Instituto Agronômico (IAC), 32p., (Boletim técnico, 138), 1992.

[42] GONÇALVES, P.S.; BATAGLIA,O C.; ORTOLANI, A A., FONSECA, F. S. Manual de heveicultura para o Estado de São Paulo. Campinas, Instituto Agronômico de Campinas, Abril de 1998, 59p.

[43] MANUAL CATI A cultura da seringueira para o Estado de São Paulo (CATI) Coordenadoria de Assistência Técnica Integrada, Campinas, n.72, Junho $1999,90 \mathrm{p}$.

[44] MARTINS, A. M. L. RAMOS, N. P., GONÇALVES, P. S., SCOTT DO VAL, $\mathrm{K}$., Influência de porta-enxertos no crescimento de clones de seringueira no Estado de São Paulo. Pesquisa Agropecuária Brasileira, v. 35, n. 9, p. 1743, 2000.

[45] GONÇALVES, P.S., MARTINS, A. M. L; GORGULHO, E. P., BORTOLETTO, N., BERMOND, G., Avaliação do vigor de seis diferentes populações de porta-enxertos de seringueira. Pesquisa Agropecuária Brasileira, v. 29 , n. 4 , p. 443 , abril, 1994.

[46] SEKHAR, B. C., Degradation and crosslinking of polyisoprene in Hevea brasiliensis Latex during processing and storage, Journal of Polymer Science, v.48, p. 133-137, 1960.

[47] SEKHAR, B. C., Inhibition of hardenig in natural rubber. In: NATURAL. RUBBER. CONFERENCE, Kuala Lumpur, 1960. Proceedings. Kuala Lumpur, s.ed., p. 512-519, 1960.

[48] GAN, S., N., Storage Hardening of natural rubber. Journal of Macromolecular Science - Pure Applied Chemistry., v.A 33, n.12, p. 1939-1948, 1996.

[49] ROY, S., GUPTA, B. R., MAITI, B.R., Effect of acid concentration and other reaction parameters on epoxidation of natural rubber latex. Industrial Engineering Chemistry Research. v.30, p.2573-2576, 1991.

[50] ENG, A. H., et al. Epoxide groups in natural rubber. I. ${ }^{13} \mathrm{C}-\mathrm{NMR}$ Study of Oxidative degraded rubbers. Journal of Rubber Research, v. 1, n. 2. p. 67-76, 1998.

[51] BURFIELD, D. R., Storage Hardening of natural rubber: an examination of the current mechanistic proposals. Journal of Natural Rubber Research, v.1, n.13, p.202-208, 1986. 
[52] TANGPAKDEE, J., MIZOKOSHI, M., ENDO, A., TANAKA, Y., Novel method for preparation of low molecular weight natural rubber latex. Rubber Chemistry Technology, v. 71, n.4, p.795-802, 1998.

[53] LI, S. D., YU. H.P., PENG, Z., Study on variation of structure and properties of natural rubber during accelerated storage. Journal of Applied Polymer Science, v.70, n.9, p. 1779-1783, 1998.

[54] Disponível em: http://www.di.com/AppNotes/Nanoindenting.html

[55] WEISENHORN, A. L, HANSMA, P.K., ALBRECHT, T. R., QUATE, C. F., Forces in atomic microscopy in air and water Applied Physical Letter, v.54, n.26, p.2651-2653, 1989.

[56] AIMÉ, J.P., ELKAAKOUR, Z., ODIN, C., BOUHACINA, T., MICHEL, D., CURÉLY, J., DAUTANT, A., Comments of the use of the force mode in atomic force microscopy for polymer films. Journal of Applied Physics, v.76, n.2, p.754$762,1994$.

[57] RADMMACHER M., TILLMAN, R. W., GAUB, H. E., Imagining viscoelasticity by force modulation with the atomic force microscope. Biophysical Journal, v. 64, n.3, p735-742, 1993.

[58] MIZES, H. A., LOH, K. G., MILLER, R. J. D., AHUJA, S. K., GRABOWSKI, E. F., Submicrom probe of polymer adhesion with atomic force microscopy: dependences on topography and material inhomogeneities. Applied Physics Letters. v. 59, n.22, p. 2901-2903, 1991.

[59] DAMMER U., POPESCU, O., WAGNER, P., ANSELMETTI, D., GUNTHERODT, H. J., MISEVIC, G. N., Binding strenght between cell adhesion proteoglycans measured by atomic force microscopy. Science v.267, n. 5201, p.1173$1175,1995$.

[60] FLORI, E.L.,MOY, V.T., GAUB, H. E., Adhesion force and energies between individual ligand receptor. Science, v.264, n.5157, p. 415-417, 1994.

[61] BINNING, G.; QUATE, C. F.; GERBER, C. H., Atomic Force Microscopic, Physical Review Letter, v. 56 n.9, p. 930-933, 1986.

[62] CHEN, C. S. MRKSICH, M., HUANG, S., WHITESIDES, G. M., INGBER, D. E., Geometric control of cell life and death. Science, v. 276, n. 5317, p. 1425-1428, 1996.

[63] STRONJNY, A., XIA, X., TSOU, A.,GERBERICH, W. W., Techniques and consideration for nanoindentation measurements of polymer thin films. Journal of Adhesion Science and Technology; v.12, n. 12, p.1299-1391, 1998. 
[64] STRONJNY, A., GERBERICH, W. W., Experimental analyses of viscoelastic behaviour in nanoindentation and nanotribology., Materials Research Society Symposium Proceedings, v. 522, p. 159-154, 1998.

[65] DRECHSLER, D., KARBACH, A., FUCHS, H., Nanoindentation on polycarbonate/polymethyl methacrylate blends, Applied Physics A: Materials Science \& Processing, v. A.66, n. 7, p.825-829, 1998.

[66] BRISCOE, B. J., SEBASTIAN, K.S.,ADAMS, M. J., The effect of Indenter Geometry on the elastic response to indentation. Journal of Physies D: Applied. Physics, v. 27, n. 6., p. 1156-1162, 1994.

[67] BRISCOE B.J., SINHA, S.K., SEBASTIAN, K.S., Application on the compliance method to microhardness measurements of organic polymers. Philosophical Magazine. A. v.74, n. 5, p. 1159-1169, 1996.

[68] KLAPPERICH, C., KOMVOPOULOS, K., PRUITT, L., Nanomechanical properties of polymers determined from nanoindentation experiements. Journal of Tribology, v.123, n.3, p.624-631, 2001.

[69] CHIZHIK, S. A., HUANG, Z., GORBUNOV, V. V., MYSHKIN, N. K., TSUKRUK, V. V., Micromechanical properties of elastic polymeric materials as probed by scaning Force Microcopy. Langmuir, v.14, n. 10, p. 2606-2609, 1998.

[70] JOHNSON, K. L., Contact Machanics. Cambridge, Cambridge University Press, 1985, p.85-106.

[71] BOUSSINESQ, J.; Applications des Potentiels a l'etude de équilibre et du mouvement des solides élastiques.1885, Paris, Blanchard, 1969, Reprint.

[72] SNEDDON, I. N., The relation between load and penetration in the axisymmetric Boussinesq problem for a punch of arbitratry profile. International Journal of Engineering Science, v.3, n. 1, p.47, 1965.

[73] TABOR, D; A simple theory of static and dynamic hardeness. Proceedings of the Royal Society of London Series A - Mathematical and Physical Sciences, v.192, n.1029, pp.247-274, 1948.

[74] STILLWELL, N. A., TABOR, D., Elastic recovery of conical indentations. Proceedings of the Physical Society, v.78, n. 2, p.169-179, 1961.

[75] BULYCHEV, S. I, ALEKHIN, V. P., SHORSHOROV, M. Kh., TERNORSKI, A. P., Determining Young's modulus from the indenter penetration diagram. Zavod. Lab. v. 41, n.9, p.1137, 1975.

[76] PHARR, G. M. OLIVER, W. C. BROTZEN, F. R. On the generality of the relationship between contact stiffness, contact area, and elastic modulus during indentation, Journal of Material Research, v.7, n.3, p. 613-617, 1992. 
[77] CRIPPS, A. F. Nanoindentation. Berlin, Mechanical Engineering Series, Springer-Verlag, (Mechanical Engineering Series) 2002.

[78] LOUBET, J. L., GEORGES, J. M., MARCHESINI, O., MEIILE, G., Vickers indentation curves of magnesium-oxide (MgO). Journal of Tribology Transactions of the ASME, v.106, n.1, p.43-46, 1984.

[79] DORNER, M. F., NIX, W. D., A method for interpreting the data from dephsensing indentation instruments, Journal of Material Research, v. 1, n.4, p. 601$609,1986$.

[80] OLIVER, W. C., Pharr,G. M., An improved technique for determining hardness and elastic modulus. Journal of Material Research. v.7, n.6, 1564-1583, 1992.

[81] OLIVER, W. C., Pharr,G. M. On the generality of the relationship among contact stifiness, contact area, and elastic modulus during indentation. Journal of Material Research. v.7, n.3, p.613-617, 1992.

[82] VANLANDINGHAM, J.S., VILLARUBIA, J. S., GUTHRIE, W. FR., MEYERS, G. F., Advances in Scanning Probe Microsocopy of Polymers. In: Macromolecular Symposia, v. 167, p.15-44, 2001.

[83] VANLANDINGHAM, J.S., VILLARUBIA, J. S., GUTHRIE, W. FR., MEYERS, G. F., Nanoindentation of Polymers: Overview. ACS Polymer Preprints, v. 41, n.2, p.1412-1413, 2000

[84] SHULL, K. R., AHN, D., CHEN, W. L., FLANIGAN, C. M., CROSBY, A. J., Axisymmetric adhesion tests of soft materials. Macromolecular Chemistry Physics v. 199 , n. 4, p. $489-511,1998$.

[85] PAIVA, A., SHELlER, N., FOSTER, M. D., CROSBY, A. J., SHULL, K. R., Study of the surface adhesion of pressure-sensitive adhesives by atomic force microscopy and spherical indenter tests. Macromolecules, v.33, n. 5, p.1878-1881, 2000.

[86] PAIVA, A., SHELlER, N., FOSTER, M. D., CROSBY, A. J., SHULL, K. R., Microindentation and nanoindentation studies of ageing in pressure-sensitive adhesives. Macromolecules, v.34, n. 7, p.2269-2276, 2001.

[87] GONÇALVES, S.P., Cadeia produtiva da borracha natural para o Estado de São Paulo, 1998 (artigo não publicado).

[88] KOEHLER, H. S., Capítulo 12: Efeitos de Competição, In: JUNIOR, P. R., Estatística Experimental. p. 110-116, Universidade Federal do Paraná, Curitiba, 1994. p.110-116. 
[89] GONÇALVES, P. G., SOUZA, S. R., BRIOSCHI, A. P., FILHO, A. C. V., MAY, A., ALARCON, R. S. C., Efeito da freqüência de sangria e estimulação no desempenho produtivo e econômico de clones de seringueira. Pesquisa Agropecuária Brasileira, v. 35., n.6, p. 1081-1091, 2000.

[90] ASSOCIAÇÃO BRASILEIRA DE NORMAS TÉCNICAS. NBR 11597: Borracha Natural. Rio de Janeiro, 1993.

[91] YIP, E. Clonal Characterization of latex and rubber properties. Journal of Natural Rubber Research, v.5, n.1, p.52-80, 1990.

[92] HASMA, H., OTHMAN, A. B., Role of some non-rubber constituents on thermal oxidative ageing of natural rubber. Journal of Natural Rubber Research, v.5, n.1, p.1-8, 1990 .

[93] OTHMAN, A.B; HEPBURN.C; HASMA,H. Influence of non-rubber constituents on elastic properties of natural rubber vulcanizates. Plastics, Rubber and Composites Processing and Applications, v.19, p.185-194, 1993.

[94] ROUX, Y, SAINTE-BEUVE, J.; NKENGAFAC, J.; NKENG, J.; NGOLEMASANGO, F.; GOBINA, S.., seasonal and clonal variations in the latex and raw rubber of Hevea brasiliensis. Journal of Rubber Research, v.3, n.3, p142, 2000.

[95] SUBRAMANIAM, A. Molecular weight and other properties of natural rubber: A study of clonal variation In: INTERNATIONAL RUBBER CONFERENCE, 1, Kuala Lumpur, Proceedings 1975, Kuala Lumpur, Rubber Research Institute of Malaysia, 1975, p.41-49.

[96] NAIR, S. Dependence of bulk viscosities (Mooney and Wallace) on molecular parameters of natural rubber Journal of. Rubber Research Institute of Malaysia, v. 23, n.1, p. $76,1970$.

[97] BATEMAN, D., SEKAHAR, B. C., Significance of PRI in raw and vulcanised natural rubber. Journal of Rubber Research Institute of Malaysia v.19. n.3, p.133, 1966.

[98] NA-RANONG, N., de LIVONNIÉRE, H. and JACOB, J.L. Natural rubber: doubts about the PRI. Plantations, Recherche, Development, Mars-April, 1995.

[99] SEKARAN, N. Characterisation of natural rubber for greater consistency. Rubber World, v.198, n.4, p. 27-30, 1988.

[100] SAMBHI, M. S., Analysis of the plasticity retention index of the standard Malaysian rubber scheme Journal of Natural Rubber Research. v.4, n.2, p.133$140,1989$.

[101] TANGPAKDEE, J; TANAKA, Y. Characterization of sol and gel in Hevea natural rubber. Rubber Chemistry and Technology, v. 70, n.5, p. 707-713, 1997. 
[102] GREGORY, M. J.; TAN, A. S. Some observations on storage hardening of natural rubber. In: INTERNATIONAL RUBBER CONFERENCE, 4, Kuala Lumpur, 1975, Proceedings, Kuala Lumpur, Rubber Research Institute of Malaysia, 1975, p. 28-38.

[103] RUBBER RESEARCH INSTITUTE OF MALAYSIA - Revisions to standard malaysian rubber scheme. Malaysia, SMR Bulletin 9, 1979

[104] HASMA, H. Lipds Associated with rubber particles and their possible role in Mechanical stability of latex concentrades. Journal of Natural Rubber Research, v.6, n.2, p.105-114, 1991.

[105] VIEIRA, S. Introdução à bioestatística. Rio de Janeiro, Ed. Campus, 1998, p. 146-147.

[106] KNIGHT, G. T.; TAN, A. N. Dynamic and related properties of natural rubber. In: INTERNATIONAL RUBBER CONFERENCE, 4, Kuala Lumpur 1975, Proceedings, Kuala Lumpur, Rubber Research Institute of Malaysia, 1975, p. 115139.

[107] TANAKA, Y., Structural characterization of natural polyisoprenes: Solve the mystery of natural rubber based on structural study. Rubber Chemistry and Technology, v. 74, n.3, p.355-375, 2001

[108] LU, F. J., HSU, S. L., A vibrational spectroscopy analysis of the structure of natural rubber, Rubber Chemistry and Technology, v. 60, n.4, p.647-658, 1987.

[109] SILVERSTAIN, R. M., BASSLER, G. C., MORRIL, T. C. Identificação de Compostos Orgânicos. $5^{\mathrm{a}}$ Ed. Rio de Janeiro, Ed Guanabara Koogan, 1994, p. 85.

[110] LI, S. D., YU, P. H., PENG, Z., ZHU, C. S., LI, P. S., Study on thermal degradation of sol and gel of natural rubber. Journal of Applied Polymer Science, v. 75, n.11, p. 1339-1344, 2000.

[111] BRANDRUP, J., IMMERGUT, E. H., Polymer Handbook, $2^{\mathrm{a}}$ ed., New York, John Willey and Sons, 1975.

[112] BONFILS, F.; CHAR, C.; GARNIER, Y.; SANAGO, A.; SAINT-BEUVE, J. Inherent molar mass distribution of clones and properties crumb natural rubber. Journal of Rubber Research, v. 3, n. 3, p.164-168, 2000.

[113] BONFILS, F.; FLORI, A., SAINT-BEUVE, J., Relations between Wallace plasticity and $\mathrm{M}_{\mathrm{w}}$ for natural rubber. Journal of Applied Polymer Science, v.74, n.13, p. 3078-3087, 1999.

[114] LUCAS, E. F., SOARES, B. G., MONTEIRO, E., Caracterização de polímeros. determinação de peso molecular e análise térmica. Rio de Janeiro, Ed. E-Papers, 2001, p. 309. 
[115] SIRCAR, A. K., GALASKA, M. L., RODRIGUES, R. P., CHARTOFF, R. P., Glass transition temperature of elastomers using thermal analysis techniques. Rubber Chemistry Technology, v. 72, n. 3, p. 514-536, 1999.

[116] DELL'ANTONIA, A. C., Estudo do desempenho mecânico e térmico de compostos de borracha natural (NR) de diferentes clones. São Carlos, SP, 2003, Dissertação (Mestrado)-IQSC, Universidade de São Paulo.

[117] DOMKE, J., RADMACHER, M., Measuring the elastic properties of thin films with the atomic force microscope. Langmuir, v. 14. n. 12. p.3320-3325, 1998.

[118] WEISENHORN, M. K., KHORSANDI, M., KASAS, S., GOTOZOPS, V., CELIO, M. R., BUTT, H. J. Deformation and height anomaly of soft surfaces studied with the AFM. Nanotechnology, v.4, n. 2, p. 106-103, 1993.

[119] MAREANUKROH, M., EBY, R. K., SCAVUZZO, R. J., HAMED, G. R., Use of the atomic force microscope as a nanoindenter to characterize elastomers. Rubber Chemistry Technology, v. 73, n.5, p. 912-925, 2002. 


\section{ANEXO I}

Para se fazer os cálculos das análises de variância é preciso calcular as seguintes quantidades [105]:

a) os graus de liberdade:

de tratamentos: $\mathrm{k}-1$

do total: $(\mathrm{n}-1)$

de resíduo: $(n-1)-(k-1)=(n-k)$

b) o valor $\mathrm{C}$, dado pelo total geral elevado ao quadrado e dividido pelo número de dados. $\mathrm{O}$ valor $\mathrm{C}$ é chamado correção.

$$
C=\frac{\left(\sum x\right)^{2}}{n}
$$

c) a soma de quadrados total:

$$
S Q T=\sum x^{2}-C
$$

d) a soma de quadrados de tratamentos:

$$
S Q T_{r}=\frac{\sum T^{2}}{r}-C
$$

e) a soma de quadrados do resíduo:

$$
S Q R=S Q T-S Q T r
$$


f) o quadrado médio de tratamentos:

$$
Q M T r=\frac{S Q T r}{k-1}
$$

g) o quadrado médio do resíduo

$$
Q M R=\frac{S Q R}{n-k}
$$

h) o valor de F

$$
F=\frac{Q M T r}{Q M R}
$$




\section{ANEXO II}

Tabela A. 1. Limites Unilaterais de F ao nível de $5 \%$ de probabilidade.

\begin{tabular}{|c|c|c|c|c|c|c|c|c|c|c|c|}
\hline & 1 & 2 & 3 & 4 & 5 & 6 & 7 & 8 & 9 & 10 & 11 \\
\hline 1 & 161,4 & 199,5 & 215,7 & 224,6 & 230.2 & 234,0 & 236,8 & 238,9 & 240,5 & 241,9 & 243,0 \\
\hline 2 & 18,51 & 19,00 & 19,16 & 19,25 & 19,30 & 19,33 & 19,35 & 19,37 & 19,38 & 19,40 & 19,40 \\
\hline 3 & 10.13 & 9,55 & 9.28 & 9,12 & 9,01 & 8,94 & 8,89 & 8,85 & 8,81 & 8,79 & 8,76 \\
\hline 4 & 7,71 & 6,94 & 6,59 & 6,39 & 6,26 & 6,16 & 6,09 & 6,04 & 6,00 & 5.96 & 5,93 \\
\hline 5 & 6,61 & 5,79 & 5,41 & 5,19 & 5.05 & 4,95 & 4,88 & 4,82 & 4,77 & 4,74 & 4,70 \\
\hline 6 & 5,99 & 5,14 & 4,76 & 4,53 & 4,39 & 4,28 & 4,21 & 4,15 & 4,10 & 4,06 & 4.03 \\
\hline 7 & 5,59 & 4,74 & 4,35 & 4,12 & 3,97 & 3,87 & 3,79 & 3,73 & 3,68 & 3,64 & 3,60 \\
\hline 8 & 5,32 & 4,46 & 4,07 & 3,84 & 3,69 & 3,58 & 3,50 & 3,44 & 3,39 & 3,35 & 3,31 \\
\hline 9 & 5,12 & 4,26 & 3,86 & 3,63 & 3.48 & 3,37 & 3,29 & 3,23 & 3,18 & 3,14 & 3,10 \\
\hline 10 & 4,96 & 4,10 & 3,71 & 3,48 & 3,33 & 3,22 & 3,14 & 3,07 & 3,02 & 2,98 & 2,94 \\
\hline 11 & 4,84 & 3,98 & 3,59 & 3,36 & 3,20 & 3,09 & 3,01 & 2,95 & 2,90 & 2,85 & 2.82 \\
\hline 12 & 4,75 & 3,89 & 3,49 & 3,26 & 3,11 & 3,00 & 2,91 & 2,85 & 2,80 & 2,75 & 2,72 \\
\hline 13 & 4,67 & 3,81 & 3,41 & 3,18 & 3,03 & 2,92 & 2,83 & 2,77 & 2,71 & 2,67 & 2,63 \\
\hline 14 & 4,60 & 3,74 & 3,34 & 3,11 & 2,96 & 2,85 & 2,76 & 2,70 & 2,65 & 2,60 & 2,50 \\
\hline 15 & 4,54 & 3,68 & 3,29 & 3,06 & 2,90 & 2,79 & 2,71 & 2,64 & 2,59 & 2.54 & 2,51 \\
\hline 16 & 4,49 & 3,63 & 3,24 & 3,01 & 2,85 & 2,74 & 2,66 & 2,59 & 2,54 & 2,49 & 2,45 \\
\hline 17 & 4,45 & 3,59 & 3,20 & 2,96 & 2,81 & 2,70 & 2,61 & 2,55 & 2,49 & 2,45 & 2,41 \\
\hline 18 & 4,41 & 3,55 & 3,16 & 2,93 & 2,77 & 2,66 & 2,58 & 2,51 & 2,46 & 2,41 & 2,37 \\
\hline 19 & 4.38 & 3,52 & 3,13 & 2,90 & 2,74 & 2,63 & 2,54 & 2,48 & 2,42 & 2,38 & 2,34 \\
\hline 20 & 4,35 & 3,49 & 3,10 & 2,87 & 2,71 & 2,60 & 2,51 & 2,45 & 2,39 & 2,35 & 2.31 \\
\hline 21 & 4,32 & 3,47 & 3,07 & 2,84 & 2,68 & 2,57 & 2,49 & 2,42 & 2,37 & 2,32 & 2,28 \\
\hline 22 & 4,30 & 3,44 & 3,05 & 2,82 & 2,66 & 2,55 & 2,46 & 2,40 & 2,34 & 2,30 & 2,26 \\
\hline 23 & 4,28 & 3,42 & 3.03 & 2,80 & 2,64 & 2,53 & 2,44 & 2,37 & 2,32 & 2,27 & 2,24 \\
\hline 24 & 4,26 & 3,40 & 3,01 & 2,78 & 2,62 & 2,51 & 2,42 & 2,36 & 2,30 & 2,25 & 2,22 \\
\hline 25 & 4,24 & 3,39 & 2,99 & 2,76 & 2,60 & 2,49 & 2,40 & 2,34 & 2,28 & 2,24 & 2,20 \\
\hline 26 & 4,23 & 3,37 & 2,98 & 2,74 & 2,59 & 2,47 & 2,39 & 2,32 & 2,27 & 2,22 & 2,18 \\
\hline 27 & 4,21 & 3,35 & 2,96 & 2,73 & 2,57 & 2,46 & 2,37 & 2,31 & 2,25 & 2,20 & 2,16 \\
\hline 28 & 4,20 & 3,34 & 2,95 & 2,71 & 2,56 & 2,45 & 2,36 & 2,29 & 2,24 & 2,19 & 2,15 \\
\hline 29 & 4,18 & 3,33 & 2,93 & 2,70 & 2,55 & 2,43 & 2,35 & 2,28 & 2,22 & 2,18 & 2,14 \\
\hline 30 & 4,17 & 3,32 & 2,92 & 2,69 & 2,53 & 2,42 & 2,33 & 2,27 & 2,21 & 2,16 & 2,12 \\
\hline 40 & 4,08 & 3,23 & 2,84 & 2,61 & 2,45 & 2,34 & 2,25 & 2,18 & 2,12 & 2,08 & 2,04 \\
\hline 60 & 4,00 & 3,15 & 2,76 & 2.53 & 2,37 & 2,25 & 2,17 & 2,10 & 2,04 & 1,99 & 1,95 \\
\hline 120 & 3,92 & 3,07 & 2,68 & 2.45 & 2,29 & 2,17 & 2,09 & 2,02 & 1,96 & 1,91 & 1,86 \\
\hline$\infty$ & 3,84 & 3,00 & 2,60 & 2,37 & 2,21 & 2,10 & 2,01 & 1,94 & 1,88 & 1,83 & 1,70 \\
\hline
\end{tabular}


Tabela A. 2. Limites Unilaterais de $\mathrm{F}$ ao nível de 5\% de probabilidade.

\begin{tabular}{|c|c|c|c|c|c|c|c|c|c|c|c|}
\hline 12 & 13 & 14 & 15 & 16 & 20 & 24 & 30 & 40 & 60 & 120 & $\infty$ \\
\hline 243,9 & 244,4 & 245,0 & 245,9 & 246,0 & 248,0 & 249,1 & 250,1 & 251,1 & 252,2 & 253,3 & 254,3 \\
\hline 19,41 & 19,42 & 19,42 & 19,43 & 19,43 & 19,45 & 19,45 & 19,46 & 19,47 & 19,48 & 19,49 & 19,50 \\
\hline 8,74 & 8,72 & 8,71 & 8,70 & 8,69 & 8,66 & 8,64 & 8,62 & 8,59 & 8,57 & 8,55 & 8,53 \\
\hline 5,91 & 5,89 & 5,87 & 5,86 & 5,84 & 5,80 & 5,77 & 5,75 & 5,72 & 5,69 & 5,66 & 5,63 \\
\hline 4,68 & 4,66 & 4,64 & 4,62 & 4,60 & 4,56 & 4,53 & 4,50 & 4,46 & 4,43 & 4,40 & 4,36 \\
\hline 4,00 & 3,98 & 3,96 & 3,94 & 3,92 & 3,87 & 3,84 & 3,81 & 3,77 & 3,74 & 3,70 & 3,67 \\
\hline 3,57 & 3,55 & 3,52 & 3,51 & 3,49 & 3,44 & 3,41 & 3,38 & 3,34 & 3,30 & 3,27 & 3,23 \\
\hline 3,28 & 3,25 & 3,23 & 3,22 & 3,20 & 3,15 & 3,12 & 3,08 & 3,04 & 3,01 & 2,97 & 2,93 \\
\hline 3,07 & 3,04 & 3,02 & 3,01 & 2,98 & 2,94 & 2,90 & 2,86 & 2,83 & 2,79 & 2,75 & 2,71 \\
\hline 2,91 & 2,88 & 2,86 & 2,85 & 2,82 & 2,77 & 2,74 & 2,70 & 2,66 & 2,62 & 2,58 & 2,54 \\
\hline 2,79 & 2,76 & 2,74 & 2,72 & 2,70 & 2,65 & 2,61 & 2,57 & 2,53 & 2,49 & 2,45 & 2,40 \\
\hline 2,69 & 2,66 & 2,64 & 2,62 & 2,60 & $2 ; 54$ & 2,51 & 2,47 & 2,43 & 2,38 & 2,34 & 2,30 \\
\hline 2,60 & 2,57 & 2,55 & 2,53 & 2,51 & 2,46 & 2,42 & 2,38 & 2,34 & 2,30 & 2,25 & 2,21 \\
\hline 2,53 & 2,50 & 2,48 & 2,46 & 2,44 & 2.39 & 2,35 & 2,31 & 2,27 & 2,22 & 2,18 & 2,13 \\
\hline 2,48 & 2,45 & 2,43 & 2,40 & 2,39 & 2,33 & 2,29 & 2,25 & 2,20 & 2,16 & 2,11 & 2,07 \\
\hline 2,42 & 2,39 & 2,37 & 2,35 & 2,33 & 2,28 & 2,24 & 2,19 & 2,15 & 2,11 & 2,06 & 2,01 \\
\hline 2,38 & 2,35 & 2,33 & 2,31 & 2.29 & 2,23 & 2,19 & 2,15 & 2,10 & 2,06 & 2,01 & 1,96 \\
\hline 2,34 & 2,31 & 2,29 & 2,27 & 2,25 & 2,19 & 2,15 & 2,11 & 2,06 & 2,02 & 1,97 & 1,92 \\
\hline 2,31 & 2,28 & 2.26 & 2,23 & 2,21 & 2,16 & 2,11 & 2,07 & 2,03 & 1,98 & 1,93 & 1,88 \\
\hline 2,28 & 2,25 & 2,23 & 2,20 & 2,18 & 2,12 & 2,08 & 2,04 & 1,99 & 1,95 & 1,90 & 1.84 \\
\hline 2.25 & 2,22 & 2,20 & 2,18 & 2,15 & 2,10 & 2,05 & 2,01 & 1,96 & 1,92 & 1,87 & 1,81 \\
\hline 2,23 & 2,20 & 2,18 & 2,15 & 2,13 & 2,07 & 2,03 & 1,98 & 1,94 & 1,89 & 1,84 & 1,78 \\
\hline 2,20 & 2,17 & 2,14 & 2,13 & 2,10 & 2,05 & 2,01 & 1,96 & 1,91 & 1,86 & 1,81 & 1.76 \\
\hline 2,18 & 2,15 & 2,13 & 2,11 & 2,09 & 2,03 & 1,98 & 1,94 & 1,89 & 1,84 & 1,79 & 1,73 \\
\hline 2,16 & 2,13 & 2,11 & 2,09 & 2,06 & 2,01 & 1,96 & 1,92 & 1,87 & 1,82 & 1,77 & 1,71 \\
\hline 2,15 & 2,12 & 2,10 & 2,07 & 2,05 & 1,99 & 1,95 & 1,90 & 1,85 & 1,80 & 1,75 & 1,69 \\
\hline 2,13 & 2,10 & 2,08 & 2,06 & 2,03 & 1,97 & 1,93 & 1,88 & 1,84 & 1,79 & 1,73 & 1,67 \\
\hline 2,12 & 2,09 & 2,06 & 2,04 & 2,02 & 1,96 & 1,91 & 1,87 & 1,82 & 1,77 & 1,71 & 1,65 \\
\hline 2,10 & 2,07 & 2,05 & 2,03 & 2,00 & 1,94 & 1,90 & 1,85 & 1,81 & 1,75 & 1,70 & 1,64 \\
\hline 2,09 & 2,06 & 2,04 & 2,01 & 1,99 & 1,93 & 1,89 & 1,84 & 1,79 & 1,74 & 1,68 & 1,62 \\
\hline 2,00 & 1,97 & 1,95 & 1,92 & 1,90 & 1,84 & 1,79 & 1,74 & 1,69 & 1,64 & 1,58 & 1,51 \\
\hline 1,92 & 1,89 & 1,86 & 1,84 & 1,81 & 1,75 & 1,70 & 1,65 & 1,59 & 1,53 & 1,47 & 1,39 \\
\hline 1,83 & 1,80 & 1,77 & 1,75 & 1,73 & 1,66 & 1,61 & 1,55 & 1,50 & 1,43 & 1,35 & 1,25 \\
\hline 1,75 & 1,72 & 1,69 & 1,67 & 1,64 & 1,57 & 1,52 & 1,46 & 1,39 & 1,32 & 1,22 & 1,00 \\
\hline
\end{tabular}


Tabela A. 3. Limites Unilaterais de F ao nível de 1\% de probabilidade.

\begin{tabular}{|c|c|c|c|c|c|c|c|c|c|c|c|}
\hline & 1 & 2 & 3 & 4 & 5 & 6 & 7 & 8 & 9 & 10 & 11 \\
\hline $\begin{array}{l}1 \\
2 \\
3 \\
4 \\
5\end{array}$ & \begin{tabular}{|c|}
4052 \\
98,50 \\
34,12 \\
21,20 \\
16,26
\end{tabular} & \begin{tabular}{|c|}
5000 \\
99,00 \\
30,82 \\
18,00 \\
13,27
\end{tabular} & \begin{tabular}{|l|}
5403 \\
99,17 \\
29,46 \\
16,69 \\
12,06
\end{tabular} & $\begin{array}{l}5625 \\
99,25 \\
28,71 \\
15,98 \\
11,39\end{array}$ & \begin{tabular}{|c|}
5764 \\
99,30 \\
28,24 \\
15,52 \\
10,97
\end{tabular} & $\mid \begin{array}{c}5859 \\
99,33 \\
27,91 \\
15,21 \\
10,67\end{array}$ & $\begin{array}{l}5928 \\
99,36 \\
27,67 \\
14,98 \\
10,46\end{array}$ & \begin{tabular}{|c|}
5982 \\
99,37 \\
27,49 \\
14,80 \\
10,29
\end{tabular} & $\mid \begin{array}{l}6022 \\
99,39 \\
27,35 \\
14,66 \\
10,16\end{array}$ & \begin{tabular}{|l|}
6056 \\
99,40 \\
27,23 \\
14,55 \\
10,05
\end{tabular} & $\begin{array}{r}6082 \\
99,41 \\
27,13 \\
14,45 \\
9,96\end{array}$ \\
\hline $\begin{array}{r}6 \\
7 \\
8 \\
9 \\
10\end{array}$ & $\begin{array}{l}13,75 \\
12,25 \\
11,26 \\
10,56 \\
10,04\end{array}$ & $\begin{array}{r}10,92 \\
9,55 \\
8,65 \\
8,02 \\
7,56\end{array}$ & $\begin{array}{l}9,78 \\
8,45 \\
7,59 \\
6,99 \\
6,55\end{array}$ & & & $\begin{array}{l}8,47 \\
7,19 \\
6,37 \\
5,80 \\
5,39\end{array}$ & $\begin{array}{l}8,26 \\
6,99 \\
6,18 \\
5,61 \\
5,20\end{array}$ & $\begin{array}{l}8,10 \\
6,84 \\
6,03 \\
5,47 \\
5,06\end{array}$ & $\begin{array}{l}7,98 \\
6,72 \\
5,91 \\
5,35 \\
4,94\end{array}$ & $\begin{array}{l}7,87 \\
6,62 \\
5,81 \\
5,26 \\
4,85\end{array}$ & $\begin{array}{l}7,79 \\
6,54 \\
5,74 \\
5,18 \\
4,78\end{array}$ \\
\hline $\begin{array}{l}15 \\
15\end{array}$ & & & & & & & & $\begin{array}{l}4,74 \\
4,50 \\
4,30 \\
4,14 \\
4,00\end{array}$ & & $\begin{array}{l}4,54 \\
4,30 \\
4,10 \\
3,94 \\
3,80\end{array}$ & $\begin{array}{l}3,86 \\
3,73\end{array}$ \\
\hline $\begin{array}{l}16 \\
17 \\
18 \\
19 \\
20\end{array}$ & & & $\begin{array}{l}5,29 \\
5,18 \\
5,09 \\
5,01 \\
4,94\end{array}$ & $\begin{array}{l}4,77 \\
4,67 \\
4,58 \\
4,50 \\
4,43\end{array}$ & & 3,87 & $\begin{array}{l}4,03 \\
3,93 \\
3,84 \\
3,77 \\
3,70\end{array}$ & $\begin{array}{l}3,89 \\
3,79 \\
3,71\end{array}$ & 3.78 & $\begin{array}{l}3,69 \\
3,59 \\
3,51 \\
3,43 \\
3,37\end{array}$ & $\begin{array}{l}3,61 \\
3,52 \\
3,44 \\
3,36 \\
3,30\end{array}$ \\
\hline $\begin{array}{l}21 \\
22 \\
23 \\
24 \\
25\end{array}$ & & & $\begin{array}{l}4,87 \\
4,82 \\
4,76 \\
4,72 \\
4,68\end{array}$ & $\begin{array}{l}4,37 \\
4,31 \\
4,26 \\
4,22 \\
4,18\end{array}$ & & & & $\begin{array}{l}3,51 \\
3,45 \\
3,41 \\
3,36\end{array}$ & $\begin{array}{l}3,30 \\
3,26 \\
3,22\end{array}$ & $\begin{array}{l}3,31 \\
3,26 \\
3,21 \\
3,17 \\
3,13\end{array}$ & $\begin{array}{l}3,14 \\
3,09 \\
3,05\end{array}$ \\
\hline $\begin{array}{l}2 \\
2 \\
2 \\
2 \\
3\end{array}$ & $\begin{array}{l}7,64 \\
7,60 \\
7,56\end{array}$ & $\begin{array}{l}5,53 \\
5,49 \\
5,45 \\
5,42 \\
5,39\end{array}$ & $\begin{array}{l}4,64 \\
4,60 \\
4,57 \\
4,54 \\
4,51\end{array}$ & $\begin{array}{l}4,14 \\
4,11 \\
4,07 \\
4,04 \\
4,02\end{array}$ & 3,70 & $\begin{array}{l}3,50 \\
3,47\end{array}$ & $\begin{array}{l}3,42 \\
3,39 \\
3,36 \\
3,33 \\
3,30\end{array}$ & $\begin{array}{l}3,20 \\
3,17\end{array}$ & $\begin{array}{l}3,12 \\
3,09 \\
3,07\end{array}$ & $\begin{array}{l}3,09 \\
3,06 \\
3,03 \\
3,00 \\
2,98\end{array}$ & $\begin{array}{l}2,95 \\
2,92 \\
2,90\end{array}$ \\
\hline $\begin{array}{r}40 \\
60 \\
120 \\
00\end{array}$ & & $\begin{array}{l}5,18 \\
4,98 \\
4,79 \\
4,61\end{array}$ & $\begin{array}{l}3,95 \\
3,78\end{array}$ & $\begin{array}{l}3,83 \\
3,65 \\
3,48 \\
3,32\end{array}$ & $\begin{array}{l}3,51 \\
3,34 \\
3,17 \\
3,02\end{array}$ & $\begin{array}{l}3,29 \\
3,12 \\
2,96 \\
2,80\end{array}$ & $\begin{array}{l}3,1 \\
2,9 \\
2,7 \\
2,6\end{array}$ & $\begin{array}{l}2,66 \\
2,51\end{array}$ & $\begin{array}{l}2,89 \\
2,72 \\
2,56 \\
2,41\end{array}$ & $\begin{array}{l}2,80 \\
2,63 \\
2,47 \\
2,32\end{array}$ & $\begin{array}{l}2,73 \\
2,56 \\
2,40 \\
2,24\end{array}$ \\
\hline
\end{tabular}


Tabela A. 4. Limites Unilaterais de F ao nível de 1\% de probabilidade.

\begin{tabular}{|c|c|c|c|c|c|c|c|c|c|c|c|}
\hline 12 & 13 & 14 & 15 & 16 & 20 & 24 & 30 & 40 & 60 & 120 & $\infty$ \\
\hline $\begin{array}{r}6106 \\
99,42 \\
27,05 \\
14,37 \\
9,89\end{array}$ & \begin{tabular}{|c|}
6125 \\
99,42 \\
26,98 \\
14,30 \\
9,83
\end{tabular} & $\begin{array}{c}6142 \\
99,43 \\
26,92 \\
14,24 \\
9,77\end{array}$ & \begin{tabular}{|c|}
6157 \\
99,43 \\
26,87 \\
14,20 \\
9,72
\end{tabular} & \begin{tabular}{|c|}
6169 \\
99,44 \\
26,83 \\
14,15 \\
9,68
\end{tabular} & $\mid$\begin{tabular}{c|}
6209 \\
99,45 \\
26,69 \\
$1+, 02$ \\
9.55
\end{tabular} & $\begin{array}{c}6235 \\
99,46 \\
26,60 \\
13,93 \\
9,47\end{array}$ & $\left|\begin{array}{c|}6261 \\
99,47 \\
26,50 \\
13,84 \\
9,38\end{array}\right|$ & $\mid \begin{array}{c}6287 \\
99,47 \\
26,41 \\
13,75 \\
9,29\end{array}$ & \begin{tabular}{|c|}
6313 \\
99,48 \\
26,32 \\
13,65 \\
9,20
\end{tabular} & $\begin{array}{c}6339 \\
99,49 \\
26,22 \\
13,56 \\
9,11\end{array}$ & $\begin{array}{r}6366 \\
99.50 \\
26,13 \\
13.46 \\
9,02\end{array}$ \\
\hline $\begin{array}{l}7,72 \\
6,47 \\
5,67 \\
5,11 \\
4,71\end{array}$ & $\begin{array}{l}7,66 \\
6,41 \\
5,61 \\
5,05 \\
4,65\end{array}$ & $\begin{array}{l}7,60 \\
6,35 \\
5,56 \\
5,00 \\
4,60\end{array}$ & $\begin{array}{l}7,56 \\
6,31 \\
5,52 \\
4,96 \\
4,56\end{array}$ & $\begin{array}{l}7,52 \\
6,27 \\
5,48 \\
4,92 \\
4,52\end{array}$ & $\begin{array}{l}7,40 \\
6,16 \\
5,36 \\
4,81 \\
4,41\end{array}$ & $\begin{array}{l}7,31 \\
6,07 \\
5,28 \\
4,73 \\
4,33\end{array}$ & \begin{tabular}{|l|}
7,23 \\
5,99 \\
5,20 \\
4,65 \\
4,25
\end{tabular} & $\begin{array}{l}7,14 \\
5,91 \\
5,12 \\
4,57 \\
4,17\end{array}$ & $\begin{array}{l}7,06 \\
5,82 \\
5,03 \\
4,48 \\
4,08\end{array}$ & $\begin{array}{l}6,97 \\
5,74 \\
4,95 \\
4,40 \\
4,00\end{array}$ & $\begin{array}{l}6,88 \\
5,65 \\
4,86 \\
4,31 \\
3,91\end{array}$ \\
\hline $\begin{array}{l}4,40 \\
4,16 \\
3,96 \\
3,80 \\
3,67\end{array}$ & $\begin{array}{l}4,34 \\
4,10 \\
3,90 \\
3,75 \\
3,61\end{array}$ & $\begin{array}{l}4,29 \\
4,05 \\
3,85\end{array}$ & $\begin{array}{l}4,25 \\
4,01 \\
3,82 \\
3,66 \\
3,52\end{array}$ & $\begin{array}{l}4,21 \\
3,98 \\
3,78 \\
3,62 \\
3,48\end{array}$ & $\begin{array}{l}4,10 \\
3,86 \\
3,66 \\
3,51 \\
3,37\end{array}$ & $\begin{array}{l}4,02 \\
3,78 \\
3,59 \\
3,43 \\
3,29\end{array}$ & $\begin{array}{l}3,94 \\
3,70 \\
3,51 \\
3,35 \\
3,21\end{array}$ & $\begin{array}{l}3,86 \\
3,62 \\
3,43 \\
3,27 \\
3,13\end{array}$ & $\begin{array}{l}3,78 \\
3,54 \\
3,34 \\
3,18 \\
3,05\end{array}$ & $\begin{array}{l}3,69 \\
3,45 \\
3,25 \\
3,09 \\
2,96\end{array}$ & $\begin{array}{l}3,60 \\
3,36 \\
3,17 \\
3,00 \\
2,87\end{array}$ \\
\hline $\begin{array}{l}3,55 \\
3,46 \\
3,37 \\
3,30 \\
3,23\end{array}$ & $\begin{array}{l}3,50 \\
3,40 \\
3,32 \\
3,24 \\
3,18\end{array}$ & $\begin{array}{l}3.35 \\
3,27 \\
3,19 \\
3,13\end{array}$ & $\begin{array}{l}3,31 \\
3,23 \\
3,15 \\
3,09\end{array}$ & $\begin{array}{l}3,12 \\
3,05\end{array}$ & $\begin{array}{l}3,26 \\
3,16 \\
3,08 \\
3,00 \\
2,94\end{array}$ & $\begin{array}{l}3,18 \\
3,08 \\
3,00 \\
2,92 \\
2,86\end{array}$ & $\begin{array}{l}3,10 \\
3,00 \\
2,92 \\
2,84 \\
2,78\end{array}$ & $\begin{array}{l}3,02 \\
2,92 \\
2,84 \\
2,76 \\
2,69\end{array}$ & $\begin{array}{l}2,93 \\
2,83 \\
2,75 \\
2,67 \\
2,61\end{array}$ & $\begin{array}{l}2,84 \\
2,75 \\
2,66 \\
2,58 \\
2,52\end{array}$ & $\begin{array}{l}2.75 \\
2,65 \\
2,57 \\
2,49 \\
2.42\end{array}$ \\
\hline $\begin{array}{l}3,17 \\
3,12 \\
3,07 \\
3.03 \\
2,99\end{array}$ & $\begin{array}{l}3,12 \\
3,07 \\
3,02 \\
2,98 \\
2,94\end{array}$ & 2,89 & 2,85 & & $\begin{array}{l}2,78 \\
2,74 \\
2,70\end{array}$ & $\begin{array}{l}2,80 \\
2,75 \\
2,70 \\
2,66 \\
2,62\end{array}$ & $\begin{array}{l}2,72 \\
2,67 \\
2,62 \\
2,58 \\
2,54\end{array}$ & $\begin{array}{l}2,64 \\
2,58 \\
2,54 \\
2,49 \\
2,45\end{array}$ & $\begin{array}{l}2,55 \\
2,50 \\
2,45 \\
2,40 \\
2,36\end{array}$ & $\begin{array}{l}2,46 \\
2,40 \\
2,35 \\
2,31 \\
2,27\end{array}$ & $\begin{array}{l}2,36 \\
2,31 \\
2,26 \\
2,21 \\
2,17\end{array}$ \\
\hline $\begin{array}{l}2,96 \\
2.93 \\
2,90 \\
2,87 \\
2,84\end{array}$ & $\begin{array}{l}2,91 \\
2,88 \\
2,85 \\
2,82 \\
2,79\end{array}$ & $\begin{array}{l}2 ; 80 \\
2,77 \\
2,74\end{array}$ & $\begin{array}{l}2,81 \\
2,78 \\
2,75 \\
2,73 \\
2,70\end{array}$ & $\begin{array}{l}2,77 \\
2,74 \\
2,71 \\
2,68 \\
2,66\end{array}$ & $\begin{array}{l}2.63 \\
2,60 \\
2,57 \\
2,55\end{array}$ & $\begin{array}{l}2,58 \\
2,55 \\
2,52 \\
2,49 \\
2,47\end{array}$ & $\begin{array}{l}2,50 \\
2,47 \\
2,44 \\
2,41 \\
2,39\end{array}$ & $\begin{array}{l}2,42 \\
2,38 \\
2,35 \\
2,33 \\
2,30\end{array}$ & $\begin{array}{l}2,33 \\
2,29 \\
2,26 \\
2,23 \\
2,21\end{array}$ & $\begin{array}{l}2.23 \\
2,20 \\
2,17 \\
2,14 \\
2,11\end{array}$ & $\begin{array}{l}2.13 \\
2.10 \\
2.06 \\
2.03 \\
2,01\end{array}$ \\
\hline $\begin{array}{l}2,66 \\
2,50 \\
2,34 \\
2,18\end{array}$ & $\begin{array}{l}2,61 \\
2,45 \\
2,29 \\
2,12\end{array}$ & $\begin{array}{l}2,24 \\
2,07\end{array}$ & $\begin{array}{l}2,52 \\
2,35 \\
2,19 \\
2,04\end{array}$ & $\begin{array}{l}2,49 \\
2,32 \\
2,16 \\
.1,99\end{array}$ & $\begin{array}{l}2.37 \\
2,20 \\
2,03 \\
1,88\end{array}$ & $\begin{array}{l}2,29 \\
2,12 \\
1,95 \\
1,79\end{array}$ & $\begin{array}{l}2,20 \\
2,03 \\
1,86 \\
1,70\end{array}$ & $\begin{array}{l}2,11 \\
1,94 \\
1,76 \\
1,59\end{array}$ & \begin{tabular}{|l|}
2,02 \\
1,84 \\
1,66 \\
1,47
\end{tabular} & $\begin{array}{l}1,92 \\
1,73 \\
1,53 \\
1,32\end{array}$ & $\begin{array}{l}1,80 \\
1,60 \\
1,38 \\
1,00\end{array}$ \\
\hline
\end{tabular}

Tabelas de F retiradas do livro: Curso de Estatística Experimental, Frederico Pimentel Gomes, $12{ }^{\text {a }}$ Ed. Piracicaba, 1987. 


\section{ANEXO III}

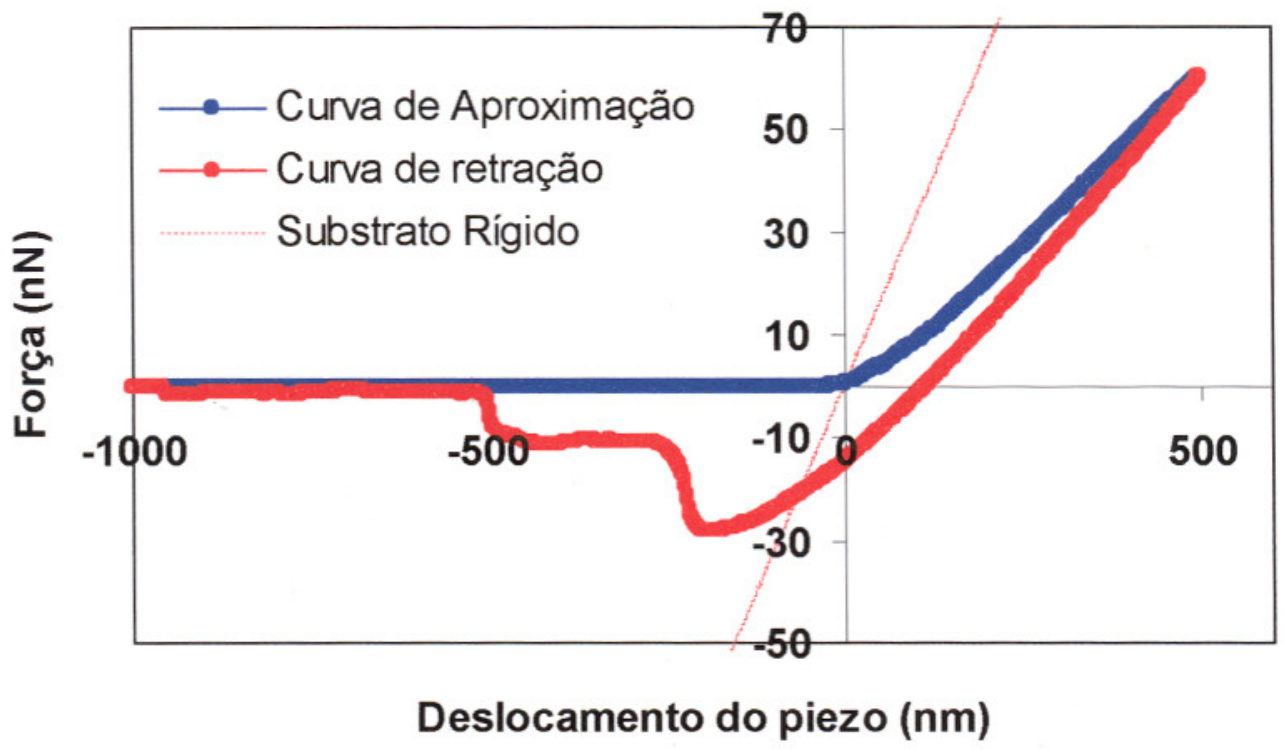

Figura A. 1. Gráfico de Força $(\mathrm{nN})$ versus deslocamento do piezo $(\mathrm{nm})$ obtida através de medida de nanoindentação para o clone IAN 873.

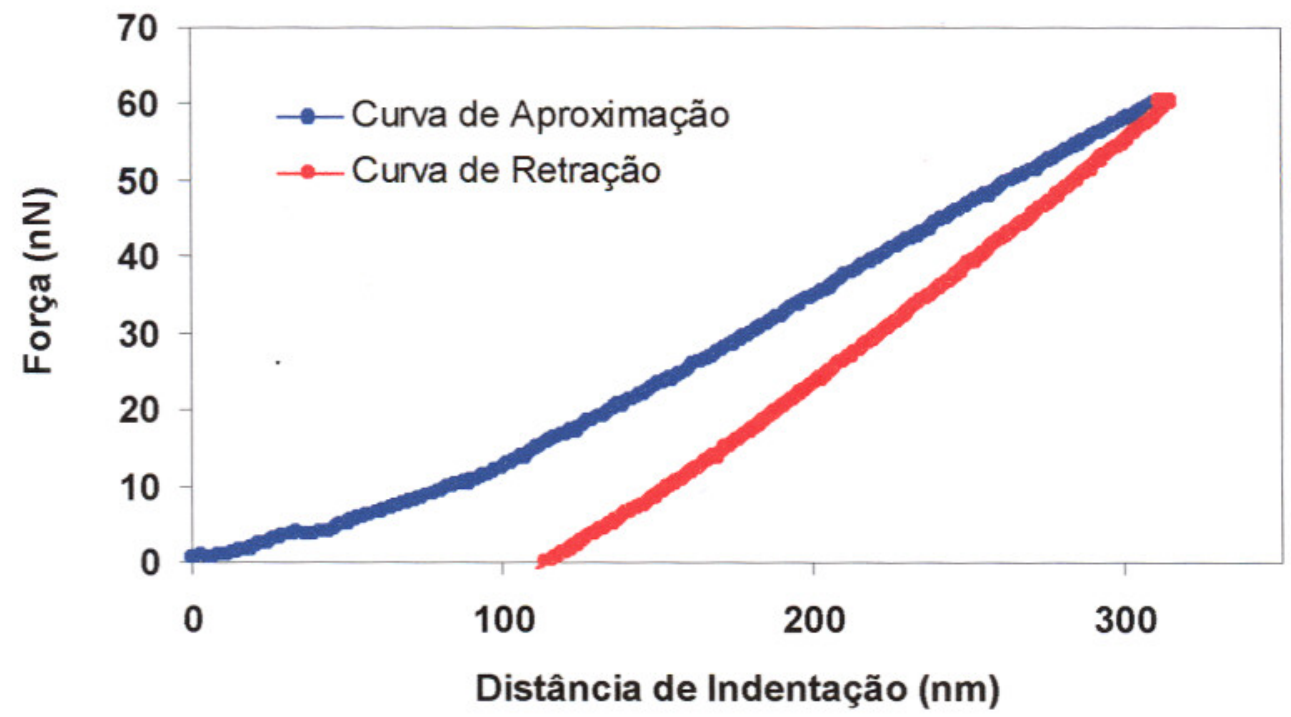

Figura A. 2. Gráfico de Força $(\mathrm{nN})$ versus distância de nanoindentação (nm) para medida de nanoindentação para o clone IAN 873. 


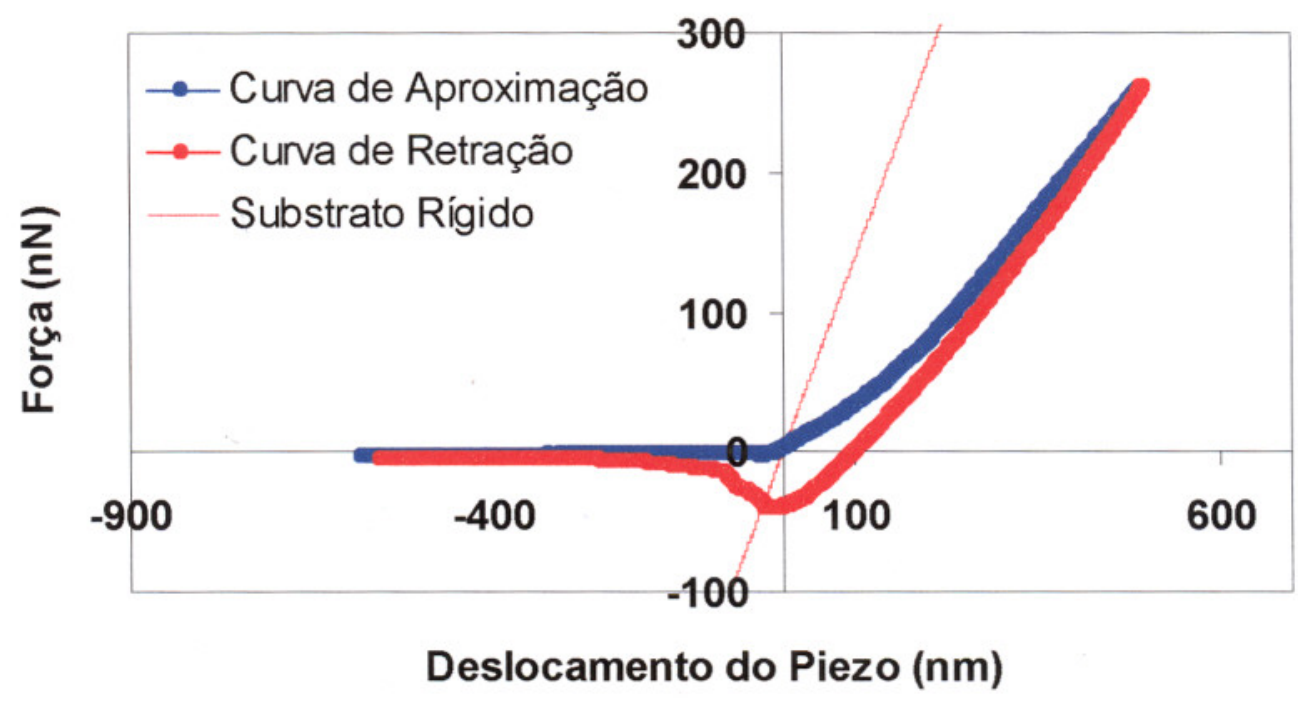

Figura A. 3. Gráfico de Força $(\mathrm{nN})$ versus deslocamento do piezo (nm) obtida através de medida de nanoindentação para o clone PB 235.

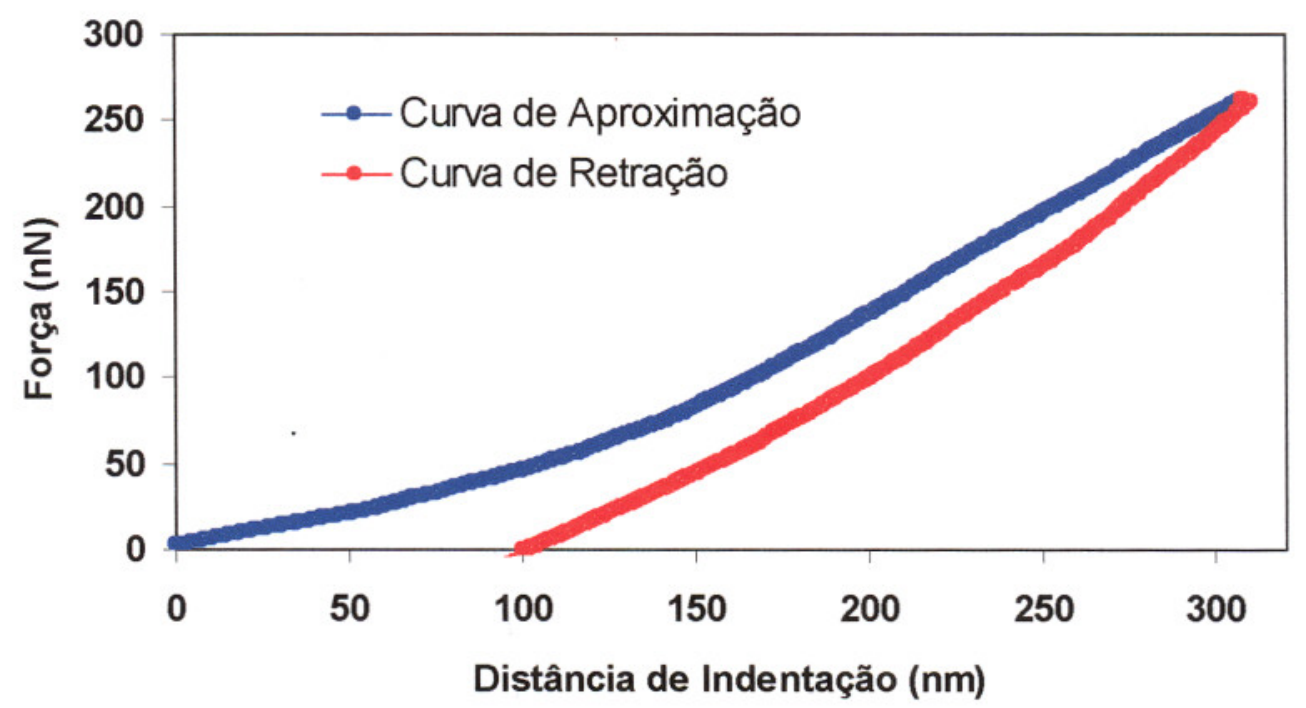

Figura A. 4. Gráfico de Força $(\mathrm{nN})$ versus distância de nanoindentação (nm) para medida de nanoindentação para o clone PB 235. 


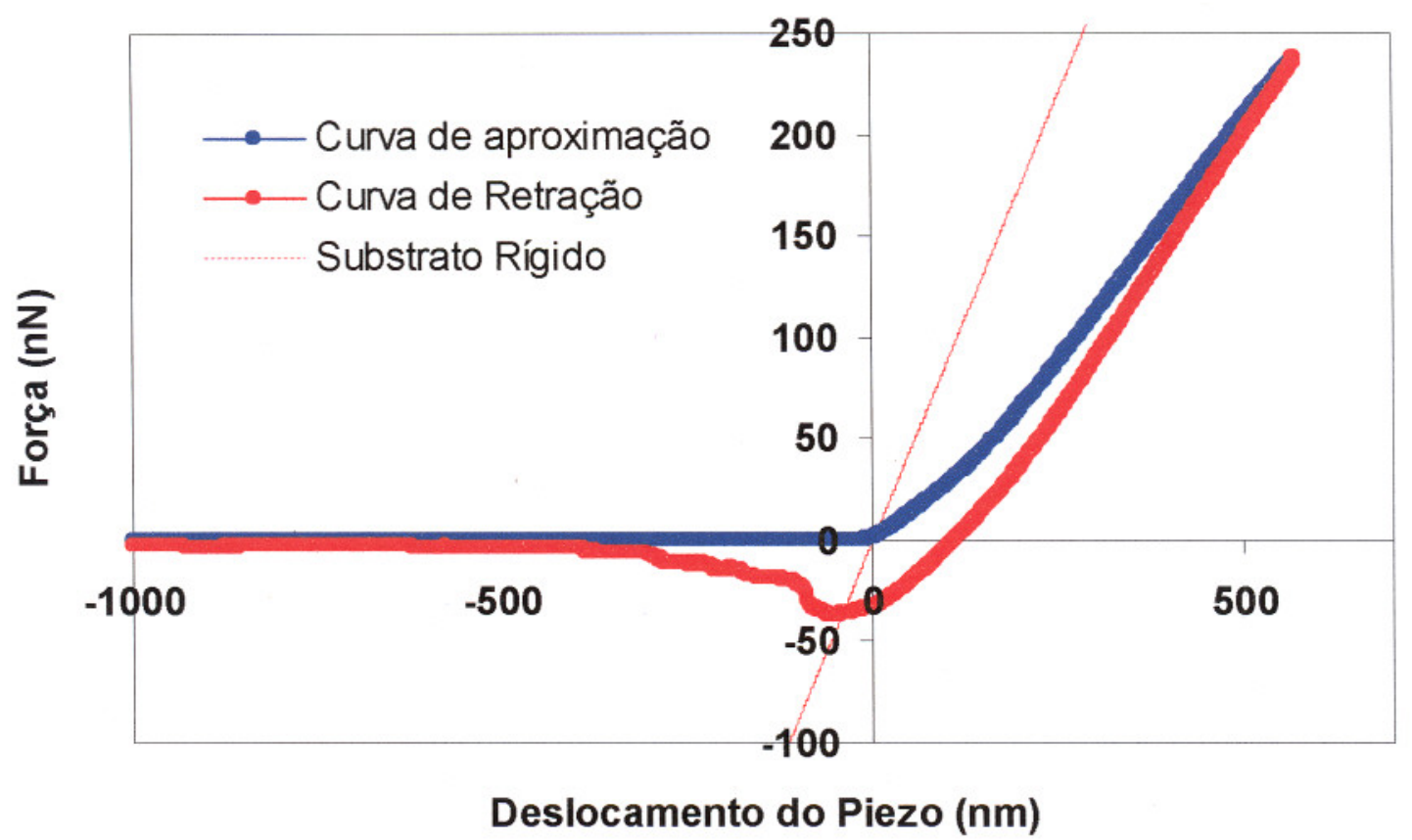

Figura A. 5. Gráfico de Força $(\mathrm{nN})$ versus deslocamento do piezo $(\mathrm{nm})$ obtida através de medida de nanoindentação para o clone GT 1.

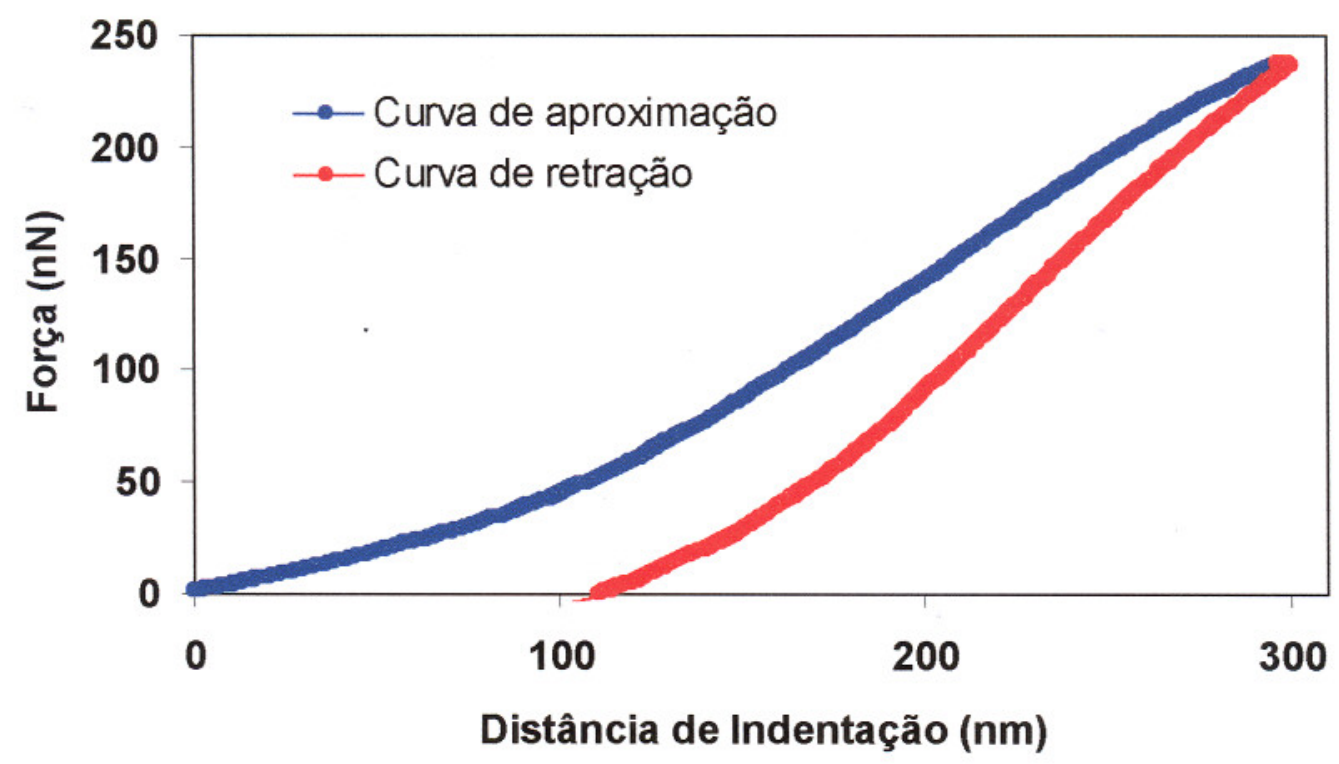

Figura A. 6. Gráfico de Força $(\mathrm{nN})$ versus distância de nanoindentação $(\mathrm{nm})$ para medida de nanoindentação para o clone GT 1. 